Cochrane Database of Systematic Reviews

\title{
Silodosin for the treatment of lower urinary tract symptoms in men with benign prostatic hyperplasia (Review)
}

Jung JH, Kim J, MacDonald R, Reddy B, Kim MH, Dahm P

Jung JH, Kim J, MacDonald R, Reddy B, Kim MH, Dahm P.

Silodosin for the treatment of lower urinary tract symptoms in men with benign prostatic hyperplasia.

Cochrane Database of Systematic Reviews 2017, Issue 11. Art. No.: CD012615.

DOI: 10.1002/14651858.CD012615.pub2.

www.cochranelibrary.com 
TABLE OF CONTENTS

ABSTRACT

PLAIN LANGUAGE SUMMARY

SUMMARY OF FINDINGS

BACKGROUND

OBJECTIVES

METHODS

RESULTS

Figure 1.

Figure 2.

Figure 3.

DISCUSSION

AUTHORS' CONCLUSIONS

ACKNOWLEDGEMENTS

REFERENCES

CHARACTERISTICS OF STUDIES

DATA AND ANALYSES

Analysis 1.1. Comparison 1 Silodosin versus placebo, Outcome 1 Urologic symptom scores (short term).

Analysis 1.2. Comparison 1 Silodosin versus placebo, Outcome 2 Quality of life (short term).

Analysis 1.3. Comparison 1 Silodosin versus placebo, Outcome 3 Treatment withdrawal due to any reason (short term). ........

Analysis 1.4. Comparison 1 Silodosin versus placebo, Outcome 4 Treatment withdrawal due to adverse events (short term). ...

Analysis 1.5. Comparison 1 Silodosin versus placebo, Outcome 5 Cardiovascular adverse events (short term).

Analysis 1.6. Comparison 1 Silodosin versus placebo, Outcome 6 Sexual adverse events (short term).

Analysis 2.1. Comparison 2 Silodosin versus tamsulosin, Outcome 1 Urologic symptom scores (short term).

Analysis 2.2. Comparison 2 Silodosin versus tamsulosin, Outcome 2 Quality of life (short term).

Analysis 2.3. Comparison 2 Silodosin versus tamsulosin, Outcome 3 Treatment withdrawal due to any reason (short term). ....

Analysis 2.4. Comparison 2 Silodosin versus tamsulosin, Outcome 4 Treatment withdrawal due to adverse events (short term).

Analysis 2.5. Comparison 2 Silodosin versus tamsulosin, Outcome 5 Cardiovascular adverse events (short term).

Analysis 2.6. Comparison 2 Silodosin versus tamsulosin, Outcome 6 Sexual adverse events (short term).

Analysis 3.1. Comparison 3 Silodosin versus naftopidil, Outcome 1 Urologic symptom scores (short term).

Analysis 3.2. Comparison 3 Silodosin versus naftopidil, Outcome 2 Quality of life (short term).

Analysis 3.3. Comparison 3 Silodosin versus naftopidil, Outcome 3 Treatment withdrawal due to any reason (short term). .....

Analysis 3.4. Comparison 3 Silodosin versus naftopidil, Outcome 4 Treatment withdrawal due to adverse events (short term). .

Analysis 3.5. Comparison 3 Silodosin versus naftopidil, Outcome 5 Cardiovascular adverse events (short term).

Analysis 3.6. Comparison 3 Silodosin versus naftopidil, Outcome 6 Sexual adverse events (short term).

Analysis 4.1. Comparison 4 Silodosin versus alfuzosin, Outcome 1 Urologic symptom scores (short term).

Analysis 4.2. Comparison 4 Silodosin versus alfuzosin, Outcome 2 Quality of life (short term).

Analysis 4.3. Comparison 4 Silodosin versus alfuzosin, Outcome 3 Cardiovascular adverse events (short term).

Analysis 4.4. Comparison 4 Silodosin versus alfuzosin, Outcome 4 Sexual adverse events (short term). 
[Intervention Review]

\section{Silodosin for the treatment of lower urinary tract symptoms in men with benign prostatic hyperplasia}

Jae Hung Jung1,2,3, Jiye Kim4, Roderick MacDonald5, Balaji Reddy ${ }^{6}$, Myung Ha Kim7, Philipp Dahm²,3

1Department of Urology, Yonsei University Wonju College of Medicine, Wonju, Korea, South. 2Department of Urology, University of Minnesota, Minneapolis, Minnesota, USA. 3Urology Section, Minneapolis VA Health Care System, Minneapolis, Minnesota, USA. 4Department of Plastic Surgery, Yonsei University Wonju College of Medicine, Wonju, Korea, South. 5 General Internal Medicine (111-0), Minneapolis VA Medical Center, Minneapolis, Minnesota, USA. ${ }^{6}$ Department of Urology, Massachusetts General Hospital, Boston, USA. ${ }^{7}$ Yonsei Wonju Medical Library, Yonsei University Wonju College of Medicine, Wonju, Korea, South

Contact address: Jae Hung Jung, Department of Urology, Yonsei University Wonju College of Medicine, 20 Ilsan-ro, Wonju, Gangwon, 26426, Korea, South.geneuro95@yonsei.ac.kr.

Editorial group: Cochrane Urology Group.

Publication status and date: New, published in Issue 11, 2017.

Citation: Jung JH, Kim J, MacDonald R, Reddy B, Kim MH, Dahm P. Silodosin for the treatment of lower urinary tract symptoms in men with benign prostatic hyperplasia. Cochrane Database of Systematic Reviews 2017, Issue 11. Art. No.: CD012615. DOI: 10.1002/14651858.CD012615.pub2.

Copyright @ 2017 The Cochrane Collaboration. Published by John Wiley \& Sons, Ltd.

\section{A B S T R A C T}

\section{Background}

A variety of alpha-blockers are used for treating lower urinary tract symptoms (LUTS) in men with benign prostatic hyperplasia (BPH). Silodosin is a novel, more selective alpha-blocker, which is specific to the lower urinary tract and may have fewer side effects than other alpha-blockers.

\section{Objectives}

To assess the effects of silodosin for the treatment of LUTS in men with BPH.

\section{Search methods}

We performed a comprehensive search using multiple databases (Cochrane Library, MEDLINE, EMBASE, Scopus, Google Scholar, and Web of Science), trials registries, other sources of grey literature, and conference proceedings with no restrictions on the language of publication or publication status up until 13 June 2017.

\section{Selection criteria}

We included all parallel, randomized controlled trials. We also included cross-over designs.

\section{Data collection and analysis}

Two review authors independently classified studies and abstracted data from the included studies. We performed statistical analyses using a random-effects model and interpreted them according to the Cochrane Handbook for Systematic Reviews of Interventions. We rated the quality of evidence according to the GRADE approach.

\section{Main results}

We included 19 unique studies with 4295 randomized participants across four comparisons for short-term follow-up. The mean age, prostate volume, and International Prostate Symptom Score were 66.5 years, $38.2 \mathrm{~mL}$, and 19.1, respectively.

\section{Silodosin versus placebo}


Based on four studies with a total of 1968 randomized participants, silodosin may reduce urologic symptom scores in an appreciable number of men (mean difference (MD) -2.65, 95\% confidence interval (Cl) -3.23 to -2.08 ; low-quality evidence). Silodosin likely does not result in a clinically important reduction in quality of life (MD $-0.42,95 \% \mathrm{Cl}-0.71$ to -0.13 ; moderate-quality evidence). It may not increase rates of treatment withdrawal for any reason (relative risk (RR) $1.08,95 \% \mathrm{Cl} 0.70$ to 1.66 ; low-quality evidence). We are uncertain about the effect of silodosin on cardiovascular adverse events (RR $1.28,95 \% \mathrm{Cl} 0.67$ to 2.45 ; very low-quality evidence). Silodosin likely increases sexual adverse events (RR $26.07,95 \% \mathrm{Cl} 12.36$ to 54.97; moderate-quality evidence); this would result in 180 more sexual adverse events per 1000 men ( $95 \% \mathrm{Cl} 82$ more to 388 more).

\section{Silodosin versus tamsulosin}

Based on 13 studies with a total of 2129 randomized participants, silodosin may result in little to no difference in urologic symptom scores ( $M D-0.04,95 \% \mathrm{Cl}-1.31$ to 1.24 ; low-quality evidence) and quality of life (MD - $0.15,95 \% \mathrm{Cl}-0.53$ to 0.22 ; low-quality evidence). We are uncertain about treatment withdrawals for any reason ( $R R 1.02,95 \% \mathrm{Cl} 0.62$ to 1.69 ; very low-quality evidence). Silodosin may result in little to no difference in cardiovascular adverse events ( $R R 0.77,95 \% \mathrm{Cl} 0.53$ to 1.12 ; low-quality evidence). Silodosin likely increases sexual adverse events (RR $6.05,95 \% \mathrm{Cl} 3.55$ to 10.31 ; moderate-quality evidence); this would result in 141 more sexual adverse events per 1000 men (95\% Cl 71 more to 261 more).

\section{Silodosin versus naftopidil}

Based on five studies with a total of 763 randomized participants, silodosin may result in little to no differences in urologic symptom scores (MD - $0.85,95 \% \mathrm{Cl}-2.57$ to 0.87 ; low-quality evidence), quality of life (MD $-0.17,95 \% \mathrm{Cl}-0.60$ to 0.27 ; low-quality evidence), treatment withdrawal for any reason ( $\mathrm{RR} 1.25,95 \% \mathrm{Cl} 0.81$ to 1.93 ; low-quality evidence), and cardiovascular adverse events (RR $1.02,95 \% \mathrm{Cl} 0.41$ to 2.56; low-quality evidence). Silodosin likely increases sexual adverse events (RR $5.93,95 \% \mathrm{Cl} 2.16$ to 16.29 ; moderate-quality evidence); this would result in 74 more sexual adverse events per 1000 men ( $95 \% \mathrm{Cl} 17$ more to 231 more).

\section{Silodosin versus alfuzosin}

Based on two studies with a total of 155 randomized participants, silodosin may or may not result in a clinically important increase in urologic symptom scores (MD 3.83, 95\% Cl 0.12 to 7.54; low-quality evidence). Silodosin likely results in little to no difference in quality of life (MD 0.14, $95 \% \mathrm{Cl}-0.46$ to 0.74 ; moderate-quality evidence). We found no event of treatment withdrawal for any reason. Silodosin may not reduce cardiovascular adverse events (RR $0.67,95 \% \mathrm{Cl} 0.36$ to 1.24 ; low-quality evidence) but likely increases sexual adverse events (RR $37.21,95 \% \mathrm{Cl} 5.32$ to 260.07 ; moderate-quality evidence); this would result in 217 more sexual adverse events per 1000 men (95\% $\mathrm{Cl}$ 26 more to 1000 more).

\section{Authors' conclusions}

Silodosin may reduce urologic symptom scores in an appreciable number of men compared to placebo. Quality of life and treatment withdrawals for any reason appears similar. Its efficacy appears similar to that of other alpha blockers (tamsulosin, naftopidil and alfuzosin) but the rate of sexual side effects is likely higher. Our certainty in the estimates of effect was lowered due to study limitations, inconsistency and imprecision.

\section{PLAIN LANGUAGE SUMMARY}

\section{Silodosin for the treatment of lower urinary tract symptoms in men with benign prostatic hyperplasia}

\section{Review question}

Does silodosin improve bothersome urinary symptoms in men with an enlarged prostate?

\section{Background}

Prostate enlargement is common in men as they get older and may cause difficulties in urination such as a weak stream, having to get up at night and a feeling of not emptying the bladder completely. Silodosin is a newer medication that may help with these symptoms and may cause fewer unwanted drug effects. We did this review to compare silodosin to placebo (dummy drug) and other medications.

\section{Study characteristics}

We included 19 studies with 4295 men. Participants' average age was 66.5 years. All studies included men aged over 40 years and reported that on average these men had a moderate degree of bothersome urinary symptoms.

\section{Key results}

Silodosin may improve urinary symptoms compared to placebo. It may have comparable effects on urinary symptoms, quality of life, treatment discontinuation for any reason, and unwanted drug effects compared to other medications. However, silodosin likely increases unwanted sexual side effects compared to placebo and other medications. 


\section{Quality of the evidence}

The quality of evidence for most outcomes was low. This means that the true effect may be substantially different from what this review shows. 


\section{SUMMARY OF FINDINGS}

Summary of findings for the main comparison. Silodosin compared to placebo for the treatment of lower urinary tract symptoms in men with benign prostatic hyperplasia (short term)

Silodosin compared to placebo for the treatment of lower urinary tract symptoms in men with benign prostatic hyperplasia (short term)

Participants: men with lower urinary tract symptoms suggesting benign prostatic hyperplasia

Setting: likely outpatients

Intervention: silodosin

Comparator: placebo

\begin{tabular}{|c|c|c|c|c|c|}
\hline \multirow[t]{2}{*}{ Outcomes } & \multirow{2}{*}{$\begin{array}{l}\text { № of participants } \\
\text { (studies) }\end{array}$} & \multirow{2}{*}{$\begin{array}{l}\text { Quality of the evi- } \\
\text { dence } \\
\text { (GRADE) }\end{array}$} & \multirow{2}{*}{$\begin{array}{l}\text { Relative effect } \\
(95 \% \mathrm{Cl})\end{array}$} & \multicolumn{2}{|c|}{ Anticipated absolute effects ${ }^{\star}(95 \% \mathrm{Cl})$} \\
\hline & & & & Risk with placebo & Risk difference with silodosin \\
\hline $\begin{array}{l}\text { QoL } \\
\text { Assessed with: IPSS-QoL } \\
\text { Scale from: } 0 \text { (best: delighted) to } 6 \\
\text { (worst: terrible) } \\
\text { Follow-up: mean } 3 \text { months }\end{array}$ & $\begin{array}{l}820 \\
\text { (2 RCTs) }\end{array}$ & $\begin{array}{l}\oplus \oplus \oplus \ominus \\
\text { Moderate a,c }\end{array}$ & - & $\begin{array}{l}\text { The mean change of QoL } \\
\text { ranged from }-1.10 \text { to } \\
-0.80\end{array}$ & $\begin{array}{l}\text { MD } 0.42 \text { lower } \\
\text { ( } 0.71 \text { lower to } 0.13 \text { lower) }\end{array}$ \\
\hline \multirow{2}{*}{$\begin{array}{l}\text { Treatment withdrawal due to any rea- } \\
\text { son } \\
\text { Follow-up: mean } 3 \text { months }\end{array}$} & \multirow{2}{*}{$\begin{array}{l}1703 \\
\text { (3 RCTs) }\end{array}$} & \multirow{2}{*}{$\begin{array}{l}\oplus \oplus \odot \odot \\
\text { Low } a, b\end{array}$} & \multirow{2}{*}{$\begin{array}{l}\text { RR } 1.08 \\
(0.70 \text { to } 1.66)\end{array}$} & Study population & \\
\hline & & & & 83 per 1000 & $\begin{array}{l}7 \text { more per } 1000 \\
\text { ( } 25 \text { fewer to } 55 \text { more) }\end{array}$ \\
\hline \multirow{4}{*}{$\begin{array}{l}\text { Cardiovascular adverse events } \\
\text { Follow-up: mean } 3 \text { months }\end{array}$} & \multirow{4}{*}{$\begin{array}{l}1967 \\
\text { (4 RCTs) }\end{array}$} & \multirow{4}{*}{$\begin{array}{l}\oplus \odot \odot \ominus \\
\text { Very low a,b,d }\end{array}$} & \multirow[t]{4}{*}{$\begin{array}{l}\text { RR } 1.28 \\
(0.67 \text { to } 2.45)\end{array}$} & Study population & \\
\hline & & & & 42 per 1000 & $\begin{array}{l}12 \text { more per } 1000 \\
\text { (14 fewer to } 61 \text { more) }\end{array}$ \\
\hline & & & & Assumed baseline riske & \\
\hline & & & & 61 per 1000 & 17 more per 1000 \\
\hline
\end{tabular}




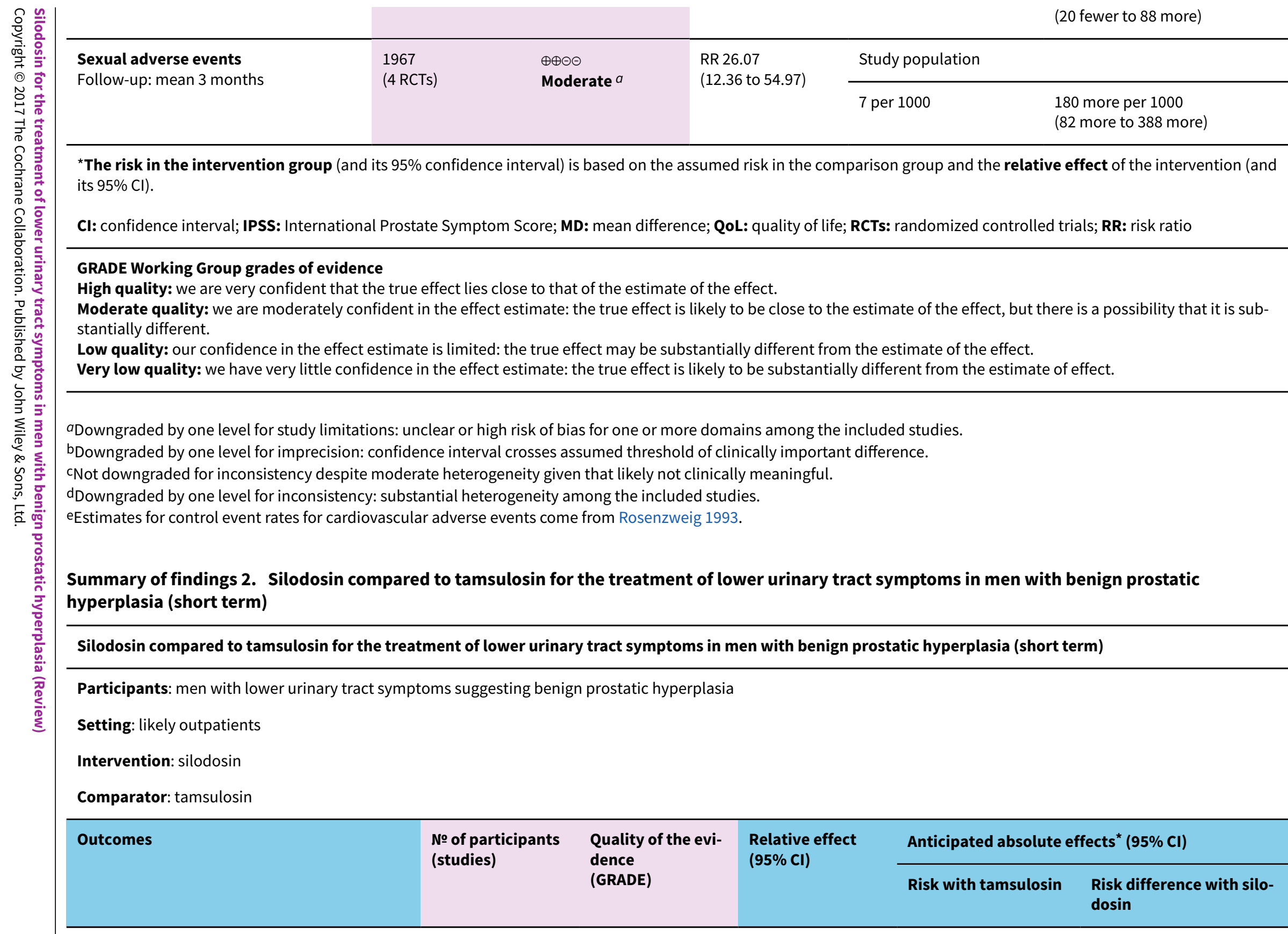

v 


\begin{tabular}{|c|c|c|c|c|c|c|}
\hline \multicolumn{2}{|c|}{ 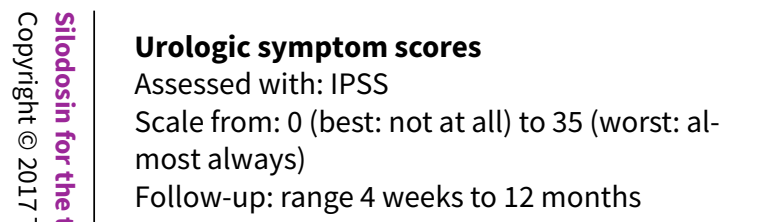 } & $\begin{array}{l}1708 \\
(10 \mathrm{RCTs})\end{array}$ & $\begin{array}{l}\oplus \oplus \ominus \ominus \\
\text { Low } a, b\end{array}$ & - & $\begin{array}{l}\text { The mean change of } \\
\text { urologic symptom } \\
\text { scores ranged from } \\
-15.60 \text { to }-4.60\end{array}$ & $\begin{array}{l}\text { MD } 0.04 \text { lower } \\
\text { (1.31 lower to } 1.24 \text { higher) }\end{array}$ \\
\hline 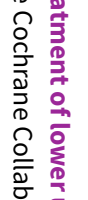 & $\begin{array}{l}\text { QoL } \\
\text { Assessed with: IPSS-QoL } \\
\text { Scale from: } 0 \text { (best: delighted) to } 6 \text { (worst: terri- } \\
\text { ble) } \\
\text { Follow-up: range } 4 \text { weeks to } 12 \text { months }\end{array}$ & $\begin{array}{l}1707 \\
(10 \text { RCTs })\end{array}$ & $\begin{array}{l}\oplus \oplus \ominus \ominus \\
\text { Low } \mathrm{a}, \mathrm{b}\end{array}$ & - & $\begin{array}{l}\text { The mean change of } \\
\text { QoL ranged from }-3.60 \\
\text { to }-0.90\end{array}$ & $\begin{array}{l}\text { MD } 0.15 \text { lower } \\
\text { ( } 0.53 \text { lower to } 0.22 \text { higher) }\end{array}$ \\
\hline 产 & \multirow{2}{*}{$\begin{array}{l}\text { Treatment withdrawal due to any reason } \\
\text { Follow-up: range } 4 \text { weeks to } 12 \text { months }\end{array}$} & \multirow{2}{*}{$\begin{array}{l}1573 \\
(10 \text { RCTs) }\end{array}$} & \multirow{2}{*}{$\begin{array}{l}\oplus \ominus \ominus \ominus \\
\text { Very low a,b,c }\end{array}$} & \multirow{2}{*}{$\begin{array}{l}\text { RR } 1.02 \\
(0.62 \text { to } 1.69)\end{array}$} & \multicolumn{2}{|l|}{ Study population } \\
\hline : & & & & & 121 per 1000 & $\begin{array}{l}2 \text { fewer per } 1000 \\
\text { (46 fewer to } 84 \text { more) }\end{array}$ \\
\hline$\underbrace{0}_{0}$ & \multirow{2}{*}{$\begin{array}{l}\text { Cardiovascular adverse events } \\
\text { Follow-up: range } 4 \text { weeks to } 3 \text { months }\end{array}$} & \multirow{2}{*}{$\begin{array}{l}1955 \\
(11 \text { RCTs })\end{array}$} & \multirow{2}{*}{$\begin{array}{l}\oplus \oplus \ominus \ominus \\
\text { Low } a, c\end{array}$} & \multirow{2}{*}{$\begin{array}{l}\text { RR } 0.77 \\
\text { (0.53 to } 1.12)\end{array}$} & \multicolumn{2}{|l|}{ Study population } \\
\hline 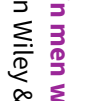 & & & & & 63 per 1000 & $\begin{array}{l}14 \text { fewer per } 1000 \\
\text { ( } 29 \text { fewer to } 8 \text { more) }\end{array}$ \\
\hline 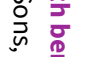 & \multirow{2}{*}{$\begin{array}{l}\text { Sexual adverse events } \\
\text { Follow-up: range } 4 \text { weeks to } 3 \text { months }\end{array}$} & \multirow{2}{*}{$\begin{array}{l}1849 \\
(10 \mathrm{RCTs})\end{array}$} & \multirow{2}{*}{$\begin{array}{l}\oplus \oplus \oplus \ominus \\
\text { Moderate } a\end{array}$} & \multirow{2}{*}{$\begin{array}{l}\text { RR } 6.05 \\
(3.55 \text { to } 10.31)\end{array}$} & \multicolumn{2}{|l|}{ Study population } \\
\hline 熍 & & & & & 28 per 1000 & $\begin{array}{l}141 \text { more per } 1000 \\
\text { ( } 71 \text { more to } 261 \text { more) }\end{array}$ \\
\hline 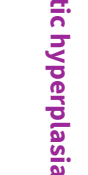 & \multicolumn{6}{|c|}{$\begin{array}{l}{ }^{*} \text { The risk in the intervention group (and its } 95 \% \text { confidence interval) is based on the assumed risk in the comparison group and the relative effect of the intervention (and } \\
\text { its } 95 \% \mathrm{CI} \text { ). }\end{array}$} \\
\hline 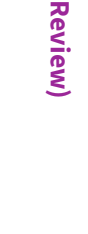 & \multicolumn{6}{|c|}{$\begin{array}{l}\text { GRADE Working Group grades of evidence } \\
\text { High quality: we are very confident that the true effect lies close to that of the estimate of the effect. } \\
\text { Moderate quality: we are moderately confident in the effect estimate: the true effect is likely to be close to the estimate of the effect, but there is a possibility that it is sub- } \\
\text { stantially different. } \\
\text { Low quality: our confidence in the effect estimate is limited: the true effect may be substantially different from the estimate of the effect. } \\
\text { Very low quality: we have very little confidence in the effect estimate: the true effect is likely to be substantially different from the estimate of effect. }\end{array}$} \\
\hline
\end{tabular}

aDowngraded by one level for study limitations: unclear or high risk of bias for one or more domains among the included studies.

bDowngraded by one level for inconsistency: considerable heterogeneity among the included studies.

cDowngraded by one level for imprecision: confidence interval crosses assumed threshold of clinically important difference. 


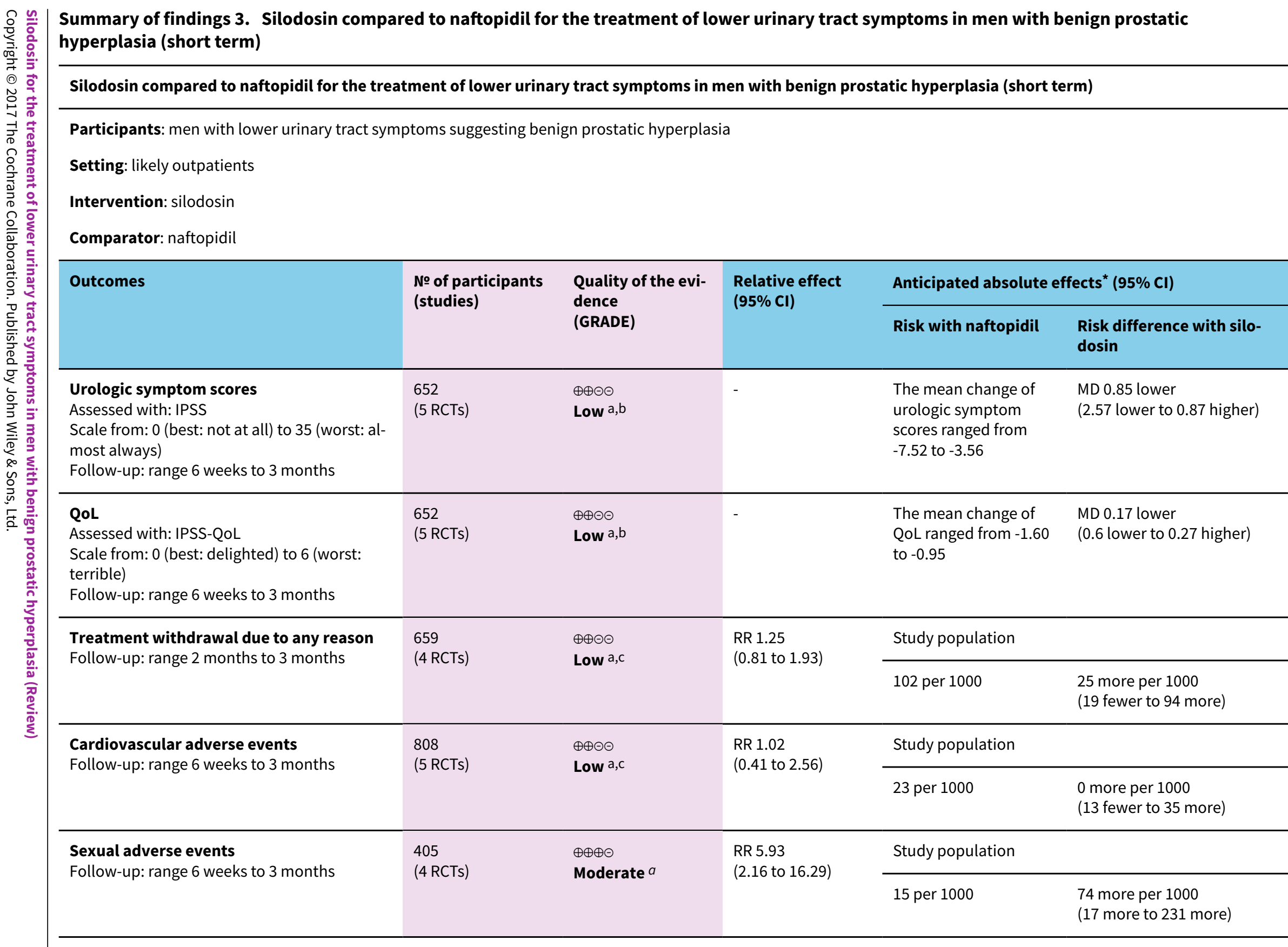




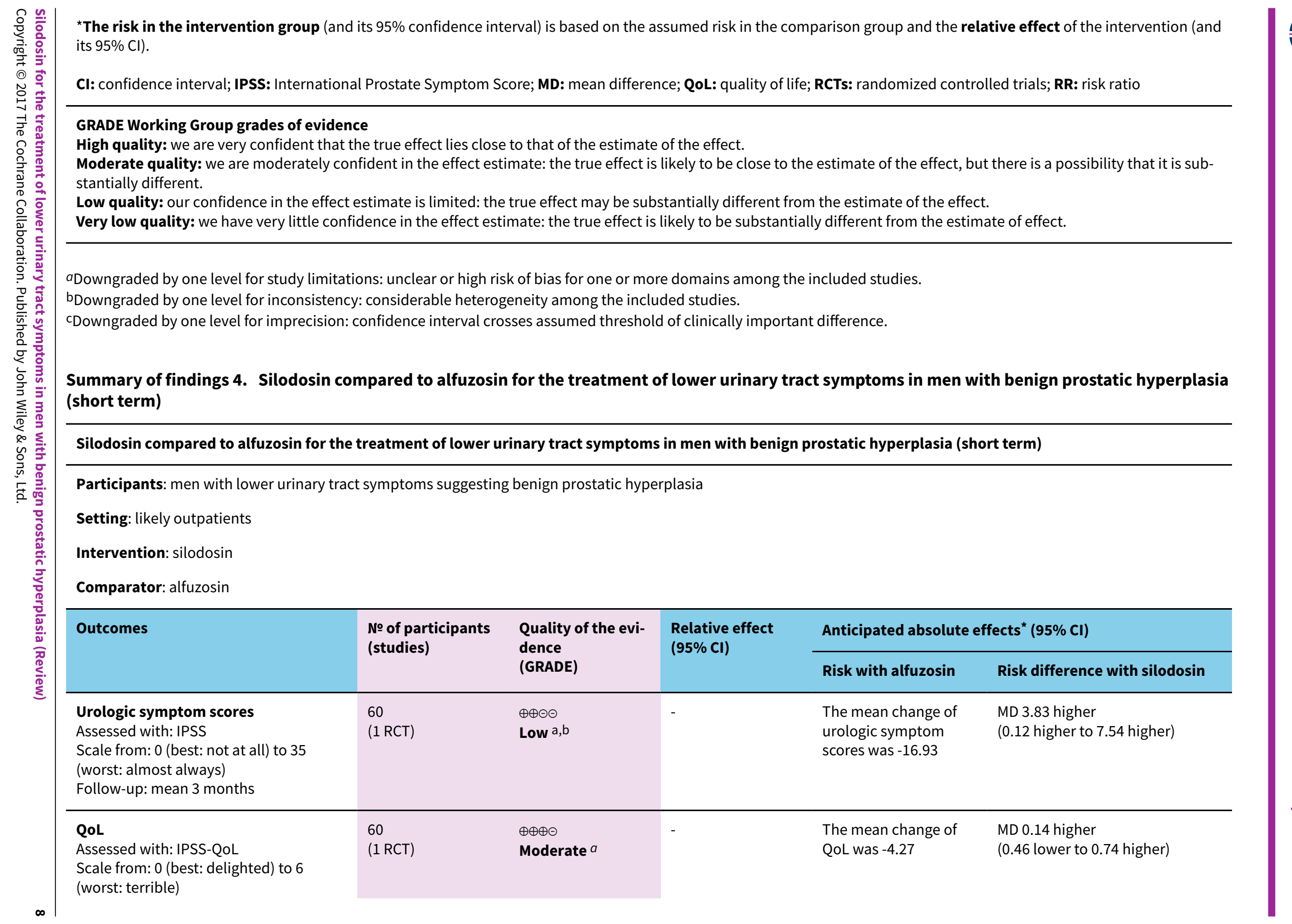




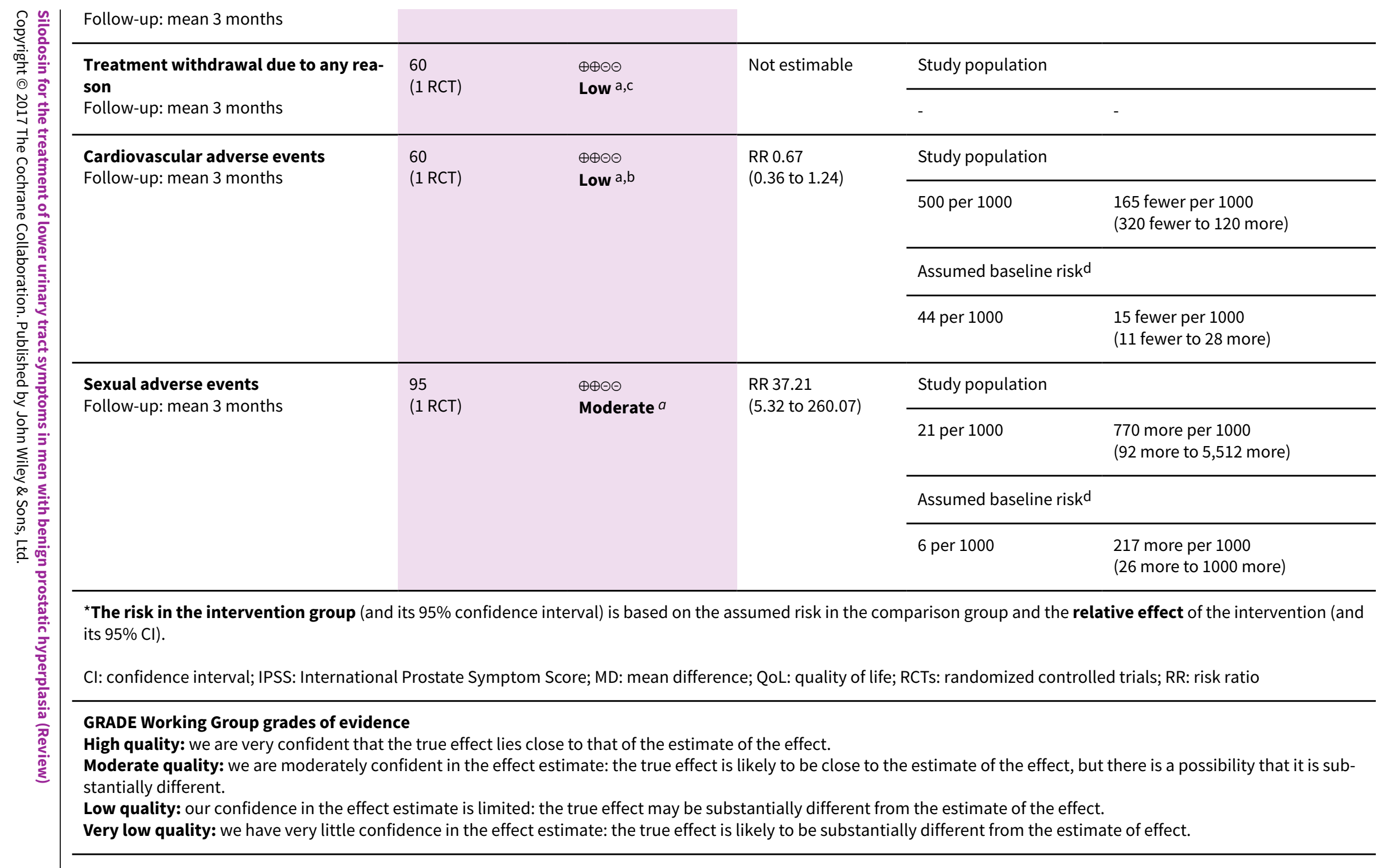

aDowngraded by one level for study limitations: unclear or high risk of bias for one or more domains in the included study.

bDowngraded by one level for imprecision: confidence interval crosses assumed threshold of clinically important difference.

cDowngraded by one level for imprecision: no event (very rare event).

dEstimates for control event rates for cardiovascular and sexual adverse events come from Van Kerrebroec 2002. 


\section{B A C K G R O U N D}

\section{Description of the condition}

Benign prostatic hyperplasia (BPH) is characterized by an unregulated proliferative process of connective tissue, smooth muscle and glandular epithelium within the prostate, and is one of the most common conditions in elderly men (Roehrborn 2008). The prevalence of $\mathrm{BPH}$ rises significantly with increased age. Autopsy studies have observed a histological prevalence of $40 \%$ and $70 \%$ in the sixth and eighth decades of life, respectively (Barry 1997; Egan 2016; Roehrborn 2008). BPH can lead to troublesome lower urinary tract symptoms (LUTS), including storage disturbances (such as daytime urinary urgency and nocturia) or voiding disturbances (such as urinary hesitancy, weak urinary stream, straining to void, and prolonged voiding), or both (AUA Practice Guidelines Committee 2003; EAU 2017; McVary 2011). LUTS secondary to $\mathrm{BPH}$ (LUTS/BPH) may negatively impact on public health and reduce quality of life because BPH can progress over time and cause serious consequences, such as acute urinary retention (AUR), urinary tract infection, and upper urinary tract deterioration (Crawford 2006; Kozminski 2015; Martin 2014). In 2000, the direct treatment cost for LUTS/BPH in the USA was more than USD 1 billion. Based on the Hospital Episode Statistics data from the UK, LUTS/BPH is the fifth most expensive disease and costs GBP 1.16 billion each year (Cornu 2010).

\section{Diagnosis}

Initial assessment of LUTS/BPH includes patient history, review of current medications, physical exam including a digital rectal examination, urinalysis, a frequency/volume chart, and validated symptom questionnaires such as the International Prostate Symptom Score (IPSS) and BPH Impact Index (BII) (EAU 2017; Juliao 2012; McVary 2011). The IPSS questionnaire is composed of three domains related to storage symptoms (frequency, urgency, and nocturia); four domains related to voiding symptoms (hesitancy, weak stream, intermittence, and incomplete emptying); and one quality of life domain (AUA Practice Guidelines Committee 2003; Barry 1992). Seven symptom domains use a six-point scale ranging from 0 (none) to 5 (5 or more) (Barry 1992). The quality of life domain is assigned a score from 1 to 6 (ordinal and range from 0 to $6: 0=$ delighted, $1=$ pleased, $2=$ mostly satisfied, $3=$ mixed, $4=$ mostly dissatisfied, $5=$ unhappy, $6=$ terrible) (AUA Practice Guidelines Committee 2003; Barry 1992).

Simultaneous with the development of the IPSS, the BII was developed to assess the effect of LUTS/BPH on the men's health. The Bll questionnaire is composed of four items: physical discomfort ( $0=$ none, 1 = only a little, $2=$ some, $3=$ a lot $)$; worry item ( $0=$ none, 1 = only a little, $2=$ some, $3=$ a lot); bother item $(0=$ not at all bothersome, $1=$ bothers me a little, $2=$ bothers me some, $3=$ bothers me a lot); the interference with usual activities item $(0=$ none of the time, $1=$ a little of the time, $2=$ some of the time, $3=$ most of the time, $4=$ all of the time) (Barry 1995). In addition, measurement of the maximum flow rate (Qmax) and postvoid residual (PVR) are widely used, noninvasive tests to evaluate joint functioning between bladder and prostate (EAU 2017; McVary 2011). Although diagnostic thresholds of Qmax and PVR have not been determined, low Qmax and large PVR have been associated with an increased risk of symptom deterioration (Crawford 2006; Kozminski 2015). Other optional tests include imaging of the urinary tract and prostate, urodynamic evaluation of bladder function, and cystoscopy to predict the response to medical therapy or determine the need for invasive therapy and therefore, the best approach (EAU 2017; McVary 2011).

\section{Treatment}

Treatment decisions are based on symptoms and degree of bother (EAU 2017; McVary 2011). Watchful waiting is a reasonable treatment strategy for men with mild LUTS (IPSS: 0 to 7 ) or those who do not perceive their symptoms to be particularly bothersome (Netto 1999). Lifestyle interventions such as modifying fluid intake or toileting behavior can be used as conservative treatments in men with mild LUTS (Yap 2009). In men with bothersome, moderate (IPSS: 8 to 19 ) to severe LUTS (IPSS: 20 to 35), surgical and medical therapies are the treatment options, and the choice of treatment depends on a number of factors such as the severity of disease, risk of progression, patient preference, and morbidity (EAU 2017; McVary 2011).

Recently, the dynamic component of BPH has been elucidated, with a focus on symptoms rather than prostate enlargement, which has led to a shift from surgery to medical treatment (Yoo 2012). Alpha-adrenergic receptor blockers (ABs), which reduce smoothmuscle tone in the prostate and bladder neck with/without 5-alpha reductase inhibitors (5-ARIs), which reduce prostate volume by inducing epithelial atrophy, are an established treatment in LUTS/ $\mathrm{BPH}$ and have been widely used as first-line therapy for decades (McConnell 2003; Milani 2005; Yoo 2012). In particular, ABs that can decrease smooth muscle tone in the prostate and bladder neck have been considered as fundamental pharmacotherapy for men with BPH (Cornu 2010; Milani 2005; Yoo 2012). Prior systematic reviews have shown that ABs can typically reduce the IPSS by $20 \%$ to $50 \%$ and increase the Qmax by $15 \%$ to $45 \%$ (MacDonald 2005; Wilt 2006). ABs are the most commonly prescribed category of drug, accounting for about $70 \%$ of all medications prescribed in 2008 (Cornu 2010). Adverse effects of ABs include postural hypotension, dizziness, headache, asthenia, syncope, peripheral edema, and retrograde ejaculation, which cause approximately $4 \%$ to $10 \%$ of men to withdraw from AB treatment (Djavan 1999; Gacci 2014; MacDonald 2005; Schulman 2003; Wilt 2006).

Other medical therapies, such as anticholinergics and desmopressin, have been used with ABs, depending on the main symptoms of patients (Brasure 2016; Dahm 2016; EAU 2017). Alternatively, a phosphodiesterase type 5 inhibitor, tadalafil $(5 \mathrm{mg}$ once daily), has been licensed for the treatment of male LUTS in the last few years, and various plant extracts have been proposed for the treatment of male LUTS (EAU 2017; Keehn 2016; Oelke 2012). In men with LUTS/BPH refractory to conservative/medical treatment or in cases of absolute clinical indications (e.g. AUR, recurrent urinary tract infection, bladder stones or diverticula, hematuria, or renal insufficiency), surgical techniques should be considered (EAU 2017; McVary 2011). Transurethral resection of the prostate (TURP) is regarded as the standard surgical procedure for the treatment of LUTS/BPH (EAU 2017; Juliao 2012; McVary 2011). Recently, minimal invasive laser therapies such as holmium laser enucleation of the prostate and photoselective vaporization were introduced as treatment alternatives to TURP (Nair 2016).

\section{Description of the intervention}

Silodosin is a new subtype selective $A B$ that was approved in Japan in 2006, and more recently has received approval in the USA 
and Europe (Kawabe 2006a; Yoshida 2007). An initial randomized, placebo-controlled trial, which was conducted in Japan showed a greater reduction in IPSS after 12 weeks' treatment compared to both tamsulosin - which is a well established AB for LUTS - and placebo. Furthermore, a clinical benefit in IPSS in the silodosin group over placebo was found from one week onwards (Kawabe 2006a). There were no significant differences in the incidence of cardiovascular adverse events between the silodosin and tamsulosin groups. Abnormal ejaculation was more frequent in the silodosin group than in the tamsulosin group $(22.3 \%$ versus $1.6 \%)$, but only five men $(2.9 \%)$ discontinued treatment due to abnormal ejaculation (Kawabe 2006a).

\section{How the intervention might work}

The Ala adrenergic receptors are a class of $G$ proteincoupled receptors that consists of three homologous subtypes, including $\mathrm{A} 1 \mathrm{a}, \mathrm{A} 1 \mathrm{~b}$, and $\mathrm{A} 1 \mathrm{~d}$ receptors. The Ala receptor subtype predominates in the human prostate, bladder neck, and urethra (Minneman 1994; Schilit 2009). On the other hand, Alb receptor subtypes are mainly expressed in the peripheral vasculature and are important in the regulation of blood pressure. Ald receptor is expressed in the detrusor muscle of the bladder and the sacral region of the spinal cord (Minneman 1994; Schilit 2009). In the initial in vitro study, it was shown that silodosin had a high binding ratio (162:1) for Ala versus Alb receptors, which can be more specific to the lower urinary tract, and may therefore induce a therapeutic effect without cardiovascular side effects, such as dizziness, headache, and orthostatic hypotension related to vasodilation, compared with the other $A B s$, which have either no specific selectivity for the different adrenergic receptor subtypes (alfuzosin, doxazosin, terazosin) or a limited selectivity for the Ala receptor (tamsulosin) (Osman 2012; Schilit 2009; Yoshida 2007).

\section{Why it is important to do this review}

It is unclear whether the high affinity of silodosin to Ala adrenergic receptor actually translates into more clinical benefits and fewer adverse effects in clinical practice (Cui 2012; Novara 2013). While there are existing systematic reviews that compare silodosin to other agents used to treat men with LUTS/BPH, none so far has used the same rigorous methodology as Cochrane Reviews, which include the GRADE approach (Cui 2012; Fusco 2016; Novara 2013). In this era, with the availability of numerous ABs to treat LUTS/ $\mathrm{BPH}$, the findings of this Cochrane Review will be relevant to policymakers, healthcare providers and patients.

\section{O B J E C T I VES}

To assess the effects of silodosin for the treatment of LUTS in men with $\mathrm{BPH}$.

\section{METHODS}

\section{Criteria for considering studies for this review}

\section{Types of studies}

We included parallel, randomized controlled trials regardless of their publication status or language of publication. We also included cross-over designs.

\section{Types of participants}

We included adult men (aged 40 years and over) with LUTS/ $\mathrm{BPH}$. The age limitation was based on the observation that the prevalence of BPH increases in middle-aged and older men (Barry 1997; Egan 2016), and is infrequent in younger men.

We excluded trials of men with a known neurogenic bladder due to spinal cord injury, multiple sclerosis, or central nervous system disease, and men who have been treated with surgery for $\mathrm{BPH}$ already. We included studies in which only a subset of participants were relevant to this review.

\section{Types of interventions}

We planned to investigate the following comparisons of experimental intervention versus comparator intervention. Concomitant interventions had to be the same in the experimental and comparator groups to establish fair comparisons.

\section{Experimental interventions}

- Silodosin

- Silodosin + any 5-ARIs (if available)

Silodosin at $8 \mathrm{mg} /$ day is the clinically recommended dosage in Japan, Europe, and the USA (Chapple 2011; Kawabe 2006a; Marks 2009). A recent study reported that silodosin at $4 \mathrm{mg} /$ day was also useful for Japanese men with BPH, in order to improve treatment compliance (Seki 2015). We included trials with a dosage of silodosin at $8 \mathrm{mg} /$ day (4 mg twice daily or $8 \mathrm{mg}$ once daily) and $4 \mathrm{mg} /$ day.

\section{Comparator interventions}

- Placebo

- Other ABs

- Other ABs + any 5-ARIs (if available)

\section{Comparisons}

- Silodosin versus placebo

- Silodosin versus other ABs

- Silodosin + any 5-ARIs versus other ABs + any 5-ARIs (if available)

\section{Types of outcome measures}

We did not use the measurement of the outcomes assessed in this review as an eligibility criterion.

\section{Primary outcomes}

- Urologic symptom scores

- Quality of life

- Treatment withdrawals for any reason

\section{Secondary outcomes}

- Treatment withdrawals due to adverse events

- AUR

- Surgical intervention for LUTS/BPH

- Cardiovascular adverse events

- Sexual adverse events 


\section{Method and timing of outcome measurement}

- Urologic symptom scores: final value or change from baseline assessed with a validated scale (such as IPSS)

- Quality of life: final value or change from baseline assessed with a validated scale (such as IPSS-quality of life or BII scores)

- Treatment withdrawals for any reason: defined as treatment discontinuation from any cause at any time after participants were randomized to intervention/comparator groups

- Treatment withdrawals due to adverse events: defined as treatment discontinuation from adverse event at any time after participants were randomized to intervention/comparator groups

- AUR: events requiring catheterization after intervention

- Surgical intervention for LUTS/BPH: events requiring other surgical treatment modalities (e.g. TURP) after intervention

- Cardiovascular adverse events: such as dizziness, headache, orthostatic hypotension, and syncope

- Sexual adverse events: such as retrograde ejaculation, anejaculation, and decreased libido

We used the clinically important difference for the review outcomes to rate the quality of the evidence in the 'Summary of finding' tables (Jaeschke 1989; Johnston 2013). When the mean difference (MD) or risk ratio (RR) is equal to or larger than the minimal clinically important difference (MCID), we would assume that many participants may have gained a clinically meaningful improvement from treatment; when the MD is at least half of the MCID but less than the MCID, an appreciable number of participants have likely achieved a clinically meaningful improvement; and when the MD is less than one-half of the MCID, it is unlikely that an appreciable number of participants have achieved a clinically meaningful improvement (Johnston 2010). We considered MCID in the IPSS and BII score to be 3 and 0.5 points, respectively (Barry 1995). We did not find any published information on a MCID for the IPSS-quality of life question. We used a MCID of 1 to assess efficacy and comparative effectiveness (Brasure 2016). We did not establish thresholds for treatment withdrawals due to adverse events, AUR, surgical intervention for LUTS/BPH, cardiovascular adverse events, and sexual adverse events. We considered the clinically important differences of all listed outcomes above as a relative risk increase of at least 25\% (Guyatt 2011a).

We considered outcomes measured up to and including 12 months after randomization as short term, and later than 12 months as long term.

- Up to 12 months (short term)

- More than 12 months (long term)

\section{Main outcomes for 'Summary of findings' tables}

We present 'Summary of findings' tables, reporting the following outcomes listed according to priority.

- Urologic symptom scores

- Quality of life

- Treatment withdrawals for any reason

- Cardiovascular adverse events

- Sexual adverse events

\section{Search methods for identification of studies}

We performed a comprehensive search with no restrictions on the language of publication or publication status. We updated searches within three months prior to the anticipated publication of the review.

\section{Electronic searches}

We initially searched the following sources from inception of each database to 1 September 2016. The date of last search of all databases was 13 June 2017. See Appendix 1.

- Cochrane Library (via Wiley)

* Cochrane Database of Systematic Reviews

* Cochrane Central Register of Controlled Trials (CENTRAL)

* Database of Abstracts of Reviews of Effects

* Health Technology Assessment Database

- MEDLINE (via Pubmed)

- EMBASE (via Ovid)

- Scopus

- Google Scholar

- Web of Science

We also searched the following trials registers on 1 September 2016 and again on 13 June 2017.

- ClinicalTrials.gov (clinicaltrials.gov/)

- World Health Organization International Clinical Trials Registry Platform search portal (apps.who.int/trialsearch/)

- Grey Literature Report (www.greylit.org/)

\section{Searching other resources}

We tried to identify other potentially eligible trials or ancillary publications by searching the reference lists of retrieved included trials, reviews, meta-analyses and health technology assessment reports. We also contacted study authors of included trials to identify any further studies that we might have missed. We contacted drug/device manufacturers for ongoing or unpublished trials. We searched for unpublished studies by handsearching the abstract proceedings of the annual meetings of the American Urological Association, European Association of Urology, and International Continence Society for the last three years (2014 to 2016) and then updated the search for the most recent year (2017).

\section{Data collection and analysis}

\section{Selection of studies}

We used reference management software to identify and remove potential duplicate records (EndNote). Two review authors (JHJ, JK) independently scanned the abstract, title, or both, of remaining records retrieved, to determine which studies should be assessed further. Two review authors (JHJ, JK) investigated all potentially relevant records as full text, mapped records to studies, and classified studies as included studies, excluded studies, studies awaiting classification, or ongoing studies, in accordance with the criteria for each provided in the Cochrane Handbook for Systematic Reviews of Interventions (Higgins 2011a). We used Covidence for title/abstract, and full-text screening. We resolved any discrepancies through consensus or recourse to a third review author (PD). If resolution of a disagreement was not possible, we 
planned to designate the study as 'awaiting classification' and contact study authors for clarification. We documented reasons for exclusion of studies that may have reasonably been expected to be included in the review in a Characteristics of excluded studies table. We present an adapted PRISMA flow diagram showing the process of study selection (Liberati 2009).

\section{Data extraction and management}

We developed a dedicated data abstraction form that we pilot tested ahead of time.

For studies that fulfilled the inclusion criteria, two review authors (JHJ, JK) independently abstracted the following information, which we provided in the Characteristics of included studies table.

- Study design

- Study dates

- Study settings and country

- Participant inclusion and exclusion criteria (e.g. age, baseline IPSS)

- Participant details, baseline demographics (e.g. age, ethnic background, IPSS)

- The number of participants by study and by study arm

- Details of relevant experimental and comparator interventions such as such as frequency (e.g. once a day or twice a day) and treatment duration (in weeks or months)

- Definitions of relevant outcomes, and method (e.g. type of instrument such as IPSS) and timing of outcome measurement (e.g. in weeks or months) as well as any relevant subgroups (e.g. based on age)

- Study funding sources

- Declarations of interest by primary investigators

We extracted outcome data relevant to this Cochrane Review as needed for calculation of summary statistics and measures of variance. For dichotomous outcomes, we obtained numbers of events and totals for population of a $2 \times 2$ table, as well as summary statistics with corresponding measures of variance. For continuous outcomes, we obtained means and standard deviations or data necessary to calculate this information.

We resolved any disagreements by discussion, or, if required, by consultation with a third review author (PD).

We provided information (including trial identifier), about potentially relevant, ongoing studies in the table Characteristics of ongoing studies.

We attempted to contact authors of included studies to obtain key missing data as needed.

\section{Dealing with duplicate and companion publications}

In the event of duplicate publications, companion documents or multiple reports of a primary study, we maximized yield of information by mapping all publications to unique studies and collating all available data. We used the most complete data-set aggregated across all known publications. In case of doubt, we gave priority to the publication reporting the longest follow-up associated with our primary or secondary outcomes.

\section{Assessment of risk of bias in included studies}

Two review authors ( $\mathrm{JHJ}, \mathrm{JK}$ ) assessed the risk of bias of each included study independently. We resolved disagreements by consensus, or by consultation with a third review author (PD).

We assessed risk of bias using Cochrane's 'Risk of bias' assessment tool (Higgins 2011b) for the following domains.

- Random sequence generation (selection bias)

- Allocation concealment (selection bias)

- Blinding of participants and personnel (performance bias)

- Blinding of outcome assessment (detection bias)

- Incomplete outcome data (attrition bias)

- Selective reporting (reporting bias)

- Other sources of bias

We judged risk of bias domains as 'low risk', 'high risk', or 'unclear risk' and evaluated individual bias items as described in the Cochrane Handbook for Systematic Reviews of Interventions (Higgins 2011b). We presented a 'Risk of bias' summary figure to illustrate these findings.

For selection bias (random sequence generation and allocation concealment), we evaluated risk of bias at a trial level.

For performance bias (blinding of participants and personnel), we considered that all outcomes were susceptible to performance bias and assessed in one group.

For detection bias (blinding of outcome assessment), we grouped outcomes as susceptible to detection bias (subjective) or not susceptible to detection bias (objective) outcomes.

We defined the following outcomes as subjective outcomes:

- Urologic symptom scores

- Quality of life

- Treatment withdrawals for any reason

- Treatment withdrawals due to adverse events

- Cardiovascular adverse events

- Sexual adverse events

We defined the following outcomes as objective outcomes:

- AUR

- Surgical intervention for LUTS/BPH

We initially assessed attrition bias (incomplete outcome data) on a per-outcome basis but created groups of outcomes based on similar reporting characteristic.

For reporting bias (selective reporting), we evaluated risk of bias on a trial level.

We further summarized the risk of bias across domains for each outcome in each included study, as well as across studies and domains for each outcome, in accordance with the approach for summary assessments of the risk of bias presented in the Cochrane Handbook for Systematic Reviews of Interventions (Higgins 2011b). 


\section{Measures of treatment effect}

We expressed dichotomous data as RRs with 95\% confidence intervals (Cls). We expressed continuous data as MDs with $95 \% \mathrm{Cls}$ unless different studies used different measures to assess the same outcome, in which case we expressed data as standardized MDs with $95 \%$ Cls.

\section{Unit of analysis issues}

The unit of analysis was the individual participant. For cross-over trials or trials with more than two intervention groups, we planned to incorporate these study designs in meta-analysis in accordance with guidance provided in the Cochrane Handbook for Systematic Reviews of Interventions (Higgins 2011c)

\section{Dealing with missing data}

We obtained missing data from study authors and performed intention-to-treat analyses if data were available; we otherwise performed available case analyses. We investigated attrition rates, for example, dropouts, losses to follow-up and withdrawals, and critically appraised issues of missing data. We did not impute missing data.

\section{Assessment of heterogeneity}

We identified heterogeneity (inconsistency) through visual inspection of the forest plots to assess the amount of overlap of Cls, and the $\mathrm{I}^{2}$ statistic, which quantifies inconsistency across studies to assess the impact of heterogeneity in the meta-analysis (Higgins 2002; Higgins 2003); we interpreted the $\mathrm{I}^{2}$ statistic as follows (Deeks 2011).

- $0 \%$ to $40 \%$ : may not be important

- $30 \%$ to $60 \%$ : may indicate moderate heterogeneity

- $50 \%$ to $90 \%$ : may indicate substantial heterogeneity

- $75 \%$ to $100 \%$ : considerable heterogeneity

When we found heterogeneity, we attempted to determine possible reasons for it by examining individual study and subgroup characteristics.

\section{Assessment of reporting biases}

We attempted to obtain study protocols to assess for selective outcome reporting.

If we included 10 studies or more investigating a particular outcome, we planned to use funnel plots to assess small study effects (Sterne 2011). Several explanations can be offered for the asymmetry of a funnel plot, including true heterogeneity of effect with respect to trial size, poor methodological design (and hence bias of small trials), and publication bias. We therefore interpreted results carefully. However, there were fewer than 10 studies for each comparison.

\section{Data synthesis}

We summarized data using a random-effects model. We interpreted random-effects meta-analyses with due consideration of the whole distribution of effects. In addition, we performed statistical analyses according to the statistical guidelines contained in the Cochrane Handbook for Systematic Reviews of Interventions (Deeks 2011). For dichotomous outcomes, we used the Mantel-Haenszel method; for continuous outcomes, we used the inverse variance method. We used Review Manager 5 software to perform analyses (RevMan 2014).

\section{Subgroup analysis and investigation of heterogeneity}

We expected the following characteristics to introduce clinical heterogeneity, and planned to carry out subgroup analyses with investigation of interactions.

- Severity of baseline symptoms based on IPSS $(0$ to $7=$ mildly symptomatic; 8 to $19=$ moderately symptomatic; 20 to $35=$ severely symptomatic)

- Participant age (less than 65 years versus 65 years and older)

These subgroup analyses are based on the following observations.

- The relationship between changes in IPSS scores and patient global ratings of improvement is influenced by the baseline scores (Barry 1995).

- Tolerability of other ABs (as the main comparator) may differ by patient age but that this may be less the case for silodosin, which would represent a potential benefit of this agent (Kozminski 2015; Lepor 2007; Schilit 2009).

We planned to perform subgroup analyses limited to the primary outcomes.

\section{Sensitivity analysis}

We planned to perform sensitivity analyses limited to the primary outcomes in order to explore the influence of the following factors (when applicable) on effect sizes.

- Restricting the analysis by taking into account risk of bias, by excluding studies at 'high risk' or 'unclear risk' of bias

\section{'Summary of findings' tables}

We presented the quality of the evidence for each outcome according to the GRADE approach, which takes into account five criteria not only related to internal validity (risk of bias, inconsistency, imprecision, publication bias), but also to external validity, such as directness of results (Guyatt 2008). For each comparison, two review authors ( $\mathrm{JHJ}, \mathrm{JK}$, or RM) independently rated the quality of evidence for each outcome as 'high', 'moderate', 'low', or 'very low' using GRADEpro GDT 2015. We resolved any discrepancies by consensus, or, if needed, by arbitration by a third review author (PD). For each comparison, we presented a summary of the evidence for the main outcomes in a 'Summary of findings' table, which provides key information about the best estimate of the magnitude of the effect in relative terms and absolute differences for each relevant comparison of alternative management strategies; numbers of participants and studies addressing each important outcome; and the rating of the overall confidence in effect estimates for each outcome (Guyatt 2011b; Schünemann 2011).

\section{RE S U L T S}

\section{Description of studies}

\section{Results of the search}

We identified 645 records through electronic database searching, including 52 records in trials registers. We found no records in the grey literature repository nor through handsearching abstract 
proceedings of relevant meetings from the last three years. We identified further six records through other sources by searching the reference lists of reviews (Alcántara Montero 2016; Brasure 2016) and one additional protocol for Takeshita 2016. After removal of duplicates, we screened the titles and abstracts of 458 records, and excluded 378 records. We screened 80 full-text articles, and excluded 23 studies ( 24 records) that did not meet the inclusion criteria or were not relevant to the question under trial. Two studies are ongoing and 12 studies are awaiting classification. We included a total of 19 studies (42 records) in the review. The flow of literature through the assessment process is shown in the PRISMA flowchart (Figure 1). 
Figure 1. Flow diagram

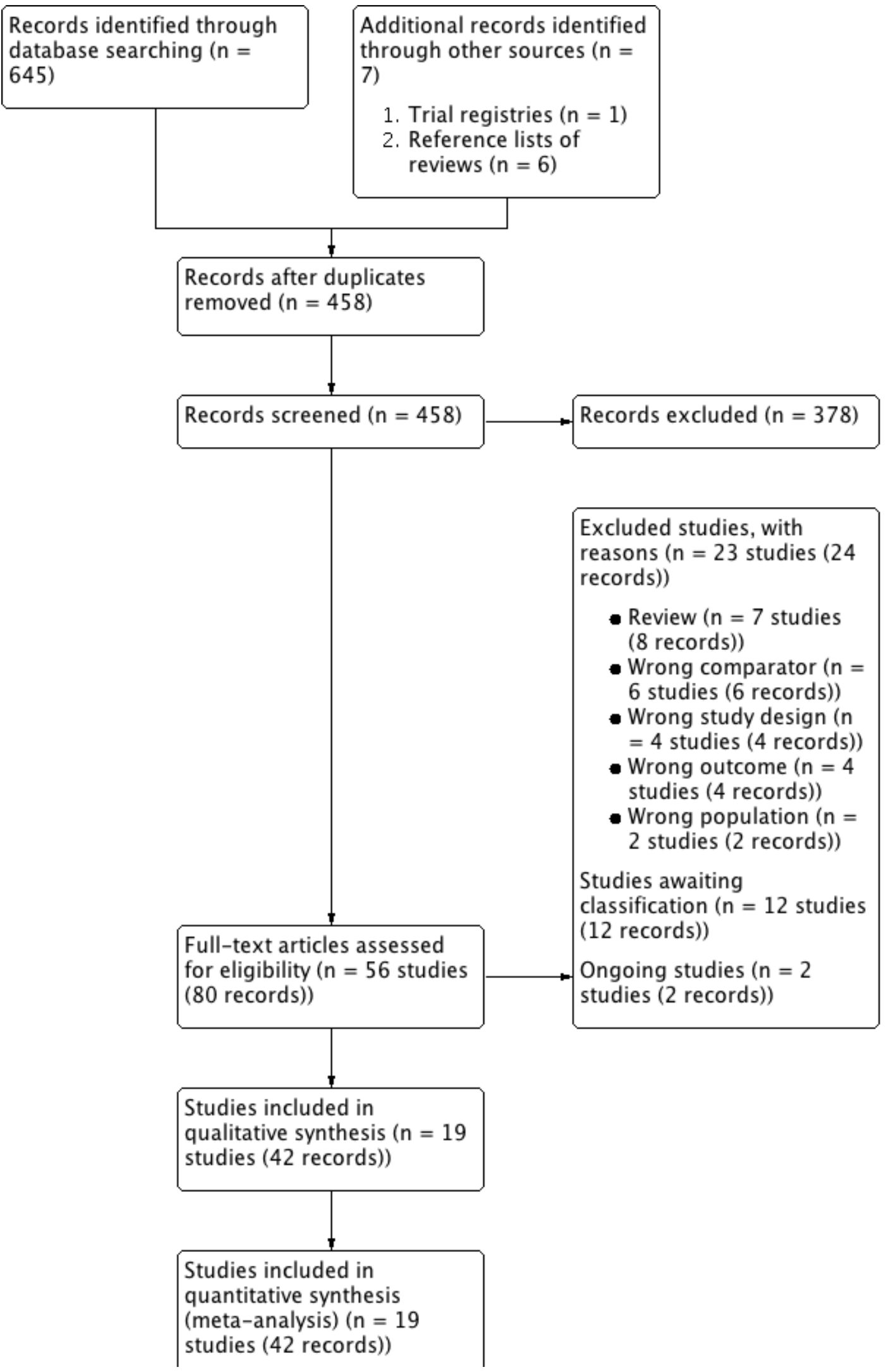


Figure 1. (Continued)

\section{studies (42 records))}

\section{Included studies}

Details of included studies are presented elsewhere (see Characteristics of included studies; Table 1; Table 2).

\section{Source of data}

We included 16 published studies, two abstract proceedings (Jung 2012; Yamanishi 2011), and one record (NCT00793819) from a trials register. Of 16 published studies, we found two studies (Pande 2014; Yokoyama 2011) by searching the reference lists of an existing review (Brasure 2016) and the remaining studies were identified through our electronic database search. Eighteen studies were published in English and one was published in Japanese (Masuda 2012), which was translated into English using Google translator. We attempted to contact all corresponding authors of included trials to obtain additional information on study methodology and results, and received replies from nine (Chapple 2011; Jung 2012; Masuda 2012; Pande 2014; Takeshita 2016; Yamaguchi 2013; Yamanishi 2011; Yokoyama 2011; Yokoyama 2012; see Appendix 2).

\section{Study design and settings}

We included 14 parallel, randomized controlled trials (Chapple 2011; Jung 2012; Kawabe 2006a; Manjunatha 2016a; Marks 2009; Matsukawa 2016; Natarajan 2015; NCT00793819; Pande 2014; Shirakawa 2013; Yamaguchi 2013; Yamanishi 2011; Yokoyama 2011; Yu 2011) and five cross-over trials (Masuda 2012; Miyakita 2010; Takeshita 2016; Watanabe 2011; Yokoyama 2012). Five of 19 studies were reported as 'double-blinded'. The participants and investigators were blinded in three studies (Marks 2009; NCT00793819; Yu 2011) and participants and personnel were blinded in one study (Chapple 2011). One study was reported to be 'double-blinded' but it was not clear who was blinded (Kawabe 2006a). Four studies were open-label trials (Jung 2012; Manjunatha 2016a; Matsukawa 2016; Shirakawa 2013). The remaining five trials had no information regarding blinding. There were three trials with run-in periods (Chapple 2011; Marks 2009; Yu 2011).

All studies were likely conducted in an outpatient clinic setting. Three studies explicitly stated that the trial was conducted in an outpatient clinic setting (Kawabe 2006a; Matsukawa 2016; Pande 2014). Most of the included studies (Jung 2012; Kawabe 2006a; Manjunatha 2016a; Masuda 2012; Matsukawa 2016; Miyakita 2010; Natarajan 2015; Pande 2014; Shirakawa 2013; Takeshita 2016; Watanabe 2011; Yamaguchi 2013; Yokoyama 2011; Yokoyama 2012; Yu 2011) were performed in Asia, except two studies, which were performed in Europe (Chapple 2011) and the USA (Marks 2009). Eight trials (Chapple 2011; Kawabe 2006a; Marks 2009; Masuda 2012; Matsukawa 2016; Miyakita 2010; Takeshita 2016; Watanabe 2011) were multicenter trials. The studies were performed from 2005 to 2015.

\section{Participants}

We included a total of 4295 randomized participants (silodosin 1955, placebo 834 , tamsulosin 1049, naftopidil 380, alfuzosin 77), of which a total of 3751 finished the trials (silodosin 1684, placebo 769 , tamsulosin 888 , naftopidil 333 , alfuzosin 77 ). However, two studies (Natarajan 2015; Yamanishi 2011), that compared silodosin to tamsulosin, did not report the number of participants who completed the trial in each group. All studies included men aged over 40 years. The mean age, prostate volume, prostate specific antigen (PSA), International Prostate Symptom Score (IPSS), and maximum flow rate (Qmax) of the participants were 66.5 years, 38.2 $\mathrm{mL}, 3.14 \mathrm{ng} / \mathrm{mL}, 19.1$, and $9.5 \mathrm{~mL} / \mathrm{s}$, respectively.

Most of the studies included participants with lower urinary tract symptoms (LUTS) of a total IPSS more than 8 (Kawabe 2006a; Manjunatha 2016a; Masuda 2012; Matsukawa 2016; Miyakita 2010; Natarajan 2015; Pande 2014; Shirakawa 2013; Takeshita 2016; Watanabe 2011; Yamaguchi 2013; Yamanishi 2011; Yokoyama 2011; Yokoyama 2012). Participants with IPSS more than 13 were included in three studies (Chapple 2011; Marks 2009; Yu 2011). Two studies (abstract Jung 2012, protocol NCT00793819) did not specify the inclusion criteria for LUTS in detail. Eight out of 19 studies included participants with a prostate volume greater than 20 mL (Kawabe 2006a; Masuda 2012; Matsukawa 2016; Miyakita 2010; Shirakawa 2013; Takeshita 2016; Yamanishi 2011; Yu 2011). Nine studies used $15 \mathrm{~mL} / \mathrm{s}$ or less in Qmax as an inclusion criterion (Chapple 2011; Kawabe 2006a; Manjunatha 2016a; Marks 2009; Matsukawa 2016; Miyakita 2010; Shirakawa 2013; Yamanishi 2011; Yu 2011). Major exclusion criteria included LUTS from any cause other than benign prostatic hyperplasia (BPH), prior treatment with other BPH medical therapy, recent acute urinary retention (AUR), raised prostate-specific antigen (PSA) level suspicious of prostate cancer, a history of prostate cancer or prior prostaterelated surgery. Chapple 2011 excluded men with improvement in the IPSS total score of $25 \%$ or more in the run-in period and Marks 2009 excluded 615 participants due to adverse events, investigator recommendation, lack of efficacy, loss-to-follow-up, protocol violation, voluntary withdrawal, or other issues during the run-in period.

\section{Intervention(s) and comparator(s)}

Silodosin was administered as an oral dose of $8 \mathrm{mg}$ ( $8 \mathrm{mg}$ once daily or $4 \mathrm{mg}$ twice daily) in all studies except one (Takeshita 2016; $4 \mathrm{mg}$ once daily). Two studies titrated the drug dose ( $4 \mathrm{mg}$ followed by 8 $\mathrm{mg}$ ) during the study period (Masuda 2012; Matsukawa 2016).

Four agents, namely placebo, tamsulosin, naftopidil, and alfuzosin were used as comparators. All comparators were administrated orally. Placebo was administrated in accordance with frequencies of silodosin (Chapple 2011; Kawabe 2006a; Marks 2009; NCT00793819). Tamsulosin was administered as an oral dose of 0.2 mg (Jung 2012; Kawabe 2006a; Miyakita 2010; Takeshita 2016; Watanabe 2011; Yokoyama 2011; Yokoyama 2012; Yu 2011) or 0.4 mg once daily (Chapple 2011; Manjunatha 2016a; Natarajan 2015; Pande 2014). One study did not specify the exact dose of tamsulosin (Yamanishi 2011). Naftopidil was administered as an oral dose of $50 \mathrm{mg}$ (Shirakawa 2013; Yokoyama 2011) or $75 \mathrm{mg}$ once daily (Yamaguchi 2013). Two studies titrated the drug dose ( $50 \mathrm{mg}$ followed by $75 \mathrm{mg}$ ) during the study period (Masuda 2012; Matsukawa 2016). Alfuzosin was administered as an oral dose of 10 mg once daily (Jung 2012; Manjunatha 2016a). 
The duration of intervention was 12 weeks in 11 (of 19) studies (Chapple 2011; Kawabe 2006a; Manjunatha 2016a; Marks 2009; Matsukawa 2016; Natarajan 2015; Pande 2014; NCT00793819; Yamaguchi 2013; Yokoyama 2011; Yu 2011). Jung 2012 and Shirakawa 2013 followed the participants for four weeks and eight weeks only, respectively. Yamanishi 2011 reported 12month follow-up data. For cross-over trials, three (Miyakita 2010; Takeshita 2016; Watanabe 2011), one (Masuda 2012), and one study (Yokoyama 2012) reported 4 weeks', 6 weeks', and 12 weeks' followup outcomes before the cross-over, respectively.

\section{Comparisons}

We included four comparisons in this review: four studies compared silodosin to placebo (Chapple 2011; Kawabe 2006a; Marks 2009; NCT00793819). Thirteen (Chapple 2011; Jung 2012; Kawabe 2006a; Manjunatha 2016a; Miyakita 2010; Natarajan 2015; Pande 2014; Takeshita 2016; Watanabe 2011; Yamanishi 2011; Yokoyama 2011; Yokoyama 2012; Yu 2011) compared silodosin to tamsulosin, five (Masuda 2012; Matsukawa 2016; Shirakawa 2013; Yamaguchi 2013; Yokoyama 2011) compared silodosin to naftopidil, and two studies (Jung 2012; Manjunatha 2016a) compared silodosin to alfuzosin. All studies used silodosin, placebo, or other ABs as monotherapy. There were no trials that compared combination therapy with silodosin or any 5-ARIs to combination therapy with other ABs and any 5-ARIs.

\section{Outcomes}

We identified all primary outcomes in each of the included studies for four comparisons. No trial reported on our predefined secondary outcomes of AUR or surgical intervention for LUTS/BPH. However, we were able to obtain additional information by contact with the study authors (Chapple 2011; Pande 2014; Yamaguchi 2013; Yokoyama 2011) which we used for the data analysis across three comparisons. Given the nature of cross-over design studies, we assumed they were not applicable to the outcomes of AUR and surgical intervention for LUTS/BPH for the analysis. Other secondary outcomes were reported in at least one of the included studies.

\section{Funding sources and conflicts of interest}

Four reported no funding source (Jung 2012; Kawabe 2006a; Manjunatha 2016a; Yokoyama 2012), and five were supported by pharmaceutical companies (Chapple 2011; Marks 2009; NCT00793819; Pande 2014; Yu 2011). The remaining did not mention a funding source.

Nine studies reported no conflicts of interest (Kawabe 2006a; Manjunatha 2016a; Pande 2014; Shirakawa 2013; Takeshita 2016; Watanabe 2011; Yamaguchi 2013; Yokoyama 2011; Yokoyama 2012), and four reported having relationships with pharmaceutical companies (Chapple 2011; Marks 2009; NCT00793819; Yu 2011). The remaining did not mention conflicts of interest.

\section{Excluded studies}

We excluded 23 studies (24 records) out of 58 studies ( 80 records) after evaluation of the full-text publications. Seven studies were reviews (Abramowicz 2009; Alcántara Montero 2016; Curran 2011; Montorsi 2010; Montorsi 2013; Prescrire Int 2011; Prescrire Int 2012). Six studies had the wrong comparator (Cakiroglu 2016; JPRNUMIN000007917; Matsukawa 2012; Matsukawa 2017; Yoshida 2017; Yoshihisa 2012). Each of four studies had the wrong study design (Araki 2013; Boeri 2016; Chapple 2009; Kawabe 2006b) and wrong study outcome (Kobayashi 2008; Kobayashi 2009; Manjunatha 2016b; Zhou 2011), respectively. Two studies had the wrong population (Michel 2011; Roehrborn 2009). Details of excluded studies are presented elsewhere (see Characteristics of excluded studies).

\section{Studies awaiting classification and ongoing trials}

We found 12 studies awaiting classification (CTRI/2010/091/000526; Devana 2014; Jha 2015; JPRNUMIN000003125; JPRN-UMIN000005151; JPRN-UMIN000008538; JPRN-UMIN000011556; Mandal 2013; Manohar 2014; Miyamae 2011; NCT01222650; Pawar 2015) that did not provide usable outcome data and two ongoing studies (JPRN-UMIN000003609; CTRI/2013/10/004112). Details of studies awaiting classification and ongoing trials are presented elsewhere (see Characteristics of studies awaiting classification; Characteristics of ongoing studies).

\section{Risk of bias in included studies}

See Figure 2; Figure 3. 
Figure 2. Risk of bias graph: review authors' judgements about each risk of bias item presented as percentages across all included studies

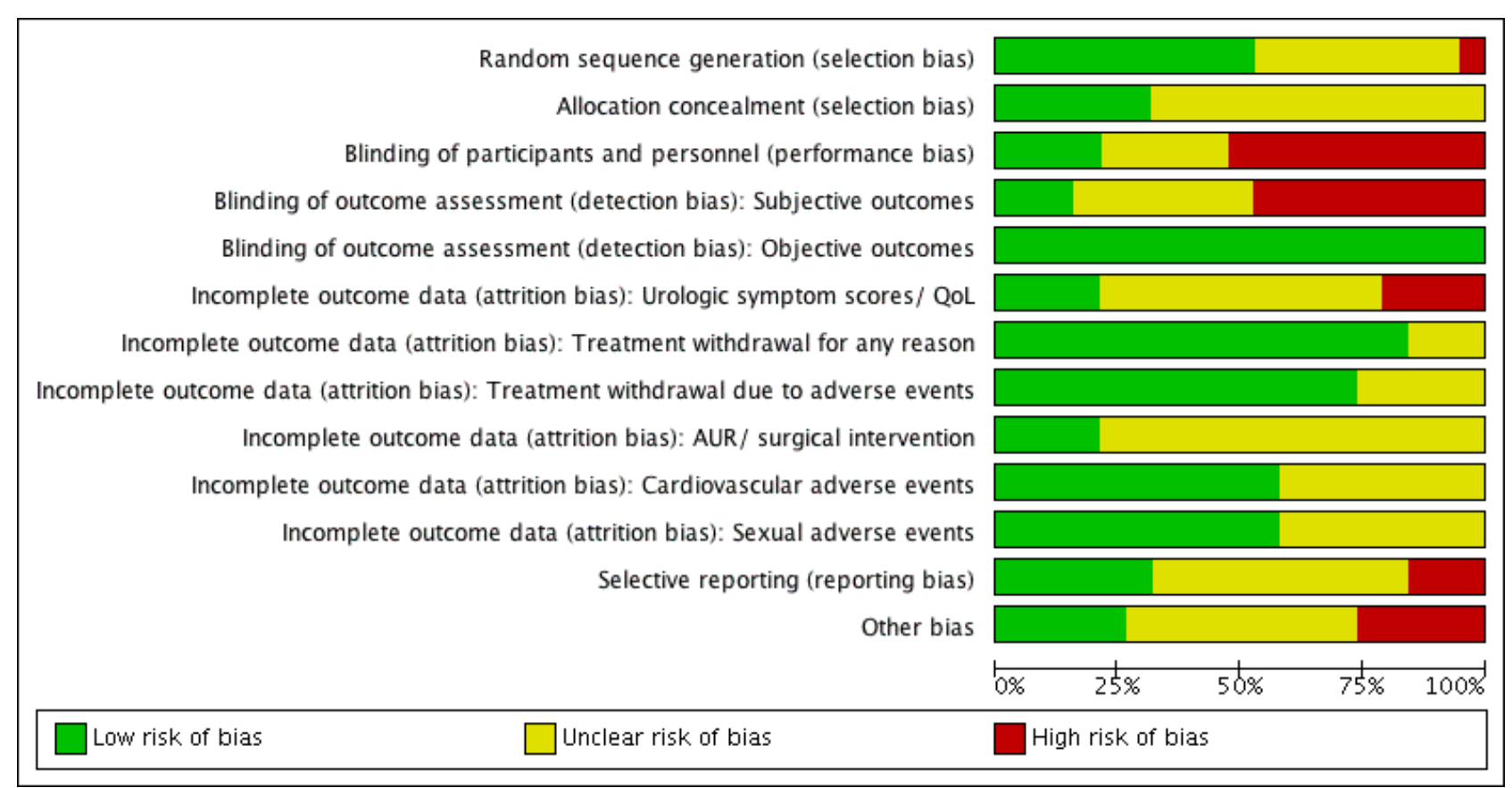


Figure 3. Risk of bias summary: review authors' judgements about each risk of bias item for each included study

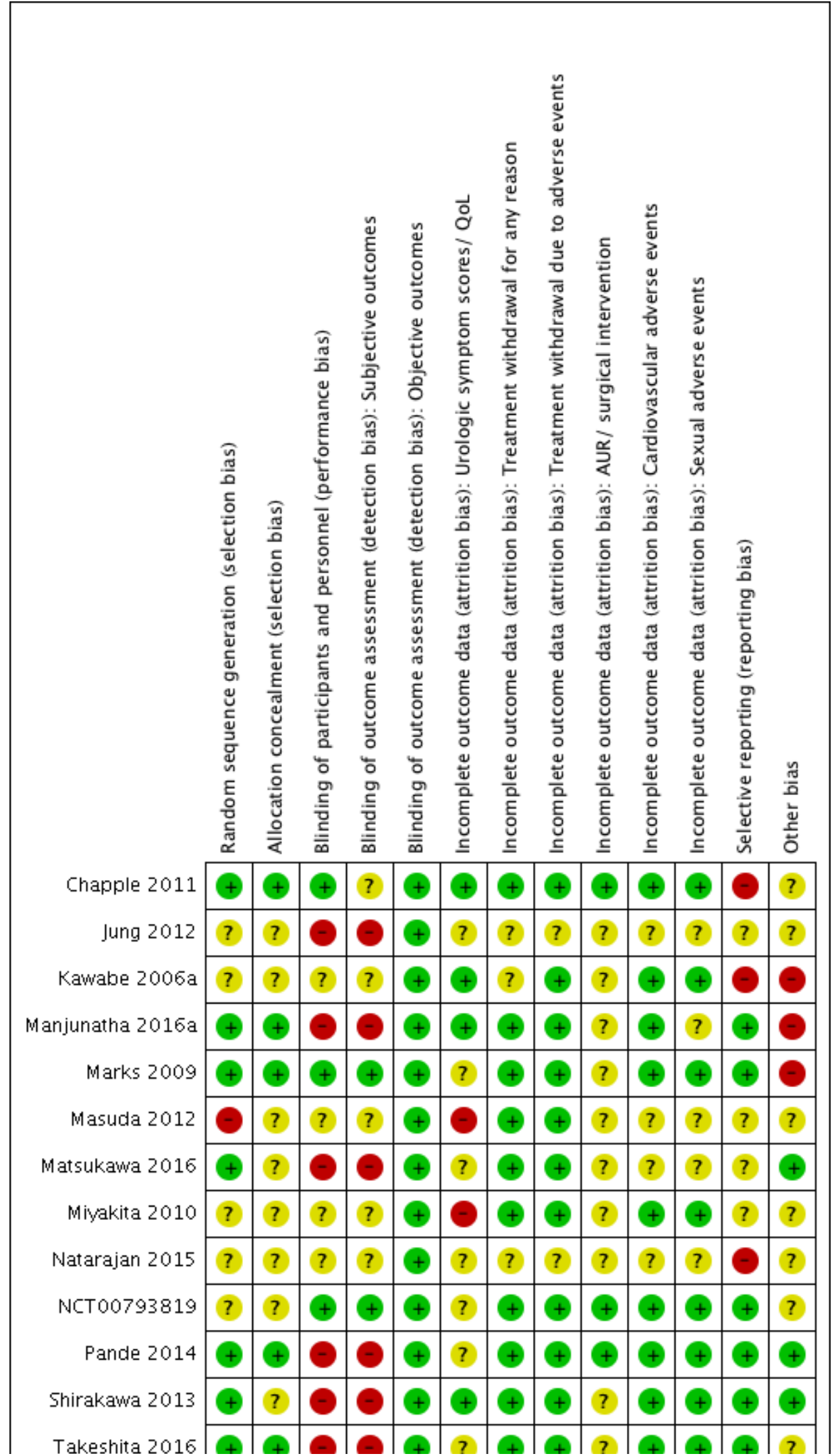


Figure 3. (Continued)

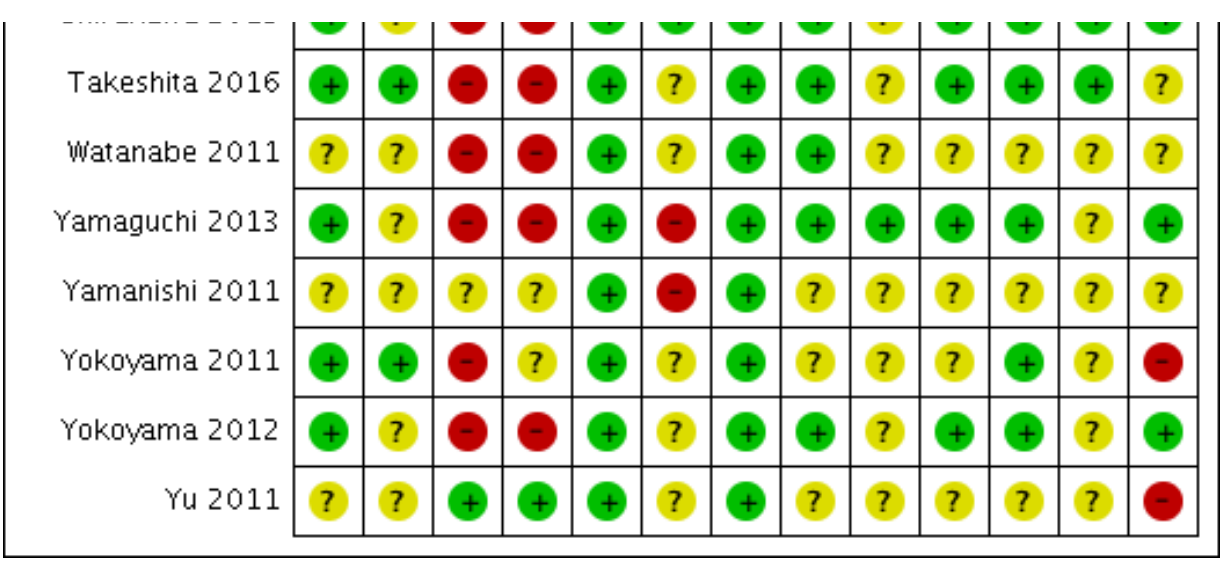

\section{Allocation}

\section{Random sequence generation}

- We rated 10 studies as low risk of bias (Chapple 2011; Manjunatha 2016a; Marks 2009; Matsukawa 2016; Pande 2014; Shirakawa 2013; Takeshita 2016; Yamaguchi 2013; Yokoyama 2011; Yokoyama 2012) and one study as high risk of bias (Masuda 2012). The remaining were judged as unclear risk of bias.

\section{Allocation concealment}

- We rated six studies as low risk of bias (Chapple 2011; Manjunatha 2016a; Marks 2009; Pande 2014; Takeshita 2016; Yokoyama 2011) and the remaining as unclear risk of bias.

\section{Blinding}

\section{Blinding of participants and personnel}

- We rated four studies as low risk of bias (Chapple 2011; Marks 2009; NCT00793819; Yu 2011). We judged 10 studies (Jung 2012; Manjunatha 2016a; Matsukawa 2016; Pande 2014; Shirakawa 2013; Takeshita 2016; Watanabe 2011; Yamaguchi 2013; Yokoyama 2011; Yokoyama 2012) as high risk of bias and the remaining as unclear risk of bias.

\section{Blinding of outcome assessment}

- Subjective outcomes: we rated three studies as low risk of bias for subjective outcomes (Marks 2009; NCT00793819; Yu 2011). We judged nine studies (Jung 2012; Manjunatha 2016a; Matsukawa 2016; Pande 2014; Shirakawa 2013; Takeshita 2016; Watanabe 2011; Yamaguchi 2013; Yokoyama 2012) as high risk of bias and the remaining as unclear risk of bias for subjective outcomes. (Subjective outcomes: urologic symptom scores, quality of life, treatment withdrawal for any reason, treatment withdrawal due to adverse events, cardiovascular adverse events, and sexual adverse events.)

- Objective outcomes: we rated all studies as low risk of bias for objective outcomes because objective outcomes are not likely to be affected by lack of blinding. (Objective outcomes: AUR and surgical intervention for LUTS/BPH.)

\section{Incomplete outcome data}

- Urologic symptom scores and quality of life: we rated four studies as low risk of bias (Chapple 2011; Kawabe 2006a;
Manjunatha 2016a; Shirakawa 2013). We judged four studies (Masuda 2012; Miyakita 2010; Yamaguchi 2013; Yamanishi 2011) as high risk of bias and the remaining as unclear risk of bias.

- Treatment withdrawal for any reason: we rated 16 studies (Chapple 2011; Manjunatha 2016a; Marks 2009; Masuda 2012; Matsukawa 2016; Miyakita 2010; NCT00793819; Pande 2014; Shirakawa 2013; Takeshita 2016; Watanabe 2011; Yamaguchi 2013; Yamanishi 2011; Yokoyama 2011; Yokoyama 2012; Yu 2011) as low risk of bias and three studies (Jung 2012; Kawabe 2006a; Natarajan 2015) as unclear risk of bias. None of the studies were rated as high risk of bias.

- Treatment withdrawal due to adverse events: we rated 14 studies (Chapple 2011; Kawabe 2006a; Manjunatha 2016a; Marks 2009; Masuda 2012; Matsukawa 2016; Miyakita 2010; NCT00793819; Pande 2014; Shirakawa 2013; Takeshita 2016; Watanabe 2011; Yamaguchi 2013; Yokoyama 2012) as low risk of bias and the remaining studies as unclear risk of bias.

- AUR and surgical intervention for LUTS/BPH: we rated four studies (Chapple 2011; NCT00793819; Pande 2014; Yamaguchi 2013) as low risk of bias and the remaining studies as unclear risk of bias.

- Cardiovascular adverse events: we rated 11 studies (Chapple 2011; Kawabe 2006a; Manjunatha 2016a; Marks 2009; Miyakita 2010; NCT00793819; Pande 2014; Shirakawa 2013; Takeshita 2016; Yamaguchi 2013; Yokoyama 2012) as low risk of bias and the remaining studies as unclear risk of bias.

- Sexual adverse events: we rated 11 studies (Chapple 2011; Kawabe 2006a; Marks 2009; Miyakita 2010; NCT00793819; Pande 2014; Shirakawa 2013; Takeshita 2016; Yamaguchi 2013; Yokoyama 2011; Yokoyama 2012) as low risk of bias and the remaining studies as unclear risk of bias.

\section{Selective reporting}

- We rated six studies as low risk of bias (Manjunatha 2016a; Marks 2009; NCT00793819; Pande 2014; Shirakawa 2013; Takeshita 2016). We judged three studies (Chapple 2011; Kawabe 2006a; Natarajan 2015) as high risk of bias and the remaining as unclear risk of bias.

\section{Other potential sources of bias}

- We rated five studies as low risk of bias (Matsukawa 2016; Pande 2014; Shirakawa 2013; Yamaguchi 2013; Yokoyama 2012). We judged five studies (Kawabe 2006a; Manjunatha 2016a; Marks 
2009; Yokoyama 2011; Yu 2011) as high risk of bias due to clinically important imbalances in baseline characteristics and high exclusion rates after placebo run-in periods; the remaining studies were rated as unclear risk of bias.

\section{Effects of interventions}

See: Summary of findings for the main comparison Silodosin compared to placebo for the treatment of lower urinary tract symptoms in men with benign prostatic hyperplasia (short term); Summary of findings 2 Silodosin compared to tamsulosin for the treatment of lower urinary tract symptoms in men with benign prostatic hyperplasia (short term); Summary of findings 3 Silodosin compared to naftopidil for the treatment of lower urinary tract symptoms in men with benign prostatic hyperplasia (short term); Summary of findings 4 Silodosin compared to alfuzosin for the treatment of lower urinary tract symptoms in men with benign prostatic hyperplasia (short term)

Details are presented elsewhere (see Summary of findings for the main comparison; Summary of findings 2; Summary of findings 3; Summary of findings 4).

\section{Silodosin versus placebo}

\subsection{Urologic symptom scores}

We included three randomized controlled trials (RCTs) (Chapple 2011; Kawabe 2006a; Marks 2009) with 1743 participants in the analysis (silodosin 1012, placebo 731). Silodosin may reduce urologic symptom scores in an appreciable number of men (MD $-2.65,95 \% \mathrm{Cl}-3.23$ to $-2.08 ; \mathrm{I}^{2}=0 \%$ ). We rated the quality of the evidence as low, downgrading for study limitations and imprecision (Analysis 1.1).

\subsection{Quality of life}

We included two RCTs (Chapple 2011; Kawabe 2006a) with 820 participants in the analysis (silodosin 546, placebo 274). Silodosin likely results in little or no difference in quality of life (MD - $0.42,95 \%$ $\mathrm{Cl}-0.71$ to $\left.-0.13 ; \mathrm{I}^{2}=57 \%\right)$. We rated the quality of the evidence as moderate, downgrading for study limitations (Analysis 1.2).

\subsection{Treatment withdrawal for any reason}

We included three RCTs (Chapple 2011; Marks 2009; NCT00793819) with 1703 participants in the analysis (silodosin 958, placebo 745). Silodosin may result in little or no difference in treatment withdrawal for any reason ( $\mathrm{RR} 1.08,95 \% \mathrm{Cl} 0.70$ to 1.66 ; $\mathrm{I}^{2}=42 \%$ ). We rated the quality of the evidence as low, downgrading for study limitations and imprecision (Analysis 1.3).

\subsection{Treatment withdrawal due to adverse events}

We included four RCTs (Chapple 2011; Kawabe 2006a; Marks 2009; NCT00793819) with 1967 participants in the analysis (silodosin 1133, placebo 834). Silodosin likely increases treatment withdrawal due to adverse events (RR $2.29,95 \% \mathrm{Cl} 1.41$ to $3.72 ; 12=0 \%$ ). Assuming a baseline risk of treatment withdrawal due to adverse events to be $13.0 \%$ (Preston 2000), silodosin would result in 168 more treatment withdrawals per 1000 men $(95 \% \mathrm{Cl} 53$ more to 354 more). We rated the quality of the evidence as moderate, downgrading for study limitations (Analysis 1.4).

\subsection{AUR}

We included two RCTs (Chapple 2011; NCT00793819) with 780 participants in the analysis (silodosin 492, placebo 288). We found no event for AUR in either study group.

\subsection{Surgical intervention for LUTS/BPH}

We included two RCTs (Chapple 2011; NCT00793819) with 780 participants in the analysis (silodosin 492, placebo 288). We found no event for surgical intervention for LUTS/BPH in either study group.

\subsection{Cardiovascular adverse events}

We included four RCTs (Chapple 2011; Kawabe 2006a; Marks 2009; NCT00793819) with 1967 participants in the analysis (silodosin 1133, placebo 834). We are uncertain about the effect of silodosin on cardiovascular adverse events (RR $1.28,95 \% \mathrm{Cl} 0.67$ to $2.45 ; \mathrm{I}^{2}=$ $55 \%)$. We rated the quality of the evidence as very low, downgrading for study limitations, inconsistency, and imprecision (Analysis 1.5).

\subsection{Sexual adverse events}

We included four RCTs (Chapple 2011; Kawabe 2006a; Marks 2009; NCT00793819) with 1967 participants in the analysis (silodosin 1133, placebo 834). Silodosin likely increases sexual adverse events (RR $26.07,95 \% \mathrm{Cl} 12.36$ to $54.97 ; \mathrm{I}^{2}=0 \%$ ). Silodosin would result in 180 more sexual adverse events per 1000 men (95\% Cl 82 more to 388 more). We rated the quality of the evidence as moderate, downgrading for study limitations (Analysis 1.6).

\section{Subgroup analysis}

We were unable to perform any predefined subgroup analyses because there were no relevant data in the included studies. While we found pooled analyses (Novara 2015) from two included studies (Chapple 2011; Marks 2009) that evaluated the efficacy and safety of silodosin versus placebo, we were unable to replicate these analyses ourselves.

\section{Sensitivity analysis}

We rated three RCTs (Chapple 2011; Marks 2009; NCT00793819) as low risk of bias and reanalyzed the data focused on these studies alone.

- Urologic symptom scores: we found an MD of $-2.60(95 \% \mathrm{Cl}-3.28$ to -1.92 ) with the studies rated as low risk of bias (Chapple 2011; Marks 2009) versus an MD of $-2.65(95 \% \mathrm{Cl}-3.23$ to -2.08$)$ with all included studies (Chapple 2011; Kawabe 2006a; Marks 2009).

- Quality of life: we found an MD of -0.30 (95\% Cl -0.51 to -0.09$)$ with the study rated as low risk of bias (Chapple 2011) versus an MD of $-0.42(95 \% \mathrm{Cl}-0.71$ to -0.13$)$ with all included studies (Chapple 2011; Kawabe 2006a).

- Treatment withdrawal for any reason: we rated all included studies as low risk of bias and we were unable to perform sensitivity analyses for this outcome.

\section{Silodosin versus tamsulosin}

\subsection{Urologic symptom scores}

We included 10 RCTs (Chapple 2011; Kawabe 2006a; Manjunatha 2016a; Miyakita 2010; Pande 2014; Takeshita 2016; Yamanishi 2011; Yokoyama 2011; Yokoyama 2012; Yu 2011) with 1708 participants 
in the analysis (silodosin 859, tamsulosin 849). We used the final value in one study (Pande 2014) and change from baseline in the remaining studies. Silodosin may result in little to no difference in urologic symptom scores (MD $-0.04,95 \% \mathrm{Cl}-1.31$ to $1.24 ; \mathrm{I}^{2}=87 \%$ ). We rated the quality of the evidence as low, downgrading for study limitations and inconsistency (Analysis 2.1).

\subsection{Quality of life}

We included 10 RCTs (Chapple 2011; Kawabe 2006a; Manjunatha 2016a; Miyakita 2010; Pande 2014; Takeshita 2016; Yamanishi 2011; Yokoyama 2011; Yokoyama 2012; Yu 2011) with 1707 participants in the analysis (silodosin 859, tamsulosin 848). We used the final value in two studies (Miyakita 2010; Pande 2014) and change from baseline in the remaining studies. Silodosin may result in little to no difference in quality of life (MD $-0.15,95 \% \mathrm{Cl}-0.53$ to $0.22 ; \mathrm{I}=93 \%$ ). We rated the quality of the evidence as low, downgrading for study limitations and inconsistency (Analysis 2.2).

\subsection{Treatment withdrawal for any reason}

We included 10 RCTs (Chapple 2011; Manjunatha 2016a; Natarajan 2015; Pande 2014; Takeshita 2016; Watanabe 2011; Yamanishi 2011; Yokoyama 2011; Yokoyama 2012; Yu 2011) with 1573 participants in the analysis (silodosin 788, tamsulosin 785). For the crossover trial Watanabe 2011, we applied the conservative approach of only using the number of participants who had been initially randomized, due to lack of information about the number of participants in the analysis. We are uncertain about the effect of silodosin on treatment withdrawal for any reason (RR 1.02, 95\% $\mathrm{Cl} 0.62$ to $1.69 ; \mathrm{I}^{2}=60 \%$ ). We rated the quality of the evidence as very low, downgrading for study limitations, inconsistency, and imprecision (Analysis 2.3).

\subsection{Treament withdrawal due to adverse events}

We included nine RCTs (Chapple 2011; Kawabe 2006a; Manjunatha 2016a; Natarajan 2015; Pande 2014; Takeshita 2016; Watanabe 2011; Yokoyama 2011; Yokoyama 2012) with 1572 participants in the analysis (silodosin 779, tamsulosin 793). For the cross-over trials Watanabe 2011 and Yokoyama 2012, we used only the number of participants who had been initially randomized due to lack of information about the number of participants in the analysis. Silodosin may or may not result in an important increase in treatment withdrawal due to adverse events (RR 1.96, 95\% Cl 1.12 to $3.44 ; 12=0 \%$ ). Silodosin would result in 21 more treatment withdrawals for any reason per 1000 men $(95 \% \mathrm{Cl} 3$ more to 52 more). We rated the quality of the evidence as low, downgrading for study limitations and imprecision (Analysis 2.4).

\subsection{AUR}

We included three RCTs (Chapple 2011; Pande 2014; Yokoyama 2011) with 906 participants in the analysis (silodosin 454, tamsulosin 452). We found no event for AUR in either study group.

\subsection{Surgical intervention for LUTS/BPH}

We included three RCTs (Chapple 2011; Pande 2014; Yokoyama 2011) with 906 participants in the analysis (silodosin 454, tamsulosin 452). We found no event for surgical intervention for LUTS/BPH in either study group.

\subsection{Cardiovascular adverse events}

We included 11 RCTs (Chapple 2011; Kawabe 2006a; Manjunatha 2016a; Miyakita 2010; Natarajan 2015; Pande 2014; Takeshita 2016; Watanabe 2011; Yokoyama 2011; Yokoyama 2012; Yu 2011) with 1955 participants in the analysis (silodosin 967, tamsulosin 988). For cross-over trials, we took all measurements from silodosin periods and all measurements from tamsulosin periods in Watanabe 2011 and analysed these as if the trial were a parallelgroup trial of silodosin versus tamsulosin. However, we used only the number of participants who had been initially randomized due to lack of information about the number of participants in the analysis (Miyakita 2010; Takeshita 2016; Yokoyama 2012). Silodosin may result in little to no difference in cardiovascular adverse events (RR $0.77,95 \% \mathrm{Cl} 0.53$ to $1.12 ; 1^{2}=3 \%$ ). We rated the quality of the evidence as low downgrading for study limitations and imprecision (Analysis 2.5).

\subsection{Sexual adverse events}

We included 10 RCTs (Chapple 2011; Jung 2012; Kawabe 2006a; Natarajan 2015; Pande 2014; Takeshita 2016; Watanabe 2011; Yokoyama 2011; Yokoyama 2012; Yu 2011) with 1849 participants in the analysis (silodosin 920, tamsulosin 929). For cross-over trials, we took all measurements from silodosin periods and all measurements from tamsulosin periods in Watanabe 2011. However, we used only the number of participants who had been initially randomized due to lack of information about the number of participants in the analysis (Yokoyama 2012). Silodosin likely increases sexual adverse events ( $R R 6.05,95 \% \mathrm{Cl} 3.55$ to $10.31 ; 1^{2}=$ $27 \%$ ). Silodosin would result in 141 more sexual adverse events per 1000 men ( $95 \% \mathrm{Cl} 71$ more to 261 more). We rated the quality of the evidence as moderate, downgrading for study limitations (Analysis 2.6).

\section{Subgroup analysis}

We found one cross-over trial that reported subgroup analyses according to age (70 years or older) and symptom severity (IPSS 20 or more) (Watanabe 2011). We were unable to perform preplanned subgroup analysis due to lack of information in within-study comparisons.

\section{Sensitivity analysis}

We rated only one study (Chapple 2011) as low risk of bias and were unable to perform a sensitivity analysis.

\section{Silodosin versus naftopidil}

\subsection{Urologic symptom scores}

We included five RCTs (Masuda 2012; Matsukawa 2016; Shirakawa 2013; Yamaguchi 2013; Yokoyama 2011) with 652 participants in the analysis (silodosin 325, naftopidil 327). We used final value in one study (Masuda 2012) and change from baseline in the remaining studies. Silodosin may result in little to no difference in urologic symptom scores (MD $-0.85,95 \% \mathrm{Cl}-2.57$ to $0.87 ; \mathrm{I}^{2}=84 \%$ ). We rated the quality of the evidence as low, downgrading for study limitations and inconsistency (Analysis 3.1).

\subsection{Quality of life}

We included five RCTs (Masuda 2012; Matsukawa 2016; Shirakawa 2013; Yamaguchi 2013; Yokoyama 2011) with 652 participants in the analysis (silodosin 325, naftopidil 327). We used the final values 
in one study (Masuda 2012) and change from baseline in the remaining studies. Silodosin may result in little to no difference in quality of life (MD $-0.17,95 \% \mathrm{Cl}-0.60$ to $0.27 ; 1^{2}=91 \%$ ). We rated the quality of the evidence as low, downgrading for study limitations and inconsistency (Analysis 3.2).

\subsection{Treatment withdrawal for any reason}

We included four RCTs (Matsukawa 2016; Shirakawa 2013; Yamaguchi 2013; Yokoyama 2011) with 659 participants in the analysis (silodosin 334, naftopidil 325). Silodosin may result in little to no difference in treatment withdrawal for any reason (RR 1.25, $95 \% \mathrm{Cl} 0.81$ to $1.93 ; \mathrm{I}^{2}=0 \%$ ). We rated the quality of the evidence as low, downgrading for study limitations and imprecision (Analysis 3.3).

\subsection{Treament withdrawal due to adverse events}

We included five RCTs (Masuda 2012; Matsukawa 2016; Shirakawa 2013; Yamaguchi 2013; Yokoyama 2011) with 738 participants in the analysis (silodosin 372, naftopidil 366). For the cross-over trial Masuda 2012, we used only the number of participants who had been initially randomized due to lack of information about the number of participants in the analysis. Silodosin may result in little to no difference in treatment withdrawal due to adverse events ( $\mathrm{RR} 1.38,95 \% \mathrm{Cl} 0.66$ to $2.89 ; \mathrm{I}^{2}=0 \%$ ). We rated the quality of the evidence as low downgrading for study limitations and imprecision (Analysis 3.4).

\subsection{AUR}

We included two RCTs (Yamaguchi 2013; Yokoyama 2011) with 180 participants in the analysis (silodosin 94, naftopidil 86 ). We found no event for AUR in either study group.

\subsection{Surgical intervention for LUTS/BPH}

We included two RCTs (Yamaguchi 2013; Yokoyama 2011) with 180 participants in the analysis (silodosin 94 , naftopidil 86 ). We found no event for surgical intervention for LUTS/BPH in either study group.

\subsection{Cardiovascular adverse events}

We included five RCTs (Masuda 2012; Matsukawa 2016; Shirakawa 2013; Yamaguchi 2013; Yokoyama 2011) with 808 participants in the analysis (silodosin 411, naftopidil 397). For cross-over trials, we took all measurements from silodosin periods and all measurements from tamsulosin periods in Masuda 2012. Silodosin may result in little to no difference in cardiovascular adverse events (RR $1.02,95 \% \mathrm{Cl} 0.41$ to $2.56 ; \mathrm{I}^{2}=0 \%$ ). We rated the quality of the evidence as low downgrading for study limitations and imprecision (Analysis 3.5).

\subsection{Sexual adverse events}

We included four RCTs (Masuda 2012; Shirakawa 2013; Yamaguchi 2013; Yokoyama 2011) with 405 participants in the analysis (silodosin 206, naftopidil 199). For cross-over trials, we took all measurements from silodosin periods and all measurements from tamsulosin periods in Masuda 2012. Silodosin likely increases sexual adverse events ( $R R 5.93,95 \% \mathrm{Cl} 2.16$ to $16.29 ; \mathrm{I}^{2}=0 \%$ ). Silodosin would result in 74 more sexual adverse events per 1000 men (95\% Cl 17 more to 231 more). We rated the quality of the evidence as moderate, downgrading for study limitations (Analysis 3.6).

\section{Subgroup analysis}

We were unable to perform any subgroup analyses because there were no relevant data in the included studies.

\section{Sensitivity analysis}

We rated all of the included studies as high or unclear risk of bias and were unable to perform a sensitivity analysis.

\section{Silodosin versus alfuzosin}

\subsection{Urologic symptom scores}

We included one RCT (Manjunatha 2016a) with 60 participants in the analysis (silodosin 30 , alfuzosin 30 ). Silodosin may or may not result in a clinically important increase in urologic symptom scores (MD 3.83, 95\% $\mathrm{Cl} 0.12$ to 7.54 ). We rated the quality of the evidence as low, downgrading for study limitations and imprecision (Analysis 4.1).

\subsection{Quality of life}

We included one RCT (Manjunatha 2016a) with 60 participants in the analysis (silodosin 30 , alfuzosin 30 ). Silodosin likely results in little to no difference in quality of life (MD $0.14,95 \% \mathrm{Cl}-0.46$ to 0.74 ). We rated the quality of the evidence as moderate, downgrading for study limitations (Analysis 4.2).

\subsection{Treatment withdrawal for any reason}

We included one RCT (Manjunatha 2016a) with 60 participants in the analysis (silodosin 30, alfuzosin 30). We found no event in treatment withdrawal for any reason in either study group.

\subsection{Treatment withdrawal due to adverse events}

We included one RCT (Manjunatha 2016a) with 60 participants in the analysis (silodosin 30, alfuzosin 30). We found no event in treatment withdrawal due to adverse events in either study group.

\subsection{AUR}

We did not find any study that reported this outcome.

\subsection{Surgical intervention for LUTS/BPH}

We did not find any study that reported this outcome.

\subsection{Cardiovascular adverse events}

We included one RCT (Manjunatha 2016a) with 60 participants in the analysis (silodosin 30, alfuzosin 30 ). Silodosin may result in little to no difference in cardiovascular adverse events (RR 0.67, $95 \% \mathrm{Cl} 0.36$ to 1.24 ). We rated the quality of the evidence as low, downgrading for study limitations and imprecision (Analysis 4.3).

\subsection{Sexual adverse events}

We included one RCT (Jung 2012) with 95 participants in the analysis (silodosin 48, alfuzosin 47). Silodosin likely increases sexual adverse events (RR 37.21, 95\% Cl 5.32 to 260.07). Assuming a baseline risk of $0.6 \%$ (Van Kerrebroec 2002), silodosin would result in 217 more sexual adverse events per 1000 men $(95 \% \mathrm{Cl} 26$ more to 1000 more). We rated the quality of the evidence as moderate, downgrading for study limitations (Analysis 4.4). 


\section{Subgroup analysis and sensitivity analysis}

We were unable to perform secondary analyses because there were no relevant data or too few data in the included studies.

\section{DISCUSSION}

\section{Summary of main results}

We included 19 unique studies with 4295 randomized participants across four comparisons for short-term follow-up. All studies included men aged over 40 years. The mean age and IPSS of the participants were 66.5 years and 19.1, respectively.

\section{Silodosin versus placebo}

Silodosin may reduce urologic symptom scores in an appreciable number of men but not improve quality of life appreciably. Treatment withdrawals for any reason do not appear increased. We are uncertain about the effect of silodosin on cardiovascular adverse events but silodosin likely increases sexual adverse events. There were no clinically important changes in treatment effects in a sensitivity analysis focused on low risk of bias studies.

\section{Silodosin versus tamsulosin}

Silodosin may result in little to no differences in urologic symptom scores and quality of life. We are uncertain about rates of treatment withdrawal for any reason. Silodosin may result in little to no difference in cardiovascular adverse events but likely increases sexual adverse events substantially.

\section{Silodosin versus naftopidil}

Silodosin may have similar effects in urologic symptom scores, quality of life, rates of treatment withdrawal for any reason and cardiovascular adverse events. Silodosin likely increases sexual adverse events substantially.

\section{Silodosin versus alfuzosin}

Silodosin may or may not result in a clinically important increase in urologic symptom scores and likely results in little to no difference in quality of life. We found no event in treatment withdrawal for any reason. Silodosin may not reduce cardiovascular adverse events but likely increases sexual adverse events substantially.

We were unable to perform any of the predefined subgroup analyses.

\section{Overall completeness and applicability of evidence}

There were a several limitations that related to overall completeness and applicability of evidence that deserve consideration.

- Our ability to assess the longer-term outcomes of silodosin compared to other drugs was limited given that follow-up duration in almost all studies (18 of 19) was 12 weeks or less. Given the long-term use of ABs for the treatment of LUTS/BPH in clinical practice, examining the efficacy and safety of silodosin over such a short term appears insufficient to provide assurance of long-term outcomes.

- Three of the larger trials included in this review used prerandomization run-in periods (Chapple 2011; Marks 2009; Yu 2011). This may have led to the exclusion of men who were less likely to be compliant or more prone to experiencing adverse events, thereby limiting generalizability.

- We were unable to determine the effect of silodosin on AUR or surgical interventions due to the lack of events in the included studies. This once again relates to the short follow-up period. Additional information may have to be drawn from longer-term observational studies.

- Rates of adverse events in two studies available in abstract form only were higher than those reported in full-text studies, raising concern about publication bias (Jung 2012; Yamanishi 2011).

- Although $\mathrm{ABs}$ such as silodosin are commonly used in combination with 5-ARIs, we did not find any eligible studies.

\section{Quality of the evidence}

We consistently downgraded the quality of the evidence by one or two steps to moderate or low. The most common reasons for downgrading were study limitations (issues surrounding allocation concealment and blinding), inconsistency (as reflected by high 12 -values), which we were unable to explain through secondary analyses, and imprecision (wide confidence intervals that crossed the assumed threshold of clinically important difference or due to few events).

\section{Potential biases in the review process}

Despite a comprehensive search strategy without any publication or language restrictions, it is possible that we may have missed relevant publications. A majority of studies originated from Japan and India. It is possible that some, in particular negative studies were published in non-indexed journals or presented at local meetings only and therefore may have escaped our search, resulting in potential publication bias. The number of studies included in this review were insufficient to generate funnel plots; therefore, the risk of publication bias may have been underestimated. A future update of this review should consider the inclusion of regional bibliographic databases to further enhance the search.

We attempted to contact all the study authors on several occasions seeking feedback. While we received additional information from nine study authors, others did not reply. This may represent a source of bias.

For cross-over trials, we tried to extract the data before crossover, as if the study were a parallel-group trial, in accordance with Cochrane Handbook for Systematic Reviews of Interventions (Higgins 2011c). However, two cross-over trials reported adverse events using all measurements from silodosin periods and all measurements from tamsulosin periods (Masuda 2012; Watanabe 2011). This may have given rise to a unit of analysis error. For other cross-over trials, we used the number of participants initially randomized as a more conservative approach. In addition, one cross-over trial used the event rate to report individual adverse events, which may also result in a unit of analysis error (double counting) (Masuda 2012).

\section{Agreements and disagreements with other studies or reviews}

To date, no published systematic review exists that focuses on silodosin and has applied the same rigorous methodology as this Cochrane Review, which includes a published protocol, a focus on 
patient-important outcomes, an exhaustive literature search and an assessment of the quality of the evidence using GRADE.

In a recently reported systematic review and meta-analysis, a variety of $A B$ s including silodosin were found to have a similar efficacy compared to placebo but were associated with significantly higher incidences of total adverse events and treatment withdrawal (Novara 2013; Yuan 2015). On the other hand, Ding 2013 reported no significant difference in the incidence of ejaculation disorder between the silodosin and tamsulosin groups, but we are concerned that the numbers used in the meta-analysis were not accurate. A systematic review of naftopidil reported that silodosin had comparable efficacy with naftopidil but was associated with a higher incidence of sexual adverse events (Castiglione 2014). However, no meta-analysis was reported and the authors did not rate the quality of the evidence. Collectively, the results of the present review are largely consistent with those of previously published reviews compared to placebo, tamsulosin, and naftopidil.

We did not find any published systematic review comparing silodosin to alfuzosin: this review is the first.

\section{AUTHORS' CONCLUSIONS}

\section{Implications for practice}

Based on our findings, the efficacy of silodosin appears to be similar to other ABs including tamsulosin, naftopidil, and alfuzosin but it is associated with increased sexual adverse effects, specifically abnormal ejaculation, which may be an issue for sexually active men.

\section{Implications for research}

The major shortcoming of the current evidence base for silodosin is the short time-horizon of most studies, limiting our understanding of the long-term effectiveness and safety. Given that ABs such as silodosin are used for extended periods of time, typically years, longer-term trials should be performed (and could be mandated by regulatory agencies). In their absence, observational studies may help inform this issue, however, based on a recent systematic review performed by an Evidence-Based Practice Center in the United States few informative observational studies exist (Brasure 2016). There is also a consistent need for greater methodological rigor and reporting transparency.

\section{ACKNOWLEDGEMENTS}

We acknowledge the support received from the authors of included studies, Christopher R. Chapple, Gyung-woo Jung, Leonard S. Marks, Satabdi Pande, Hideki Takeshita, Kenya Yamaguchi, Tomonori Yamanishi, and Teruhiko Yokoyama by providing additional data. We are very grateful to Christopher Filson, Herney Andrés García-Perdomo, Hong Wook Kim, Stavros Gravas, and Valter Silva for having served as peer reviewers. We thank Cochrane Urology and our contact editors Mari Imamura and Muhammad Imran Omar for supporting this review. 


\section{REFERE N CES}

\section{References to studies included in this review}

\section{Chapple 2011 \{published data only\}}

Chapple CR, Montorsi F, Desgrandchamps F, Silodosin European Study Group. Efficacy of silodosin as compared with tamsulosin and placebo for the treatment of the signs and symptoms of benign prostatic hyperplasia. a multicentre, randomised, double-blind, controlled trial. European Urology Supplements 2010;9(2):313. [DOI: http://dx.doi.org/10.1016/ S1569-9056(10)60978-5]

* Chapple CR, Montorsi F, Tammela TL, Wirth M, Koldewijn E, Fernandez Fernandez E, et al. Silodosin therapy for lower urinary tract symptoms in men with suspected benign prostatic hyperplasia: results of an international, randomized, doubleblind, placebo- and active-controlled clinical trial performed in Europe. European Urology 2011;59(3):342-52. [DOI: 10.1016/ j.eururo.2010.10.046; PUBMED: 21109344]

Chapple CR, Montorsi F, Tammela Tl, Wirth M, Koldewijn E, Fernandez Fernandez E. Silodosin therapy for lower urinary tract symptoms in men with suspected benign prostatic hyperplasia: results of an international, randomized, doubleblind, placebo- and active-controlled clinical trial performed in Europe. Urologia 2012;5:38-42, 44-5. [PUBMED: 23342615]

EUCTR2005-005665-11-GB. Evaluation of the efficacy and safety of silodosin vs. Tamsulosin and placebo in the treatment of the signs and symptoms of benign prostatic hyperplasia. Multicentre, randomised, double-blind, controlled trial with an optional long-term open-label extension phase. apps.who.int/ trialsearch/Trial2.aspx?TrialID=EUCTR2005-005665-11-GB (date first received 10 October 2017).

NCT00359905. Evaluation of the Efficacy and Safety of Silodosin in the Treatment of the Signs and Symptoms of BPH. https://clinicaltrials.gov/ct2/show/NCT00359905? term $=$ NCT00359905\&rank $=1$ (date first received 10 October 2017).

\section{Jung 2012 \{published data only\}}

* Jung GW, Park SJ, Seo J. Effect of short-term treatment with silodosin on ejaculatory function in sexually active men with benign prostate hyperplasia. Journal of Urology 2012; Vol. 187, issue 4 Supplement:e511. [DOI: http://dx.doi.org/10.1016/ j.juro.2012.02.1581]

Park SJ, Jung GW, Seo JH. Effect of short-term treatment with silodosin on ejaculatory function in sexually active men with benign prostate hyperplasia. European Urology Supplements 2012;11(1):e744. [DOI: http://dx.doi.org/10.1016/ S1569-9056(12)60741-6]

\section{Kawabe 2006a \{published data only\}}

* Kawabe K, Yoshida M, Homma Y, Silodosin Clinical Study Group. Silodosin, a new alpha1A-adrenoceptor-selective antagonist for treating benign prostatic hyperplasia: results of a phase III randomized, placebo-controlled, double-blind study in Japanese men. BJU International 2006;98(5):1019-24. [DOI: 10.1111/j.1464-410X.2006.06448.x; PUBMED: 16945121]
Yoshida M, Kawabe K, Homma Y. Silodosin, a new effective alpha $1 \mathrm{~A}$-adrenoceptor selective antagonist for the treatment of benign prostatic hyperplasia: results of a phase 3 randomized, placebo-controlled, double-blind study. Journal of Urology 2005;173(4 Supplement):445.

\section{Manjunatha 2016a \{published data only\}}

CTRI/2013/07/003805. A clinical study of the effects of the three licensed drugs alfuzosin, tamsulosin and silodosin in patients with benign prostatic hyperplasia, a disease predominantly causing urinary problems in aging men. apps.who.int/ trialsearch/Trial2.aspx?TrialID=CTRI/2013/07/003805 (date first received 01 September 2017).

* Manjunatha R, Pundarikaksha HP, Madhusudhana HR, Amarkumar J, Hanumantharaju BK. A randomized, comparative, open-label study of efficacy and tolerability of alfuzosin, tamsulosin and silodosin in benign prostatic hyperplasia. Indian Journal of Pharmacology 2016; Vol. 48, issue 2:134-40. [DOI: 10.4103/0253-7613.178825; PUBMED: 27127315]

\section{Marks 2009 \{published data only\}}

Gittelman MC, Marks LS, Hill LA, Volinn W, Hoel G. Efficacy and safety of silodosin in different age groups of men with symptoms of benign prostatic hyperplasia. Journal of the American Geriatrics Society 2009;57(Supplement s1):S122. [DOI: 10.1111/j.1532-5415.2009.02272.x]

* Marks LS, Gittelman MC, Hill LA, Volinn W, Hoel G. Rapid efficacy of the highly selective a1A-adrenoceptor antagonist silodosin in men with signs and symptoms of benign prostatic hyperplasia: pooled results of 2 phase 3 studies. Journal of Urology 2009;181(6):2634-40. [DOI: 10.1016/j.juro.2009.02.034; PUBMED: 19371887]

Marks LS, Gittelman MC, Hill LA, Volinn W, Hoel G. Rapid efficacy of the highly selective $a 1 \mathrm{~A}$-adrenoceptor antagonist silodosin in men with signs and symptoms of benign prostatic hyperplasia: pooled results of 2 phase 3 studies. Journal of Urology 2013;189(1 Suppl):S122-8. [DOI: http://dx.doi.org/10.1016/ j.juro.2012.11.020]

Marks LS, Gittelman MC, Hill LA, Volinn W, Hoel G. Rapid response of irritative and obstructive urinary symptoms of benign prostatic hyperplasia to treatment with silodosin in 2 randomized studies. Journal of Urology 2009;181(4):694. [DOI: http://dx.doi.org/10.1016/S0022-5347(09)61943-1]

NCT00224107. A New Drug for Benign Prostatic Hyperplasia (BPH) Compared With Placebo. clinicaltrials.gov/ct2/show/ NCT00224107?term=NCT00224107\&rank=1 (date first received 10 October 2017).

NCT00224120. A new drug for benign prostatic hyperplasia (BPH) compared with placebo. clinicaltrials.gov/ct2/show/ NCT00224120?term=NCT00224120\&rank=1 (date first received 10 October 2017).

NCT00224133. The evaluation of the safety of a new drug for benign prostatic hyperplasia used for 9 
months. clinicaltrials.gov/ct2/show/NCT00224133? term=NCT00224133\&rank $=1$ (date first received 10 October 2017)

\section{Masuda 2012 \{published data only\}}

Masuda M, Jinza S, Masuko H, Asakura T, Hashiba T. Comparison of naftopidil and silodosin in the treatment of male lower urinary tract symptoms associated with benign prostatic hyperplasia: a randomized, crossover study. Acta Urologica Japonica 2012;58(12):671-8. [PUBMED: 23328162]

\section{Matsukawa 2016 \{published data only\}}

Matsukawa Y, Funahashi Y, Takai S, Majima T, Ogawa T, Narita H, et al. Comparison of silodosin and naftopidil for efficacy in the treatment of benign prostatic enlargement complicated by overactive bladder: a randomized, prospective study (SNIPER study). Journal of Urology 2017;197(2):452-8. [DOI: 10.1016/ j.juro.2016.08.111; PUBMED: 27615436]

\section{Miyakita 2010 \{published data only\}}

Miyakita H, Yokoyama E, Onodera Y, Utsunomiya T, Tokunaga M, Tojo T, et al. Short-term effects of crossover treatment with silodosin and tamsulosin hydrochloride for lower urinary tract symptoms associated with benign prostatic hyperplasia. International Journal of Urology 2010;17(10):869-75. [DOI: http://dx.doi.org/10.1111/j.1442-2042.2010.02614.x]

\section{Natarajan 2015 \{published data only\}}

Natarajan B, Kalra Y. Silodosin versus tamsulosin in symptomatic benign prostatic hyperplasia-Our experience. Journal Of Pharmacy 2015;5(6):8-10. [DOI: 10.9790/XXXXXXXXX]

\section{NCT00793819 \{unpublished data only\}}

NCT00793819. A double-blind, placebo-controlled phase 2 study of silodosin $8 \mathrm{mg}$ daily for the treatment of nocturia in men with benign prostatic hyperplasia. clinicaltrials.gov/ct2/ show/NCT00793819?term=NCT00793819\&rank=1 (date first received 01 September 2017).

\section{Pande 2014 \{published data only\}}

CTRI/2014/01/004366. Evaluation of the effectiveness and safety of silodosin in comparison to tamsulosin in benign prostatic hyperplasia. ctri.nic.in/Clinicaltrials/pdf_generate.php? trialid $=7666 \&$ EncHid=\&modid $=\&$ compid $=\% 27, \% 277666$ det $\% 27$ (date first received 10 October 2017).

\section{* Pande S, Hazra A, Kundu AK. Evaluation of silodosin in comparison to tamsulosin in benign prostatic hyperplasia: a randomized controlled trial. Indian Journal of Pharmacology 2014;46(6):601-7. [DOI: 10.4103/0253-7613.144912]}

\section{Shirakawa 2013 \{published data only\}}

JPRN-UMIN000008331. A comparative study on the clinical effects of silodosin and naftopidil in Japanese patients with lower urinary tract symptoms associated with benign prostatic hyperplasia. apps.who.int/trialsearch/Trial2.aspx? TrialID=JPRN-UMIN000008331 (date first received 10 October 2017).

Shirakawa T, Haraguchi T, Matsumoto M, Morishita S, Minayoshi K, Miyazaki J, et al. A comparative study on the clinical effects of silodosin and naftopidil in patients with lower urinary tract symptoms associated with benign prostatic hyperplasia. Urology 2010;76(3 Supplement):S106.

Shirakawa T, Haraguchi T, Matsumoto Y, Takeda M, Morishita S, Minayoshi K, et al. A comparative study on the clinical effects of silodosin and naftopidil in patients with lower urinary tract symptoms associated with benign prostatic hyperplasia. International Urogynecology Journal and Pelvic Floor Dysfunction 2011;22:S1209.

Shirakawa T, Haraguchi T, Matsumoto Y, Takeda M, Morishita S, Minayoshi K, et al. A comparative study on the clinical effects of silodosin and naftopidil in patients with lower urinary tract symptoms associated with benign prostatic hyperplasia (abstract number 887 ). Joint Meeting of the International Continence Society (ICS) and the International Urogynecological Association. 2010:23-27.

* Shirakawa T, Haraguchi T, Shigemura K, Morishita S, Minayoshi K, Miyazaki J, et al. Silodosin versus naftopidil in Japanese patients with lower urinary tract symptoms associated with benign prostatic hyperplasia: a randomized multicenter study. International Journal of Urology 2013; Vol. 20, issue 9:903-10. [DOI: 10.1111/iju.12055; PUBMED: 23252453]

Shirakawa T, Soga H, Haraguchi T, Takeda M, Morishita S, Sakai Y, et al. A comparative study on the clinical effects of silodosin and naftopidil in patients with lower urinary tract symptoms associated with benign prostatic hyperplasia (abstract number 608). 38th Annual Meeting of the International Continence Society (ICS). 2008:20-24.

\section{Takeshita 2016 \{published data only\}}

JPRN-UMIN000004918. Silodosin 4mg versus tamsulosin $0.2 \mathrm{mg}$ once daily; randomized crossover study. apps.who.int/ trialsearch/Trial2.aspx?TrialID=JPRN-UMIN000004918 (date first received 25 October 2017).

* Takeshita H, Moriyama S, Arai Y, Washino S, Saito K, Chiba K, et al. Randomized crossover comparison of the short-term efficacy and safety of single half-dose silodosin and tamsulosin hydrochloride in men with lower urinary tract symptoms secondary to benign prostatic hyperplasia. LUTS: Lower Urinary Tract Symptoms 2016;8(1):38-43. [DOI: 10.1111/luts.12106]

\section{Watanabe 2011 \{published data only\}}

* Watanabe T, Ozono S, Kageyama S. A randomized crossover study comparing patient preference for tamsulosin and silodosin in patients with lower urinary tract symptoms associated with benign prostatic hyperplasia. Journal of International Medical Research 2011;39(1):129-42. [PUBMED: 21672315 ]

Watanabe T, Ozono S, Kageyama S. Erratum to A randomized crossover study comparing patient preference for tamsulosin and silodosin in patients with lower urinary tract symptoms associated with benign prostatic hyperplasia ( $\mathrm{J}$ Int Med Res 2011;39:129-42). Journal of International Medical Research 2011;39(3):1122. 
Yamaguchi 2013 \{published data only\}

Takahashi S, Yamaguchi K. Treatment of benign prostatic hyperplasia and aging: impacts of alpha-1 blockers on sexual function. Journal of Men's Health 2011;8(Supplement 1):S25-8.

* Yamaguchi K, Aoki Y, Yoshikawa T, Hachiya T, Saito T, Takahashi S. Silodosin versus naftopidil for the treatment of benign prostatic hyperplasia: a multicenter randomized trial. International Journal of Urology 2013;20(12):1234-8. [DOI: 10.1111/iju.12160; PUBMED: 23731168]

Yamanishi 2011 \{published data only\}

Yamanishi T, Sakakibara R, Uchiyama T. Comparison of the effects of silodosin and tamsulosin for the treatment of benign prostatic hyperplasia (Abstract number 290). 41st Annual Meeting of the International Continence Society. 2011.

\section{Yokoyama 2011 \{published data only\}}

Yokoyama T, Hara R, Fukumoto K, Fujii T, Jo Y, Miyaji Y, et al. Effects of three types of alpha-1 adrenoceptor blocker on lower urinary tract symptoms and sexual function in males with benign prostatic hyperplasia. International Journal of Urology 2011;18(3):225-30. [DOI: 10.1111/j.1442-2042.2010.02708.x; PUBMED: 21272091]

\section{Yokoyama 2012 \{published data only\}}

Yokoyama T, Fukumoto K, Hara R, Fujii T, Jo Y, Miyaji Y, et al. Comparison of different a1-adrenoceptor antagonists, tamsulosin hydrochloride and silodosin for treatment of male lower urinary tract symptoms: a prospective randomized crossover study. International Journal of Urology 2011;18(5):404. [DOI: 10.1111/j.1442-2042.2011.02758.x]

* Yokoyama T, Hara R, Fujii T, Jo Y, Miyaji Y, Nagai A. Comparison of two different a1-adrenoceptor antagonists, tamsulosin and silodosin, in the treatment of male lower urinary tract symptoms suggestive of benign prostatic hyperplasia: a prospective randomized crossover study. LUTS: Lower Urinary Tract Symptoms 2012;4(1):14-8. [DOI: 10.1111/ j.1757-5672.2011.00099.x; PUBMED: 26676453]

\section{Yu 2011 \{published data only\}}

Yu HJ, Lin AT, Yang SS, Tsui KH, Wu HC, Cheng CL, et al. Noninferiority of silodosin to tamsulosin in treating patients with lower urinary tract symptoms (LUTS) associated with benign prostatic hyperplasia (BPH). BJU International 2011;108(11):1843-8. [DOI: 10.1111/j.1464-410X.2011.10233.x; PUBMED: 21592295 ]

\section{References to studies excluded from this review}

\section{Abramowicz 2009 \{published data only\}}

Abramowicz M, Zuccotti G, Pflomm JM, Daron SM, Houst BM, Zanone CE, et al. Silodosin (Rapaflo) for benign prostatic hyperplasia. Medical Letter on Drugs and Therapeutics 2009;51(1303):3-4.

\section{Alcántara Montero 2016 \{published data only\}}

Alcántara Montero A. Silodosin in the treatment of lower urinary tract symptoms due to benign prostatic hyperplasia: The standard approach and «real life» use [Silodosina en el tratamiento de los síntomas del tracto urinario inferior en el varón por hiperplasia benigna de próstata: enfoque estándar y uso en la «vida real»]. Revista Mexicana de Urología 2016;76(6):352-9. [DOI: 10.1016/j.uromx.2016.09.005]

* Alcántara Montero A. The role of alpha blockers in the treatment of lower urinary tract symptoms/benign prostatic hyperplasia: are all the same? Silodosin in "real life". Semergen 2016;42 Suppl 2:1-9. [DOI: 10.1016/S1138-3593(16)30245-3; PUBMED: 27889014 ]

\section{Araki 2013 \{published data only\}}

Araki T, Monden K, Araki M. Comparison of 7 al-adrenoceptor antagonists in patients with lower urinary tract symptoms associated with benign prostatic hyperplasia: a short-term crossover study. Acta Medica Okayama 2013;67(4):245-51. [PUBMED: 23970323]

\section{Boeri 2016 \{published data only\}}

Boeri L, Capogrosso P, Ventimiglia E, La Croce G, Moretti D, Scano R, et al. Clinically meaningful improvements in LUTS/ $\mathrm{BPH}$ severity in men treated with silodosin plus Serenoa repens or silodosin alone. Journal of Urology 2016;195(4):e464. [DOI: http://dx.doi.org/10.1016/j.juro.2016.02.1501]

\section{Cakiroglu 2016 \{published data only\}}

Cakiroglu B, Hazar I, Sinanoglu O, Arda E, Ekici S. Comparison of transurethral incision and silodosin in LUTS patients in terms of retrograde ejaculation. European Urology Supplements 2016;5(15):e1236. [DOI: 10.1016/S1569-9056(16)15063-8]

\section{Chapple 2009 \{published data only\}}

Chapple CR, Silodosin European Study Group. Silodosin: a new $\alpha$-adrenoceptor antagonist highly selective for the lower urinary tract. European Urology Supplements 2009;8(4):238. [DOI: http:// dx.doi.org/10.1016/S1569-9056(09)60467-X]

\section{Curran 2011 \{published data only\}}

Curran MP. Silodosin: treatment of the signs and symptoms of benign prostatic hyperplasia. Drugs 2011;71(7):897-907. [DOI: 10.2165/11204780-000000000-00000]

\section{JPRN-UMIN000007917 \{unpublished data only\}}

JPRN-UMIN000007917. Efficacy of silodosin in benign prostatic hyperplasia with overactive bladder. apps.who.int/trialsearch/ Trial2.aspx?TrialID=JPRN-UMIN000007917 (date first received 01 September 2017).

\section{Kawabe 2006b \{published data only\}}

Kawabe K, Yoshida M, Arakawa S, Takeuchi H. Long-term evaluation of silodosin, a new a1A-adrenoceptor selective antagonist for the treatment of benign prostatic hyperplasia: phase III long-term study. Japanese Journal of Urological Surgery 2006;19:153-64.

\section{Kobayashi 2008 \{published data only\}}

Kobayashi K, Masumori N, Hisasue SI, Kato R, Hashimoto K, Itoh $\mathrm{N}$, et al. Inhibition of seminal emission Is the main cause of anejaculation induced by a new highly selective a1ABlocker in normal volunteers. Journal of Sexual Medicine 2008;5(9):2185-90. [DOI: 10.1111/j.1743-6109.2008.00779.x] 
Kobayashi 2009 \{published data only\}

Kobayashi K, Masumori N, Kato R, Hisasue S, Furuya R, Tsukamoto T. Orgasm is preserved regardless of ejaculatory dysfunction with selective alpha 1A-blocker administration. International Journal of Impotence Research 2009;21(5):306-10. [DOI: 10.1038/ijir.2009.27]

\section{Manjunatha 2016b \{published data only\}}

Manjunatha R, Pundarikaksha HP, Madhusudhana HR. A prospective analysis of the cost-effectiveness of alfuzosin, tamsulosin and silodosin for 12 weeks in benign prostatic hyperplasia. International Journal of Basic \& Clinical Pharmacology 2016;5(6):2481-7. [DOI: 10.18203/2319-2003.ijbcp20164109]

\section{Matsukawa 2012 \{published data only\}}

Matsukawa Y, Hattori R, Mazima T, Yamamoto T, Yoshino Y, Gotoh M. Is combination therapy with an anticholinergic agent and an alpha1-adrenoceptor antagonist useful as firstline treatment in patients with benign prostatic hyperplasia complicated by overactive bladder? A randomized, prospective, comparative study using a urodynamic study. European Urology Supplements 2012;11(1):e753. [DOI: http://dx.doi.org/10.1016/ S1569-9056(12)60750-7]

\section{Matsukawa 2017 \{published data only\}}

Matsukawa Y, Takai S, Funahashi Y, Majima T, Kato M, Yamamoto T, et al. Effects of withdrawing alpha-1 blocker from the combination therapy with alpha-1 blocker and 5alpha-reductase inhibitor in patients with lower urinary tract symptoms suggestive of benign prostatic hyperplasia: a prospective and comparative trial using urodynamics. Journal of Urology 2017 [Epub ahead of print]; Vol. May. [DOI: 10.1016/ j.juro.2017.05.031; PUBMED: 28499730 ]

\section{Michel 2011 \{published data only\}}

Michel MC, Casi M, Antonellini A. Silodosin consistently improves nocturia in men with LUTS suggestive of $\mathrm{BPH}$. Analysis of three phase III placebo-controlled studies. European Urology Supplements 2011;10(2):121-2. [DOI: http://dx.doi.org/10.1016/ S1569-9056(11)60327-8]

\section{Montorsi 2010 \{published data only\}}

Montorsi F. Profile of silodosin. European Urology Supplements 2010;9(4):491-5. [DOI: 10.1016/j.eursup.2010.04.001]

\section{Montorsi 2013 \{published data only\}}

Montorsi F. Profile of silodosin. Urologiia 2013;2:112-4, 116-7. [PUBMED: 23789376 ]

Prescrire Int 2011 \{published data only\} Prescribe International. Silodosin. Prescrire International 2011;20(118):180.

\section{Prescrire Int 2012 \{published data only\}}

Prescribe International. Silodosin: erectile and ejaculatory disorders. Prescrire International 2012; Vol. 21, issue 127:129.

\section{Roehrborn 2009 \{published data only\}}

Roehrborn CG, Lepor H, Kaplan SA. Retrograde ejaculation induced by silodosin is the result of relaxation of smooth musculature in the male uro-genital tracts and is associated with greater urodynamic and symptomatic improvements in men LUTS secondary to BPH. Journal of Urology 2009;181(4):694-5. [DOI: http://dx.doi.org/10.1016/ S0022-5347(09)61944-3]

\section{Yoshida 2017 \{published data only\}}

Yoshida M, Origasa H, Seki N. Comparison of silodosin versus tadalafil in patients with lower urinary tract symptoms associated with benign prostatic hyperplasia. Lower Urinary Tract Symptoms 2017 [Epub ahead of print]; Vol. April. [DOI: 10.1111/luts.12177; 28439987]

\section{Yoshihisa 2012 \{published data only\}}

Yoshihisa M, Ryohei H, Shun T, Tokunori Y, Momokazu G. The effect of combination therapy with an anticholinergic agent and an + 1-adrenoceptor antagonist in patients with benign prostatic hyperplasia complicated by an overactive bladder: a randomized, prospective, comparative, urodynamic study. International Journal of Urology 2012;19:180. [DOI: 10.1111/ j.1442-2042.2012.03167.x]

\section{Zhou 2011 \{published data only\}}

Zhou Y, Sun PH, Liu YW, Zhao X, Meng L, Cui YM. Safety and pharmacokinetic studies of silodosin, a new alpha(1A)adrenoceptor selective antagonist, in healthy Chinese male subjects. Biological and Pharmaceutical Bulletin 2011;34(8):1240-5. [PUBMED: 21804212 ]

\section{References to studies awaiting assessment}

CTRI/2010/091/000526 \{unpublished data only\}

CTRI/2010/091/000526. A clinical trial to study the effects of silodosin in patients with benign prostatic hyperplasia. apps.who.int/trialsearch/Trial2.aspx? TrialID=CTRI/2010/091/000526 (date first received 01 September 2017).

Devana 2014 \{published data only\}

Devana SK, Singh SK, Ravi Mohan SM, Mandal AK. A prospective randomized study on the short term efficacy of three alpha 1 adrenergic blockers in patients with symptomatic benign prostatic hyperplasia. Indian Journal of Urology 2014; Vol. 30:S96.

\section{Jha 2015 \{published data only\}}

Jha SK, Kumar A, Vasudeva P, Kumar R, Singh H, Kumar G. Prospective randomised comparative study of safety and efficacy of silodosin versus tamsulosin in the medical management of benign prostatic enlargement causing lower urinary tract symptoms. Indian Journal of Urology 2015; Vol. 31:S69.

\section{JPRN-UMIN000003125 \{unpublished data only\}}

JPRN-UMIN000003125. CLSS-based assessment of alfaadrenoceptor blockers for male LUTS (CLAM-STUDY). apps.who.int/trialsearch/Trial2.aspx?TrialID=JPRNUMIN000003125 (date first received 01 September 2017). 
JPRN-UMIN000005151 \{unpublished data only\}

JPRN-UMIN000005151. The clinical study for evaluating the early efficacy and safety of alpha-1-adrenoreceptor antagonists in patient with benign prostatic hyperplasia. apps.who.int/ trialsearch/Trial2.aspx?TrialID=JPRN-UMIN000005151 (date first received 01 September 2017).

\section{JPRN-UMIN000008538 \{unpublished data only\}}

JPRN-UMIN000008538. Comparison of the long-term efficacy of silodosin and tamsulosin for the treatment of benign prostatic hyperplasia. apps.who.int/trialsearch/Trial2.aspx? TrialID=JPRN-UMIN000008538 (date first received 01 September 2017)

\section{JPRN-UMIN000011556 \{unpublished data only\}}

JPRN-UMIN000011556. Comparative study of early efficacy of once-daily dosing between silodosin $4 \mathrm{mg}$ and tamsulosin $0.2 \mathrm{mg}$ for voiding symptoms associated with benign prostatic hyperplasia. apps.who.int/trialsearch/Trial2.aspx? TrialID=JPRN-UMIN000011556 (date first received 01 September 2017).

\section{Mandal 2013 \{published data only\}}

Mandal A, Devana S, Singh S, Mavuduru R. Evaluation of short term efficacy of different alfa adrenergic blockers on LUTS in patients with symptomatic BPH. Journal of Endourology 2013; Vol. 27:A75-76.

\section{Manohar 2014 \{published data only\}}

Manohar CS, Kamath AJ. Prospective randomize study of clinical out come of management of luts in BPH using silodosin/ tamsulosin/alfuzosin. Indian Journal of Urology 2014; Vol. 30:S94-5

\section{Miyamae 2011 \{published data only\}}

Miyamae K, Kitani K, Miyamoto K, Nakakuma K, Yamamoto T, Maehara A, et al. Investigation of the early effects of 1-blockers in a comparative study focusing on patient evaluation. International Urogynecology Journal and Pelvic Floor Dysfunction 2011; Vol. 22:S253-4.

\section{NCT01222650 \{unpublished data only\}}

NCT01222650. A randomized, double-blind, placebocontrolled, multicentre study of KSO-0400 in BPH patients with LUTS. clinicaltrials.gov/ct2/show/NCT01222650? term=NCT01222650\&rank $=1$ (date first received 01 September 2017).

\section{Pawar 2015 \{published data only\}}

Pawar DS, Kumar A, Singh R, Singh SK. Comparative evaluation of silodosin and tamsulosin in treatment of patients with lower urinary tract symptoms with benign prostatic hyperplasia. Indian Journal of Urology 2015; Vol. 31:S137.

\section{References to ongoing studies}

\section{CTRI/2013/10/004112 \{unpublished data only\}}

CTRI/2013/10/004112. A study to find out the medication which offers maximum health benefits with minimum spending by the patient among the three commonly used medications in the treatment of benign prostatic hyperplasia, a disease in aging men which results in bothersome urinary problems. apps.who.int/trialsearch/Trial2.aspx? TrialID=CTRI/2013/10/004112 (date first received 01 September 2017).

JPRN-UMIN000003609 \{unpublished data only\}

JPRN-UMIN000003609. The effects of selective alpha-1adrenergic receptor antagonists in patients with lower urinary tract symptoms caused by benign prostatic hyperplasia who failed to obtain sufficient efficacy by previous alpha-1-blockades. A comparison of naftopidil or silodosin. apps.who.int/trialsearch/Trial2.aspx?TrialID=JPRNUMIN000003609 (date first received 01 September 2017).

\section{Additional references}

\section{AUA Practice Guidelines Committee 2003}

AUA Practice Guidelines Committee. AUA guideline on management of benign prostatic hyperplasia (2003). Chapter 1 : Diagnosis and treatment recommendations. Journal of Urology 2003;170(2 Pt 1):530-47.

\section{Barry 1992}

Barry MJ, Fowler FJ Jr, O'Leary MP, Bruskewitz RC, Holtgrewe HL, Mebust WK, et al. The American Urological Association symptom index for benign prostatic hyperplasia. The Measurement Committee of the American Urological Association. Journal of Urology 1992;148(5):1549-57; discussion 1564.

\section{Barry 1995}

Barry MJ, Williford WO, Chang Y, Machi M, Jones KM, WalkerCorkery $\mathrm{E}$, et al. Benign prostatic hyperplasia specific health status measures in clinical research: how much change in the American Urological Association symptom index and the benign prostatic hyperplasia impact index is perceptible to patients?. Journal of Urology 1995;154(5):1770-4.

\section{Barry 1997}

Barry MJ, Fowler FJ Jr, Bin L, Pitts JC 3rd, Harris CJ, Mulley AG Jr. The natural history of patients with benign prostatic hyperplasia as diagnosed by North American urologists. Journal of Urology 1997;157(1):10-4; discussion 14-5.

\section{Brasure 2016}

Brasure M, MacDonald R, Dahm P, Olson CM, Nelson VA, Fink HA, et al. AHRQ comparative effectiveness reviews. Newer Medications for Lower Urinary Tract Symptoms Attributed to Benign Prostatic Hyperplasia: a Review. Rockville (MD): Agency for Healthcare Research and Quality (US), 2016.

\section{Castiglione 2014}

Castiglione F, Benigni F, Briganti A, Salonia A, Villa L, Nini A, et al. Naftopidil for the treatment of benign prostate hyperplasia: a systematic review. Current Medical Research and Opinion 2014;30(4):719-32.

\section{Cornu 2010}

Cornu JN, Cussenot O, Haab F, Lukacs B. A widespread population study of actual medical management of lower 
urinary tract symptoms related to benign prostatic hyperplasia across Europe and beyond official clinical guidelines. European Urology 2010;58(3):450-6.

\section{Covidence [Computer program]}

Veritas Health Innovation. Covidence. Version accessed 17 November 2017. Melbourne, Australia: Veritas Health Innovation, 2013.

\section{Crawford 2006}

Crawford ED, Wilson SS, McConnell JD, Slawin KM, Lieber MC, Smith JA, et al. Baseline factors as predictors of clinical progression of benign prostatic hyperplasia in men treated with placebo. Journal of Urology 2006;175(4):1422-6; discussion 1426-7.

\section{Cui 2012}

Cui Y, Zong $\mathrm{H}$, Zhang Y. The efficacy and safety of silodosin in treating BPH: a systematic review and meta-analysis. International Urology and Nephrology 2012;44(6):1601-9.

\section{Dahm 2016}

Dahm P, Brasure M, MacDonald R, Olson CM, Nelson VA, Fink HA, et al. Comparative effectiveness of newer medications for lower urinary tract symptoms attributed to benign prostatic hyperplasia: a systematic review and meta-analysis. European Urology 2016 Oct 4 [Epub ahead of print]. [DOI: 10.1016/ j.eururo.2016.09.032]

\section{Deeks 2011}

Deeks JJ, Higgins JP, Altman DG, editor(s). Chapter 9: Analysing data and undertaking meta-analyses. In: Higgins JP, Green S, editor(s). Cochrane Handbook for Systematic Reviews of Interventions Version 5.1.0 (updated March 2011). The Cochrane Collaboration, 2011. Available from handbook.cochrane.org.

\section{Ding 2013}

Ding H, Du W, Hou ZZ, Wang HZ, Wang ZP. Silodosin is effective for treatment of LUTS in men with BPH: a systematic review. Asian Journal of Andrology 2013;15(1):121-8.

\section{Djavan 1999}

Djavan B, Marberger M. A meta-analysis on the efficacy and tolerability of alpha1-adrenoceptor antagonists in patients with lower urinary tract symptoms suggestive of benign prostatic obstruction. European Urology 1999;36(1):1-13.

\section{EAU 2017}

European Association of Urology. Treatment of non-neurogenic male LUTS. uroweb.org/guideline/treatment-of-nonneurogenic-male-luts/ (date first received 17 August 2017).

\section{Egan 2016}

Egan KB. The epidemiology of benign prostatic hyperplasia associated with lower urinary tract symptoms: prevalence and incident rates. Urologic Clinics of North America 2016;43(3):289-97.

\section{EndNote [Computer program]}

Clarivate Analytics. EndNote. Version 7.5. Clarivate Analytics, 2016.

\section{Fusco 2016}

Fusco F, Palmieri A, Ficarra V, Giannarini G, Novara G, Longo N, et al. Alpha1-blockers improve benign prostatic obstruction in men with lower urinary tract symptoms: a systematic review and meta-analysis of urodynamic studies. European Urology 2016;69(6):1091-101.

\section{Gacci 2014}

Gacci M, Ficarra V, Sebastianelli A, Corona G, Serni S, Shariat SF, et al. Impact of medical treatments for male lower urinary tract symptoms due to benign prostatic hyperplasia on ejaculatory function: a systematic review and meta-analysis. Journal of Sexual Medicine 2014;11(6):1554-66.

\section{GRADEpro GDT 2015 [Computer program]}

McMaster University (developed by Evidence Prime). GRADEpro GDT 2015. Version accessed 17 November 2017. Hamilton (ON): McMaster University (developed by Evidence Prime), 2015.

\section{Guyatt 2008}

Guyatt GH, Oxman AD, Vist GE, Kunz R, Falck-Ytter Y, Schünemann HJ, GRADE Working Group. GRADE: what is "quality of evidence" and why is it important to clinicians?. BMJ (Clinical Research Ed.) 2008;336(7651):995-8. [DOI: 10.1136/ bmj.39490.551019.BE]

\section{Guyatt 2011a}

Guyatt GH, Oxman AD, Kunz R, Brozek J, Alonso-Coello P, Rind $D$, et al. GRADE guidelines 6 . Rating the quality of evidence--imprecision. Journal of Clinical Epidemiology 2011;64(12):1283-93.

\section{Guyatt 2011b}

Guyatt G, Oxman AD, Akl EA, Kunz R, Vist G, Brozek J, et al. GRADE guidelines: 1 . Introduction-GRADE evidence profiles and summary of findings tables. Journal of Clinical Epidemiology 2011;64(4):383-94. [DOI: 10.1016/j.jclinepi.2010.04.026]

\section{Higgins 2002}

Higgins JPT, Thompson SG. Quantifying heterogeneity in a meta-analysis. Statistics in Medicine 2002;21(11):1539-58. [DOI: 10.1002/sim.1186]

\section{Higgins 2003}

Higgins JPT, Thompson SG, Deeks JJ, Altman DG. Measuring inconsistency in meta-analyses. BMJ (Clinical Research Ed.) 2003;327(7414):557-60. [DOI: 10.1136/bmj.327.7414.557]

\section{Higgins 2011a}

Higgins JPT, Deeks JJ (editors). Chapter 7: Selecting studies and collecting data. In: Higgins JPT, Green S (editors), Cochrane Handbook for Systematic Reviews of Interventions Version 5.1.0 (updated March 2011). The Cochrane Collaboration, 2011. Available from handbook.cochrane.org.

\section{Higgins 2011b}

Higgins JP, Altman DG, Sterne JAC, editor(s). Chapter 8: Assessing risk of bias in included studies. In: Higgins JP, Green S, editor(s). Cochrane Handbook for Systematic Reviews of Interventions Version 5.1.0 (updated March 2011). The Cochrane Collaboration, 2011. Available from handbook.cochrane.org. 


\section{Higgins 2011c}

Higgins JP, Deeks JJ, Altman DG, editor(s). Chapter 16: Special topics in statistics. In: Higgins JP, Green S, editor(s). Cochrane Handbook for Systematic Reviews of Interventions Version 5.1.0 (updated March 2011). The Cochrane Collaboration, 2011. Available from handbook.cochrane.org.

\section{Jaeschke 1989}

Jaeschke R, Singer J, Guyatt GH. Measurement of health status. Ascertaining the minimal clinically important difference. Controlled Clinical Trials 1989;10(4):407-15.

\section{Johnston 2010}

Johnston BC, Thorlund K, Schunemann HJ, Xie F, Murad MH, Montori VM, et al. Improving the interpretation of quality of life evidence in meta-analyses: the application of minimal important difference units. Health and Quality of Life Outcomes 2010;8:116.

\section{Johnston 2013}

Johnston BC, Patrick DL, Busse JW, Schünemann HJ, Agarwal A, Guyatt GH. Patient-reported outcomes in meta-analyses--Part 1 : assessing risk of bias and combining outcomes. Health and Quality of Life Outcomes 2013;11:109.

\section{Juliao 2012}

Juliao AA, Plata M, Kazzazi A, Bostanci Y, Djavan B. American Urological Association and European Association of Urology guidelines in the management of benign prostatic hypertrophy: revisited. Current Opinion in Urology 2012;22(1):34-9.

\section{Keehn 2016}

Keehn A, Taylor J, Lowe FC. Phytotherapy for benign prostatic hyperplasia. Curr Urology Reports 2016;17(7):53.

\section{Kozminski 2015}

Kozminski MA, Wei JT, Nelson J, Kent DM. Baseline characteristics predict risk of progression and response to combined medical therapy for benign prostatic hyperplasia (BPH). BJU International 2015;115(2):308-16.

\section{Lepor 2007}

Lepor H. Alpha blockers for the treatment of benign prostatic hyperplasia. Reviews in Urology 2007;9(4):181-90.

\section{Liberati 2009}

Liberati A, Altman DG, Tetzlaff J, Mulrow C, Gøtzsche PC, Ioannidis JPA, et al. The PRISMA statement for reporting systematic reviews and meta-analyses of studies that evaluate health care interventions: explanation and elaboration. PLoS Medicine 2009;6(7):e1000100. [DOI: 10.1371/ journal.pmed.1000100]

\section{MacDonald 2005}

MacDonald R, Wilt TJ. Alfuzosin for treatment of lower urinary tract symptoms compatible with benign prostatic hyperplasia: a systematic review of efficacy and adverse effects. Urology 2005;66(4):780-8.

\section{Martin 2014}

Martin S, Lange K, Haren MT, Taylor AW, Wittert G. Risk factors for progression or improvement of lower urinary tract symptoms in a prospective cohort of men. Journal of Urology 2014;191(1):130-7.

\section{McConnell 2003}

McConnell JD, Roehrborn CG, Bautista OM, Andriole GL Jr, Dixon CM, Kusek JW, et al. Medical Therapy of Prostatic Symptoms (MTOPS) Research Group. The long-term effect of doxazosin, finasteride, and combination therapy on the clinical progression of benign prostatic hyperplasia. New England Journal of Medicine 2003;349(25):2387-98.

\section{McVary 2011}

McVary KT, Roehrborn CG, Avins AL, Barry MJ, Bruskewitz RC, Donnell RF, et al. Update on AUA guideline on the management of benign prostatic hyperplasia. Journal of Urology 2011;185(5):1793-803.

\section{Milani 2005}

Milani S, Djavan B. Lower urinary tract symptoms suggestive of benign prostatic hyperplasia: latest update on alphaadrenoceptor antagonists. BJU International 2005;95 Suppl 4:29-36.

\section{Minneman 1994}

Minneman KP, Esbenshade TA. Alpha 1-adrenergic receptor subtypes. Annual Review of Pharmacology and Toxicology 1994;34:117-33.

\section{Nair 2016}

Nair SM, Pimentel MA, Gilling PJ. A review of laser treatment for symptomatic BPH (benign prostatic hyperplasia). Current Urology Reports 2016;17(6):45.

\section{Netto 1999}

Netto NR Jr, de Lima ML, Netto MR, D'Ancona CA. Evaluation of patients with bladder outlet obstruction and mild international prostate symptom score followed up by watchful waiting. Urology 1999;53(2):314-6.

\section{Novara 2013}

Novara G, Tubaro A, Sanseverino R, Spatafora S, Artibani W, Zattoni $\mathrm{F}$, et al. Systematic review and meta-analysis of randomized controlled trials evaluating silodosin in the treatment of non-neurogenic male lower urinary tract symptoms suggestive of benign prostatic enlargement. World Journal of Urology 2013;31(4):997-1008.

\section{Novara 2015}

Novara G, Chapple CR, Montorsi F. Individual patient data from registrational trials of silodosin in the treatment of non-neurogenic male lower urinary tract symptoms (LUTS) associated with benign prostatic hyperplasia (BPH): subgroup analyses of efficacy and safety data. BJU International 2015;115(5):802-14.

\section{Oelke 2012}

Oelke M, Giuliano F, Mirone V, Xu L, Cox D, Viktrup L. Monotherapy with tadalafil or tamsulosin similarly improved 
lower urinary tract symptoms suggestive of benign prostatic hyperplasia in an international, randomised, parallel, placebo controlled clinical trial. European Urology 2012;61(5):917-25.

\section{Osman 2012}

Osman NI, Chapple CR, Cruz F, Desgrandchamps F, Llorente C, Montorsi F. Silodosin: a new subtype selective alpha-1 antagonist for the treatment of lower urinary tract symptoms in patients with benign prostatic hyperplasia. Expert Opinion on Pharmacotherapy 2012;13(14):2085-96.

\section{Preston 2000}

Preston RA, Materson BJ, Reda DJ, Williams DW. Placeboassociated blood pressure response and adverse effects in the treatment of hypertension: observations from a Department of Veterans Affairs Cooperative Study. Archives of Internal Medicine 2000;160(10):1449-54.

\section{RevMan 2014 [Computer program]}

Nordic Cochrane Centre, The Cochrane Collaboration. Review Manager 5 (RevMan 5). Version 5.3. Copenhagen: Nordic Cochrane Centre, The Cochrane Collaboration, 2014.

\section{Roehrborn 2008}

Roehrborn CG. Pathology of benign prostatic hyperplasia. International Journal of Impotence Research 2008;20 Suppl 3:S11-8.

\section{Rosenzweig 1993}

Rosenzweig P, Brohier S, Zipfel A. The placebo effect in healthy volunteers: influence of experimental conditions on the adverse events profile during phase I studies. Clinical Pharmacology and Therapeutics 1993;54(5):578-83.

\section{Schilit 2009}

Schilit S, Benzeroual KE. Silodosin: a selective alpha1Aadrenergic receptor antagonist for the treatment of benign prostatic hyperplasia. Clinical Therapeutics 2009;31(11):2489-502.

\section{Schulman 2003}

Schulman CC. Lower urinary tract symptoms/benign prostatic hyperplasia: minimizing morbidity caused by treatment. Urology 2003;62(3 Suppl 1):24-33.

\section{Schünemann 2011}

Schünemann HJ, Oxman AD, Higgins JPT, Vist GE, Glasziou P, Guyatt GH. Chapter 11: Presenting results and 'Summary of findings' tables. In: Higgins JP, Green S, editor(s), Cochrane Handbook for Systematic Reviews of Interventions Version 5.1.0 (updated March 2011). The Cochrane Collaboration, 2011. Available from handbook.cochrane.org.

\section{CHARACTERISTICS OF STUDIES}

\section{Characteristics of included studies [ordered by study ID]}

\section{Seki 2015}

Seki N, Takahashi R, Yamaguchi A, Ito K, Takayama K, Nanri K, et al. Non-inferiority of silodosin $4 \mathrm{mg}$ once daily to twice daily for storage symptoms score evaluated by the International Prostate Symptom Score in Japanese patients with benign prostatic hyperplasia: a multicenter, randomized, parallel-group study. International Journal of Urology 2015;22(3):311-6.

\section{Sterne 2011}

Sterne JAC, Egger M, Moher D (editors). Chapter 10: Addressing reporting biases. In: Higgins JPT, Green S (editors). Cochrane Handbook for Systematic Reviews of Intervention. Version 5.1.0 (updated March 2011). The Cochrane Collaboration, 2011. Available from handbook.cochrane.org.

\section{Van Kerrebroec 2002}

Van Kerrebroec P, Jardin A, Van Cangh P, Laval KU, ALFORTI Study Group. Long-term safety and efficacy of a once-daily formulation of alfuzosin $10 \mathrm{mg}$ in patients with symptomatic benign prostatic hyperplasia: open-label extension study. European Urology 2002;41(1)(1):54-60; discussion 60-1.

\section{Wilt 2006}

Wilt TJ, MacDonald R. Doxazosin in the treatment of benign prostatic hypertrophy: an update. Clinical Interventions in Aging 2006;1(4):389-401.

\section{Yap 2009}

Yap TL, Brown C, Cromwell DA, Van der Meulen J, Emberton M. The impact of self-management of lower urinary tract symptoms on frequency-volume chart measures. BJU International 2009;104(8):1104-8.

\section{Yoo 2012}

Yoo TK, Cho HJ. Benign prostatic hyperplasia: from bench to clinic. Korean Journal of Urology 2012;53(3):139-48.

\section{Yoshida 2007}

Yoshida M, Homma Y, Kawabe K. Silodosin, a novel selective alpha $1 \mathrm{~A}$-adrenoceptor selective antagonist for the treatment of benign prostatic hyperplasia. Expert Opinion on Investigational Drugs 2007;16(12):1955-65.

\section{Yuan 2015}

Yuan JQ, Mao C, Wong SYS, Yang ZY, Fu XH, Dai XY, et al. Comparative effectiveness and safety of monodrug therapies for lower urinary tract symptoms associated with benign prostatic hyperplasia a network meta-analysis. Medicine 2015;94(27):7.

* Indicates the major publication for the study

Chapple 2011 
Dates when study was conducted: May 2006-May 2007

Participants

Inclusion criteria: men $\geq 50$ years with LUTS (defined by a stable IPSS total score $\geq 13$ points), bladder outlet obstruction (defined by a Qmax $4 \mathrm{~mL} / \mathrm{s}-15 \mathrm{~mL} / \mathrm{s}$, with a minimum voided volume of $\geq 125 \mathrm{~mL}$ ), and the evidence of satisfactory compliance with study medication $(80 \%-120 \%$ during the placebo run-in period)

Exclusion criteria: men with improvement in the IPSS total score $\geq 25 \%$ in the run-in period, PVR $\geq 250$ $\mathrm{mL}$, intravesical obstruction from any cause other than $\mathrm{BPH}$, history of any procedure considered an intervention for $\mathrm{BPH}$, active urinary tract infection or history of recurrent urinary tract infections, current prostatitis or diagnosis of chronic prostatitis, history of prostate or invasive bladder cancer, significant postural hypotension, use of 5-ARIs within 6 months, or use of an a-blocker or phytotherapy within 2 weeks before entry

\section{Total number of participants randomly assigned: 955}

Group A (Silodosin)

- number of all participants randomly assigned: 381

- age (years): $65.8 \pm 7.70$

- prostate volume $(\mathrm{mL})$ : not reported

- PSA (ng/mL): not reported

- IPSS: $19.1 \pm 4.2$

- $\operatorname{Qmax}(\mathrm{mL} / \mathrm{s}): 10.78 \pm 2.726$

Group B (Tamsulosin)

- number of all participants randomly assigned: 384

- age (years): $65.9 \pm 7.41$

- prostate volume $(\mathrm{mL})$ : not reported

- PSA (ng/mL): not reported

- IPSS: $18.9 \pm 4.3$

- $\operatorname{Qmax}(\mathrm{mL} / \mathrm{s}): 10.27 \pm 2.726$

Group C (Placebo)

- number of all participants randomly assigned: 190

- age (years): $66.0 \pm 7.37$

- prostate volume $(\mathrm{mL})$ : not reported

- PSA (ng/mL): not reported

- IPSS: $19.3 \pm 4.3$

- $\operatorname{Qmax}(\mathrm{mL} / \mathrm{s}): 10.32 \pm 2.816$

Interventions

Run-in period: 4 weeks, single-blind, placebo run-in period

Group A: silodosin 8 mg once daily

Group B: tamsulosin $0.4 \mathrm{mg}$ once daily

Group C: placebo once daily

Duration: 12 weeks

Outcomes Primary outcome

- change from baseline in the total score (questions 1-7) of the IPSS

How measured: IPSS questionnaire 
Time points reported: baseline and end of study

\section{Secondary outcome}

- IPSS storage and voiding symptoms subscores

- QoL

- Qmax

- percentage of treatment responders by IPSS (decrease from baseline $\geq 25 \%$ ) and by Qmax (increase from baseline $\geq 30 \%$ )

How measured: IPSS questionnaire, uroflowmetry

Time points measured: IPSS: see primary outcome/Qmax: at the same time periods as IPSS

Time points reported: baseline and end of study

\section{Safety outcomes}

How measured: adverse events, physical examination (BP, heart rate), laboratory tests, and a 12-lead electrocardiogram

Time points measured: at each visit

Time points reported: at each visit

Subgroup: a post hoc analysis was conducted in the subgroup of participants with nocturia at baseline (defined as at least two voids per night), as assessed by question 7 of the IPSS

\begin{tabular}{ll}
\hline Funding sources & Recordati Ireland Ltd \\
\hline Declarations of interest & $\begin{array}{l}\text { Financial disclosures: I certify that all conflicts of interest, including specific financial interests and re- } \\
\text { lationships and affiliations relevant to the subject matter or materials discussed in the manuscript (eg, } \\
\text { employment/affiliation, grants or funding, consultancies, honoraria, stock ownership or options, ex- } \\
\text { pert testimony, royalties, or patents filed, received, or pending), are the following: Christopher R. Chap- } \\
\text { ple and Francesco Montorsi are consultants and researchers for Recordati. Teuvo L.J. Tammela, Man- } \\
\text { fred Wirth, Evert Koldewijn, and Eldiberto Fernandez Fernandez are researchers for Recordati }\end{array}$
\end{tabular}

Notes Language of publication: English

Data (unadjusted IPSS and IPSS-QoL, AUR, and surgical intervention) were given by contact with study author

\section{Risk of bias}

\begin{tabular}{|c|c|c|}
\hline Bias & Authors' judgement & Support for judgement \\
\hline $\begin{array}{l}\text { Random sequence genera- } \\
\text { tion (selection bias) }\end{array}$ & Low risk & $\begin{array}{l}\text { Quote: "randomly assigned (in a ratio of 2:2:1, with stratification by center, } \\
\text { with blocks of five assigned to each center, produced and managed centrally } \\
\text { by an international contract research organization)" }\end{array}$ \\
\hline $\begin{array}{l}\text { Allocation concealment } \\
\text { (selection bias) }\end{array}$ & Low risk & $\begin{array}{l}\text { Quote: "managed centrally by an international contract research organiza- } \\
\text { tion" }\end{array}$ \\
\hline $\begin{array}{l}\text { Blinding of participants } \\
\text { and personnel (perfor- } \\
\text { mance bias) } \\
\text { All outcomes }\end{array}$ & Low risk & $\begin{array}{l}\text { Quote: "A multicenter double-blind, placebo- and active-controlled paral- } \\
\text { lel group clinical study, all study personnel and participants were blinded to } \\
\text { treatment assignment for the entire duration of the study" }\end{array}$ \\
\hline $\begin{array}{l}\text { Blinding of outcome as- } \\
\text { sessment (detection bias) }\end{array}$ & Unclear risk & Judgement: no information given \\
\hline
\end{tabular}


Chapple 2011 (Continued)

Subjective outcomes

$\begin{array}{ll}\text { Blinding of outcome as- } & \text { Low risk Judgement: objective outcomes are not likely affected by lack of blinding } \\ \text { sessment (detection bias) }\end{array}$

Objective outcomes

\begin{tabular}{|c|c|c|}
\hline $\begin{array}{l}\text { Incomplete outcome data } \\
\text { (attrition bias) } \\
\text { Urologic symptom scores/ } \\
\text { QoL }\end{array}$ & Low risk & $\begin{array}{l}\text { Judgement: } 10 / 381(2.6 \%) \text { in silodosin, } 8 / 384(2.1 \%) \text { in tamsulosin, and 5/190 } \\
(2.6 \%) \text { in placebo group were not included in analysis }\end{array}$ \\
\hline $\begin{array}{l}\text { Incomplete outcome data } \\
\text { (attrition bias) } \\
\text { Treatment withdrawal for } \\
\text { any reason }\end{array}$ & Low risk & $\begin{array}{l}\text { Judgement: all participants who were randomized in each group were includ- } \\
\text { ed in analysis }\end{array}$ \\
\hline $\begin{array}{l}\text { Incomplete outcome data } \\
\text { (attrition bias) } \\
\text { Treatment withdrawal } \\
\text { due to adverse events }\end{array}$ & Low risk & $\begin{array}{l}\text { Judgement: all participants who were randomized in each group were includ- } \\
\text { ed in analysis }\end{array}$ \\
\hline $\begin{array}{l}\text { Incomplete outcome data } \\
\text { (attrition bias) } \\
\text { AUR/ surgical intervention }\end{array}$ & Low risk & $\begin{array}{l}\text { Judgement: all participants who were randomized in each group were includ- } \\
\text { ed in analysis }\end{array}$ \\
\hline $\begin{array}{l}\text { Incomplete outcome data } \\
\text { (attrition bias) } \\
\text { Cardiovascular adverse } \\
\text { events }\end{array}$ & Low risk & $\begin{array}{l}\text { Judgement: all participants who were randomized in each group were includ- } \\
\text { ed in analysis }\end{array}$ \\
\hline $\begin{array}{l}\text { Incomplete outcome data } \\
\text { (attrition bias) } \\
\text { Sexual adverse events }\end{array}$ & Low risk & $\begin{array}{l}\text { Judgement: all participants who were randomized in each group were includ- } \\
\text { ed in analysis }\end{array}$ \\
\hline $\begin{array}{l}\text { Selective reporting (re- } \\
\text { porting bias) }\end{array}$ & High risk & $\begin{array}{l}\text { Judgement: Protocol (NCT00359905) was revised after completion of study } \\
\text { (2009) and percentage of treatment responders was added as secondary out- } \\
\text { come. } \\
\text { All primary and secondary endpoints were measured at 7, 14, 28, 56, } 84 \text { day, } \\
\text { but only reported at } 12 \text { weeks } \\
\text { Unadjusted data for analysis for IPSS and QoL were not reported }\end{array}$ \\
\hline Other bias & Unclear risk & Judgement: 4 weeks' placebo run-in period \\
\hline
\end{tabular}

Jung 2012

Methods Study design: open-label, randomized comparative study

Setting/Country: not reported/South Korea

Dates when study was conducted: not reported

Participants

Inclusion criteria: sexually active men with $\mathrm{BPH}$

Exclusion criteria: not reported

Total number of participants randomly assigned: 138 
Jung 2012 (Continued)

\section{Group A (Silodosin)}

- number of all participants randomly assigned: 48

- age (years): not reported

- prostate volume $(\mathrm{mL})$ : not reported

- PSA (ng/mL): not reported

- IPSS: not reported

- $\operatorname{Qmax}(\mathrm{mL} / \mathrm{s})$ : not reported

Group B (Tamsulosin)

- number of all participants randomly assigned: 43

- age (years): not reported

- prostate volume $(\mathrm{mL})$ : not reported

- PSA (ng/mL): not reported

- IPSS: not reported

- Qmax (mL/s): not reported

Group C (Alfusocin)

- number of all participants randomly assigned: 47

- age (years): not reported

- prostate volume $(\mathrm{mL})$ : not reported

- PSA (ng/mL): not reported

- IPSS: not reported

- Qmax (mL/s): not reported

Run-in period: none

Group A: silodosin $8 \mathrm{mg}$ once daily

Group B: tamsulosin $0.2 \mathrm{mg}$ once daily

Group C: alfuzosin $10 \mathrm{mg}$ once daily

Duration: 4 weeks

\begin{tabular}{ll}
\hline Outcomes & IPSS \\
& - Male Sexual Health Questionnaire (MSHQ) evaluating erection, ejaculation and sexual satisfaction \\
& How measured: IPSS, MSHQ \\
& Time points measured: baseline and on the 4th week of medication \\
& Time points reported: baseline and on the 4th week of medication \\
& Subgroup: none \\
\hline Funding sources & None \\
\hline Declarations of interest & Not reported \\
\hline Notes & Language of publication: English \\
\hline
\end{tabular}

\section{Risk of bias}


Jung 2012 (Continued)

\begin{tabular}{lll} 
Bias & Authors' judgement & Support for judgement \\
\hline $\begin{array}{l}\text { Random sequence genera- } \\
\text { tion (selection bias) }\end{array}$ & Unclear risk & Judgement: no information given \\
\hline $\begin{array}{l}\text { Allocation concealment } \\
\text { (selection bias) }\end{array}$ & Unclear risk & Judgement: no information given \\
\hline $\begin{array}{l}\text { Blinding of participants } \\
\text { and personnel (perfor- } \\
\text { mance bias) }\end{array}$ & High risk & Quote: "open-label, randomized comparative study" \\
$\begin{array}{l}\text { All outcomes } \\
\end{array}$ & &
\end{tabular}

\begin{tabular}{lll}
\hline $\begin{array}{l}\text { Blinding of outcome as- } \\
\text { sessment (detection bias) } \\
\text { Subjective outcomes }\end{array}$ & High risk Quote: "open-label, randomized comparative study" \\
\hline $\begin{array}{l}\text { Blinding of outcome as- } \\
\text { sessment (detection bias) } \\
\text { Objective outcomes }\end{array}$ & Low risk Judgement: objective outcomes are not likely affected by lack of blinding \\
\hline $\begin{array}{l}\text { Incomplete outcome data } \\
\text { (attrition bias) } \\
\text { Urologic symptom scores/ }\end{array}$ &
\end{tabular}

Incomplete outcome data Unclear risk Judgement: no information given
(attrition bias)
Treatment withdrawal for
any reason

\begin{tabular}{|c|c|c|}
\hline $\begin{array}{l}\text { Incomplete outcome data } \\
\text { (attrition bias) } \\
\text { Treatment withdrawal } \\
\text { due to adverse events }\end{array}$ & Unclear risk & Judgement: no information given \\
\hline $\begin{array}{l}\text { Incomplete outcome data } \\
\text { (attrition bias) } \\
\text { AUR/ surgical intervention }\end{array}$ & Unclear risk & Judgement: no information given \\
\hline $\begin{array}{l}\text { Incomplete outcome data } \\
\text { (attrition bias) } \\
\text { Cardiovascular adverse } \\
\text { events }\end{array}$ & Unclear risk & Judgement: no information given \\
\hline $\begin{array}{l}\text { Incomplete outcome data } \\
\text { (attrition bias) } \\
\text { Sexual adverse events }\end{array}$ & Unclear risk & Judgement: the number of participants excluded in analysis was not reported \\
\hline $\begin{array}{l}\text { Selective reporting (re- } \\
\text { porting bias) }\end{array}$ & Unclear risk & $\begin{array}{l}\text { Judgement: protocol was not published and no information related to the re- } \\
\text { view outcomes given }\end{array}$ \\
\hline Other bias & Unclear risk & Judgement: abstract only \\
\hline
\end{tabular}


Kawabe 2006a

Methods
Study design: randomized, double-blind, placebo-controlled study

Setting/Country: 88 centers/outpatient/Japan

Dates when study was conducted: not reported
Inclusion criteria: men $\geq 50$ years with total IPSS of $\geq 8$, an associated QoL score of $\geq 3$, prostate volume (measured by transabdominal or transrectal US) of $\geq 20 \mathrm{~mL}$, a Q $\max$ of $<15 \mathrm{~mL} / \mathrm{s}$ with a voided volume of $\geq 100 \mathrm{~mL}$ and a PVR of $<100 \mathrm{~mL}$

Exclusion criteria: men who had antiandrogen preparations for 1 year before the study or had a prostatectomy, intrapelvic radiation therapy or prostatic hyperthermia (transurethral microwave hyperthermia or transurethral needle ablation). Men who had prostate cancer or suspected prostate cancer, neurogenic bladder, bladder neck constriction, urethral stricture, bladder calculus, severe bladder diverticulum, active urinary tract infection requiring medical treatment, renal impairment (serum creatinine $\geq 2.0 \mathrm{mg} / \mathrm{dL}$ ) and other complications considered likely to affect micturition, severe hepatic disorders, severe cardiovascular disease and a history of orthostatic hypotension

\section{Total number of participants randomly assigned: 457}

Group A (Silodosin)

- number of all participants randomly assigned: 176

- age (years): $65.4 \pm 7.0$

- prostate volume $(\mathrm{mL}): 36.0 \pm 16.9$

- PSA (ng/mL): not reported

- IPSS: $17.1 \pm 5.7$

- $\operatorname{Qmax}(\mathrm{mL} / \mathrm{s}): 9.89 \pm 2.72$

Group B (Tamsulosin)

- number of all participants randomly assigned: 192

- age (years): $65.6 \pm 7.0$

- prostate volume $(\mathrm{mL}): 35.7 \pm 14.4$

- PSA (ng/mL): not reported

- IPSS: $17.0 \pm 5.7$

- $\operatorname{Qmax}(\mathrm{mL} / \mathrm{s}): 9.43 \pm 2.79$

Group C (Placebo)

- number of all participants randomly assigned: 89

- age (years): $65.0 \pm 6.9$

- prostate volume $(\mathrm{mL}): 35.2 \pm 16.0$

- PSA (ng/mL): not reported

- IPSS: $17.1 \pm 6.1$

- $\operatorname{Qmax}(\mathrm{mL} / \mathrm{s}): 9.96 \pm 2.65$

Interventions Run-in period: none

Group A: oral silodosin $4 \mathrm{mg}$ twice daily

Group B: oral tamsulosin $0.2 \mathrm{mg}$ once daily

Group C: oral placebo twice daily

Duration: 12 weeks

Outcomes Primary outcome

- change in the total IPSS from baseline 
How measured: IPSS questionnaire

Time points measured: at the end of wash-out period and at 1, 2, 4, 8 and 12 weeks during the treatment period

Time points reported: at the end of wash-out period and at 1,2 , and 12 weeks during the treatment period

\section{Secondary outcome}

- change in Qmax and urodynamics

- IPSS voiding and storage scores and QoL score

How measured: IPSS questionnaire, uroflowmetry

Time points measured: at the end of wash-out period and at 1, 2, 4, 8 and 12 weeks during the treatment period

Time points reported: at the end of wash-out period and 12 weeks

\section{Safety outcomes}

How measured: adverse events, physical examinations (BP and heart rate), clinical laboratory tests (hematology, blood chemistry and urine analysis)

Time points measured: at the start of the observation period and at 4 and 12 weeks of treatment (follow-up visit)

Time points reported: at the start of the observation period and at 12 weeks of treatment

Subgroup: analysis based on LUTS severity, post hoc investigation in Qmax among the 3 treatment groups in the overall subgroup of participants with a change in voided volume of $<50 \%$ before and after treatment

\begin{tabular}{ll}
\hline Funding sources & None \\
\hline Declarations of interest & None \\
\hline
\end{tabular}

Notes Language of publication: English

\section{Risk of bias}

\begin{tabular}{|c|c|c|}
\hline Bias & Authors' judgement & Support for judgement \\
\hline $\begin{array}{l}\text { Random sequence genera- } \\
\text { tion (selection bias) }\end{array}$ & Unclear risk & $\begin{array}{l}\text { Quote: "randomized, double-blind, placebo controlled study" } \\
\text { Judgement: the randomization method was not defined }\end{array}$ \\
\hline $\begin{array}{l}\text { Allocation concealment } \\
\text { (selection bias) }\end{array}$ & Unclear risk & Judgement: no information given \\
\hline $\begin{array}{l}\text { Blinding of participants } \\
\text { and personnel (perfor- } \\
\text { mance bias) } \\
\text { All outcomes }\end{array}$ & Unclear risk & $\begin{array}{l}\text { Quote: "randomized, double-blind, placebo controlled study" } \\
\text { Judgement: placebo-controlled study, but double-blind was not clear who was } \\
\text { blinded }\end{array}$ \\
\hline $\begin{array}{l}\text { Blinding of outcome as- } \\
\text { sessment (detection bias) } \\
\text { Subjective outcomes }\end{array}$ & Unclear risk & $\begin{array}{l}\text { Quote: "randomized, double-blind, placebo controlled study" } \\
\text { Judgement: double-blind was not clear who was blinded }\end{array}$ \\
\hline $\begin{array}{l}\text { Blinding of outcome as- } \\
\text { sessment (detection bias) }\end{array}$ & Low risk & Judgement: objective outcomes are not likely affected by lack of blinding \\
\hline
\end{tabular}


Kawabe 2006a (Continued)

Objective outcomes

\begin{tabular}{|c|c|c|}
\hline $\begin{array}{l}\text { Incomplete outcome data } \\
\text { (attrition bias) } \\
\text { Urologic symptom scores/ } \\
\text { QoL }\end{array}$ & Low risk & $\begin{array}{l}\text { Judgement: } 1 / 176(0.5 \%) \text { in silodosin group, } 0 / 192(0 \%) \text { in tamsulosin, and } \\
0 / 89(0 \%) \text { were not included in analysis }\end{array}$ \\
\hline $\begin{array}{l}\text { Incomplete outcome data } \\
\text { (attrition bias) } \\
\text { Treatment withdrawal for } \\
\text { any reason }\end{array}$ & Unclear risk & Judgement: no information given \\
\hline $\begin{array}{l}\text { Incomplete outcome data } \\
\text { (attrition bias) } \\
\text { Treatment withdrawal } \\
\text { due to adverse events }\end{array}$ & Low risk & $\begin{array}{l}\text { Judgement: } 1 / 176(0.5 \%) \text { in silodosin group, } 0 / 192(0 \%) \text { in tamsulosin, and } \\
0 / 89(0 \%) \text { were not included in analysis }\end{array}$ \\
\hline $\begin{array}{l}\text { Incomplete outcome data } \\
\text { (attrition bias) } \\
\text { AUR/ surgical intervention }\end{array}$ & Unclear risk & Judgement: no information given \\
\hline $\begin{array}{l}\text { Incomplete outcome data } \\
\text { (attrition bias) } \\
\text { Cardiovascular adverse } \\
\text { events }\end{array}$ & Low risk & $\begin{array}{l}\text { Judgement: } 1 / 176(0.5 \%) \text { in silodosin group, } 0 / 192(0 \%) \text { in tamsulosin, and } \\
0 / 89(0 \%) \text { were not included in analysis }\end{array}$ \\
\hline $\begin{array}{l}\text { Incomplete outcome data } \\
\text { (attrition bias) } \\
\text { Sexual adverse events }\end{array}$ & Low risk & $\begin{array}{l}\text { Judgement: } 1 / 176(0.5 \%) \text { in silodosin group, } 0 / 192(0 \%) \text { in tamsulosin, and } \\
0 / 89(0 \%) \text { were not included in analysis }\end{array}$ \\
\hline $\begin{array}{l}\text { Selective reporting (re- } \\
\text { porting bias) }\end{array}$ & High risk & $\begin{array}{l}\text { Judgement: protocol was not published and additional post hoc subgroup in- } \\
\text { vestigation was not defined in method section }\end{array}$ \\
\hline Other bias & High risk & $\begin{array}{l}\text { Judgement: baseline imbalance in QoL; primary endpoint was adjusted analy- } \\
\text { sis by baseline QoL. Drug administration times were different between groups }\end{array}$ \\
\hline
\end{tabular}

Manjunatha 2016a

Methods Study design: prospective, randomized, comparative, open-label study

Setting/Country: tertiary care hospital/India

Dates when study was conducted: June 2013-June 2014

Participants Inclusion criteria: men $\geq 45$ years with symptomatic BPH with IPSS of $\geq 8$, QoL of $\geq 3$, and Qmax of $<15$ $\mathrm{mL} / \mathrm{s}$, but $>4 \mathrm{~mL} / \mathrm{s}$ with a voided volume of $>100 \mathrm{~mL}$

Exclusion criteria: severe hepatic or renal insufficiency, urinary tract infections, urethral stricture, neurogenic bladder, $P S A \geq 5 \mathrm{ng} / \mathrm{mL}$, history of urethral or prostatic surgery, hypotension or severe untreated hypertension, history of esophageal or intestinal obstruction, history of multiple drug abuse, significant psychiatric problems, serious disease or malignancy, increased risk of QTc (corrected QT Interval in the heart's electrical cycle) prolongation (e.g. hypokalemia, concomitant use of Class la and III antiarrhythmics, antipsychotics, tricyclic antidepressants, etc.), concomitant use of 5-ARIs and strong cytochrome P450 3A4 inhibitors, likelihood of requiring catheterization within next 3 months

\section{Total number of participants randomly assigned: 90}

Group A (Silodosin) 
Manjunatha 2016a (Continued)

- number of all participants randomly assigned: 30

- age (years): $64.00 \pm 11.14$

- prostate volume $(\mathrm{mL}): 40.57 \pm 16.45$

- PSA (ng/mL): $1.89 \pm 1.06$

- IPSS: $15.93 \pm 6.03$

- $\operatorname{Qmax}(\mathrm{mL} / \mathrm{s}): 10.03 \pm 3.35$

Group B (Tamsulosin)

- number of all participants randomly assigned: 30

- age (years): $63.60 \pm 9.05$

- prostate volume $(\mathrm{mL}): 40.33 \pm 21.55$

- PSA (ng/mL): $2.21 \pm 1.33$

- IPSS: $21.63 \pm 7.63$

- $\operatorname{Qmax}(\mathrm{mL} / \mathrm{s}): 9.58 \pm 3.62$

Group C (Alfuzosin)

- number of all participants randomly assigned: 30

- age (years): $63.43 \pm 8.91$

- prostate volume $(\mathrm{mL}): 44.43 \pm 27.72$

- PSA (ng/mL): $2.29 \pm 1.27$

- IPSS: $19.2 \pm 9.6$

- $\operatorname{Qmax}(\mathrm{mL} / \mathrm{s}): 10.18 \pm 3.45$

Group A: silodosin capsule $8 \mathrm{mg}$ once daily in the morning (before breakfast)

Group B: tamsulosin tablet/capsule $0.4 \mathrm{mg}$ (before meals) once daily at bedtime

Group C: alfuzosin sustained release tablet $10 \mathrm{mg}$ (immediately after meals) once daily

Duration: 12 weeks

Outcomes

Primary outcome

- change in total IPSS from baseline

How measured: IPSS questionnaire

Time points measured: baseline, after 2 weeks (visit 1), 4 weeks (visit 2), 8 weeks (visit 3), and 12 weeks (visit 4)

Time points reported: baseline, after 2 weeks (visit 1), 4 weeks (visit 2), 8 weeks (visit 3), and 12 weeks (visit 4)

\section{Secondary outcome}

- change in Qmax

- subjective symptom scores of IPSS (voiding and storage scores)

- QoL

How measured: uroflowmetry, IPSS questionnaire

Time points measured: baseline, after 2 weeks (visit 1), 4 weeks (visit 2), 8 weeks (visit 3), and 12 weeks (visit 4)

Time points reported: baseline, after 2 weeks (visit 1), 4 weeks (visit 2), 8 weeks (visit 3), and 12 weeks (visit 4) 
Manjunatha 2016a (Continued)

\section{Safety outcomes}

How measured: side effects, cardiovascular parameters, pulse rate, and BP (supine and standing)

Time points measured: baseline, after 2 weeks (visit 1), 4 weeks (visit 2), 8 weeks (visit 3), and 12 weeks (visit 4)

Time points reported: cumulative results from follow-up visits

Subgroup: none

\begin{tabular}{ll}
\hline Funding sources & None \\
\hline Declarations of interest & None \\
\hline Notes & Language of publication: English
\end{tabular}

\section{Risk of bias}

\begin{tabular}{|c|c|c|}
\hline Bias & Authors' judgement & Support for judgement \\
\hline $\begin{array}{l}\text { Random sequence genera- } \\
\text { tion (selection bias) }\end{array}$ & Low risk & $\begin{array}{l}\text { Quote: "prospective, randomized". } \\
\text { Judgement: random number table in protocol }\end{array}$ \\
\hline $\begin{array}{l}\text { Allocation concealment } \\
\text { (selection bias) }\end{array}$ & Low risk & $\begin{array}{l}\text { Judgement: no information in article, but "Sequentially numbered, sealed, } \\
\text { opaque envelopes" in protocol }\end{array}$ \\
\hline $\begin{array}{l}\text { Blinding of participants } \\
\text { and personnel (perfor- } \\
\text { mance bias) } \\
\text { All outcomes }\end{array}$ & High risk & Judgement: open-label randomized study \\
\hline $\begin{array}{l}\text { Blinding of outcome as- } \\
\text { sessment (detection bias) } \\
\text { Subjective outcomes }\end{array}$ & High risk & Judgement: open-label randomized study \\
\hline $\begin{array}{l}\text { Blinding of outcome as- } \\
\text { sessment (detection bias) } \\
\text { Objective outcomes }\end{array}$ & Low risk & Judgement: objective outcomes are not likely affected by lack of blinding \\
\hline $\begin{array}{l}\text { Incomplete outcome data } \\
\text { (attrition bias) } \\
\text { Urologic symptom scores/ } \\
\text { QoL }\end{array}$ & Low risk & $\begin{array}{l}\text { Quote: "there were no drop-outs or protocol violations during the study and all } \\
\text { the ninety subjects were included in the analysis" }\end{array}$ \\
\hline $\begin{array}{l}\text { Incomplete outcome data } \\
\text { (attrition bias) } \\
\text { Treatment withdrawal for } \\
\text { any reason }\end{array}$ & Low risk & $\begin{array}{l}\text { Quote: "there were no drop-outs or protocol violations during the study and all } \\
\text { the ninety subjects were included in the analysis" }\end{array}$ \\
\hline $\begin{array}{l}\text { Incomplete outcome data } \\
\text { (attrition bias) } \\
\text { Treatment withdrawal } \\
\text { due to adverse events }\end{array}$ & Low risk & $\begin{array}{l}\text { Quote: "there were no drop-outs or protocol violations during the study and all } \\
\text { the ninety subjects were included in the analysis" }\end{array}$ \\
\hline $\begin{array}{l}\text { Incomplete outcome data } \\
\text { (attrition bias) } \\
\text { AUR/ surgical intervention }\end{array}$ & Unclear risk & Judgement: no information given \\
\hline
\end{tabular}


Manjunatha 2016a (Continued)

Incomplete outcome data Low risk (attrition bias)

Cardiovascular adverse

events
Quote: "there were no drop-outs or protocol violations during the study and all the ninety subjects were included in the analysis"

$\begin{array}{ll}\begin{array}{l}\text { Incomplete outcome data } \\ \text { (attrition bias) }\end{array} & \text { Unclear risk }\end{array}$

losin and alfuzosin group were not reported

Sexual adverse events

$\begin{array}{ll}\begin{array}{l}\text { Selective reporting (re- } \\ \text { porting bias) }\end{array} & \text { Low risk } \\ \text { was published and the prespecified outcomes were well described. }\end{array}$

porting bias) was published and the prespecified outcomes were well described.

Other bias High risk Judgement: probably, baseline imbalance in IPSS score, PSA, PVR (silodosin
group has markedly lower) and prostate volume (alfuzosin group has markedly higher prostate volume).

Marks 2009

Methods

Study design: parallel-group, double-blind, randomized study

Setting/Country: multicenter/USA

Dates when study was conducted: May 2005-August 2006

Participants

Inclusion criteria: men aged $\geq 50$ years with an IPSS of $\geq 13$, a Qmax of $4 \mathrm{~mL} / \mathrm{s}-15 \mathrm{~mL} / \mathrm{s}$ and a PVR $<250$ $\mathrm{mL}$

Exclusion criteria: men with intravesical obstruction unrelated to BPH; bladder calculi; history of or current condition affecting bladder function; prior surgical intervention to relieve BPH or bladder neck obstruction; active urinary tract infection or history of recurrent urinary tract infection within the past 2 years; prostatitis within the past 3 months; BPH-unrelated urinary retention within the past 3 months; and a history of recurring prostatitis ( $>3$ times within the past year), prior or current prostate cancer or PSA $>10 \mathrm{ng} / \mathrm{mL}$; prior invasive bladder cancer; bladder catheterization or bladder or prostate instrumentation within the past 30 days and history of or current significant postural hypotension, including changes in systolic ( $>30 \mathrm{~mm} \mathrm{Hg}$ ) or diastolic ( $>20 \mathrm{~mm} \mathrm{Hg}$ ) BP or heart rate (more than 20 beats per minute), and lightheadedness, fainting, blurred vision, profound weakness or syncope upon change in position

\section{Total number of participants randomly assigned: 923}

Group A (Silodosin)

- number of all participants randomly assigned: 466

- age (years): $64.6 \pm 8.1$

- prostate volume $(\mathrm{mL})$ : not reported

- PSA (ng/mL): not reported

- IPSS: $21.3 \pm 5.1$

- $Q \max (\mathrm{mL} / \mathrm{s}): 8.7 \pm 2.6$

Group B (Placebo)

- number of all participants randomly assigned: 457

- age (years): $64.7 \pm 8.1$

- prostate volume $(\mathrm{mL})$ : not reported

- PSA (ng/mL): not reported

- IPSS: $21.3 \pm 4.9$ 
Marks 2009 (Continued)

$$
\text { - } \operatorname{Qmax}(\mathrm{mL} / \mathrm{s}): 8.9 \pm 2.8
$$

Run-in period: single-blind, placebo run in for 4 weeks
Group A: silodosin $8 \mathrm{mg}$ once daily with breakfast
Group B: placebo once daily with breakfast
Duration: 12 weeks

Outcomes

Primary outcome

- mean change from baseline to week 12 in total IPSS

How measured: IPSS questionnaire

Time points measured: at weeks 0 (baseline), 0.5, 1, 2, 4 and 12

Time points reported: at weeks 0 (baseline), 0.5, 1, 2, 4 and 12

\section{Secondary outcome}

- mean change in Qmax from baseline to week 12

How measured: uroflow assessed by study investigator and a blinded central reader

Time points measured: at baseline, 2-6 h after the first dose, and at weeks 1, 2, 4 and 12

Time points reported: at baseline, 2-6 $\mathrm{h}$ after the first dose, and at weeks 1, 2, 4 and 12

\section{Safety outcomes}

How measured: adverse event/additional safety assessments included 12-lead electrocardiograms, clinical laboratory tests and vital sign measurements including postural hypotension tests and physical examinations

Time points measured: at every visit except at post-randomization week 0.5

Time points reported: cumulative results from follow-up visits

\section{Subgroup: none}

Funding sources Allergan, American Medical Systems, Astellas, Bayer, Beckman Coulter, Diagnostic Ultrasound, GTX, GlaxoSmithKline, Gen-Probe, Indevus, Light Sciences Oncology, Lilly/ICOS, Merck, Novartis, Onconome, Pfizer, Sanofi, Solvay, Watson, National Institutes of Health, CapCURE, Pardee Foundation and Seder Foundation

Declarations of interest Allergan, American Medical Systems, Astellas, Bayer, Beckman Coulter, Diagnostic Ultrasound, GTX, GlaxoSmithKline, Gen-Probe, Indevus, Light Sciences Oncology, Lilly/ICOS, Merck, Novartis, Onconome, Pfizer, Sanofi, Solvay, Watson, National Institutes of Health, CapCURE, Pardee Foundation and Seder Foundation

Notes Language of publication: English

Study author reply: "Pharmaceutics only have the data". We cannot contact study supporter in pharmaceutics due to wrong email address

\section{Risk of bias}

\begin{tabular}{lll}
\hline Bias & Authors' judgement & Support for judgement \\
\hline $\begin{array}{l}\text { Random sequence genera- } \\
\text { tion (selection bias) }\end{array}$ & Low risk & $\begin{array}{l}\text { Quote: "randomly assigned (1:1) to double-blind treatment, randomization } \\
\text { schedule using PROC PLAN in SAS." }\end{array}$ \\
\hline
\end{tabular}


Marks 2009 (Continued)

$\begin{aligned} & \text { Allocation concealment } \\ & \text { (selection bias) }\end{aligned} \quad$ Low risk Judgement: no information in article, but "Sequentially numbered, sealed,
opaque envelopes" in protocol

Blinding of participants Low risk
and personnel (performance bias)
All outcomes

ment assignment be needed to ensure the patient's well-being. If unblinding
of the investigator, site personnel or the patient was required in a particular
case that patient was to be discontinued from the study."

Quote: "Blinding was maintained throughout the study by the use of identical medication packaging with placebo matching silodosin in size and external appearance. Emergency information labels that indicated the patient's assigned treatment were available to the investigator should knowledge of treatment assignment be needed to ensure the patient's well-being. If unblinding case that patient was to be discontinued from the study."
Quote: "Blinding was maintained throughout the study by the use of identical medication packaging with placebo matching silodosin in size and external appearance. Emergency information labels that indicated the patient's assigned treatment were available to the investigator should knowledge of treatment assignment be needed to ensure the patient's well-being. If unblinding of the investigator, site personnel or the patient was required in a particular case that patient was to be discontinued from the study."

\begin{tabular}{lll}
\hline $\begin{array}{l}\text { Blinding of outcome as- } \\
\text { sessment (detection bias) } \\
\text { Objective outcomes }\end{array}$ & Low risk & Judgement: objective outcomes are not likely affected by lack of blinding \\
\hline $\begin{array}{l}\text { Incomplete outcome data } \\
\text { (attrition bias) }\end{array}$ & Unclear risk & $\begin{array}{l}\text { Judgement: discontinued/lost to follow-up were } 53 / 466(11.4 \%) \text { and } 38 / 457 \\
(8.3 \%), \text { Loss of follow-up } 6 / 466(1.3 \%) \text { and } 3 / 457(0.3 \%), \text { but discrepancies }\end{array}$ \\
$\begin{array}{l}\text { Urologic symptom scores/ } \\
\text { QoL }\end{array}$ & $\begin{array}{l}\text { in the reason of discontinuation }(47 / 466,35 / 457) \text { between intervention and } \\
\text { placebo group. Last observations were carried forward to impute values miss- } \\
\text { ing for week } 12\end{array}$
\end{tabular}

\begin{tabular}{|c|c|c|}
\hline $\begin{array}{l}\text { Incomplete outcome data } \\
\text { (attrition bias) }\end{array}$ & Low risk & $\begin{array}{l}\text { Judgement: all participants who were randomized in each group were includ- } \\
\text { ed in analysis }\end{array}$ \\
\hline
\end{tabular}

Judgement: discontinued/lost to follow-up were 53/466 (11.4\%) and 38/457 $(8.3 \%)$, Loss of follow-up $6 / 466(1.3 \%)$ and $3 / 457(0.3 \%)$, but discrepancies placebo group. Last observations were carried forward to impute values miss-
Judgement: all participants who were randomized in each group were includ-

Treatment withdrawal for any reason

\begin{tabular}{|c|c|c|}
\hline $\begin{array}{l}\text { Incomplete outcome data } \\
\text { (attrition bias) }\end{array}$ & Low risk & $\begin{array}{l}\text { Judgement: all participants who were randomized in each group were includ- } \\
\text { ed in analysis }\end{array}$ \\
\hline
\end{tabular}

due to adverse events

\begin{tabular}{|c|c|c|}
\hline $\begin{array}{l}\text { Incomplete outcome data } \\
\text { (attrition bias) } \\
\text { AUR/ surgical intervention }\end{array}$ & Unclear risk & Judgement: no information given \\
\hline $\begin{array}{l}\text { Incomplete outcome data } \\
\text { (attrition bias) } \\
\text { Cardiovascular adverse } \\
\text { events }\end{array}$ & Low risk & $\begin{array}{l}\text { Judgement: all participants who were randomized in each group were includ- } \\
\text { ed in analysis }\end{array}$ \\
\hline $\begin{array}{l}\text { Incomplete outcome data } \\
\text { (attrition bias) } \\
\text { Sexual adverse events }\end{array}$ & Low risk & $\begin{array}{l}\text { Judgement: all participants who were randomized in each group were includ- } \\
\text { ed in analysis }\end{array}$ \\
\hline $\begin{array}{l}\text { Selective reporting (re- } \\
\text { porting bias) }\end{array}$ & Low risk & $\begin{array}{l}\text { Judgement: protocols (NCT00224107, NCT00224120) were published and the } \\
\text { prespecified outcomes were well described }\end{array}$ \\
\hline Other bias & High risk & $\begin{array}{l}\text { Judgement: single-blind placebo run-in for } 4 \text { weeks; participants with } \geq 30 \% \\
\text { decrease in IPSS or an increase in Qmax of } \geq 3 \mathrm{~mL} / \mathrm{s} \text { during the run-in period } \\
\text { were excluded from randomization }\end{array}$ \\
\hline
\end{tabular}


Dates when study was conducted: November 2009-March 2011

Participants

Inclusion criteria: men $\geq 50$ years with prostate estimated volume of $>20 \mathrm{~cm}^{3}$, IPSS of $\geq 8$, a QoL score of $\geq 3$ points

Exclusion criteria: men with organic diseases other than BPH (prostate cancer, bladder tumor, prostatitis, urethral stricture, etc.), transurethral resection of prostate or minimally invasive treatment, under catheterization and under self-donating urination, active urinary tract infections, combined neuropathic bladder and nervous system disorder, received hormone-based prostatic hyperplasia treatment medicine 6 months before the start of the study, received androgen-receptor blocking agent 6 weeks before the study, and those judged unsuitable by the attending physician

\section{Total number of participants randomly assigned: 92}

\section{Group A (Silodosin)}

- number of all participants randomly assigned: 44

- age (years): $66.5 \pm 5.6$

- prostate volume $(\mathrm{mL}): 38.8 \pm 13.1$

- PSA (ng/mL): not reported

- IPSS: $18.6 \pm 5.5$

- $\operatorname{Qmax}(\mathrm{mL} / \mathrm{s}): 8.0 \pm 3.7$

Group B (Naftopidil)

- number of all participants randomly assigned: 48

- age (years): $68.5 \pm 5.7$

- prostate volume $(\mathrm{mL}): 45.7 \pm 17.8$

- PSA (ng/mL): not reported

- IPSS: $17.6 \pm 5.0$

- $\operatorname{Qmax}(\mathrm{mL} / \mathrm{s}): 9.3 \pm 4.9$

Group A: silodosin $2 \mathrm{mg}-4 \mathrm{mg}$ twice a day for 2 weeks in the morning and evening, and $4 \mathrm{mg}$ twice daily in the morning and evening for 4 more weeks, if there were no problems such as side effects

Group B: naftopidil $50 \mathrm{mg}-75 \mathrm{mg}$ once in the morning for 2 weeks, and if there were no problems such as side effects $75 \mathrm{mg}$ was administered once in the morning for 4 more weeks

Duration: 6 weeks (before cross-over)/total 12 weeks

Outcomes

\section{Primary outcome}

- total score of IPSS

How measured: IPSS questionnaire

Time points measured: before and after treatment ( 6 weeks and 12 weeks)

Time points reported: before and after treatment ( 6 weeks and 12 weeks)

\section{Secondary outcome}

- IPSS subscore 
Masuda 2012 (Continued)

- QoL score

- OABSS

- Qmax

- PVR

- participant preference for the drug

How measured: IPSS: IPSS questionnaire/OABSS: OABSS questionnaire/PVR: abdominal US/patient preference: questionnaire survey

Time points measured: before administration of the drug and 4 weeks, 8 weeks

Time points reported: before administration of the drug and 4 weeks, 8 weeks

\section{Safety outcomes}

How measured: adverse events

Time points measured: not reported

Time points reported: at the end of study (12 weeks)

Subgroup: none

\begin{tabular}{ll}
\hline Funding sources & Not reported \\
\hline Declarations of interest & Not reported \\
\hline
\end{tabular}

Notes Language of publication: Japanese

No wash-out period between cross-over

\section{Risk of bias}

\begin{tabular}{|c|c|c|}
\hline Bias & Authors' judgement & Support for judgement \\
\hline $\begin{array}{l}\text { Random sequence genera- } \\
\text { tion (selection bias) }\end{array}$ & High risk & $\begin{array}{l}\text { Quote: "all patients who got consent were assigned in turn to 'Naf-Silo group' } \\
\text { and 'Silo-Naf group' alternately" }\end{array}$ \\
\hline $\begin{array}{l}\text { Allocation concealment } \\
\text { (selection bias) }\end{array}$ & Unclear risk & Judgement: no information given \\
\hline $\begin{array}{l}\text { Blinding of participants } \\
\text { and personnel (perfor- } \\
\text { mance bias) } \\
\text { All outcomes }\end{array}$ & Unclear risk & Judgement: no information given \\
\hline $\begin{array}{l}\text { Blinding of outcome as- } \\
\text { sessment (detection bias) } \\
\text { Subjective outcomes }\end{array}$ & Unclear risk & Judgement: no information given \\
\hline $\begin{array}{l}\text { Blinding of outcome as- } \\
\text { sessment (detection bias) } \\
\text { Objective outcomes }\end{array}$ & Low risk & Judgement: objective outcomes are not likely affected by lack of blinding \\
\hline $\begin{array}{l}\text { Incomplete outcome data } \\
\text { (attrition bias) } \\
\text { Urologic symptom scores/ } \\
\text { QoL }\end{array}$ & High risk & $\begin{array}{l}\text { Judgement: } 14 / 44(31.9 \%) \text { and } 14 / 48(29.2 \%) \text { participants in the silodosin and } \\
\text { naftopidil group were not included in the analysis }\end{array}$ \\
\hline
\end{tabular}




\section{Masuda 2012 (Continued)}

Incomplete outcome data (attrition bias)

Treatment withdrawal for any reason
Low risk Judgement: all participants who were randomized in each group were included in analysis

$\begin{array}{ll}\begin{array}{l}\text { Incomplete outcome data } \\ \text { (attrition bias) }\end{array} & \text { Jow risk } \\ \end{array}$
ed in analysis

due to adverse events

Incomplete outcome data Unclear risk Judgement: not available (cross-over trial)

(attrition bias)

AUR/ surgical intervention

\begin{tabular}{|c|c|c|}
\hline $\begin{array}{l}\text { Incomplete outcome data } \\
\text { (attrition bias) }\end{array}$ & Unclear risk & $\begin{array}{l}\text { Judgement: } 5 / 88(5.7 \%) \text { and } 17 / 96(17.8 \%) \text { participants in the silodosin and } \\
\text { tamsulosin group were not included in the analysis }\end{array}$ \\
\hline
\end{tabular}

Cardiovascular adverse

events

$\begin{aligned} & \text { Incomplete outcome data } \\ & \text { (attrition bias) }\end{aligned}$
$\begin{aligned} & \text { Sexual adverse events } \\ & \text { Unclear risk }\end{aligned}$

Sexual adverse events

\begin{tabular}{|c|c|c|}
\hline $\begin{array}{l}\text { Selective reporting (re- } \\
\text { porting bias) }\end{array}$ & Unclear risk & $\begin{array}{l}\text { Judgement: prespecified study outcomes were well described but protocol } \\
\text { was not published }\end{array}$ \\
\hline
\end{tabular}

Other bias Unclear risk Judgement: no wash-out period

Matsukawa 2016

Study design: prospective, open-label, randomized study
Setting/Country: 52 urologists participated at a total of 44 investigational sites/outpatients/Japan
Dates when study was conducted: May 2012-September 2013

Participants

Inclusion criteria: men with total IPSS 8 or greater, IPSS QoL score 3 or greater, total OABSS 3 or greater, 1 or more urinary urgency episodes per week, prostate volume $20 \mathrm{ml}$ or greater on transabdominal US, Qmax less than $15 \mathrm{ml}$ per second at a voided volume of $100 \mathrm{ml}$ or greater and PVR less than $150 \mathrm{ml}$, and age 50 years or greater

Exclusion criteria: men received oral treatment with a1-blockers, anticholinergic agents, 5a-reductase inhibitors, antidepressants, anti-anxiety agents or sex hormonal agents, they had neurogenic bladder dysfunction, bladder calculi or active urinary tract infection, severe cardiac disease, renal dysfunction (serum creatinine levels $2 \mathrm{mg} / \mathrm{dl}$ or more) or hepatic dysfunction (aspartate and alanine aminotransferase concentrations more than twice normal values)

Total number of participants randomly assigned: 350

\section{Group A (Silodosin)}

- number of all participants randomly assigned: 175

- age (years): $70.6 \pm 7.8$

- prostate volume $(\mathrm{mL}): 39.6 \pm 16.7$

- PSA (ng/mL): $3.0 \pm 3.1$

- IPSS: $18.8 \pm 6.2$

- $\operatorname{Qmax}(\mathrm{mL} / \mathrm{s}): 8.2 \pm 3.6$ 
Matsukawa 2016 (Continued)

\section{Group B (Naftopidil)}

- number of all participants randomly assigned: 175

- age (years): $70.3 \pm 7.8$

- prostate volume $(\mathrm{mL}): 38.6 \pm 14.8$

- PSA (ng/mL): $3.0 \pm 3.1$

- IPSS: $18.9 \pm 6.1$

- $\operatorname{Qmax}(\mathrm{mL} / \mathrm{s}): 8.4 \pm 3.0$

Interventions

Run-in period: none

Group A: silodosin $4 \mathrm{mg}$ per day for 4 weeks, followed by $8 \mathrm{mg}$ per day for 8 weeks

Group B: naftopidil $50 \mathrm{mg}$ per day for 4 weeks, followed by $75 \mathrm{mg}$ per day for 8 weeks

Duration: 12 weeks

Primary outcome
Outcomes changes in IPSS
- changes in IPSS QoL
How measured: IPSS and OABSS questionnaire
Time points measured: baseline 4 and 12 weeks after the start of treatment
Time points reported: baseline 4 and 12 weeks after the start of treatment
Secondary outcome
- changes in Qmax
How measured: uroflowmetry
Time points measured: baseline 4 and 12 weeks after the start of treatment
Time points reported: baseline 4 and 12 weeks after the start of treatment

\section{Safety outcomes}

How measured: not reported

Time points measured: not reported

Time points reported: not reported

Subgroup: none

\begin{tabular}{ll}
\hline Funding sources & Not reported \\
\hline Declarations of interest & Not reported \\
\hline Notes & Language of publication: English \\
\hline Risk of bias & \\
\hline Bias & Authors' judgement Support for judgement \\
\hline
\end{tabular}


Matsukawa 2016 (Continued)

Random sequence genera- Low risk Quote: "Simple randomization using a random number table" tion (selection bias)

\begin{tabular}{lll}
\hline $\begin{array}{l}\text { Allocation concealment } \\
\text { (selection bias) }\end{array}$ & Unclear risk & Judgement: no information given \\
\hline $\begin{array}{l}\text { Blinding of participants } \\
\text { and personnel (perfor- } \\
\text { mance bias) }\end{array}$ & High risk & Quote: "prospective, open label, randomized" \\
All outcomes & \\
\hline
\end{tabular}

\begin{tabular}{|c|c|c|}
\hline $\begin{array}{l}\text { Blinding of outcome as- } \\
\text { sessment (detection bias) }\end{array}$ & High risk & Quote: "prospective, open label, randomized" \\
\hline
\end{tabular}

sessment (detection bias)

Subjective outcomes

Blinding of outcome as- Low risk Judgement: objective outcomes are not likely affected by lack of blinding
sessment (detection bias)
Objective outcomes

Objective outcomes

Incomplete outcome data Unclear risk
(attrition bias)
Urologic symptom scores/
QoL

\begin{tabular}{|c|c|c|}
\hline $\begin{array}{l}\text { Incomplete outcome data } \\
\text { (attrition bias) }\end{array}$ & Low risk & $\begin{array}{l}\text { Judgement: all subjects who were randomized in each group were included in } \\
\text { analysis }\end{array}$ \\
\hline
\end{tabular}

any reason
Judgement: 18/175 (10.2\%) and 18/175 (10.2\%) participants in silodosin and naftopidil group were not included in analysis

$\begin{array}{ll}\begin{array}{l}\text { Incomplete outcome data } \\ \text { (attrition bias) }\end{array} & \text { Low risk } \\ \text { Treatment withdrawal } & \text { analysis }\end{array}$

due to adverse events

\begin{tabular}{|c|c|c|}
\hline $\begin{array}{l}\text { Incomplete outcome data } \\
\text { (attrition bias) } \\
\text { AUR/ surgical intervention }\end{array}$ & Unclear risk & Judgement: no information given \\
\hline $\begin{array}{l}\text { Incomplete outcome data } \\
\text { (attrition bias) } \\
\text { Cardiovascular adverse } \\
\text { events }\end{array}$ & Unclear risk & $\begin{array}{l}\text { Judgement: information was partly reported (the number of withdrawal due } \\
\text { to cardiovascular adverse events were only reported) }\end{array}$ \\
\hline $\begin{array}{l}\text { Incomplete outcome data } \\
\text { (attrition bias) } \\
\text { Sexual adverse events }\end{array}$ & Unclear risk & Judgement: no information given \\
\hline $\begin{array}{l}\text { Selective reporting (re- } \\
\text { porting bias) }\end{array}$ & Unclear risk & $\begin{array}{l}\text { Judgement: prespecified outcomes were well described, but protocol was not } \\
\text { published }\end{array}$ \\
\hline Other bias & Low risk & Judgement: not detected \\
\hline
\end{tabular}

Miyakita 2010

Methods Study design: randomized, cross-over study


Dates when study was conducted: May 2006-July 2007

Participants

Inclusion criteria: men with IPSS $\geq 8$ points; QoL score $\geq 3$ points; prostate volume measured by US $\geq$ $20 \mathrm{~mL}$; void volume $\geq 100 \mathrm{~mL}$; and $\mathrm{Qmax}<15 \mathrm{~mL} / \mathrm{s}$

Exclusion criteria: already used any a1-blocker for the treatment of hypertension; taking vardenafil hydrochloride hydrate; and otherwise judged by an attending physician to be inappropriate

Total number of participants randomly assigned: 97

Group A (Silodosin)

- number of all participants randomly assigned: 46

- age (years): $68.2 \pm 8.6$

- prostate volume $(\mathrm{mL}): 41.3 \pm 25.3$

- PSA (ng/mL): not reported

- IPSS: $16.6 \pm 5.2$

- $\operatorname{Qmax}(\mathrm{mL} / \mathrm{s}): 9.4 \pm 3.5$

Group B (Tamsulosin)

- number of all participants randomly assigned: 51

- age (years): $70.1 \pm 8.9$

- prostate volume $(\mathrm{mL}): 37.8 \pm 16.3$

- PSA (ng/mL): not reported

- IPSS: $18.2 \pm 5.8$

- $\operatorname{Qmax}(\mathrm{mL} / \mathrm{s}): 9.7 \pm 4.4$

Group A: silodosin $8 \mathrm{mg} / \mathrm{d}$ (4 mg/dose, twice daily)

Group B: tamsulosin $0.2 \mathrm{mg} / \mathrm{d}$ (0.2 mg/dose, once daily)

Duration: 4 weeks (before cross-over)/total 8 weeks

\section{Primary outcome}

- change in total IPSS from baseline

How measured: IPSS questionnaire

Time points measured: before administration of the drug and 1, 2, 4, 6 and 8 weeks after initiation of administration

Time points reported: before administration of the drug, and 4 weeks and 8 weeks

\section{Secondary outcome}

- Qmax

- PVR

- BP

- heart rate

- participant preference for the drug

How measured: not reported

Time points measured: before administration of the drug, and 4 weeks and 8 weeks

Time points reported: before administration of the drug, and 4 weeks and 8 weeks 


\section{Safety outcomes}

How measured: adverse events

Time points measured: throughout the study period

Time points reported: throughout the study period

Subgroup: none

\begin{tabular}{ll}
\hline Funding sources & Not reported \\
\hline Declarations of interest & Not reported
\end{tabular}

Notes Language of publication: English

No wash-out period between cross-over

\section{Risk of bias}

\begin{tabular}{|c|c|c|}
\hline Bias & Authors' judgement & Support for judgement \\
\hline $\begin{array}{l}\text { Random sequence genera- } \\
\text { tion (selection bias) }\end{array}$ & Unclear risk & Judgement: no information given \\
\hline $\begin{array}{l}\text { Allocation concealment } \\
\text { (selection bias) }\end{array}$ & Unclear risk & Judgement: no information given \\
\hline $\begin{array}{l}\text { Blinding of participants } \\
\text { and personnel (perfor- } \\
\text { mance bias) } \\
\text { All outcomes }\end{array}$ & Unclear risk & Judgement: no information given \\
\hline $\begin{array}{l}\text { Blinding of outcome as- } \\
\text { sessment (detection bias) } \\
\text { Subjective outcomes }\end{array}$ & Unclear risk & Judgement: no information given \\
\hline $\begin{array}{l}\text { Blinding of outcome as- } \\
\text { sessment (detection bias) } \\
\text { Objective outcomes }\end{array}$ & Low risk & Judgement: objective outcomes are not likely affected by lack of blinding \\
\hline $\begin{array}{l}\text { Incomplete outcome data } \\
\text { (attrition bias) } \\
\text { Urologic symptom scores/ } \\
\text { QoL }\end{array}$ & High risk & $\begin{array}{l}\text { Judgement: } 12 / 46(26.1 \%) \text { and } 20 / 51(39.3 \%) \text { participants in the silodosin and } \\
\text { tamsulosin group were not included in the analysis }\end{array}$ \\
\hline $\begin{array}{l}\text { Incomplete outcome data } \\
\text { (attrition bias) } \\
\text { Treatment withdrawal for } \\
\text { any reason }\end{array}$ & Low risk & $\begin{array}{l}\text { Judgement: all participants who were randomized in each group were includ- } \\
\text { ed in analysis }\end{array}$ \\
\hline $\begin{array}{l}\text { Incomplete outcome data } \\
\text { (attrition bias) } \\
\text { Treatment withdrawal } \\
\text { due to adverse events }\end{array}$ & Low risk & $\begin{array}{l}\text { Judgement: all participants who were randomized in each group were includ- } \\
\text { ed in analysis }\end{array}$ \\
\hline $\begin{array}{l}\text { Incomplete outcome data } \\
\text { (attrition bias) } \\
\text { AUR/ surgical intervention }\end{array}$ & Unclear risk & Judgement: not available (cross-over trial) \\
\hline
\end{tabular}


Miyakita 2010 (Continued)

Incomplete outcome data Low risk Judgement: all participants who were randomized in each group were includ(attrition bias) ed in analysis

Cardiovascular adverse

events
Incomplete outcome data Low risk (attrition bias)

Sexual adverse events

Selective reporting (re- Unclear risk porting bias)
Judgement: all participants who were randomized in each group were included in analysis

Other bias Unclear risk Judgement: no wash-out period

Natarajan 2015

Methods Study design: parallel, randomized

Setting/Country: tertiary hospital/Tamil Nadu, India

Dates when study was conducted: August 2013-April 2015

Participants

Inclusion criteria: men $>50$ years with bothersome LUTS from BPH and IPSS > 7

Exclusion criteria: history of LUTS but not BPH, AUR in past 6 months, raised PSA level at baseline, serious co-morbidity of vital organs, use of concomitant medication having anticholinergic, androgenic or estrogenic influence, on other $a$-adrenergic antagonists or diuretics or with a history of prostatic or per urethral surgery or substance abuse

\section{Total number of participants randomly assigned: 57}

\section{Group A (Silodosin)}

- number of all participants randomly assigned: 28

- age (years): 61-62

- prostate volume $(\mathrm{mL})$ : not reported

- PSA (ng/mL): not reported

- IPSS: not reported

- Qmax (mL/s): not reported

Group B (Tamsulosin)

- number of all participants randomly assigned: 29

- age (years): 61-62

- prostate volume $(\mathrm{mL})$ : not reported

- PSA (ng/mL): not reported

- IPSS: not reported

- Qmax (mL/s): not reported

Interventions Run-in period: none

Group A: silodosin $8 \mathrm{mg}$ capsule once daily after dinner

Group B: tamsulosin $0.4 \mathrm{mg}$ controlled-release capsule once daily after dinner

Duration: 12 weeks 
Natarajan 2015 (Continued)

Outcomes

\section{Primary outcome}

- change in the total IPSS and QoL

- change in the total QoL

How measured: IPSS questionnaire

Time points measured: baseline and 12 weeks

Time points reported: baseline and 12 weeks

\section{Secondary outcome}

- proportion of participants who became completely or relatively symptom free (IPSS $<8)$ after 12 weeks of treatment

- change in prostate size

- change in Qmax

How measured: IPSS, US by blinded radiologist, uroflowmetry by blinded operator

Time points measured: baseline and 12 weeks

Time points reported: symptom free and change in Qmax not reported; change in prostate size, baseline and 12 weeks

\section{Safety outcomes}

How measured: adverse affects

Time points measured: at follow-up visits (4, 8, 12 weeks)

Time points reported: cumulative results from follow-up visits

Subgroup: none

Funding sources Not reported

Declarations of interest

Not reported

Notes Language of publication: English

\section{Risk of bias}

\begin{tabular}{lll}
\hline Bias & Authors' judgement & Support for judgement \\
\hline $\begin{array}{l}\text { Random sequence genera- } \\
\text { tion (selection bias) }\end{array}$ & Unclear risk & Judgement: no information given \\
\hline $\begin{array}{l}\text { Allocation concealment } \\
\text { (selection bias) }\end{array}$ & Unclear risk & Judgement: no information given \\
\hline $\begin{array}{l}\text { Blinding of participants } \\
\text { and personnel (perfor- } \\
\text { mance bias) } \\
\text { All outcomes }\end{array}$ & Unclear risk & Judgement: no information given \\
\hline
\end{tabular}


Natarajan 2015 (Continued)

Blinding of outcome as- Low risk_ Judgement: objective outcomes are not likely affected by lack of blinding sessment (detection bias)

Objective outcomes

Incomplete outcome data Unclear risk Judgement: no information given
(attrition bias)
Urologic symptom scores/
QoL

Incomplete outcome data Unclear risk Judgement: no information given
(attrition bias)
Treatment withdrawal for
any reason

Incomplete outcome data Unclear risk Judgement: no information given

(attrition bias)

Treatment withdrawal

due to adverse events

Incomplete outcome data Unclear risk Judgement: no information given
(attrition bias)
AUR/ surgical intervention

\begin{tabular}{|c|c|c|}
\hline $\begin{array}{l}\text { Incomplete outcome data } \\
\text { (attrition bias) } \\
\text { Cardiovascular adverse } \\
\text { events }\end{array}$ & Unclear risk & Judgement: no information given \\
\hline $\begin{array}{l}\text { Incomplete outcome data } \\
\text { (attrition bias) } \\
\text { Sexual adverse events }\end{array}$ & Unclear risk & Judgement: no information given \\
\hline \multirow[t]{2}{*}{$\begin{array}{l}\text { Selective reporting (re- } \\
\text { porting bias) }\end{array}$} & High risk & $\begin{array}{l}\text { Quote: "Silodosin showed a significant decrease in IPSS versus tamsulosin at } 2 \\
\text { weeks" }\end{array}$ \\
\hline & & $\begin{array}{l}\text { Judgement: protocol was not published and there was no information of } 2 \\
\text { weeks' follow-up. Secondary endpoints (proportion of participants who be- } \\
\text { came completely or relatively symptom free (IPSS }<8 \text { ), changes in Qmax) were } \\
\text { not reported }\end{array}$ \\
\hline Other bias & Unclear risk & Judgement: no data on baseline characteristics \\
\hline
\end{tabular}

\section{NCT00793819}

Methods Study design: parallel, randomized, double-blinded study

\section{Setting/Country: NR}

Dates when study was conducted: January 2009-October 2009
Participants
Inclusion criteria: men in good general health and $\geq 50$ years, with symptoms of moderate-severe BPH and nocturia ( $\geq 2$ episodes per night)
Exclusion criteria: men with 1) medical conditions that would confound the efficacy evaluation 2) medical conditions in which it would be unsafe to use an alpha-blocker 3 ) the use of concomitant drugs that would confound the efficacy evaluation 4) the use of concomitant drugs that would be unsafe with this alpha-blocker




\section{Total number of participants randomly assigned: 209}

Group A (Silodosin)

- number of all participants randomly assigned: 111

- age (years): $64.6 \pm 8.03$

- prostate volume $(\mathrm{mL})$ : not reported

- PSA (ng/mL): not reported

- IPSS: not reported

- Qmax (mL/s): not reported

Group B (Placebo)

- number of all participants randomly assigned: 98

- age (years): $64.2 \pm 8.92$

- prostate volume $(\mathrm{mL})$ : not reported

- PSA (ng/mL): not reported

- IPSS: not reported

- Qmax (mL/s): not reported

\begin{tabular}{ll}
\hline Interventions & Run-in period: not reported \\
Group A: silodosin $8 \mathrm{mg}$ daily \\
Group B: 1 placebo capsule daily \\
Duration: 12 weeks
\end{tabular}

\section{Outcomes}

\section{Primary outcome}

- change in nocturia episodes

How measured: not reported

Time points measured: before and 12 weeks after treatment

Time points reported: before and 12 weeks after treatment

\section{Secondary outcomes}

- change in QoL questionnaire responses

How measured: not reported

Time points measured: before and 12 weeks after treatment

Time points reported: before and 12 weeks after treatment

Subgroup: not reported

\begin{tabular}{ll}
\hline Funding sources & Watson Pharmaceuticals \\
\hline Declarations of interest & Watson Pharmaceuticals \\
\hline Notes & Language of publication: English \\
& Publication status: NCT00793819 (results in clinicaltrials.gov)
\end{tabular}

\section{Risk of bias}

Bias Authors' judgement Support for judgement




\begin{tabular}{|c|c|c|}
\hline $\begin{array}{l}\text { Random sequence genera- } \\
\text { tion (selection bias) }\end{array}$ & Unclear risk & Judgement: no information given \\
\hline $\begin{array}{l}\text { Allocation concealment } \\
\text { (selection bias) }\end{array}$ & Unclear risk & Judgement: no information given \\
\hline $\begin{array}{l}\text { Blinding of participants } \\
\text { and personnel (perfor- } \\
\text { mance bias) } \\
\text { All outcomes }\end{array}$ & Low risk & Quote: "parallel randomized double blinded (Participant, Investigator)" \\
\hline
\end{tabular}

\begin{tabular}{lll}
\hline $\begin{array}{l}\text { Blinding of outcome as- } \\
\text { sessment (detection bias) } \\
\text { Subjective outcomes }\end{array}$ & Low risk & Quote: "parallel randomized double blinded (Participant, Investigator)" \\
\hline $\begin{array}{l}\text { Blinding of outcome as- } \\
\begin{array}{l}\text { sessment (detection bias) } \\
\text { Objective outcomes }\end{array}\end{array}$ & Low risk & Judgement: objective outcomes are not likely affected by lack of blinding \\
\hline
\end{tabular}

\begin{tabular}{l}
\hline Incomplete outcome data Unclear risk Judgement: no information given \\
(attrition bias) \\
Urologic symptom scores/ \\
QoL \\
\hline
\end{tabular}

\begin{tabular}{ll}
\hline $\begin{array}{l}\text { Incomplete outcome data } \\
\text { (attrition bias) }\end{array}$ & Judgement: all participants who were randomized in each group were includ- \\
Treatment withdrawal for & \\
any reason & \\
\hline
\end{tabular}

\begin{tabular}{lll}
\hline $\begin{array}{l}\text { Incomplete outcome data } \\
\text { (attrition bias) }\end{array}$ & Low risk & $\begin{array}{l}\text { Judgement: all participants who were randomized in each group were includ- } \\
\text { ed in analysis }\end{array}$ \\
$\begin{array}{l}\text { Treatment withdrawal } \\
\text { due to adverse events }\end{array}$ & \\
\hline $\begin{array}{l}\text { Incomplete outcome data } \\
\text { (attrition bias) }\end{array}$ & Low risk \\
AUR/ surgical intervention & & $\begin{array}{l}\text { Judgement: all participants who were randomized in each group were includ- } \\
\text { ed in analysis }\end{array}$ \\
\hline $\begin{array}{l}\text { Incomplete outcome data } \\
\text { (attrition bias) }\end{array}$ & Low risk \\
$\begin{array}{l}\text { Cardiovascular adverse } \\
\text { events }\end{array}$ & & $\begin{array}{l}\text { Judgement: all participants who were randomized in each group were includ- } \\
\text { ed in analysis }\end{array}$ \\
\hline
\end{tabular}

\begin{tabular}{lll}
\hline $\begin{array}{l}\text { Incomplete outcome data } \\
\text { (attrition bias) } \\
\text { Sexual adverse events }\end{array}$ & Low risk & $\begin{array}{l}\text { Judgement: all participants who were randomized in each group were includ- } \\
\text { ed in analysis }\end{array}$ \\
\hline $\begin{array}{l}\text { Selective reporting (re- } \\
\text { porting bias) }\end{array}$ & Low risk & $\begin{array}{l}\text { Judgement: protocol (NCT00793819) was published and the prespecified out- } \\
\text { comes were well described }\end{array}$ \\
\hline Other bias & Unclear risk & Judgement: protocol only \\
\hline
\end{tabular}


Pande 2014 (Continued)

Setting/Country: outpatient/tertiary care hospital/Kolkata, India

Dates when study was conducted: July 2012-June 2013
Inclusion criteria: ambulatory, treatment naïve, men $>50$ years with bothersome LUTS from BPH and IPSS $>7$

Exclusion criteria: history of LUTS but not BPH, AUR in past 6 months, raised PSA level at baseline, serious co-morbidity of vital organs, use of concomitant medication having anticholinergic, androgenic or estrogenic influence, on other $a$-adrenergic antagonists or diuretics or with a history of prostatic or per urethral surgery or substance abuse

\section{Total number of participants randomly assigned: 61}

Group A (Silodosin)

- number of all participants randomly assigned: 32

- age (years): $61.4 \pm 7.88$

- prostate volume $(\mathrm{mL}): 42.0 \pm 19.96$

- PSA (ng/mL): not reported

- IPSS: $18.4 \pm 3.32$

- $\operatorname{Qmax}(\mathrm{mL} / \mathrm{s}): 15.5$

Group B (Tamsulosin)

- number of all participants randomly assigned: 29

- age (years): $62.6 \pm 7.55$

- prostate volume $(\mathrm{mL}): 35.6 \pm 9.56$

- PSA (ng/mL): not reported

- IPSS: $18.4 \pm 3.94$

- $\operatorname{Qmax}(\mathrm{mL} / \mathrm{s}): 15.9$

Run-in period: none

Group A: silodosin $8 \mathrm{mg}$ capsule once daily

Group B: tamsulosin $0.4 \mathrm{mg}$ controlled-release capsule once daily

Duration: 12 weeks

Outcomes

- total IPSS score in addition to the QoL

How measured: IPSS questionnaire

Time points measured: at 4,8 and 12 weeks

Time points reported: at 4, 8 and 12 weeks

\section{Secondary outcome}

- proportion of participants who became completely or relatively symptom free (IPSS $<8)$ after 12 weeks of treatment

- change in prostate size, in terms of volume, as assessed at US by a radiologist unaware of treatment allocation

- changes in Qmax and allied parameters assessed at uroflowmetry by a blinded operator

How measured: IPSS questionnaire, US by blinded radiologist, uroflowmetry by blinded investigator

Time points measured: baseline and 12 weeks 


\section{Safety outcomes}

How measured: vital signs, treatment-emergent adverse events, postural hypotension and retrograde ejaculation, laboratory investigations (complete blood count, fasting plasma glucose, routine liver function tests and creatinine level)

Time points measured: lab - at baseline and study end/others - each visit

Time points reported: lab - at baseline and study end/others - cumulative results from follow up visits

Subgroup: none

$\begin{array}{ll}\text { Funding sources } & \text { M/s Cipla Limited, Mumbai, donated both study drugs and reimbursed part of the cost of laboratory in- } \\ \text { vestigations on request }\end{array}$

Declarations of interest None

Notes Language of publication: English

Data (IPSS, QoL, AUR, surgical intervention, cardiovascular, sexual adverse events) were given by contact with study author

\section{Risk of bias}

\begin{tabular}{lll}
\hline Bias & Authors' judgement & Support for judgement \\
\hline $\begin{array}{ll}\text { Random sequence genera- } \\
\text { tion (selection bias) }\end{array}$ & Low risk & $\begin{array}{l}\text { Quote: "randomized in 1:1 ratio to one of the two study groups in fixed blocks } \\
\text { of 8, using computer generated random number list" }\end{array}$ \\
\hline
\end{tabular}

\begin{tabular}{|c|c|c|}
\hline $\begin{array}{l}\text { Allocation concealment } \\
\text { (selection bias) }\end{array}$ & Low risk & $\begin{array}{l}\text { Quote: "Allocation concealment was achieved using the serially numbered, } \\
\text { opaque, sealed envelope technique" }\end{array}$ \\
\hline $\begin{array}{l}\text { Blinding of participants } \\
\text { and personnel (perfor- } \\
\text { mance bias) } \\
\text { All outcomes }\end{array}$ & High risk & $\begin{array}{l}\text { Quote: "single blind, parallel group, randomized, controlled trial", "The cap- } \\
\text { sules were removed from their commercial blister strip packaging and repack- } \\
\text { aged in air-tight, screw cap containers and suitably labelled and coded as tri- } \\
\text { al medication. Repackaging was done with the help of residents not otherwise } \\
\text { involved in the study. Capsule identity was not revealed to the patients who re- } \\
\text { ceived the total medication in three installments" }\end{array}$ \\
\hline & & $\begin{array}{l}\text { Judgement: participants were blinded, but investigator and observer might be } \\
\text { not blinded }\end{array}$ \\
\hline
\end{tabular}

\begin{tabular}{|c|c|c|}
\hline $\begin{array}{l}\text { Blinding of outcome as- } \\
\text { sessment (detection bias) } \\
\text { Subjective outcomes }\end{array}$ & High risk & $\begin{array}{l}\text { Quote: "single blind, parallel group, randomized, controlled trial", "The cap- } \\
\text { sules were removed from their commercial blister strip packaging and repack- } \\
\text { aged in air-tight, screw cap containers and suitably labelled and coded as tri- } \\
\text { al medication. Repackaging was done with the help of residents not otherwise } \\
\text { involved in the study. Capsule identity was not revealed to the patients who re- } \\
\text { ceived the total medication in three installments" }\end{array}$ \\
\hline & & $\begin{array}{l}\text { Judgement: participants were blinded, but investigator and observer might be } \\
\text { not blinded }\end{array}$ \\
\hline
\end{tabular}

Blinding of outcome as- Low risk Judgement: objective outcomes are not likely affected by lack of blinding sessment (detection bias) Objective outcomes

\begin{tabular}{|c|c|c|}
\hline $\begin{array}{l}\text { Incomplete outcome data } \\
\text { (attrition bias) }\end{array}$ & Unclear risk & $\begin{array}{l}\text { Judgement: } 6 / 32(18.7 \%) \text { in silodosin, } 2 / 29(6.9 \%) \text { in tamsulosin lost to fol- } \\
\text { low-up: missing data were imputed by last observation carried forward strate- } \\
\text { gy }\end{array}$ \\
\hline
\end{tabular}


Pande 2014 (Continued)

Urologic symptom scores/

QoL

\begin{tabular}{|c|c|c|}
\hline $\begin{array}{l}\text { Incomplete outcome data } \\
\text { (attrition bias) } \\
\text { Treatment withdrawal for } \\
\text { any reason }\end{array}$ & Low risk & $\begin{array}{l}\text { Judgement: all participants who were randomized in each group were includ- } \\
\text { ed in analysis }\end{array}$ \\
\hline
\end{tabular}

\begin{tabular}{|c|c|c|}
\hline $\begin{array}{l}\text { Incomplete outcome data } \\
\text { (attrition bias) }\end{array}$ & Low risk & $\begin{array}{l}\text { Judgement: all participants who were randomized in each group were includ- } \\
\text { ed in analysis }\end{array}$ \\
\hline
\end{tabular}

\begin{tabular}{ll}
\hline Incomplete outcome data & Low risk \\
(attrition bias) & Judgement: all participants who were randomized in each group were includ- \\
AUR/ surgical intervention & ed in analysis. We received the data after contacting the study author.
\end{tabular}

\begin{tabular}{|c|c|c|}
\hline $\begin{array}{l}\text { Incomplete outcome data } \\
\text { (attrition bias) } \\
\text { Cardiovascular adverse } \\
\text { events }\end{array}$ & Low risk & $\begin{array}{l}\text { Judgement: all participants who were randomized in each group were includ- } \\
\text { ed in analysis }\end{array}$ \\
\hline $\begin{array}{l}\text { Incomplete outcome data } \\
\text { (attrition bias) } \\
\text { Sexual adverse events }\end{array}$ & Low risk & $\begin{array}{l}\text { Judgement: all participants who were randomized in each group were includ- } \\
\text { ed in analysis }\end{array}$ \\
\hline $\begin{array}{l}\text { Selective reporting (re- } \\
\text { porting bias) }\end{array}$ & Low risk & $\begin{array}{l}\text { Judgement: protocol (Clinical Trials Registry-India (CTRI/2014/01/004366)) } \\
\text { was published and the prespecified outcomes were well described. Data (AUR, } \\
\text { surgical intervention, cardiovascular, sexual adverse events) were given by } \\
\text { contact with study author }\end{array}$ \\
\hline Other bias & Low risk & Judgement: not detected \\
\hline
\end{tabular}

\section{Shirakawa 2013}

\section{Methods}

Study design: randomized, open-label, controlled, multicenter study

Setting/Country: Kobe University School or other collaborating institutions/Japan

Dates when study was conducted: July 2007-March 2011
Inclusion criteria: men with: BPH/ LUTS with a total IPSS $\geq 8$ points; QoL index $\geq 3$ points; Qmax $<15$ $\mathrm{mL} / \mathrm{s}$; prostate volume $\geq 20 \mathrm{~mL}$; and either without a history of using any a1-receptor blocker (hereafter, drug-naive group) or who had continued to use tamsulosin ( $0.2 \mathrm{mg}$ once daily) for $\geq 3$ months and wanted to switch the medication to another oral drug (hereafter, drug-switching group)

Exclusion criteria: other diseases such as prostate cancer, bladder tumor, cystolithiasis, prostatitis, urethral stricture, or active urinary tract infection; complication of neurogenic bladder or disease suspected of neurogenic bladder; and whose participation in the study was deemed inappropriate by their primary physician(s)

\section{Total number of participants randomly assigned: 121}

\section{Group A (Silodosin)}

- number of all participants randomly assigned: 61

- age (years): $70.98 \pm 6.69$

- prostate volume $(\mathrm{mL}): 38.24 \pm 12.94$ 
Shirakawa 2013 (Continued)

- PSA (ng/mL): not reported

- IPSS: $17.53 \pm 5.4$

- $\operatorname{Qmax}(\mathrm{mL} / \mathrm{s}): 9.87 \pm 4.50$

Group B (Naftopidil)

- number of all participants randomly assigned: 60

- age (years): $70.50 \pm 6.58$

- prostate volume $(\mathrm{mL}): 39.39 \pm 25.96$

- PSA (ng/mL): not reported

- IPSS: $17.56 \pm 6.7$

- $\operatorname{Qmax}(\mathrm{mL} / \mathrm{s}): 11.13 \pm 6.53$

\section{Interventions}

\section{Run-in period: none}

Group A: silodosin $4 \mathrm{mg}$ twice daily

Group B: naftopidil $50 \mathrm{mg}$ once daily

Duration: 8 consecutive weeks

\begin{tabular}{|c|c|c|}
\hline Outcomes & $\begin{array}{l}\text { - total IPSS } \\
\text { - subtotal IPSS of stc } \\
\text { - subtotal IPSS of vo } \\
\text { - Qost-micturition sy } \\
\text { How measured: IPSS c } \\
\text { Time points measurec } \\
\text { Time points reported: } \\
\text { Safety outcomes } \\
\text { How measured: adver } \\
\text { Time points measurec } \\
\text { Time points reported: } \\
\text { Subgroup: drug-naï }\end{array}$ & $\begin{array}{l}\text { age symptoms } \\
\text { ing symptoms } \\
\text { ptoms } \\
\text { at baseline, } 4 \text { and } 8 \text { weeks } \\
\text { t baseline, } 4 \text { and } 8 \text { weeks } \\
\text { not reported } \\
\text { umulative results from follow-up visits } \\
\text { drug-switching }\end{array}$ \\
\hline Funding sources & \multicolumn{2}{|l|}{ Not reported } \\
\hline Declarations of interest & \multicolumn{2}{|l|}{ None } \\
\hline Notes & \multicolumn{2}{|c|}{ Language of publication: English } \\
\hline \multicolumn{3}{|l|}{ Risk of bias } \\
\hline Bias & Authors' judgement & Support for judgement \\
\hline $\begin{array}{l}\text { Random sequence genera- } \\
\text { tion (selection bias) }\end{array}$ & Low risk & Quote: "randomly assigned (using a random number table)" \\
\hline $\begin{array}{l}\text { Allocation concealment } \\
\text { (selection bias) }\end{array}$ & Unclear risk & Judgement: no information given \\
\hline
\end{tabular}


Shirakawa 2013 (Continued)

Blinding of participants $\quad$ High risk $\quad$ Quote: "randomized, open-label, controlled multicenter study"
and personnel (performance bias)

Judgement: no one was blinded (protocol)

All outcomes

\begin{tabular}{|c|c|c|}
\hline $\begin{array}{l}\text { Blinding of outcome as- } \\
\text { sessment (detection bias) } \\
\text { Subjective outcomes }\end{array}$ & High risk & $\begin{array}{l}\text { Quote: "randomized, open-label, controlled multicenter study" } \\
\text { Judgement: no one was blinded (protocol) }\end{array}$ \\
\hline
\end{tabular}

Subjective outcomes

Low risk

Judgement: objective outcomes are not likely affected by lack of blinding

Blinding of outcome as-
sessment (detection bias)

Objective outcomes

\begin{tabular}{|c|c|c|}
\hline $\begin{array}{l}\text { Incomplete outcome data } \\
\text { (attrition bias) }\end{array}$ & Low risk & $\begin{array}{l}\text { Judgement: } 5 / 61(8.2 \%) \text { and } 4 / 60(6.7 \%) \text { participants in silodosin and nafto- } \\
\text { pidil were not included in analysis }\end{array}$ \\
\hline
\end{tabular}

QoL

\begin{tabular}{|c|c|c|}
\hline $\begin{array}{l}\text { Incomplete outcome data } \\
\text { (attrition bias) } \\
\text { Treatment withdrawal for } \\
\text { any reason }\end{array}$ & Low risk & $\begin{array}{l}\text { Judgement: all participants who were randomized in each group were includ- } \\
\text { ed in analysis }\end{array}$ \\
\hline $\begin{array}{l}\text { Incomplete outcome data } \\
\text { (attrition bias) } \\
\text { Treatment withdrawal } \\
\text { due to adverse events }\end{array}$ & Low risk & $\begin{array}{l}2 / 61(3.3 \%) \text { and } 3 / 60(5.0 \%) \text { participants in silodosin and naftopidil were not } \\
\text { included in analysis }\end{array}$ \\
\hline $\begin{array}{l}\text { Incomplete outcome data } \\
\text { (attrition bias) } \\
\text { AUR/ surgical intervention }\end{array}$ & Unclear risk & Judgement: no information given \\
\hline $\begin{array}{l}\text { Incomplete outcome data } \\
\text { (attrition bias) } \\
\text { Cardiovascular adverse } \\
\text { events }\end{array}$ & Low risk & $\begin{array}{l}\text { Judgement: } 2 / 61(3.3 \%) \text { and } 3 / 60(5.0 \%) \text { participants in silodosin and nafto- } \\
\text { pidil were not included in analysis }\end{array}$ \\
\hline $\begin{array}{l}\text { Incomplete outcome data } \\
\text { (attrition bias) } \\
\text { Sexual adverse events }\end{array}$ & Low risk & $\begin{array}{l}\text { Judgement: } 2 / 61(3.3 \%) \text { and } 3 / 60(5.0 \%) \text { participants in silodosin and nafto- } \\
\text { pidil were not included in analysis }\end{array}$ \\
\hline $\begin{array}{l}\text { Selective reporting (re- } \\
\text { porting bias) }\end{array}$ & Low risk & $\begin{array}{l}\text { Judgement: protocol (UMIN000008331) was published. While the results were } \\
\text { shown separately in participants with drug naïve and switching group, review } \\
\text { outcomes were well described }\end{array}$ \\
\hline Other bias & Low risk & Not detected \\
\hline
\end{tabular}

Takeshita 2016

\begin{tabular}{ll}
\hline Methods & Study design: randomized, cross-over study \\
& Setting/Country: 4 community-based hospitals/Japan \\
& Dates when study was conducted: February 2011-July 2014 \\
\hline Participants & $\begin{array}{l}\text { Inclusion criteria: men aged } \geq 50 \text { years with LUTS/BPH, an IPSS of } \geq 8, \text { QoL score of } \geq 3 \text {, and US-esti- } \\
\text { mated prostatic volume of } \geq 20 \mathrm{~mL}\end{array}$ \\
\hline
\end{tabular}


Exclusion criteria: those that had taken any alpha-blocker within the previous 28 days; those currently taking phosphodiesterase type 5 inhibitors, 5-ARIs, or antiandrogens; those with severe renal dysfunction (estimated glomerular filtration rate $<30 \mathrm{~mL} / \mathrm{min}$ per $1.73 \mathrm{~m}^{2}$ ); and those judged to be inappropriate by the attending physicians

\section{Total number of participants randomly assigned: 34}

\section{Group A (Silodosin)}

- number of all participants randomly assigned: 18

- age (years): $69.6 \pm 5.4$

- prostate volume $(\mathrm{mL}): 38.7 \pm 11.6$

- PSA (ng/mL): $5.9 \pm 5.9$

- IPSS: $17.1 \pm 7.3$

- $\operatorname{Qmax}(\mathrm{mL} / \mathrm{s}): 9.5 \pm 4.9$

Group B (Tamsulosin)

- number of all participants randomly assigned: 16

- age (years): $69.4 \pm 7.0$

- prostate volume $(\mathrm{mL}): 47.3 \pm 30.4$

- PSA (ng/mL): $5.4 \pm 4.4$

- IPSS: $15.2 \pm 7.0$

- $\operatorname{Qmax}(\mathrm{mL} / \mathrm{s}): 10.2 \pm 3.8$

Interventions

Run-in period: none

Group A: silodosin $4 \mathrm{mg}$ once daily in the morning

Group B: tamsulosin $0.2 \mathrm{mg}$ once daily in the morning

Duration: 4 weeks (before cross-over)/total 8 weeks

Outcomes

\section{Primary outcome}

- changes in IPSS and QoL score

How measured: IPSS questionnaire

Time points measured: baseline to weeks 4 and 8

Time points reported: baseline to weeks 4 and 8

\section{Secondary outcome}

- uroflowmetry

- BP

- changes in subjective parameters including IPSS subscores and OABSS

- participant preference for the drug

How measured: participant preference for the drug by self-administered questionnaire

Time points measured: before administration of the drug, and 4 weeks and 8 weeks

Time points reported: before administration of the drug, and 4 weeks and 8 weeks

\section{Safety outcomes}

How measured: adverse events

Time points measured: baseline to weeks 4 and 8 
Takeshita 2016 (Continued)

Time points reported: baseline to weeks 4 and 8

Subgroup: none

\begin{tabular}{ll}
\hline Funding sources & Not reported \\
\hline Declarations of interest & None \\
\hline Notes & Language of publication: English \\
& No wash-out period between cross-over \\
& $\begin{array}{l}\text { Data (IPSS, QoL, treatment withdrawal, cardiovascular, sexual adverse events) were given by contact } \\
\text { with study author }\end{array}$ \\
\end{tabular}

\section{Risk of bias}

\begin{tabular}{lll}
\hline Bias & Authors' judgement & Support for judgement \\
\hline $\begin{array}{l}\text { Random sequence genera- } \\
\text { tion (selection bias) }\end{array}$ & Low risk & Judgement: author reply "random number table" \\
\hline $\begin{array}{l}\text { Allocation concealment } \\
\text { (selection bias) }\end{array}$ & Low risk & Judgement: author reply "sealed opaque envelope" \\
\hline $\begin{array}{l}\text { Blinding of participants } \\
\begin{array}{l}\text { and personnel (perfor- } \\
\text { mance bias) }\end{array}\end{array}$ & High risk & Quote: "open-label, randomized crossover study" \\
All outcomes & \\
\hline
\end{tabular}

Blinding of outcome as-
$\begin{aligned} & \text { sessment (detection bias) } \\ & \text { Subjective outcomes }\end{aligned}$

Blinding of outcome as- Low risk Judgement: objective outcomes are not likely affected by lack of blinding
$\begin{aligned} & \text { sessment (detection bias) } \\ & \text { Objective outcomes }\end{aligned}$

\begin{tabular}{ll}
\hline $\begin{array}{l}\text { Incomplete outcome data } \\
\text { (attrition bias) }\end{array}$ & Unclear risk \\
$\begin{array}{l}\text { Urologic symptom scores/ } \\
\text { QoL }\end{array}$ & $\begin{array}{l}\text { Judgement: } 2 / 18(11.2 \%) \text { and } 2 / 16(12.5 \%) \text { participants in the silodosin and } \\
\text { tamsulosin group were not included in the analysis }\end{array}$ \\
\hline $\begin{array}{l}\text { Incomplete outcome data } \\
\text { (attrition bias) }\end{array}$ & Low risk \\
$\begin{array}{l}\text { Treatment withdrawal for } \\
\text { any reason }\end{array}$ & $\begin{array}{l}\text { Judgement: all participants who were randomized in each group were includ- } \\
\text { ed in analysis }\end{array}$
\end{tabular}

\begin{tabular}{lll}
\hline $\begin{array}{l}\text { Incomplete outcome data } \\
\text { (attrition bias) }\end{array}$ & Low risk & $\begin{array}{l}\text { Judgement: all participants who were randomized in each group were includ- } \\
\text { ed in analysis } \\
\begin{array}{l}\text { dreatment withdrawal } \\
\text { due to adverse events }\end{array}\end{array}$ \\
\hline $\begin{array}{l}\text { Incomplete outcome data } \\
\text { (attrition bias) }\end{array}$ & Unclear risk & Judgement: not available (cross-over trial) \\
AUR/ surgical intervention & & \\
\hline $\begin{array}{l}\text { Incomplete outcome data } \\
\text { (attrition bias) }\end{array}$ & Low risk & $\begin{array}{l}\text { Judgement: all participants who were randomized in each group were includ- } \\
\text { ed in analysis }\end{array}$
\end{tabular}


Takeshita 2016 (Continued) Cardiovascular adverse events

\begin{tabular}{lll}
\hline $\begin{array}{l}\text { Incomplete outcome data } \\
\text { (attrition bias) } \\
\text { Sexual adverse events }\end{array}$ & Low risk & $\begin{array}{l}\text { Judgement: all participants who were randomized in each group were includ- } \\
\text { ed in analysis }\end{array}$ \\
\hline $\begin{array}{l}\text { Selective reporting (re- } \\
\text { porting bias) }\end{array}$ & Low risk & $\begin{array}{l}\text { Judgement: protocol (JPRN-UMIN000004918) was published and prespecified, } \\
\text { study outcomes were analyzed as planned. Data (IPSS, QoL, treatment with- } \\
\text { drawal, cardiovascular, sexual adverse events) were provided after contact } \\
\text { with study author }\end{array}$ \\
\hline Other bias & Unclear risk & Judgement: no wash-out period \\
\hline
\end{tabular}

\section{Watanabe 2011}

\begin{tabular}{|c|c|}
\hline Methods & $\begin{array}{l}\text { Study design: randomized, cross-over study } \\
\text { Setting/Country: } 3 \text { institutions/Japan } \\
\text { Dates when study was conducted: February 2008-September } 2009\end{array}$ \\
\hline Participants & $\begin{array}{l}\text { Inclusion criteria: men with LUTS associated with BPH and had an IPSS } \geq 8 \text { and an IPSS-QoL score } \geq 2 \\
\text { Exclusion criteria: not reported } \\
\text { Total number of participants randomly assigned: } 102 \\
\text { Group A (Silodosin) } \\
\text { - number of all participants randomly assigned: } 51 \\
\text { - age (years): } 69.3 \pm 8.3 \\
\text { - prostate volume (mL): } 36.6 \pm 18.3 \\
\text { - PSA (ng/mL): not reported } \\
\text { - IPSS: } 16.4 \pm 5.0 \\
\text { - Qmax (mL/s): } 9.1 \pm 5.7 \\
\text { Group B (Tamsulosin) } \\
\text { - number of all participants randomly assigned: } 51 \\
\text { - age (years): } 69.9 \pm 8.4 \\
\text { - prostate volume (mL): } 35.1 \pm 13.0 \\
\text { - PSA (ng/mL): not reported } \\
\text { - IPSS: } 18.1 \pm 6.2 \\
\text { - Qmax (mL/s): } 8.8 \pm 5.2\end{array}$ \\
\hline
\end{tabular}

Interventions

\section{Run-in period: none}

Group A: silodosin $4 \mathrm{mg}$, orally, twice daily

Group B: tamsulosin $0.2 \mathrm{mg}$, orally, once daily

Duration: 4 weeks (before cross-over)/total 8 weeks

\section{Outcomes}

\section{Primary outcome}

- participant preference for the drug and reason of preference 
Watanabe 2011 (Continued)

How measured: questionnaire and open question

Time points measured: 8 weeks

Time points reported: 8 weeks

\section{Secondary outcome}

- IPSS

- IPSS-QoL

- Qmax

- mean urinary flow rate

- PVR

How measured: not reported

Time points measured: baseline and at 4 and 8 weeks

Time points reported: baseline and at 4 and 8 weeks

\section{Safety outcomes}

How measured: adverse events

Time points measured: not reported

Time points reported: during the study

Subgroup: age $\geq 70 /$ IPSS $\geq 20$

\begin{tabular}{ll}
\hline Funding sources & Not reported \\
\hline Declarations of interest & None \\
\hline
\end{tabular}

Notes Language of publication: English

No wash-out period between cross-over

\section{Risk of bias}

\begin{tabular}{|c|c|c|}
\hline Bias & Authors' judgement & Support for judgement \\
\hline $\begin{array}{l}\text { Random sequence genera- } \\
\text { tion (selection bias) }\end{array}$ & Unclear risk & Judgement: no information given \\
\hline $\begin{array}{l}\text { Allocation concealment } \\
\text { (selection bias) }\end{array}$ & Unclear risk & Judgement: no information given \\
\hline $\begin{array}{l}\text { Blinding of participants } \\
\text { and personnel (perfor- } \\
\text { mance bias) } \\
\text { All outcomes }\end{array}$ & High risk & Quote: "open-label study" \\
\hline $\begin{array}{l}\text { Blinding of outcome as- } \\
\text { sessment (detection bias) } \\
\text { Subjective outcomes }\end{array}$ & High risk & Quote: "open-label study" \\
\hline $\begin{array}{l}\text { Blinding of outcome as- } \\
\text { sessment (detection bias) } \\
\text { Objective outcomes }\end{array}$ & Low risk & Judgement: objective outcomes are not likely affected by lack of blinding \\
\hline
\end{tabular}


Watanabe 2011 (Continued)

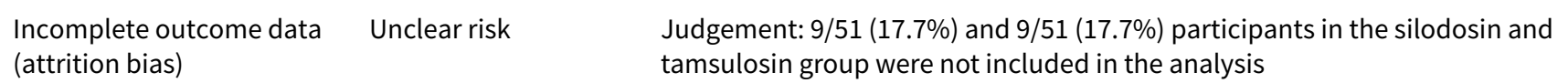

Urologic symptom scores/

QoL

\begin{tabular}{|c|c|c|}
\hline $\begin{array}{l}\text { Incomplete outcome data } \\
\text { (attrition bias) } \\
\text { Treatment withdrawal for } \\
\text { any reason }\end{array}$ & Low risk & $\begin{array}{l}\text { Judgement: all participants who were randomized in each group were includ- } \\
\text { ed in analysis }\end{array}$ \\
\hline $\begin{array}{l}\text { Incomplete outcome data } \\
\text { (attrition bias) } \\
\text { Treatment withdrawal } \\
\text { due to adverse events }\end{array}$ & Low risk & $\begin{array}{l}\text { Judgement: all participants who were randomized in each group were includ- } \\
\text { ed in analysis }\end{array}$ \\
\hline $\begin{array}{l}\text { Incomplete outcome data } \\
\text { (attrition bias) } \\
\text { AUR/ surgical intervention }\end{array}$ & Unclear risk & Judgement: not available (cross-over trial) \\
\hline $\begin{array}{l}\text { Incomplete outcome data } \\
\text { (attrition bias) } \\
\text { Cardiovascular adverse } \\
\text { events }\end{array}$ & Unclear risk & $\begin{array}{l}\text { Judgement: } 14 / 102(13.8 \%) \text { and } 11 / 102(10.8 \%) \text { participants in the silodosin } \\
\text { and tamsulosin group were not included in the analysis (study author reported } \\
\text { the results after cross-over) }\end{array}$ \\
\hline $\begin{array}{l}\text { Incomplete outcome data } \\
\text { (attrition bias) } \\
\text { Sexual adverse events }\end{array}$ & Unclear risk & $\begin{array}{l}\text { Judgement: } 14 / 102(13.8 \%) \text { and } 11 / 102(10.8 \%) \text { participants in the silodosin } \\
\text { and tamsulosin group were not included in the analysis (study author reported } \\
\text { the results after cross-over) }\end{array}$ \\
\hline $\begin{array}{l}\text { Selective reporting (re- } \\
\text { porting bias) }\end{array}$ & Unclear risk & Judgement: no protocol available \\
\hline Other bias & Unclear risk & Judgement: no wash-out period \\
\hline
\end{tabular}

\section{Yamaguchi 2013}

\begin{tabular}{ll}
\hline Methods & Study design: parallel, randomized trial \\
Setting/Country: Nihon University School of Medicine/Japan \\
Dates when study was conducted: December 2007-November 2010 \\
\hline Inclusion criteria: men with BPH $\geq 50$ years with significant LUTS and deteriorated QoL, with IPSS of $\geq 8$ \\
and its QoL score of $\geq 3$ \\
Exclusion criteria: established prostate cancer, neurogenic bladder and any other complications that \\
affect micturitional status; underwent prostate surgery, intervention or radiation therapy \\
Total number of participants randomly assigned: 109 \\
Group A (Silodosin) \\
- number of all participants randomly assigned: 58 \\
- age (years): $69.3 \pm 7.8$ \\
- prostate volume $(\mathrm{mL}): 33.2 \pm 21.2$ \\
- PSA (ng/mL): $2.8 \pm 3.3$ \\
- IPSS: $16.9 \pm 5.5$ \\
- Qmax $(\mathrm{mL} / \mathrm{s}): 10.4 \pm 5.0$
\end{tabular}


Yamaguchi 2013 (Continued)

\section{Group B (Naftopidil)}

- number of all participants randomly assigned: 51

- age (years): $70.0 \pm 7.0$

- prostate volume $(\mathrm{mL}): 39.5 \pm 18.0$

- PSA (ng/mL): $3.9 \pm 3.5$

- IPSS: $18.9 \pm 7.0$

- $\operatorname{Qmax}(\mathrm{mL} / \mathrm{s}): 9.9 \pm 5.3$

\begin{tabular}{ll}
\hline Run-in period: none \\
Group A: silodosin $8 \mathrm{mg} / \mathrm{d}$ \\
Group B: naftopidil $75 \mathrm{mg} / \mathrm{d}$ \\
Duration: 12 weeks \\
- IPSS \\
- QoL \\
- IIEF-5 \\
- Qmax \\
- PVR \\
How measured: questionnaire, uroflowmetry \\
Time points measured: before and 4, 8, and 12 weeks after treatment \\
Time points reported: IPSS, QoL, IIEF-5: before and 4, 8, and 12 weeks after treatment/Qmax, PVR: be- \\
fore and 12 weeks after treatment
\end{tabular}

Subgroup: none

\begin{tabular}{ll}
\hline Funding sources & Not reported \\
\hline Declarations of interest & None
\end{tabular}

Notes Language of publication: English

Data (IPSS, QoL, treatment withdrawal, AUR, surgical intervention, cardiovascular adverse events) were given by contact with study author

\section{Risk of bias}

\begin{tabular}{lll}
\hline Bias & Authors' judgement & Support for judgement \\
\hline $\begin{array}{l}\text { Random sequence genera- } \\
\text { tion (selection bias) }\end{array}$ & Low risk & Judgement: author reply "random number table envelope method" \\
\hline $\begin{array}{l}\text { Allocation concealment } \\
\text { (selection bias) }\end{array}$ & Unclear risk & Judgement: author reply "random number table envelope method" \\
\hline $\begin{array}{l}\text { Blinding of participants } \\
\text { and personnel (perfor- } \\
\text { mance bias) }\end{array}$ & High risk & Judgement: author reply "not blinded" \\
All outcomes & \\
\hline
\end{tabular}

Blinding of outcome as-

High risk

Judgement: author reply "not blinded"

sessment (detection bias)

Subjective outcomes 
Yamaguchi 2013 (Continued)

Blinding of outcome as- Low risk_ Judgement: objective outcomes are not likely affected by lack of blinding sessment (detection bias)

Objective outcomes

\begin{tabular}{|c|c|c|}
\hline $\begin{array}{l}\text { Incomplete outcome data } \\
\text { (attrition bias) } \\
\text { Urologic symptom scores/ } \\
\text { QoL }\end{array}$ & High risk & $\begin{array}{l}\text { Judgement: } 17 / 58(29.3 \%) \text { and } 13 / 51(25.5) \text { participants in silodosin and nafto- } \\
\text { pidil group were not included in analysis }\end{array}$ \\
\hline
\end{tabular}

\begin{tabular}{|c|c|c|}
\hline $\begin{array}{l}\text { Incomplete outcome data } \\
\text { (attrition bias) } \\
\text { Treatment withdrawal for } \\
\text { any reason }\end{array}$ & Low risk & $\begin{array}{l}\text { Judgement: all participants who were randomized in each group were includ- } \\
\text { ed in analysis. We received the data after contacting the study author }\end{array}$ \\
\hline
\end{tabular}

\begin{tabular}{|c|c|c|}
\hline $\begin{array}{l}\text { Incomplete outcome data } \\
\text { (attrition bias) } \\
\text { Treatment withdrawal } \\
\text { due to adverse events }\end{array}$ & Low risk & $\begin{array}{l}\text { Judgement: all participants who were randomized in each group were includ- } \\
\text { ed in analysis. We received the data after contacting the study author }\end{array}$ \\
\hline
\end{tabular}

\begin{tabular}{|c|c|c|}
\hline $\begin{array}{l}\text { Incomplete outcome data } \\
\text { (attrition bias) } \\
\text { AUR/ surgical intervention }\end{array}$ & Low risk & $\begin{array}{l}\text { Judgement: all participants who were randomized in each group were includ- } \\
\text { ed in analysis. We received the data after contacting the study author }\end{array}$ \\
\hline
\end{tabular}

\begin{tabular}{|c|c|c|}
\hline $\begin{array}{l}\text { Incomplete outcome data } \\
\text { (attrition bias) } \\
\text { Cardiovascular adverse } \\
\text { events }\end{array}$ & Low risk & $\begin{array}{l}\text { Judgement: all participants who were randomized in each group were includ- } \\
\text { ed in analysis. We received the data after contacting the study author }\end{array}$ \\
\hline $\begin{array}{l}\text { Incomplete outcome data } \\
\text { (attrition bias) } \\
\text { Sexual adverse events }\end{array}$ & Low risk & $\begin{array}{l}\text { Judgement: all sexually active subjects (silodosin: } 23 / 53(44 \%) \text {, naftopidil: } \\
21 / 44(47 \%) \text { ) who were randomized in each group were included in analysis }\end{array}$ \\
\hline $\begin{array}{l}\text { Selective reporting (re- } \\
\text { porting bias) }\end{array}$ & Unclear risk & $\begin{array}{l}\text { Judgement: data (treatment withdrawal, AUR, and surgical intervention) were } \\
\text { given by contact with study author, but protocol was not published }\end{array}$ \\
\hline Other bias & Low risk & Judgement: not detected \\
\hline
\end{tabular}

Yamanishi 2011

\begin{tabular}{ll}
\hline Methods & Study design: parallel, randomized trial \\
Setting/Country: not reported \\
Dates when study was conducted: not reported \\
\hline Inclusion criteria: men with IPSS total score $\geq 8, \mathrm{Qmax}<15 \mathrm{~mL} / \mathrm{s}$, total prostate volume measured by \\
US $>20 \mathrm{~mL}$ \\
Exclusion criteria: prostate cancer, urethral stricture, apparent neurogenic bladder and those on med- \\
ication that might affect voiding function such as alpha-blockers, anticholinergics and/or antiandrogen \\
drugs \\
Total number of participants randomly assigned: 149 \\
Group A (Silodosin) \\
- number of all participants randomly assigned: 75 \\
- age (years): $71.3 \pm 8.2$
\end{tabular}


Yamanishi 2011 (Continued)

- prostate volume $(\mathrm{mL}): 42.0 \pm 23.7$

- PSA (ng/mL): $3.2 \pm 3.6$

- IPSS: $18.8 \pm 7.3$

- $\operatorname{Qmax}(\mathrm{mL} / \mathrm{s}): 7.7 \pm 2.8$

Group B (Tamsulosin)

- number of all participants randomly assigned: 74

- age (years): $72.2 \pm 7.6$

- prostate volume $(\mathrm{mL}): 41.2 \pm 23.0$

- PSA (ng/mL): $3.7 \pm 3.7$

- IPSS: $17.8 \pm 6.4$

- $\operatorname{Qmax}(\mathrm{mL} / \mathrm{s}): 8.4 \pm 3.3$

\begin{tabular}{|c|c|c|}
\hline Interventions & \multicolumn{2}{|c|}{$\begin{array}{l}\text { Run-in period: none } \\
\text { Group A: silodosin } 4 \mathrm{mg} \text { twice daily } \\
\text { Group B: tamsulosin } 0.2 \mathrm{mg}-0.4 \mathrm{mg} \text { daily } \\
\text { Duration: } 12 \text { months }\end{array}$} \\
\hline Outcomes & $\begin{array}{l}\text { - IPSS } \\
\text { - QoL } \\
\text { - average flow rate } \\
\text { - Qmax } \\
\text { - PVR } \\
\text { How measured: quest } \\
\text { Time points measurec } \\
\text { Time points reported: } \\
\text { Subgroup: none }\end{array}$ & $\begin{array}{l}\text { nnaire, uroflowmetry } \\
\text { before, and at 1, 3, } 6 \text { and } 12 \text { months after the therapy } \\
\text { efore, and at } 1,3,6 \text { and } 12 \text { months after the therapy }\end{array}$ \\
\hline Funding sources & Not reported & \\
\hline Declarations of interest & Not reported & \\
\hline Notes & $\begin{array}{l}\text { Language of publicat } \\
\text { Publication status: a }\end{array}$ & $\begin{array}{l}\text { n: English } \\
\text { stract (full text has not been published; study author reply) }\end{array}$ \\
\hline Risk of bias & & \\
\hline Bias & Authors' judgement & Support for judgement \\
\hline $\begin{array}{l}\text { Random sequence genera- } \\
\text { tion (selection bias) }\end{array}$ & Unclear risk & Judgement: no information given \\
\hline $\begin{array}{l}\text { Allocation concealment } \\
\text { (selection bias) }\end{array}$ & Unclear risk & Judgement: no information given \\
\hline $\begin{array}{l}\text { Blinding of participants } \\
\text { and personnel (perfor- } \\
\text { mance bias) } \\
\text { All outcomes }\end{array}$ & Unclear risk & Judgement: no information given \\
\hline
\end{tabular}


Yamanishi 2011 (Continued)

Blinding of outcome as- Unclear risk Judgement: no information given sessment (detection bias)

Subjective outcomes

\begin{tabular}{lll}
\hline $\begin{array}{l}\text { Blinding of outcome as- } \\
\text { sessment (detection bias) } \\
\text { Objective outcomes }\end{array}$ & Low risk & Judgement: objective outcomes are not likely affected by lack of blinding \\
\hline $\begin{array}{l}\text { Incomplete outcome data } \\
\text { (attrition bias) }\end{array}$ & High risk & $\begin{array}{l}\text { Judgement: } 19 / 75(25.3 \%) \text { and } 30 / 74(40.5 \%) \text { participants in silodosin and } \\
\text { tamsulosin were not included in analysis }\end{array}$ \\
$\begin{array}{l}\text { Qrologic symptom scores/ } \\
\text { Incomplete outcome data }\end{array}$ & Low risk & \\
$\begin{array}{l}\text { (attrition bias) } \\
\text { Treatment withdrawal for } \\
\text { any reason }\end{array}$ & & $\begin{array}{l}\text { Judgement: all participants who were randomized in each group were includ- } \\
\text { ed in analysis }\end{array}$
\end{tabular}

\begin{tabular}{lll}
\hline $\begin{array}{l}\text { Incomplete outcome data } \\
\text { (attrition bias) }\end{array}$ & Unclear risk & Judgement: no information given \\
$\begin{array}{l}\text { Treatment withdrawal } \\
\text { due to adverse events }\end{array}$ & \\
\hline $\begin{array}{l}\text { Incomplete outcome data } \\
\text { (attrition bias) } \\
\text { AUR/ surgical intervention }\end{array}$ & Unclear risk & Judgement: no information given \\
\hline $\begin{array}{l}\text { Incomplete outcome data } \\
\text { (attrition bias) } \\
\text { Cardiovascular adverse } \\
\text { events }\end{array}$ & Unclear risk & Judgement: no information given \\
\hline $\begin{array}{l}\text { Incomplete outcome data } \\
\text { (attrition bias) } \\
\text { Sexual adverse events }\end{array}$ & Unclear risk & Judgement: no information given \\
\hline $\begin{array}{l}\text { Selective reporting (re- } \\
\text { porting bias) }\end{array}$ & Unclear risk & $\begin{array}{l}\text { Judgement: protocol was not published and no information related to the re- } \\
\text { view outcomes given }\end{array}$ \\
\hline \begin{tabular}{l} 
Other bias \\
\hline
\end{tabular} & Unclear risk & Judgement: abstract only \\
\hline
\end{tabular}

Yokoyama 2011

\begin{tabular}{ll} 
Methods & Study design: parallel, randomized trial \\
& Setting/Country: Kawasaki Medical School/Japan \\
& Dates when study was conducted: June 2007-December 2008 \\
\hline Participants & Inclusion criteria: men with LUTS aged 50-80 years and with IPSS $\geq 8$ \\
& $\begin{array}{l}\text { Exclusion criteria: received oral treatment with 5-ARIs, anticholinergic agents, antidepressants, or sex } \\
\text { hormonal agents, had neurogenic bladder dysfunction, bladder calculi, or active urinary tract infection, } \\
\text { or had severe cardiac disease, renal dysfunction (serum creatinine }>2 \text { mg/dL), or hepatic dysfunction }\end{array}$
\end{tabular}

Total number of participants randomly assigned: 136 
Yokoyama 2011 (Continued)

\section{Group A (Silodosin)}

- number of all participants randomly assigned: 45

- age (years): $70.2 \pm 0.9$

- prostate volume $(\mathrm{mL}): 33.3 \pm 2.3$

- PSA (ng/mL): not reported

- IPSS: $18.7 \pm 0.7$

- $\operatorname{Qmax}(\mathrm{mL} / \mathrm{s}): 9.03 \pm 0.6$

Group B (Tamsulosin)

- number of all participants randomly assigned: 45

- age (years): $71.5 \pm 1.1$

- prostate volume $(\mathrm{mL}): 32.5 \pm 2.0$

- PSA (ng/mL): not reported

- IPSS: $18.0 \pm 1.1$

- $\operatorname{Qmax}(\mathrm{mL} / \mathrm{s}): 8.56 \pm 0.5$

Group C (Naftopidil)

- number of all participants randomly assigned: 46

- age (years): $69.1 \pm 1.2$

- prostate volume $(\mathrm{mL}): 35.0 \pm 3.1$

- PSA (ng/mL): not reported

- IPSS: $17.4 \pm 0.8$

- $\operatorname{Qmax}(\mathrm{mL} / \mathrm{s}): 8.63 \pm 0.5$

Run-in period: none

Group A: silodosin $4 \mathrm{mg}$ twice a day

Group B: tamsulosin $0.2 \mathrm{mg}$ once a day

Group C: naftopidil 50 mg once a day

Duration: 12 weeks

\begin{tabular}{ll}
\hline Outcomes & $\cdot$ IPSS \\
& $\cdot$ QoL \\
& $\cdot$ IIEF \\
& $\cdot$ Qmax \\
& $\cdot$ PVR
\end{tabular}

How measured: questionnaire (IPSS, QoL, IIEF), uroflowmetry, US (PVR)

Time points measured: before, and 1 and 3 months

Time points reported: before, and 1 and 3 months

Subgroup: none

Funding sources Not reported

Data (IPSS, QoL, AUR, and surgical intervention) from study author 
Yokoyama 2011 (Continued)

\section{Risk of bias}

\begin{tabular}{|c|c|c|}
\hline Bias & Authors' judgement & Support for judgement \\
\hline $\begin{array}{l}\text { Random sequence genera- } \\
\text { tion (selection bias) }\end{array}$ & Low risk & Judgement: study author reply "Computer generated central randomization" \\
\hline $\begin{array}{l}\text { Allocation concealment } \\
\text { (selection bias) }\end{array}$ & Low risk & Judgement: study author reply "Computer generated central randomization" \\
\hline $\begin{array}{l}\text { Blinding of participants } \\
\text { and personnel (perfor- } \\
\text { mance bias) } \\
\text { All outcomes }\end{array}$ & High risk & Judgement: study author reply "participants were not blinded" \\
\hline
\end{tabular}

Blinding of outcome as-
$\begin{aligned} & \text { sessment (detection bias) } \\ & \text { Subjective outcomes }\end{aligned}$

\begin{tabular}{ll}
\hline $\begin{array}{l}\text { Incomplete outcome data } \\
\text { (attrition bias) }\end{array}$ & Unclear risk \\
$\begin{array}{l}\text { Urologic symptom scores/ } \\
\text { QoL }\end{array}$ & $\begin{array}{l}\text { Judgement: 4/45 (8.9\%), 6/45 (13.3\%), and 4/46 (8.7) participants in silodosin, } \\
\text { tamsulosin, and naftopidil group were not included in analysis }\end{array}$ \\
\hline
\end{tabular}

\begin{tabular}{ll}
\hline Incomplete outcome data $\quad$ Low risk & $\begin{array}{l}\text { Judgement: all participants who were randomized in each group were includ- } \\
\text { ed in analysis }\end{array}$
\end{tabular}

Treatment withdrawal for ed in analysis any reason

\begin{tabular}{|c|c|c|}
\hline $\begin{array}{l}\text { Incomplete outcome data } \\
\text { (attrition bias) }\end{array}$ & Unclear risk & $\begin{array}{l}\text { Judgement: } 4 / 45(8.9 \%), 6 / 45(13.3 \%) \text {, and } 4 / 46(8.7) \text { participants in silodosin, } \\
\text { tamsulosin, and naftopidil group were not included in analysis }\end{array}$ \\
\hline
\end{tabular}

due to adverse events

\begin{tabular}{|c|c|c|}
\hline $\begin{array}{l}\text { Incomplete outcome data } \\
\text { (attrition bias) } \\
\text { AUR/ surgical intervention }\end{array}$ & Unclear risk & $\begin{array}{l}\text { Judgement: } 4 / 45(8.9 \%), 6 / 45(13.3 \%) \text {, and } 4 / 46(8.7) \text { participants in silodosin, } \\
\text { tamsulosin, and naftopidil group were not included in analysis. We received } \\
\text { the data after contacting the study author }\end{array}$ \\
\hline $\begin{array}{l}\text { Incomplete outcome data } \\
\text { (attrition bias) } \\
\text { Cardiovascular adverse } \\
\text { events }\end{array}$ & Unclear risk & $\begin{array}{l}\text { Judgement: } 4 / 45(8.9 \%), 6 / 45(13.3 \%) \text {, and } 4 / 46(8.7) \text { participants in silodosin, } \\
\text { tamsulosin, and naftopidil group were not included in analysis }\end{array}$ \\
\hline $\begin{array}{l}\text { Incomplete outcome data } \\
\text { (attrition bias) } \\
\text { Sexual adverse events }\end{array}$ & Low risk & $\begin{array}{l}\text { Judgement: all sexually active subjects (silodosin: } 11 / 45(24.4 \%) \text {, tamsulosin } \\
12 / 45(26.6 \%) \text {, naftopidil: } 15 / 46(31.9 \%)) \text { were included in analysis }\end{array}$ \\
\hline $\begin{array}{l}\text { Selective reporting (re- } \\
\text { porting bias) }\end{array}$ & Unclear risk & $\begin{array}{l}\text { Judgement: prespecified outcomes were well described and data were given } \\
\text { by study author, but protocol was not published }\end{array}$ \\
\hline Other bias & High risk & $\begin{array}{l}\text { Judgement: drug administration times were different among groups. Baseline } \\
\text { imbalance in PVR, but the fact that silodosin group had much higher PVR may } \\
\text { underestimate the effect size }\end{array}$ \\
\hline
\end{tabular}


Setting/Country: single center/Japan

Dates when study was conducted: June 2008-March 2010

Inclusion criteria: men aged 50 years who had a total
Exclusion criteria: prostate cancer, neurogenic blad
tion and other complications considered likely to affect
Total number of participants randomly assigned:
Group A (Silodosin)
- number of all participants randomly assigned: 23
- age (years): $68.9 \pm 5.6$
- prostate volume $(\mathrm{mL}): 35.0 \pm 18.4$
- PSA (ng/mL): $2.5 \pm 3.4$
- IPSS: $19.3 \pm 4.9$
- Qmax (mL/s): $7.2 \pm 2.9$
Group B $(T a m s u l o s i n)$
- number of all participants randomly assigned: 23
- age (years): $70.0 \pm 6.8$
- prostate volume $(\mathrm{mL}): 36.1 \pm 15.5$
- PSA (ng/mL): $3.5 \pm 3.7$
- IPSS: $21.1 \pm 6.8$
- Qmax (mL/s): $7.6 \pm 3.0$

Interventions Run-in period: none

Group A: silodosin 4 mg twice daily

Group B: tamsulosin 0.2 mg once daily

Duration: 3 months (before cross-over)/1 month wash-out/3 months (after cross-over)/total 7 months

\begin{tabular}{ll}
\hline Outcomes & $\cdot$ IPSS \\
& $\cdot$ QoL index \\
& $\cdot$ Qmax \\
& $\cdot$ PVR
\end{tabular}

How measured: IPSS questionnaire and transabdominal US (PVR)

Time points measured: before and after treatment (not reported in method)

Time points reported: before and after treatment ( 1 months, 3 months, 4 months, and 7 months)

\section{Safety outcomes}

How measured: adverse events

Time points measured: not reported

Time points reported: not reported

Subgroup: none 
Yokoyama 2012 (Continued)

\begin{tabular}{ll} 
Funding sources & None \\
\hline Declarations of interest & None \\
\hline Notes & Language of publication: English \\
& One month wash-out period between cross-over \\
& $\begin{array}{l}\text { Data (IPSS, QoL, treatment withdrawal for any reason, method of random sequence generation, alloca- } \\
\text { tion concealment, and blinding) were given by contact with study author }\end{array}$
\end{tabular}

\section{Risk of bias}

\begin{tabular}{lll}
\hline Bias & Authors' judgement & Support for judgement \\
\hline $\begin{array}{l}\text { Random sequence genera- } \\
\text { tion (selection bias) }\end{array}$ & Low risk & Judgement: study author reply "random number table" \\
\hline $\begin{array}{l}\text { Allocation concealment } \\
\text { (selection bias) }\end{array}$ & Unclear risk & Judgement: study author reply "sealed envelope" \\
\hline $\begin{array}{l}\text { Blinding of participants } \\
\begin{array}{l}\text { and personnel (perfor- } \\
\text { mance bias) }\end{array}\end{array}$ & High risk & Judgement: study author reply "participants were blinded" \\
All outcomes & & \\
\hline
\end{tabular}

\begin{tabular}{lll}
$\begin{array}{l}\text { Blinding of outcome as- } \\
\text { sessment (detection bias) } \\
\text { Subjective outcomes }\end{array}$ & High risk & Judgement: study author reply "participants were blinded" \\
\hline $\begin{array}{l}\text { Blinding of outcome as- } \\
\text { sessment (detection bias) } \\
\text { Objective outcomes }\end{array}$ & Low risk & Judgement: objective outcomes are not likely affected by lack of blindin \\
\hline $\begin{array}{l}\text { Incomplete outcome data } \\
\begin{array}{l}\text { (attrition bias) } \\
\text { Urologic symptom scores/ } \\
\text { QoL }\end{array}\end{array}$ \\
\hline
\end{tabular}

\begin{tabular}{|c|c|c|}
\hline $\begin{array}{l}\text { Incomplete outcome data } \\
\text { (attrition bias) } \\
\text { Treatment withdrawal for } \\
\text { any reason }\end{array}$ & Low risk & $\begin{array}{l}\text { Judgement: all participants who were randomized in each group were includ- } \\
\text { ed in analysis }\end{array}$ \\
\hline
\end{tabular}

\begin{tabular}{lll}
\hline $\begin{array}{l}\text { Incomplete outcome data } \\
\text { (attrition bias) }\end{array}$ & Low risk & $\begin{array}{l}\text { Judgement: all participants who were randomized in each group were includ- } \\
\text { ed in analysis }\end{array}$ \\
$\begin{array}{l}\text { Treatment withdrawal } \\
\text { due to adverse events }\end{array}$ & \\
\hline $\begin{array}{l}\text { Incomplete outcome data } \\
\text { (attrition bias) }\end{array}$ & Unclear risk & Judgement: not available (cross-over trial) \\
$\begin{array}{l}\text { AUR/ surgical intervention } \\
\text { Incomplete outcome data }\end{array}$ & Low risk & \\
$\begin{array}{l}\text { (attrition bias) } \\
\text { Cardiovascular adverse } \\
\text { events }\end{array}$ & $\begin{array}{l}\text { Judgement: all participants who were randomized in each group were includ- } \\
\text { ed in analysis }\end{array}$ \\
\hline
\end{tabular}


Yokoyama 2012 (Continued)

Incomplete outcome data (attrition bias)

Low risk

Sexual adverse events
Selective reporting (re- Unclear risk porting bias)

\section{ed in analysis}

Other bias Low risk Judgement: not detected

Yu 2011

Methods

Study design: parallel, randomized, double-blinded

Setting/Country: 9 medical centers/Taiwan

Dates when study was conducted: July 2007-September 2008

\section{Participants}

Inclusion criteria: men aged $\geq 40$ years with an IPSS of $\geq 13$, a health-related QoL score of $\geq 3$, a prostate volume of $\geq 20 \mathrm{~mL}$, and a Qmax of $<15 \mathrm{~mL} / \mathrm{s}$ with a voided volume of $\geq 100 \mathrm{~mL}$

Exclusion criteria: men with a history of previous prostate surgery, prostate cancer, neurogenic bladder, bladder neck constriction, urethral stricture, bladder calculus, active urinary tract infection, a PVR of $>250 \mathrm{~mL}$, exposure to sex hormone within 3 months prior to the wash-out period, renal dysfunction (serum creatinine of $>2.0 \mathrm{mg} / \mathrm{dL}$ ), a history of severe liver impairment, severe cardiovascular diseases, severe hypotension, and known hypersensitivity or history of active substance abuse (including alcohol) within the past 2 years

\section{Total number of participants randomly assigned: 209}

\section{Group A (Silodosin)}

- number of all participants randomly assigned: 105

- age (years): $67.5 \pm 9.3$

- prostate volume $(\mathrm{mL}): 44.8 \pm 24.2$

- PSA (ng/mL): not reported

- IPSS: $19.3 \pm 4.5$

- $\operatorname{Qmax}(\mathrm{mL} / \mathrm{s}): 10.3 \pm 2.8$

Group B (Tamsulosin)

- number of all participants randomly assigned: 104

- age (years): $65.0 \pm 8.8$

- prostate volume $(\mathrm{mL}): 38.2 \pm 16.7$

- PSA (ng/mL): not reported

- IPSS: $19.8 \pm 4.5$

- $\operatorname{Qmax}(\mathrm{mL} / \mathrm{s}): 10.6 \pm 2.8$

Interventions

Run-in period: 7-day wash-out and 7-day observation periods

Group A: silodosin $4 \mathrm{mg}$ twice daily

Group B: tamsulosin $0.2 \mathrm{mg}$ in the morning and one placebo capsule in the evening

Duration: 12 weeks

\section{Outcomes}

\section{Primary outcome}


Yu 2011 (Continued)

- change in the IPSS from baseline

- participants who achieved $25 \%$ reduction in the IPSS from baseline

How measured: IPSS questionnaire

Time points measured: 0 (initiation of treatment), 2, 4, 8, and 12 weeks

Time points reported: 0 (initiation of treatment), 2, 4, 8, and 12 weeks in figure

\section{Secondary outcome}

- Qmax

- health-related QoL from baseline

- changes in IPSS subscores (voiding and storage symptom scores)

How measured: uroflowmetry, IPSS questionnaire

Time points measured: 0,4 and 12 weeks/0 (initiation of treatment), 2, 4, 8, and 12 weeks

Time points reported: 0 and 12 weeks

\section{Safety outcomes}

How measured: all adverse events/BP/pulse rate/laboratory tests

Time points measured: 0 (initiation of treatment), 2, 4, 8, and 12 weeks/0, 4 and 12 weeks/follow-up visits

Time points reported: 0 and 12 weeks/cumulative results from follow-up visits (adverse events)

Subgroup: none

\begin{tabular}{ll}
\hline Funding sources & Synmosa pharmaceutical company \\
\hline Declarations of interest & All authors were study investigators for Synmosa \\
\hline Notes & Language of publication: English
\end{tabular}

\section{Risk of bias}

\begin{tabular}{|c|c|c|}
\hline Bias & Authors' judgement & Support for judgement \\
\hline $\begin{array}{l}\text { Random sequence genera- } \\
\text { tion (selection bias) }\end{array}$ & Unclear risk & Judgement: no information given \\
\hline $\begin{array}{l}\text { Allocation concealment } \\
\text { (selection bias) }\end{array}$ & Unclear risk & Judgement: no information given \\
\hline $\begin{array}{l}\text { Blinding of participants } \\
\text { and personnel (perfor- } \\
\text { mance bias) } \\
\text { All outcomes }\end{array}$ & Low risk & Quote: "both investigators and patients were 'blinded' to treatment" \\
\hline $\begin{array}{l}\text { Blinding of outcome as- } \\
\text { sessment (detection bias) } \\
\text { Subjective outcomes }\end{array}$ & Low risk & Quote: "both investigators and patients were 'blinded' to treatment" \\
\hline $\begin{array}{l}\text { Blinding of outcome as- } \\
\text { sessment (detection bias) } \\
\text { Objective outcomes }\end{array}$ & Low risk & Judgement: objective outcomes are not likely affected by lack of blinding \\
\hline
\end{tabular}




\begin{tabular}{|c|c|}
\hline Study & Reason for exclusion \\
\hline Curran 2011 & Review \\
\hline JPRN-UMIN000007917 & Wrong comparator (silodosin $4 \mathrm{mg}$ once daily versus silodosin $4 \mathrm{mg}$ twice daily) \\
\hline Kawabe 2006b & Wrong study design (non randomized study) \\
\hline Kobayashi 2008 & Wrong outcome (semen parameters) \\
\hline Kobayashi 2009 & Wrong outcome (semen parameters) \\
\hline Manjunatha 2016b & Wrong outcome (cost effectiveness) \\
\hline Matsukawa 2012 & Wrong comparator (silodosin versus silodosin and propiverine) \\
\hline Matsukawa 2017 & Wrong comparator (silodosin and dutasteride versus dutasteride) \\
\hline Michel 2011 & Wrong study population (participants with $\geq 2$ voids per night ) \\
\hline Montorsi 2010 & Review \\
\hline Montorsi 2013 & Review \\
\hline Prescrire Int 2011 & Review (medical article) \\
\hline Prescrire Int 2012 & Review (medical article) \\
\hline Roehrborn 2009 & Wrong study population (participants with retrograde ejaculation as adverse event) \\
\hline Yoshida 2017 & Wrong comparator (silodosin versus phosphodiesterase 5 inhibitor) \\
\hline Yoshihisa 2012 & Wrong comparator (silodosin versus silodosin and propiverine) \\
\hline Zhou 2011 & Wrong outcome (pharmacokinetics and adverse events (not available)) \\
\hline
\end{tabular}

Characteristics of studies awaiting assessment [ordered by study ID]

\section{CTRI/2010/091/000526}

\section{Methods}

Participants
Randomized, parallel-group, active, controlled trial

\section{Inclusion criteria}

- Ages: $>45$ years and $<80$ years

- Genders eligible for study: male only

- Men in good general health and $\geq 50$ years, with symptoms of moderate-severe BPH

- A mean symptoms score of $\geq 8$ (symptoms of BPH assessed as per American Urological Association Symptom Index, which assesses the occurrence of seven symptoms characteristic of BPH during the preceding week, each scored on a scale from 0 (absent) to 5 (severe)).

- Mean Qmax of $\leq 15 \mathrm{~mL} / \mathrm{s}$ and $\leq 4 \mathrm{~mL} / \mathrm{s}$, with a minimal voided volume of $125 \mathrm{~mL}$, and a mean PVR of $<300 \mathrm{~mL}$

- PSA values of $>4 \mathrm{ng} / \mathrm{mL}$

- Renal function defined as a serum creatinine level of $<2.0 \mathrm{mg} / \mathrm{dL}$ and creatinine clearance of $>20$ $\mathrm{mL} / \mathrm{min}$ by Cockroft and Gault formula 
CTRI/2010/091/000526 (Continued)
Interventions
Group A: silodosin capsule $8 \mathrm{mg}$
Group B: tamsulosin ER capsules $0.4 \mathrm{mg}$
Duration: 12 weeks

\begin{tabular}{ll}
\hline Outcomes & change in baseline score on the American Urological Association Symptom Index \\
- change in baseline urine flow rate \\
- change in PSA \\
- safety and tolerability
\end{tabular}

Notes Funding source: MSN Laboratories Ltd

Publication status: CTRI/2010/091/000526 (final publication status has not been clarified)

Devana 2014

\begin{tabular}{ll}
\hline Methods & Open-label, parallel study \\
\hline Participants & Inclusion criteria: men with symptomatic BPH aged 50-80 years, with IPSS $>8$ or QoL score $>2$ \\
& Exclusion criteria: not reported \\
\hline Interventions & Group A: silodosin $8 \mathrm{mg} / \mathrm{d}$ \\
& Group B: tamsulosin $0.4 \mathrm{mg} / \mathrm{d}$ \\
& Group C: alfuzosin $10 \mathrm{mg} / \mathrm{d}$ \\
& Duration: 1 month \\
\hline Outcomes & IPSS \\
- QoL scores & Qmax \\
- PVR & side effects
\end{tabular}

Notes Publication status: abstract (final publication status has not been clarified)

\begin{tabular}{ll} 
Jha 2015 & Parallel, randomized study \\
\hline Methods & Inclusion criteria: not reported \\
\hline Participants & Exclusion criteria: not reported \\
\hline Interventions & Group A: silodosin 8 mg daily at night \\
& Group B: tamsulosin 0.4 mg daily at night \\
& Duration: 6 months \\
\hline Outcomes & $\bullet$ IPSS \\
\hline
\end{tabular}


Jha 2015 (Continued)

$$
\begin{aligned}
& \text { - } \text { digital rectal exam } \\
& \text { - } \mathrm{PSA} \\
& \text { - } \mathrm{Qmax} \\
& \text { - } \mathrm{PVR} \\
& \text { - } \text { side effects }
\end{aligned}
$$

\begin{tabular}{ll}
\hline Methods & Open-label, parallel, randomized study \\
\hline Participants & $\begin{array}{l}\text { Inclusion criteria: male patients with newly diagnosed LUTS according to the treatment algorithm } \\
\text { of the Clinical Practice Guidelines for male LUTS }\end{array}$ \\
Exclusion criteria: men who meet any of the following criteria are excluded: \\
- taking anticholinergic agents, antidepressants, or antianxiety agents \\
- a history of urinary retention, urinary tract infections, macroscopic hematuria, lower urinary tract \\
- surgery, radiotherapy for the pelvic organs, or neurologic disease \\
- elevated PSA levels ( $\geq 4.0 \mathrm{ng} / \mathrm{mL}$ ) \\
- 9 th CLSS score $\geq 2$ \\
- not willing to receive drug treatment \\
- cannot answer the questionnaire by themselves \\
- classified as ineligible by the investigator
\end{tabular}

\begin{tabular}{ll}
\hline Interventions & Group A: silodosin $8 \mathrm{mg}$ daily \\
& Group B: tamsulosin $0.2 \mathrm{mg}$ daily \\
& Duration: not reported \\
\hline Outcomes & - IPSS \\
& - Overactive Bladder Symptom Score \\
& - Proflowmetry \\
& Prostate volume
\end{tabular}

Publication status: JPRN-UMIN000003125 (final publication status has not been clarified)

\begin{tabular}{ll}
\hline Methods $\quad$ Parallel, randomized study \\
\hline
\end{tabular}

Participants Inclusion criteria

Men aged $\geq 50$ years with previously-untreated BPH with total IPSS $\geq 8$ and QoL score $\geq 2$ 
Group B: tamsulosin hydrochloride $0.2 \mathrm{mg}$ daily

Duration: not reported

\begin{tabular}{ll}
\hline Outcomes & IPSS and QoL score \\
& - Uroflowmetry \\
& - prostate volume \\
& - Japanese-Gastrointestinal symptom Rating Scale \\
& - Bristol Stool Form \\
& - safety (adverse events) \\
& - rate of discontinuation
\end{tabular}

Publication status: JPRN-UMIN000005151 (final publication status has not been clarified)

\section{JPRN-UMIN000008538}

\begin{tabular}{ll}
\hline Methods & Parallel, randomized study \\
\hline Participants & Inclusion criteria \\
& Men aged $50-90$ years \\
& 1) a total IPSS of $\geq 8$ \\
& 2) Qmax of $\leq 15 \mathrm{~mL} / \mathrm{s}$ as evaluated by uroflowmetry \\
& 3) prostate volume of $\geq 15 \mathrm{~mL}$ as measured by prostatic US \\
\hline Interventions & Group A: silodosin \\
Group B: tamsulosin & Duration: not reported \\
\hline Outcomes & changes in IPSS \\
\hline & bladder diary \\
\hline
\end{tabular}

Notes $\quad$ Funding source: Dokkyo Medical University

Publication status: JPRN-UMIN000008538 (final publication status has not been clarified)

\begin{tabular}{ll}
\hline Methods & Parallel, randomized study \\
\hline Participants & Inclusion criteria \\
Men aged $\geq 50$ years \\
- Participant must have urinary symptoms associated with BPH \\
- Participant must give written informed consent
\end{tabular}


- Participant must satisfy the following conditions during screening conducted at the start of the treatment period (Day 0): the total IPSS voiding symptom score is $\geq 8$, the QoL score is $\geq 2$, prostate volume is $\geq 20 \mathrm{~mL}$, Qmax is $\leq 15 \mathrm{~mL} / \mathrm{s}$, and $P V R$ is $\leq 100 \mathrm{~mL}$

- Participant must not use prohibited concomitant drugs except at least 2 weeks before the start of the treatment period (Day 0), or the subject must be able to undergo a drug wash-out for at least 2 weeks before the start of the treatment period

- Participant must be an outpatient who can fill in the questionnaire

- Participant must be $\geq 65$ years at the time of signing the informed consent

\begin{tabular}{ll}
\hline Interventions & Group A: silodosin $4 \mathrm{mg}$, once daily after break \\
& Group B: tamsulosin $0.2 \mathrm{mg}$, once daily after brea \\
& Duration: not reported \\
\hline Outcomes & - IPSS total score and subscores \\
- QoL score \\
- Overactive bladder symptom score \\
- urodynamic parameters \\
- blood pressure \\
- adverse events and adverse drug reactions
\end{tabular}

Notes

Funding source: Kissei Pharmaceutical Co., Ltd

Publication status: JPRN-UMIN000011556 (final publication status has not been clarified)

Mandal 2013

\begin{tabular}{ll}
\hline Methods & Open-label, parallel study \\
\hline Participants & Inclusion criteria: men with symptomatic BPH aged 50-80 years with IPSS $>8$ or QoL score $>2$ \\
& $\begin{array}{l}\text { Exclusion criteria: other causes of bladder outlet obstruction, prostate and bladder malignancy, } \\
\text { renal failure, hepatic failure and prior history of prostatectomy }\end{array}$
\end{tabular}

\begin{tabular}{ll}
\hline Interventions & Group A: silodosin $8 \mathrm{mg} / \mathrm{d}$ \\
& Group B: tamsulosin $0.4 \mathrm{mg} / \mathrm{d}$ \\
& Group C: alfuzosin $10 \mathrm{mg} / \mathrm{d}$ \\
& Duration: 1 month \\
\hline Outcomes & - IPSS \\
& - QoL \\
& Q avax \\
- PVR \\
- side effects
\end{tabular}


Manohar 2014

\begin{tabular}{ll}
\hline Methods & Parallel, randomized study \\
\hline Participants & Inclusion criteria: patients of LUTS in BPH \\
& Exclusion criteria: not reported \\
\hline Interventions & Group A: silodosin $8 \mathrm{mg}$ once/d \\
& Group B: tamsulosin $0.4 \mathrm{mg}$ once/d \\
& Group C: alfuzosin $10 \mathrm{mg}$ once/d \\
& Duration: 12 weeks \\
\hline Outcomes & IPSS \\
& QoL \\
Q P & PVR \\
& safety profile
\end{tabular}

Notes Publication status: abstract (final publication status has not been clarified)

Miyamae 2011

\begin{tabular}{ll}
\hline Methods & Parallel, randomized study \\
\hline Participants & Inclusion criteria: men with untreated BPH \\
- & gave their informed consent to participate in this study \\
- outpatients aged $\geq 50$ years \\
- total IPSS of $\geq 8$ and QoL score of $\geq 3$ \\
- never been treated with an alpha-1-blocker or had not received an alpha-1-blocker for at least 4 \\
- weeks \\
Excludged by attending physicians to be eligible for participation in the study \\
\hline
\end{tabular}

\begin{tabular}{ll} 
Interventions & Group A: silodosin $4 \mathrm{mg}$ twice daily \\
& Group B: tamsulosin $0.2 \mathrm{mg}$ once daily \\
& Duration: 1 week \\
\hline Outcomes & - IPSS \\
& - Overactive Bladder Symptom Score \\
& - QoL rating scale \\
\hline
\end{tabular}

Methods Parallel, randomized, double-blind, placebo-controlled study


NCT01222650 (Continued)

Participants
Inclusion criteria: men with BPH and LUTS

Exclusion criteria: history of prostatectomy, intrapelvic radiation therapy, thermotherapy of prostate or prostatic hyperthermia, prostate cancer or suspected prostate cancer, any clinically relevant cardiovascular, hepatic or renal disorder

\begin{tabular}{ll}
\hline Interventions & Group A: not reported \\
& Group B: not reported \\
& Duration: 12 weeks \\
\hline Outcomes & - change in IPSS total score from baseline \\
& - change in IPSS subscore \\
& QoL score \\
\hline Notes & Funding from baseline \\
& Publication status: NCT01222650 (final publication status has not been clarified) \\
\hline
\end{tabular}

\section{Pawar 2015}

\begin{tabular}{|c|c|}
\hline Methods & Parallel, randomized study \\
\hline Participants & $\begin{array}{l}\text { Inclusion criteria: men }>45 \text { years with symptomatic BPH (increased daytime frequency, urgency } \\
\text { and nocturia and or voiding symptoms (hesitancy, incomplete voiding, impaired stream or inter- } \\
\text { ruption of stream), increased daytime micturition, nocturia }>2 \text {, maximum flow rate }<15 \mathrm{~mL} / \mathrm{sec} \\
\text { with a voided volume of } \geq 150 \mathrm{~mL} \text {, PVR }<100 \mathrm{~mL} \text { by abdominal US, IPSS }>13 \text { points, international } \\
\text { prostatic symptom bother score }>3 \text { points } \\
\text { Exclusion criteria: not reported }\end{array}$ \\
\hline Interventions & $\begin{array}{l}\text { Group A: silodosin } 8 \mathrm{mg} \text { once daily } \\
\text { Group B: tamsulosin } 0.2 \mathrm{mg} \text { once daily } \\
\text { Duration: } 12 \text { weeks }\end{array}$ \\
\hline Outcomes & $\begin{array}{l}\text { - clinical determination of IPSS, Qmax index } \\
\text { - Qmax (mL/s) } \\
\text { - time to maximum flow rate } \\
\text { - average flow rate } \\
\text { - average flow time } \\
\text { - PVR } \\
\text { - prostate size by transabdominal ultrasonographically } \\
\text { - adverse events }\end{array}$ \\
\hline
\end{tabular}

Publication status: abstract (final publication status has not been clarified)

BPH: benign prostatic hyperplasia; IPSS: International Prostate Symptom Score; LUTS: lower urinary tract symptoms; PSA: prostate specific antigen; PVR: postvoid residual; Qmax; maximum flow rate; QoL: quality of life; US: ultrasound

Characteristics of ongoing studies [ordered by study ID] 
CTRI/2013/10/004112

Trial name or title
A study to find out the medication which offers maximum health benefits with minimum spending by the patient among the three commonly used medications in the treatment of benign prostatic hyperplasia, a disease in aging men which results in bothersome urinary problems

\begin{tabular}{|c|c|}
\hline Methods & Randomized, parallel group trial \\
\hline Participants & $\begin{array}{l}\text { Inclusion criteria } \\
\text { - Men } \geq 45 \text { years with } \mathrm{BPH} \text { and associated LUTS } \\
\text { - } \mathrm{IPSS} \geq 8 \\
\text { - } \mathrm{QoL} \text { score } \geq 3 \\
\text { - } \mathrm{Qmax}<15 \mathrm{~mL} / \mathrm{s} \text { but }>4 \mathrm{~mL} / \mathrm{s} \text { with a voided volume of }>100 \mathrm{~mL} \\
\text { - Willingness to give written informed consent and to comply with the study procedure, and avail- } \\
\text { able for regular follow-up }\end{array}$ \\
\hline Interventions & $\begin{array}{l}\text { Group A: silodosin oral, } 8 \mathrm{mg} \text { once daily } \\
\text { Group B: tamsulosin oral, } 0.4 \mathrm{mg} \text { once daily } \\
\text { Group C: alfuzosin oral, } 10 \mathrm{mg} \text { once daily } \\
\text { Duration: } 12 \text { weeks }\end{array}$ \\
\hline Outcomes & $\begin{array}{l}\text { Treatment success is defined as } \geq 30 \% \text { improvement in IPSS from baseline and its maintenance } \\
\text { over the study period }\end{array}$ \\
\hline Starting date & September 2013 \\
\hline Contact information & manjunatha5ramaiah@gmail.com \\
\hline Notes & Funding source: none \\
\hline
\end{tabular}

\section{JPRN-UMIN000003609}

\section{Trial name or title}

The effects of selective alpha-1-adrenergic receptor antagonists in patients with lower urinary tract symptoms caused by benign prostatic hyperplasia who failed to obtain sufficient efficacy by previous alpha-1-blockades. A comparison of naftopidil or silodosin

\begin{tabular}{|c|c|}
\hline Methods & Parallel, randomized \\
\hline \multirow[t]{2}{*}{ Participants } & Inclusion criteria \\
\hline & $\begin{array}{l}\text { Men with LUTS caused by BPH who failed to obtain sufficient efficacy by naftopidil } 50 \mathrm{mg} \text { and with } \\
\text { IPSS of } \geq 9 \text {, a QoL score of } \geq 2 \text {, a prostate volume of } \geq 20 \mathrm{~mL} \text { are eligible for enrolment }\end{array}$ \\
\hline \multirow[t]{3}{*}{ Interventions } & Group A: silodosin 8 mg \\
\hline & Group B: naftopidil 75 mg \\
\hline & Duration: not reported \\
\hline Outcomes & $\begin{array}{l}\text { - IPSS } \\
\text { - QoL score } \\
\text { - blood pressure } \\
\text { - } \text { uroflowmetry }\end{array}$ \\
\hline
\end{tabular}


JPRN-UMIN000003609 (Continued)

Starting date May 2010

Contact information Email address was not given

Notes

Funding source: none

BPH: benign prostatic hyperplasia; IPSS: International Prostate Symptom Score; LUTS: lower urinary tract symptoms; Qmax; maximum flow rate; QoL: quality of life

\section{DATA AND ANALYSES}

\section{Comparison 1. Silodosin versus placebo}

\begin{tabular}{|c|c|c|c|c|}
\hline Outcome or subgroup title & No. of studies & $\begin{array}{l}\text { No. of partici- } \\
\text { pants }\end{array}$ & Statistical method & Effect size \\
\hline $\begin{array}{l}1 \text { Urologic symptom scores (short } \\
\text { term) }\end{array}$ & 3 & 1743 & $\begin{array}{l}\text { Mean Difference (IV, Random, } \\
95 \% \mathrm{Cl} \text { ) }\end{array}$ & $-2.65[-3.23,-2.08]$ \\
\hline 2 Quality of life (short term) & 2 & 820 & $\begin{array}{l}\text { Mean Difference (IV, Random, } \\
95 \% \mathrm{CI} \text { ) }\end{array}$ & $-0.42[-0.71,-0.13]$ \\
\hline $\begin{array}{l}3 \text { Treatment withdrawal due to any } \\
\text { reason (short term) }\end{array}$ & 3 & 1703 & $\begin{array}{l}\text { Risk Ratio (M-H, Random, } \\
95 \% \mathrm{Cl})\end{array}$ & $1.08[0.70,1.66]$ \\
\hline $\begin{array}{l}4 \text { Treatment withdrawal due to ad- } \\
\text { verse events (short term) }\end{array}$ & 4 & 1967 & $\begin{array}{l}\text { Risk Ratio (M-H, Random, } \\
95 \% \mathrm{Cl})\end{array}$ & $2.29[1.41,3.72]$ \\
\hline $\begin{array}{l}5 \text { Cardiovascular adverse events } \\
\text { (short term) }\end{array}$ & 4 & 1967 & $\begin{array}{l}\text { Risk Ratio (M-H, Random, } \\
95 \% \mathrm{Cl})\end{array}$ & $1.28[0.67,2.45]$ \\
\hline 6 Sexual adverse events (short term) & 4 & 1967 & $\begin{array}{l}\text { Risk Ratio (M-H, Random, } \\
95 \% \mathrm{Cl})\end{array}$ & $\begin{array}{l}26.07[12.36, \\
54.97]\end{array}$ \\
\hline
\end{tabular}

\section{Analysis 1.1. Comparison 1 Silodosin versus placebo, Outcome 1 Urologic symptom scores (short term).}

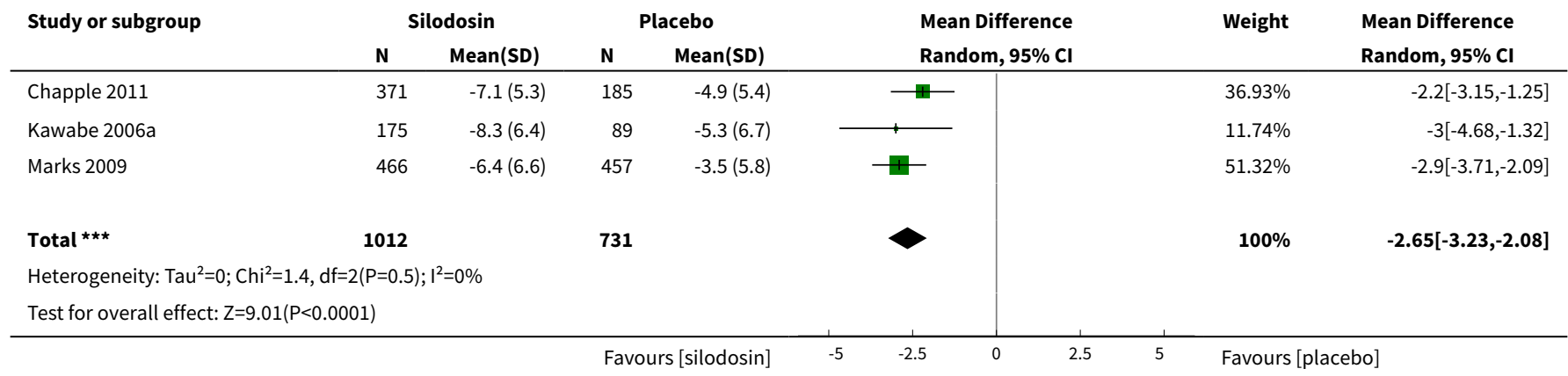


Analysis 1.2. Comparison 1 Silodosin versus placebo, Outcome 2 Quality of life (short term).

\begin{tabular}{|c|c|c|c|c|c|c|c|}
\hline \multirow[t]{2}{*}{ Study or subgroup } & \multicolumn{2}{|c|}{ Silodosin } & \multicolumn{2}{|c|}{ Placebo } & \multirow{2}{*}{$\begin{array}{l}\text { Mean Difference } \\
\text { Random, } 95 \% \mathrm{Cl}\end{array}$} & \multirow[t]{2}{*}{ Weight } & \multirow{2}{*}{$\begin{array}{l}\text { Mean Difference } \\
\text { Random, } 95 \% \mathrm{Cl}\end{array}$} \\
\hline & $\mathbf{N}$ & Mean(SD) & $\mathbf{N}$ & Mean(SD) & & & \\
\hline Chapple 2011 & 371 & $-1.1(1.3)$ & 185 & $-0.8(1.1)$ & + & $59.1 \%$ & $-0.3[-0.51,-0.09]$ \\
\hline Kawabe 2006a & 175 & $-1.7(1.4)$ & 89 & $-1.1(1.2)$ & $\Pi$ & $40.9 \%$ & $-0.6[-0.92,-0.28]$ \\
\hline Total $\star \star \star ~$ & 546 & & 274 & & 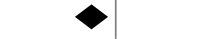 & $100 \%$ & $-0.42[-0.71,-0.13]$ \\
\hline \multicolumn{8}{|c|}{ Heterogeneity: $\mathrm{Tau}^{2}=0.03 ; \mathrm{Chi}^{2}=2.35, \mathrm{df}=1(\mathrm{P}=0.13) ; \mathrm{I}^{2}=57.36 \%$} \\
\hline & & & $\mathrm{Fa}$ & dosin] & -1 & Favour & \\
\hline
\end{tabular}

Analysis 1.3. Comparison 1 Silodosin versus placebo, Outcome 3 Treatment withdrawal due to any reason (short term).

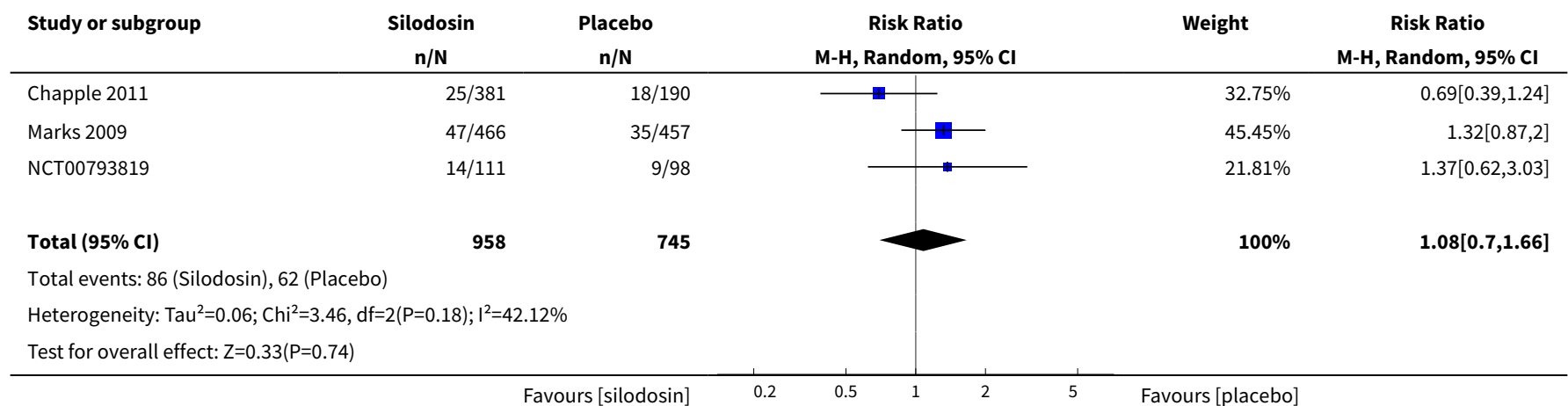

\section{Analysis 1.4. Comparison 1 Silodosin versus placebo, Outcome \\ 4 Treatment withdrawal due to adverse events (short term).}

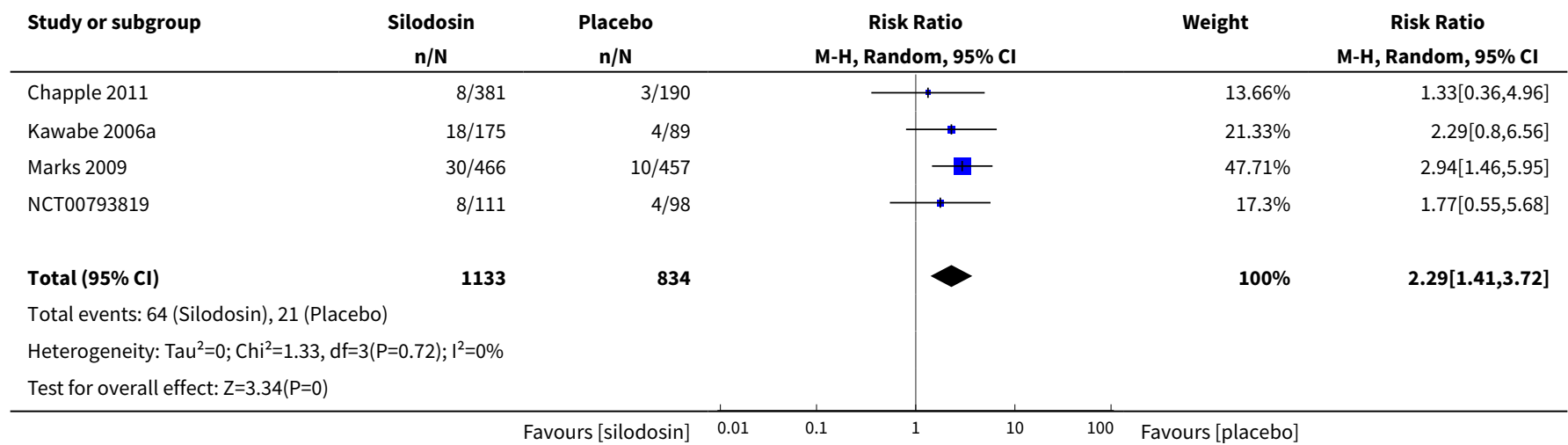


Analysis 1.5. Comparison 1 Silodosin versus placebo, Outcome 5 Cardiovascular adverse events (short term).

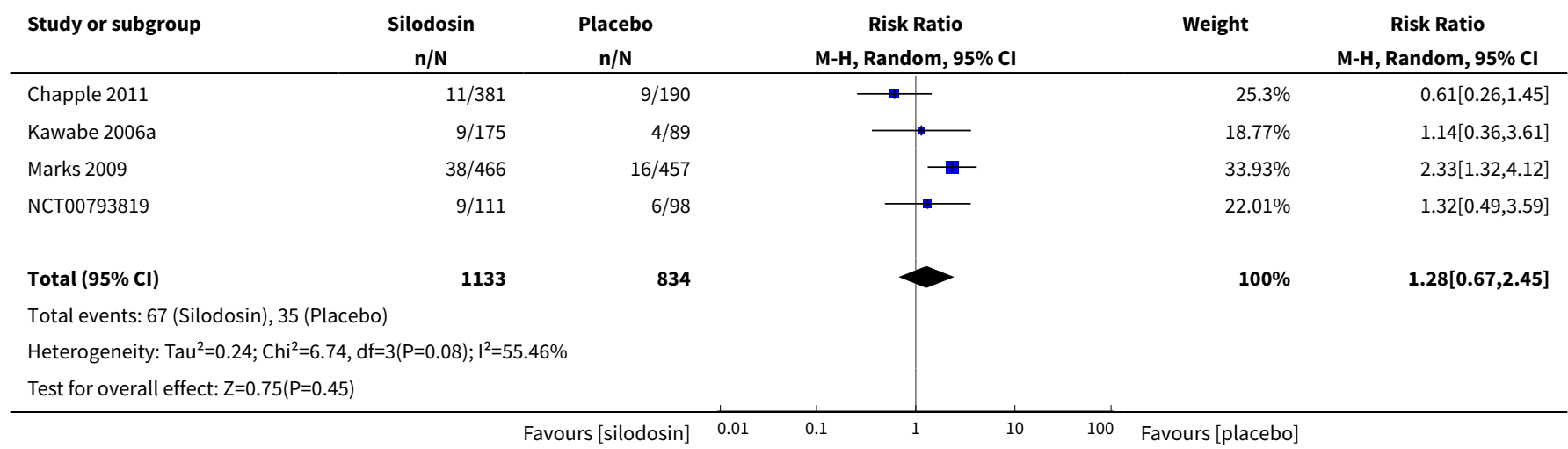

Analysis 1.6. Comparison 1 Silodosin versus placebo, Outcome 6 Sexual adverse events (short term).

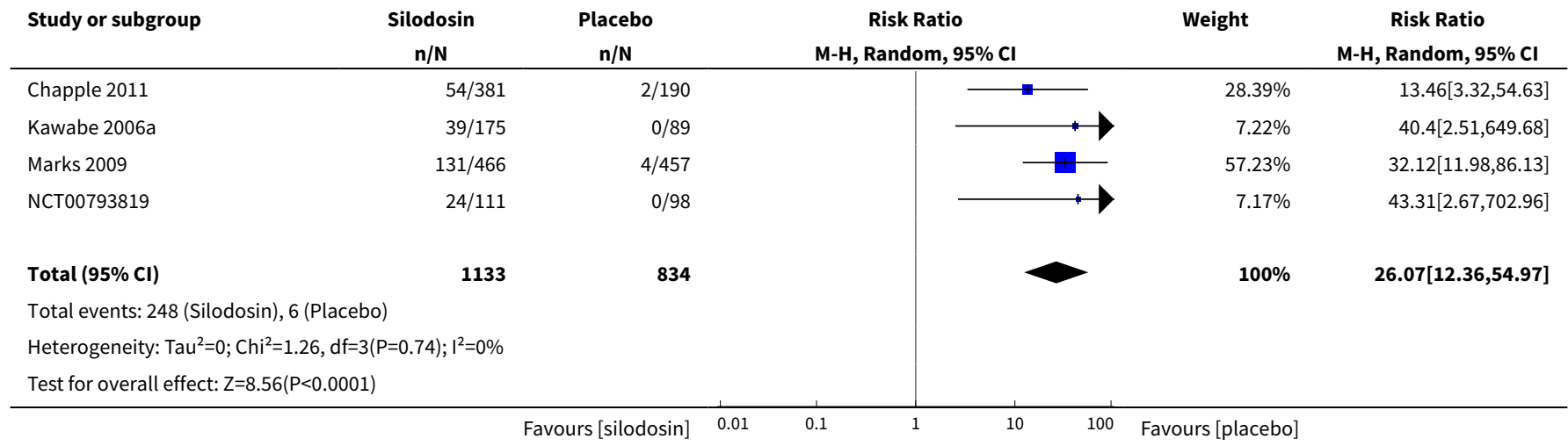

\section{Comparison 2. Silodosin versus tamsulosin}

\begin{tabular}{|c|c|c|c|c|}
\hline Outcome or subgroup title & No. of studies & $\begin{array}{l}\text { No. of partici- } \\
\text { pants }\end{array}$ & Statistical method & Effect size \\
\hline $\begin{array}{l}1 \text { Urologic symptom scores (short } \\
\text { term) }\end{array}$ & 10 & 1708 & $\begin{array}{l}\text { Mean Difference (IV, Random, } \\
95 \% \mathrm{CI} \text { ) }\end{array}$ & $-0.04[-1.31,1.24]$ \\
\hline 2 Quality of life (short term) & 10 & 1707 & $\begin{array}{l}\text { Mean Difference (IV, Random, } \\
95 \% \mathrm{CI} \text { ) }\end{array}$ & $-0.15[-0.53,0.22]$ \\
\hline $\begin{array}{l}3 \text { Treatment withdrawal due to any } \\
\text { reason (short term) }\end{array}$ & 10 & 1573 & $\begin{array}{l}\text { Risk Ratio (M-H, Random, } \\
95 \% \mathrm{Cl})\end{array}$ & $1.02[0.62,1.69]$ \\
\hline $\begin{array}{l}4 \text { Treatment withdrawal due to ad- } \\
\text { verse events (short term) }\end{array}$ & 9 & 1572 & $\begin{array}{l}\text { Risk Ratio (M-H, Random, } \\
95 \% \mathrm{Cl})\end{array}$ & $1.96[1.12,3.44]$ \\
\hline $\begin{array}{l}5 \text { Cardiovascular adverse events } \\
\text { (short term) }\end{array}$ & 11 & 1955 & $\begin{array}{l}\text { Risk Ratio (M-H, Random, } \\
95 \% \mathrm{Cl})\end{array}$ & $0.77[0.53,1.12]$ \\
\hline
\end{tabular}




\begin{tabular}{lllll}
\hline Outcome or subgroup title & No. of studies & $\begin{array}{l}\text { No. of partici- } \\
\text { pants }\end{array}$ & Statistical method & Effect size \\
\hline 6 Sexual adverse events (short term) & 10 & 1849 & $\begin{array}{l}\text { Risk Ratio (M-H, Random, } \\
95 \% \mathrm{Cl})\end{array}$ & $6.05[3.55,10.31]$ \\
\hline
\end{tabular}

Analysis 2.1. Comparison 2 Silodosin versus tamsulosin, Outcome 1 Urologic symptom scores (short term).

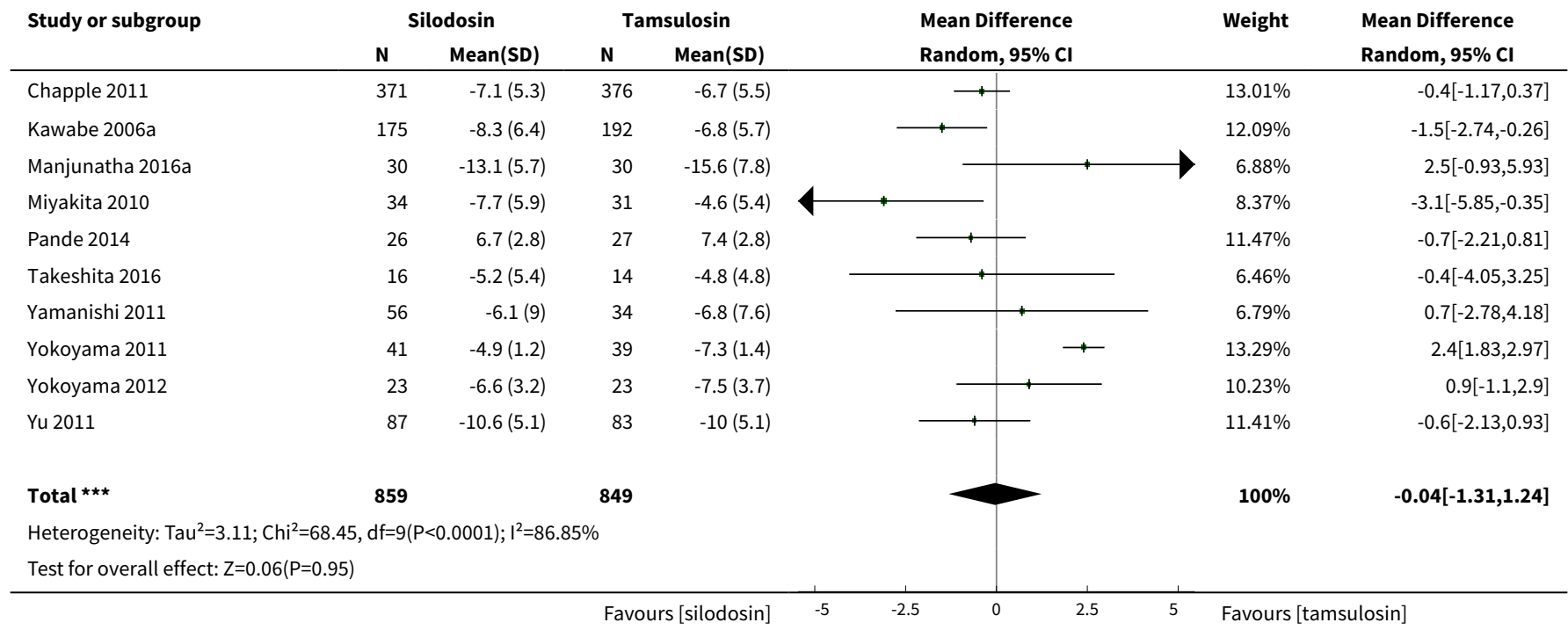

Analysis 2.2. Comparison 2 Silodosin versus tamsulosin, Outcome 2 Quality of life (short term).

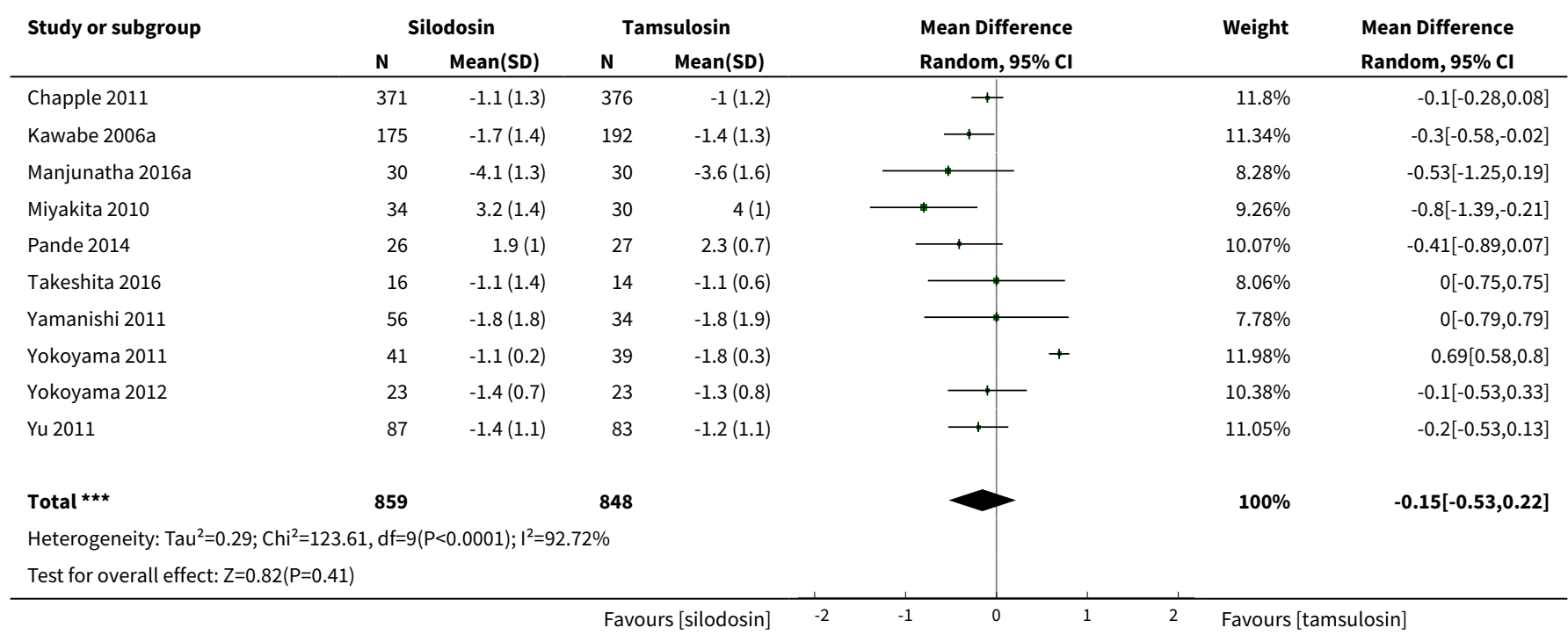


Analysis 2.3. Comparison 2 Silodosin versus tamsulosin, Outcome 3 Treatment withdrawal due to any reason (short term).

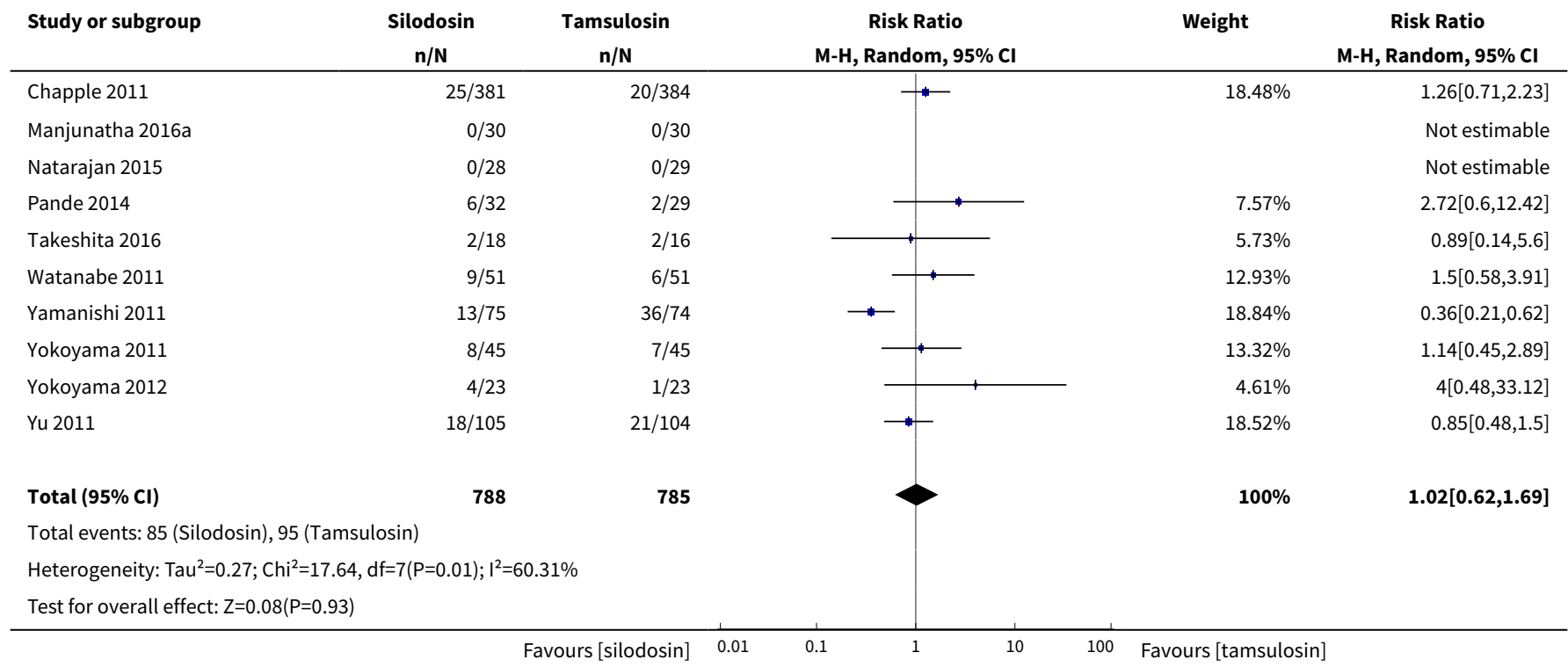

Analysis 2.4. Comparison 2 Silodosin versus tamsulosin, Outcome 4 Treatment withdrawal due to adverse events (short term).

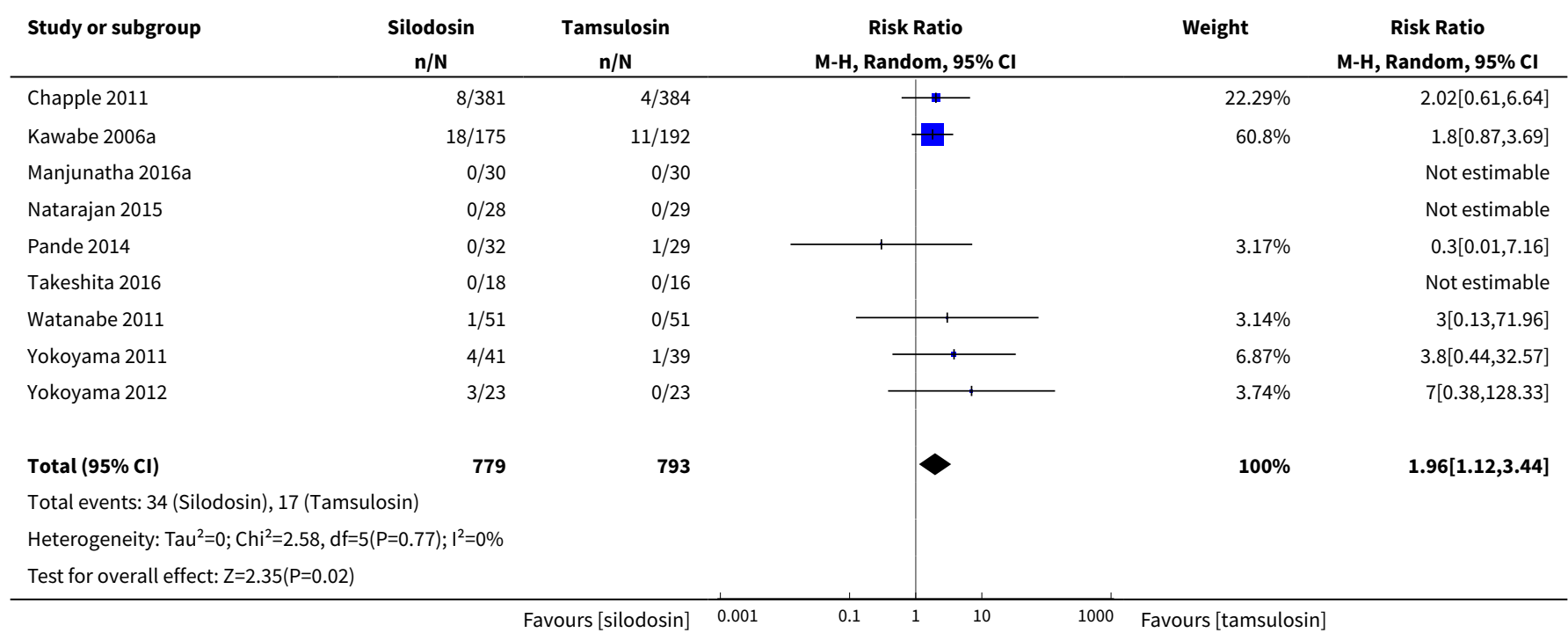

Analysis 2.5. Comparison 2 Silodosin versus tamsulosin, Outcome 5 Cardiovascular adverse events (short term).

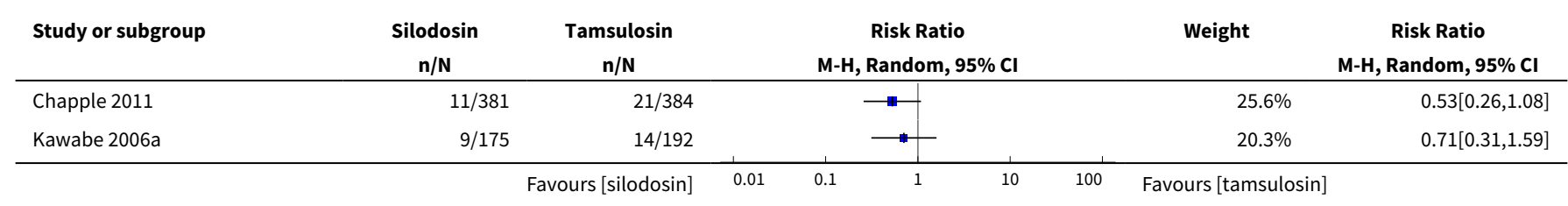




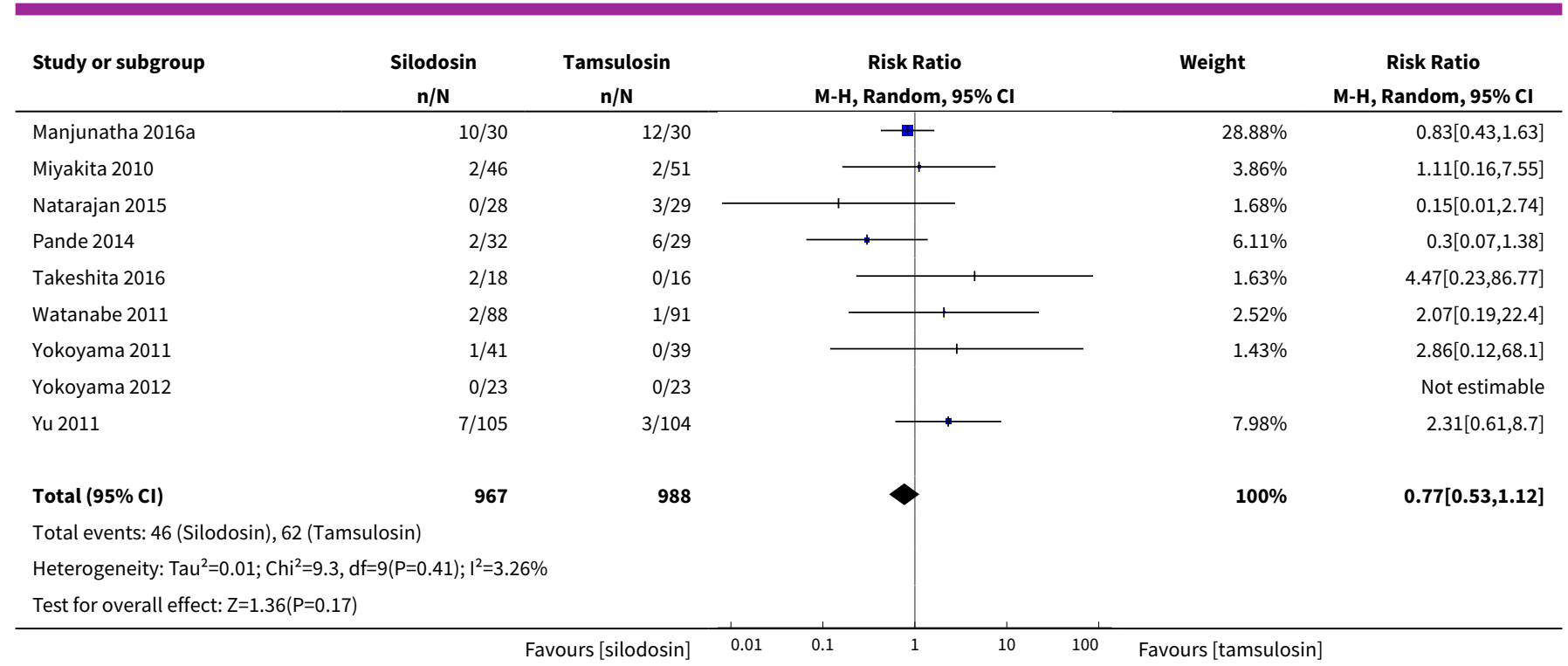

Analysis 2.6. Comparison 2 Silodosin versus tamsulosin, Outcome 6 Sexual adverse events (short term).

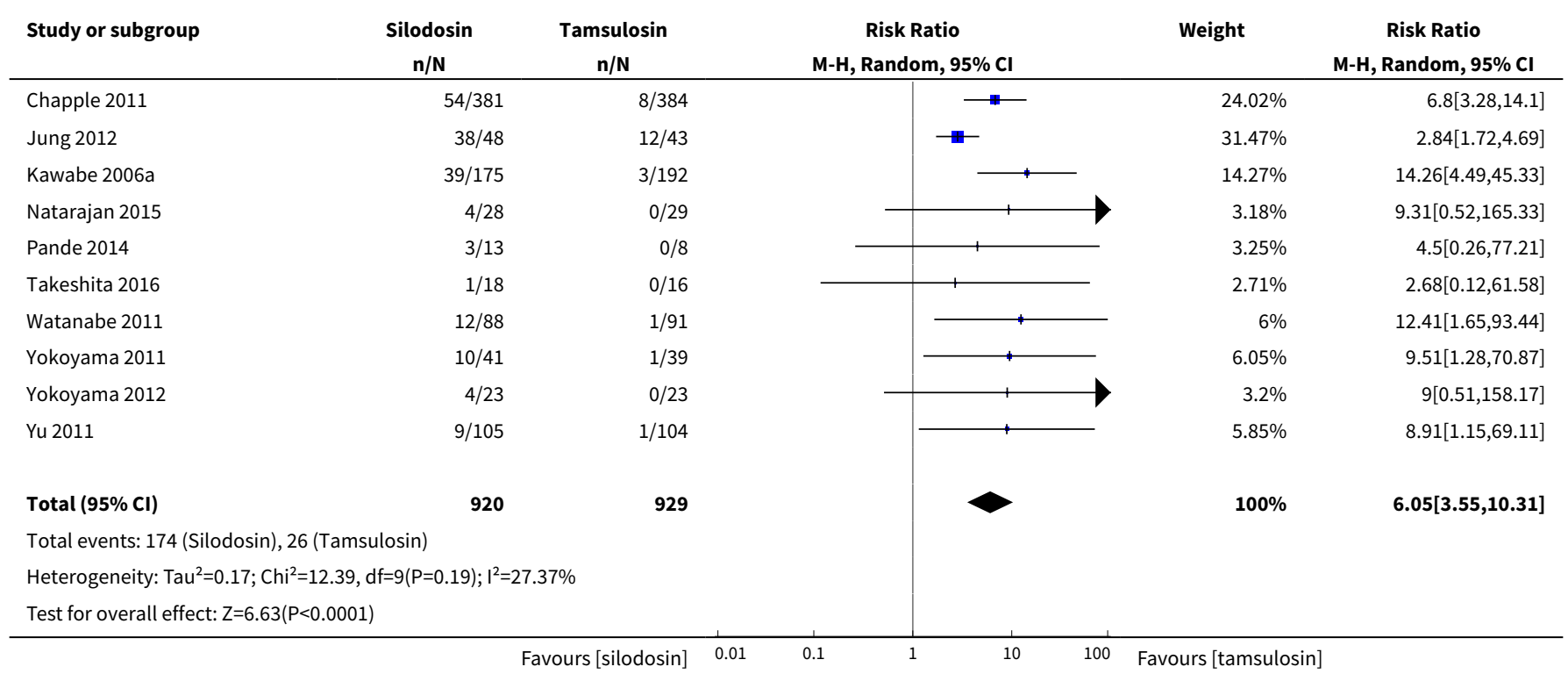

\section{Comparison 3. Silodosin versus naftopidil}

\begin{tabular}{lllll}
\hline Outcome or subgroup title & No. of studies & $\begin{array}{l}\text { No. of partici- } \\
\text { pants }\end{array}$ & Statistical method & Effect size \\
\hline $\begin{array}{l}1 \text { Urologic symptom scores (short } \\
\text { term) }\end{array}$ & 5 & 652 & $\begin{array}{l}\text { Mean Difference (IV, Random, } \\
95 \% \mathrm{Cl})\end{array}$ & $-0.85[-2.57,0.87]$ \\
\hline 2 Quality of life (short term) & 5 & 652 & $\begin{array}{l}\text { Mean Difference (IV, Random, } \\
95 \% \mathrm{Cl})\end{array}$ & $-0.17[-0.60,0.27]$ \\
\hline
\end{tabular}




\begin{tabular}{|c|c|c|c|c|}
\hline Outcome or subgroup title & No. of studies & $\begin{array}{l}\text { No. of partici- } \\
\text { pants }\end{array}$ & Statistical method & Effect size \\
\hline $\begin{array}{l}3 \text { Treatment withdrawal due to any } \\
\text { reason (short term) }\end{array}$ & 4 & 659 & $\begin{array}{l}\text { Risk Ratio (M-H, Random, } \\
95 \% \mathrm{Cl})\end{array}$ & $1.25[0.81,1.93]$ \\
\hline $\begin{array}{l}4 \text { Treatment withdrawal due to ad- } \\
\text { verse events (short term) }\end{array}$ & 5 & 738 & $\begin{array}{l}\text { Risk Ratio (M-H, Random, } \\
95 \% \mathrm{Cl})\end{array}$ & $1.38[0.66,2.89]$ \\
\hline $\begin{array}{l}5 \text { Cardiovascular adverse events } \\
\text { (short term) }\end{array}$ & 5 & 808 & $\begin{array}{l}\text { Risk Ratio (M-H, Random, } \\
95 \% \mathrm{Cl} \text { ) }\end{array}$ & $1.02[0.41,2.56]$ \\
\hline 6 Sexual adverse events (short term) & 4 & 405 & $\begin{array}{l}\text { Risk Ratio (M-H, Random, } \\
95 \% \mathrm{Cl} \text { ) }\end{array}$ & $5.93[2.16,16.29]$ \\
\hline
\end{tabular}

Analysis 3.1. Comparison 3 Silodosin versus naftopidil, Outcome 1 Urologic symptom scores (short term).

\begin{tabular}{|c|c|c|c|c|c|c|c|c|}
\hline \multirow{3}{*}{$\begin{array}{l}\text { Study or subgroup } \\
\text { Masuda } 2012\end{array}$} & \multicolumn{2}{|c|}{ Silodosin } & \multicolumn{2}{|c|}{ Naftopidil } & \multirow{2}{*}{\multicolumn{2}{|c|}{$\begin{array}{l}\text { Mean Difference } \\
\text { Random, } 95 \% \mathrm{CI}\end{array}$}} & \multirow[t]{2}{*}{ Weight } & \multirow{2}{*}{$\begin{array}{l}\text { Mean Difference } \\
\text { Random, } 95 \% \mathrm{CI}\end{array}$} \\
\hline & $\mathbf{N}$ & Mean(SD) & $\mathbf{N}$ & Mean(SD) & & & & \\
\hline & 30 & $10(4.8)$ & 34 & $10.8(4.7)$ & $*$ & 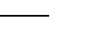 & $17.51 \%$ & $-0.8[-3.13,1.53]$ \\
\hline Matsukawa 2016 & 157 & $-7.5(6.6)$ & 157 & $-6.2(6.6)$ & 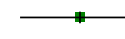 & & $21.82 \%$ & $-1.3[-2.75,0.15]$ \\
\hline Shirakawa 2013 & 56 & $-6(5.3)$ & 56 & $-3.6(5.9)$ & & & $18.81 \%$ & $-2.46[-4.53,-0.39]$ \\
\hline Yamaguchi 2013 & 41 & $-7.4(5.4)$ & 38 & $-5.8(6)$ & . & - & $16.6 \%$ & $-1.6[-4.12,0.92]$ \\
\hline Yokoyama 2011 & 41 & $-4.9(1.2)$ & 42 & $-6.1(1.1)$ & & $\rightarrow$ & $25.26 \%$ & $1.2[0.7,1.7]$ \\
\hline Total $\star \star \star$ & 325 & & 327 & & & - & $100 \%$ & $-0.85[-2.57,0.87]$ \\
\hline \multicolumn{9}{|c|}{ Heterogeneity: $\mathrm{Tau}^{2}=2.99 ; \mathrm{Chi}^{2}=24.93, \mathrm{df}=4(\mathrm{P}<0.0001) ; \mathrm{I}^{2}=83.95 \%$} \\
\hline \multicolumn{9}{|c|}{ Test for overall effect: $Z=0.97(P=0.33)$} \\
\hline
\end{tabular}

Analysis 3.2. Comparison 3 Silodosin versus naftopidil, Outcome 2 Quality of life (short term).

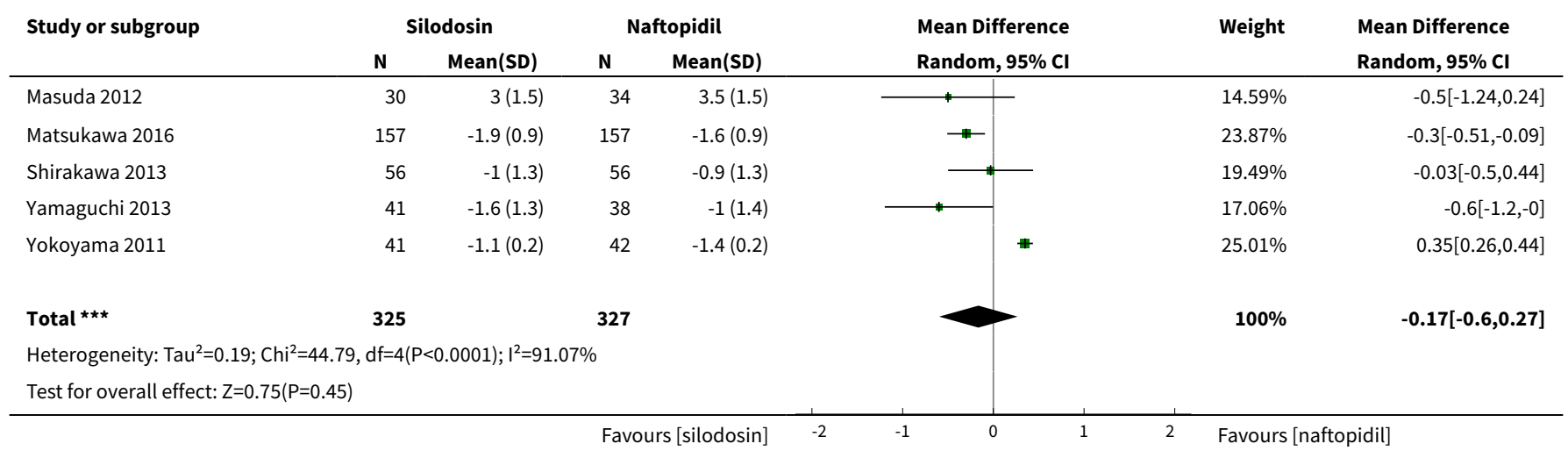


Analysis 3.3. Comparison 3 Silodosin versus naftopidil, Outcome 3 Treatment withdrawal due to any reason (short term).

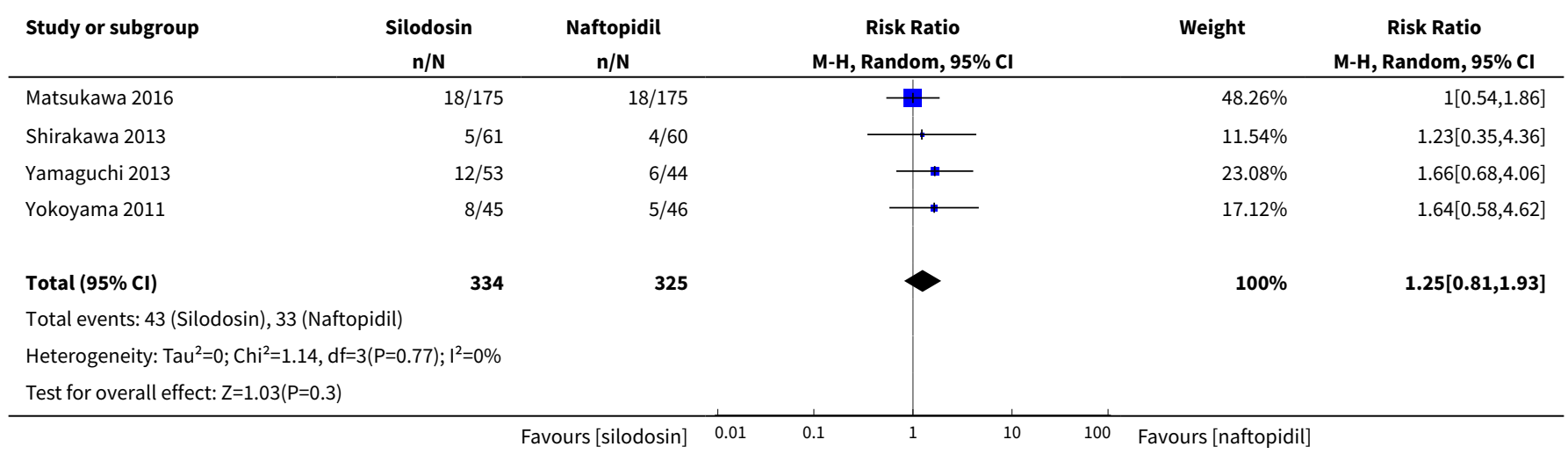

Analysis 3.4. Comparison 3 Silodosin versus naftopidil, Outcome 4 Treatment withdrawal due to adverse events (short term).

\begin{tabular}{|c|c|c|c|c|c|}
\hline Study or subgroup & $\begin{array}{c}\text { Silodosin } \\
\mathrm{n} / \mathrm{N}\end{array}$ & $\begin{array}{c}\text { Naftopidil } \\
\mathrm{n} / \mathrm{N}\end{array}$ & $\begin{array}{c}\text { Risk Ratio } \\
\text { M-H, Random, 95\% Cl }\end{array}$ & Weight & $\begin{array}{c}\text { Risk Ratio } \\
\text { M-H, Random, } 95 \% \text { Cl }\end{array}$ \\
\hline Masuda 2012 & $1 / 44$ & $2 / 48$ & - & $9.74 \%$ & $0.55[0.05,5.81]$ \\
\hline Matsukawa 2016 & $7 / 175$ & $8 / 175$ & 1 & $55.3 \%$ & $0.88[0.32,2.36]$ \\
\hline Shirakawa 2013 & $3 / 59$ & $1 / 57$ & & $10.92 \%$ & $2.9[0.31,27.05]$ \\
\hline Yamaguchi 2013 & $5 / 53$ & $1 / 44$ & & $12.24 \%$ & $4.15[0.5,34.22]$ \\
\hline Yokoyama 2011 & $4 / 41$ & $1 / 42$ & $\longrightarrow$ & $11.8 \%$ & $4.1[0.48,35.13]$ \\
\hline Total $(95 \% \mathrm{Cl})$ & 372 & 366 & & $100 \%$ & $1.38[0.66,2.89]$ \\
\hline \multicolumn{6}{|c|}{ Total events: 20 (Silodosin), 13 (Naftopidil) } \\
\hline \multicolumn{6}{|c|}{ Heterogeneity: $\mathrm{Tau}^{2}=0 ; \mathrm{Chi}^{2}=3.91, \mathrm{df}=4(\mathrm{P}=0.42) ; \mathrm{I}^{2}=0 \%$} \\
\hline Test for overall effect & & & & & \\
\hline
\end{tabular}

\section{Analysis 3.5. Comparison 3 Silodosin versus naftopidil, Outcome 5 Cardiovascular adverse events (short term).}

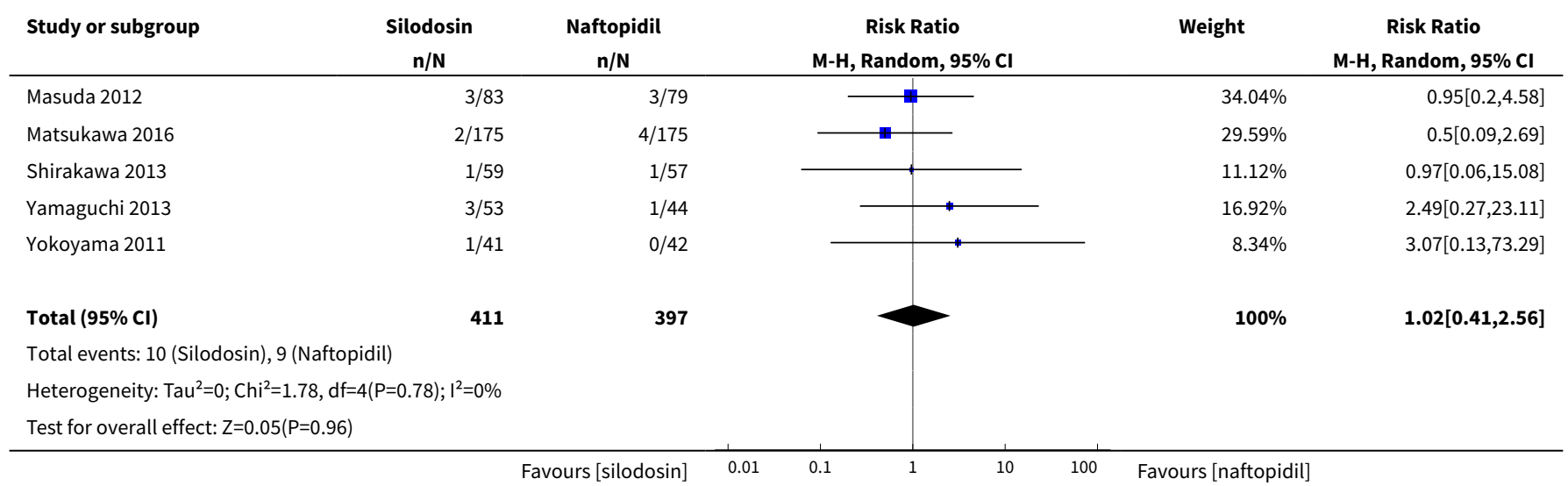


Analysis 3.6. Comparison 3 Silodosin versus naftopidil, Outcome 6 Sexual adverse events (short term).

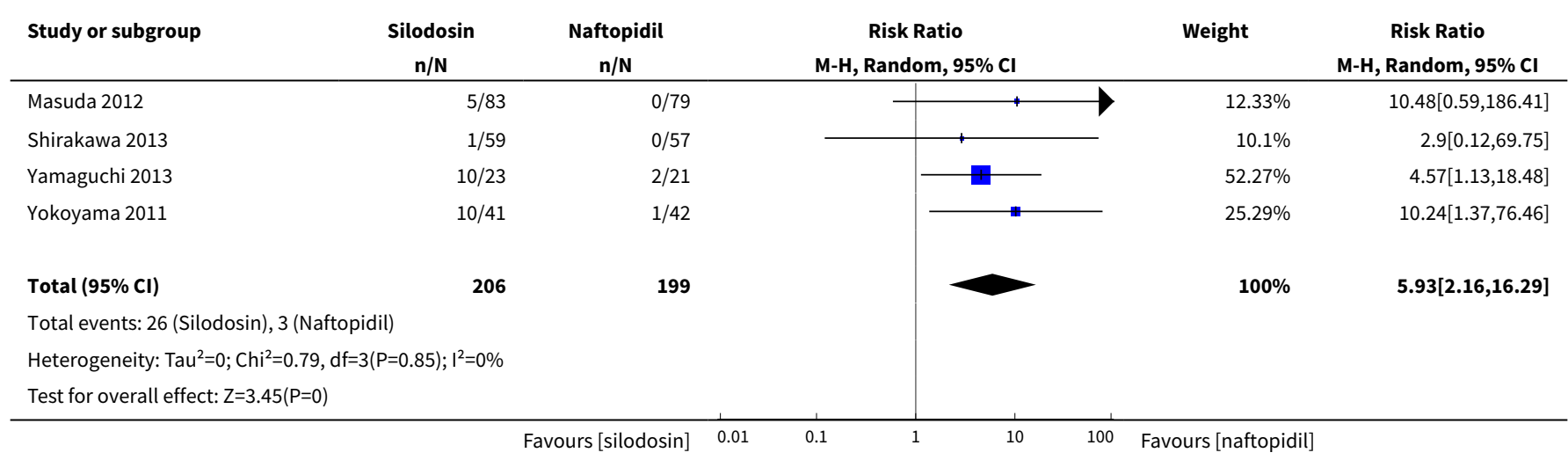

\section{Comparison 4. Silodosin versus alfuzosin}

\begin{tabular}{|c|c|c|c|c|}
\hline Outcome or subgroup title & No. of studies & $\begin{array}{l}\text { No. of partici- } \\
\text { pants }\end{array}$ & Statistical method & Effect size \\
\hline $\begin{array}{l}1 \text { Urologic symptom scores (short } \\
\text { term) }\end{array}$ & 1 & 60 & $\begin{array}{l}\text { Mean Difference (IV, Random, } \\
95 \% \mathrm{CI})\end{array}$ & $3.83[0.12,7.54]$ \\
\hline 2 Quality of life (short term) & 1 & 60 & $\begin{array}{l}\text { Mean Difference (IV, Random, } \\
95 \% \mathrm{CI} \text { ) }\end{array}$ & $0.14[-0.46,0.74]$ \\
\hline $\begin{array}{l}3 \text { Cardiovascular adverse events } \\
\text { (short term) }\end{array}$ & 1 & 60 & $\begin{array}{l}\text { Risk Ratio (M-H, Random, 95\% } \\
\mathrm{CI} \text { ) }\end{array}$ & $0.67[0.36,1.24]$ \\
\hline 4 Sexual adverse events (short term) & 1 & 95 & $\begin{array}{l}\text { Risk Ratio (M-H, Random, 95\% } \\
\text { Cl) }\end{array}$ & $\begin{array}{l}37.21[5.32 \\
260.07]\end{array}$ \\
\hline
\end{tabular}

Analysis 4.1. Comparison 4 Silodosin versus alfuzosin, Outcome 1 Urologic symptom scores (short term).

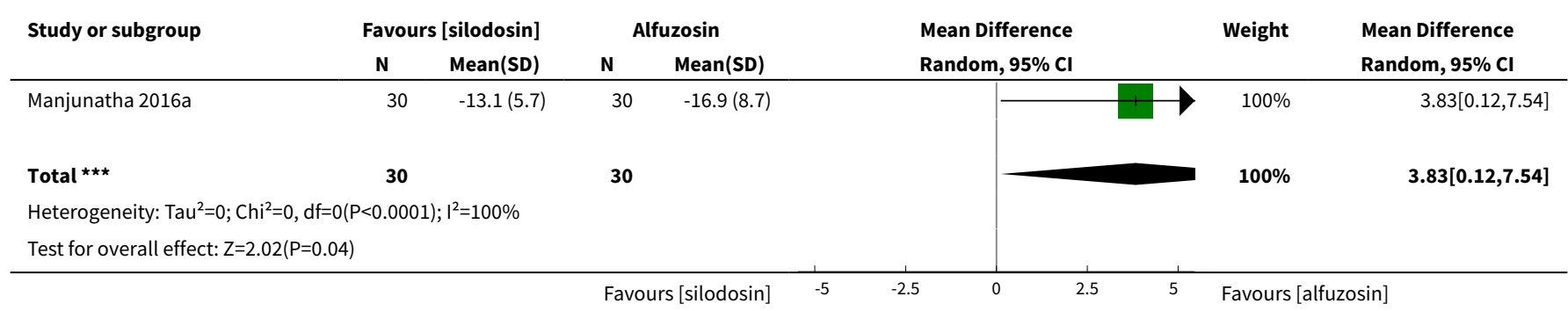


Analysis 4.2. Comparison 4 Silodosin versus alfuzosin, Outcome 2 Quality of life (short term).

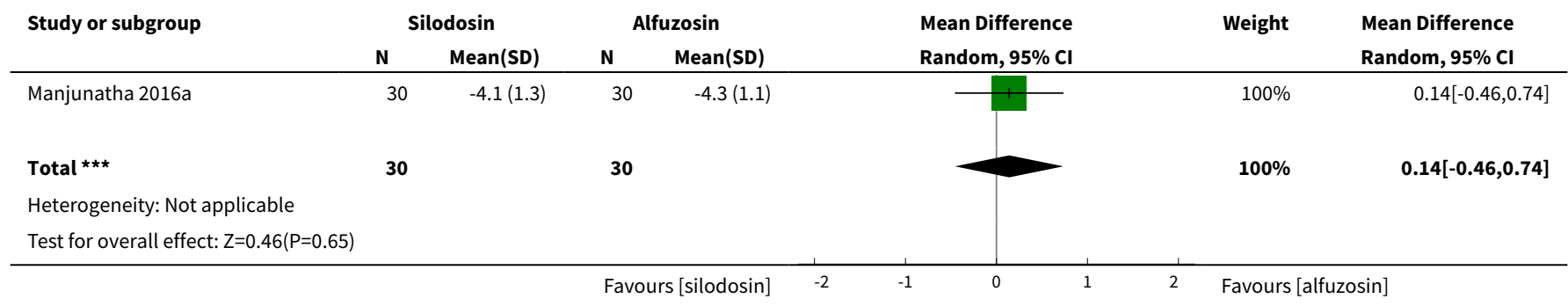

Analysis 4.3. Comparison 4 Silodosin versus alfuzosin, Outcome 3 Cardiovascular adverse events (short term).

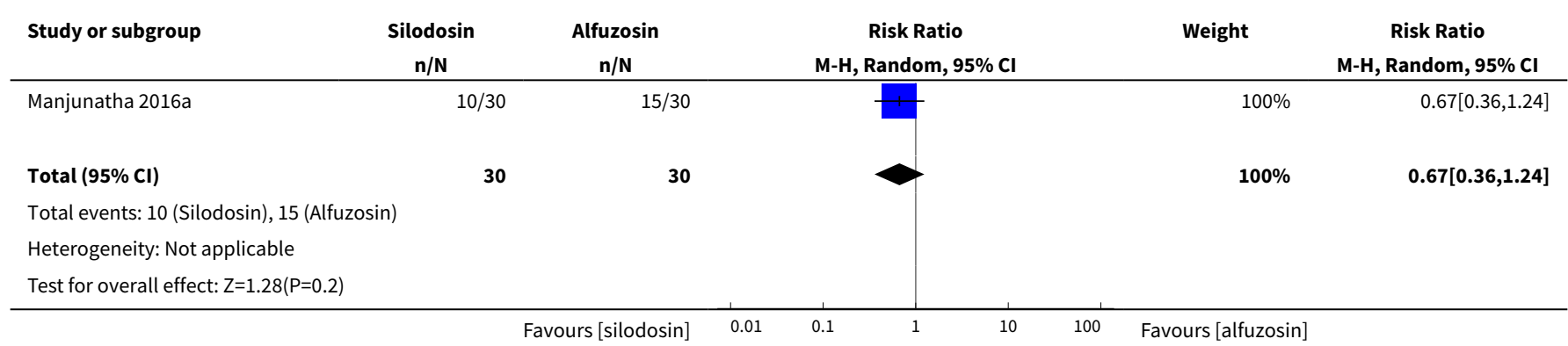

Analysis 4.4. Comparison 4 Silodosin versus alfuzosin, Outcome 4 Sexual adverse events (short term).

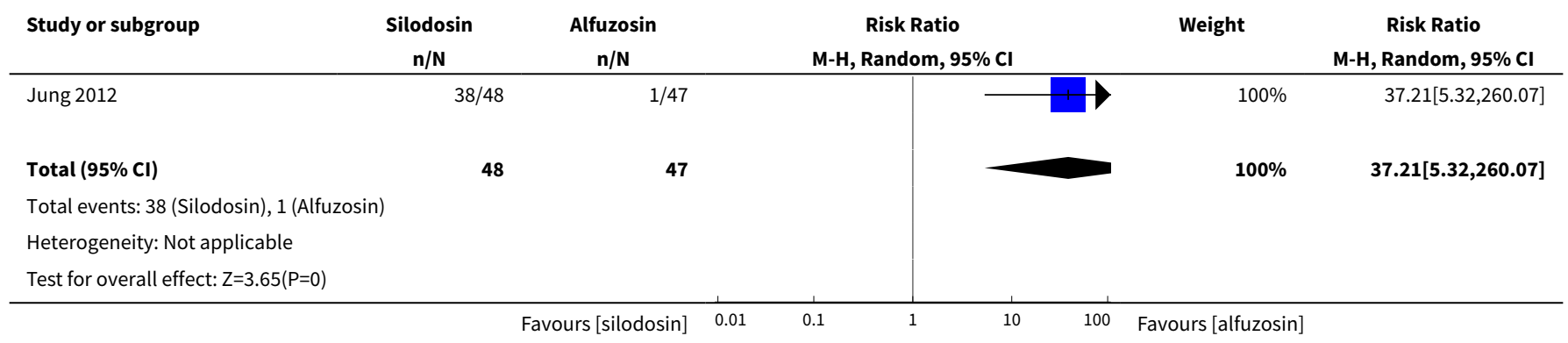




\begin{tabular}{|c|c|c|c|c|c|c|c|c|c|}
\hline \multirow{2}{*}{ 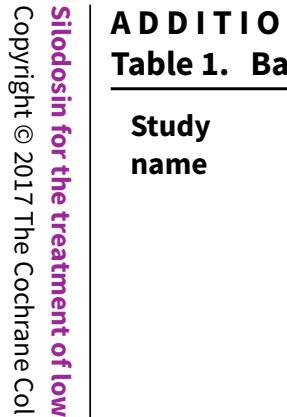 } & & \multirow[b]{2}{*}{ Setting } & \multirow[b]{2}{*}{ Description of participants } & \multirow[b]{2}{*}{$\begin{array}{l}\text { Intervention(s) } \\
\text { and } \\
\text { comparator(s) }\end{array}$} & \multirow[b]{2}{*}{$\begin{array}{l}\text { Duration } \\
\text { of } \\
\text { interven- } \\
\text { tion } \\
\text { (duration } \\
\text { of } \\
\text { fol- } \\
\text { low-up) }\end{array}$} & \multirow[b]{2}{*}{ Age } & \multirow[b]{2}{*}{$\begin{array}{l}\text { Prostate } \\
\text { volume }\end{array}$} & \multirow[b]{2}{*}{ IPSS } \\
\hline & $\begin{array}{l}\text { Trial } \\
\text { period } \\
\text { (year to } \\
\text { year) }\end{array}$ & Country & & & & & & & \\
\hline \multirow[t]{3}{*}{$\begin{array}{l}\text { Chapple } \\
2011\end{array}$} & \multirow[t]{3}{*}{$2006-2007$} & \multirow[t]{3}{*}{ Europe } & \multirow{3}{*}{$\begin{array}{l}72 \text { hospi- } \\
\text { tal clin- } \\
\text { ics and in- } \\
\text { patient } \\
\text { units in } 11 \\
\text { countries }\end{array}$} & \multirow{3}{*}{$\begin{array}{l}\text { Men } \geq 50 \text { years with LUTS (de- } \\
\text { fined by a stable IPSS total } \\
\text { score } \geq 13 \text { points), bladder out- } \\
\text { let obstruction (defined by a } \\
\text { Qmax between } 4 \text { and } 15 \mathrm{~mL} / \mathrm{s} \text {, } \\
\text { with a minimum voided volume } \\
\text { of } \geq 125 \mathrm{~mL} \text { ) }\end{array}$} & $\begin{array}{l}\text { Silodosin } 8 \mathrm{mg} \text { once dai- } \\
\text { ly }\end{array}$ & \multirow[t]{3}{*}{12 weeks } & $65.8 \pm 7.70$ & \multirow[t]{3}{*}{ NR } & $19.1 \pm 4.2$ \\
\hline & & & & & $\begin{array}{l}\text { Tamsulosin } 0.4 \mathrm{mg} \text { once } \\
\text { daily }\end{array}$ & & $65.9 \pm 7.41$ & & $18.9 \pm 4.3$ \\
\hline & & & & & Placebo once daily & & $66.0 \pm 7.37$ & & $19.3 \pm 4.3$ \\
\hline \multirow[t]{3}{*}{ Jung 2012} & \multirow[t]{3}{*}{ NR } & \multirow[t]{3}{*}{$\begin{array}{l}\text { South Ko- } \\
\text { rea }\end{array}$} & \multirow[t]{3}{*}{ NR } & \multirow[t]{3}{*}{ Sexually active men with BPH } & $\begin{array}{l}\text { Silodosin } 8 \mathrm{mg} \text { once dai- } \\
\text { ly }\end{array}$ & \multirow[t]{3}{*}{4 weeks } & \multirow[t]{3}{*}{ NR } & \multirow[t]{3}{*}{ NR } & \multirow[t]{3}{*}{ NR } \\
\hline & & & & & $\begin{array}{l}\text { Tamsulosin } 0.2 \mathrm{mg} \text { once } \\
\text { daily }\end{array}$ & & & & \\
\hline & & & & & $\begin{array}{l}\text { Alfuzosin } 10 \mathrm{mg} \text { once } \\
\text { daily }\end{array}$ & & & & \\
\hline \multirow[t]{3}{*}{$\begin{array}{l}\text { Kawabe } \\
2006 a\end{array}$} & \multirow[t]{3}{*}{ NR } & \multirow[t]{3}{*}{ Japan } & \multirow{3}{*}{$\begin{array}{l}88 \text { cen- } \\
\text { ters/out- } \\
\text { patient }\end{array}$} & \multirow{3}{*}{$\begin{array}{l}\text { Men } \geq 50 \text { years with LUTS (IPSS } \\
\text { of } \geq 8 \text {, an associated QoL score } \\
\text { of } \geq 3 \text { ) and prostate volume of } \geq \\
20 \mathrm{~mL}\end{array}$} & $\begin{array}{l}\text { Silodosin } 4 \text { mg twice dai- } \\
\text { ly }\end{array}$ & \multirow[t]{3}{*}{12 weeks } & $65.4 \pm 7.0$ & $36.0 \pm 16.9$ & $17.1 \pm 5.7$ \\
\hline & & & & & $\begin{array}{l}\text { Tamsulosin } 0.2 \mathrm{mg} \text { once } \\
\text { daily }\end{array}$ & & $65.6 \pm 7.0$ & $35.7 \pm 14.4$ & $17.0 \pm 5.7$ \\
\hline & & & & & Placebo twice daily & & $65.0 \pm 6.9$ & $35.2 \pm 16.0$ & $17.1 \pm 6.1$ \\
\hline \multirow[t]{3}{*}{$\begin{array}{l}\text { Manju- } \\
\text { natha } \\
2016 a\end{array}$} & \multirow[t]{3}{*}{$2013-2014$} & \multirow[t]{3}{*}{ India } & \multirow[t]{3}{*}{$\begin{array}{l}\text { Tertiary } \\
\text { care hos- } \\
\text { pital }\end{array}$} & \multirow{3}{*}{$\begin{array}{l}\text { Men } \geq 45 \text { years with sympto- } \\
\text { matic } B P H \text { with LUTS (IPSS of } \geq \\
8, \mathrm{Q} \text { L of } \geq 3 \text {, and Qmax of }<15 \\
\mathrm{~mL} / \mathrm{s} \text {, but }>4 \mathrm{~mL} / \mathrm{s} \text { with a void- } \\
\text { ed volume of }>100 \mathrm{~mL} \text { ) }\end{array}$} & $\begin{array}{l}\text { Silodosin } 8 \mathrm{mg} \text { once dai- } \\
\text { ly }\end{array}$ & \multirow[t]{3}{*}{12 weeks } & $\begin{array}{l}64.00 \pm \\
11.14\end{array}$ & $\begin{array}{l}40.57 \pm \\
16.45\end{array}$ & $\begin{array}{l}15.93 \pm \\
6.03\end{array}$ \\
\hline & & & & & $\begin{array}{l}\text { Tamsulosin } 0.4 \text { mg once } \\
\text { daily }\end{array}$ & & $\begin{array}{l}63.60 \pm \\
9.05\end{array}$ & $\begin{array}{l}40.33 \pm \\
21.55\end{array}$ & $\begin{array}{l}21.63 \pm \\
7.63\end{array}$ \\
\hline & & & & & $\begin{array}{l}\text { Alfuzosin } 10 \mathrm{mg} \text { once } \\
\text { daily }\end{array}$ & & $\begin{array}{l}63.43 \pm \\
8.91\end{array}$ & $\begin{array}{l}44.43 \pm \\
27.72\end{array}$ & $19.2 \pm 9.6$ \\
\hline
\end{tabular}




\begin{tabular}{|c|c|c|c|c|c|c|c|c|c|}
\hline $\begin{array}{l}\text { Marks } \\
2009\end{array}$ & $2005-2006$ & USA & $\begin{array}{l}\text { Multicen- } \\
\text { ter }\end{array}$ & $\begin{array}{l}\text { Men } \geq 50 \text { years with IPSS } \geq 13 \\
\text { Qmax } 4 \mathrm{~mL} / \mathrm{s}-15 \mathrm{~mL} / \mathrm{s} \text { and } a \\
\text { PVR }<250 \mathrm{~mL}\end{array}$ & $\begin{array}{l}\text { Silodosin } 8 \text { mg once dai- } \\
\text { ly } \\
\text { Placebo once daily }\end{array}$ & 12 weeks & $64.7 \pm 8.1$ & NR & $21.3 \pm 5.1$ \\
\hline \multirow[t]{2}{*}{$\begin{array}{l}\text { Masuda } \\
2012\end{array}$} & \multirow[t]{2}{*}{$2009-2011$} & \multirow[t]{2}{*}{ Japan } & \multirow[t]{2}{*}{ NR } & \multirow[t]{2}{*}{$\begin{array}{l}\text { Men } \geq 50 \text { years with prostate } \\
\text { estimated volume of }>20 \mathrm{~mL} \text {, } \\
\text { IPSS } \geq 8 \text {, QoL score } \geq 3 \text { points }\end{array}$} & $\begin{array}{l}\text { Silodosin } 2 \mathrm{mg}-4 \mathrm{mg} \\
\text { twice/d for } 2 \text { weeks, fol- } \\
\text { lowed by } 4 \mathrm{mg} \text { twice/d } \\
\text { for } 4 \text { weeks }\end{array}$ & \multirow[t]{2}{*}{$\begin{array}{l}6 \text { weeks } \\
\text { (before } \\
\text { cross- } \\
\text { over)/total } \\
12 \text { weeks }\end{array}$} & $66.5 \pm 5.6$ & $38.8 \pm 13.1$ & $18.6 \pm 5.5$ \\
\hline & & & & & $\begin{array}{l}\text { Naftopidil } 50 \text { mg- } 75 \text { mg } \\
\text { once/d for } 2 \text { weeks, fol- } \\
\text { lowed by } 75 \text { mg once/d } \\
\text { for } 4 \text { weeks }\end{array}$ & & $68.5 \pm 5.7$ & $45.7 \pm 17.8$ & $17.6 \pm 5.0$ \\
\hline \multirow[t]{2}{*}{$\begin{array}{l}\text { Mat- } \\
\text { sukawa } \\
2016\end{array}$} & \multirow[t]{2}{*}{$2012-2013$} & \multirow[t]{2}{*}{ Japan } & \multirow{2}{*}{$\begin{array}{l}52 \text { urolo- } \\
\text { gists par- } \\
\text { ticipat- } \\
\text { ed at a to- } \\
\text { tal of } 44 \\
\text { investi- } \\
\text { gational } \\
\text { sites/out- } \\
\text { patients }\end{array}$} & \multirow[t]{2}{*}{$\begin{array}{l}\text { Men with LUTS (IPSS } \geq 8 \text {, IPSS } \\
\text { QoL score } 3 \text { ) and prostate vol- } \\
\text { ume } \geq 20 \mathrm{~mL}\end{array}$} & $\begin{array}{l}\text { Silodosin } 4 \mathrm{mg} / \mathrm{d} \text { for } 4 \\
\text { weeks, followed by } 8 \\
\mathrm{mg} / \mathrm{d} \text { for } 8 \text { weeks }\end{array}$ & \multirow[t]{2}{*}{12 weeks } & $70.6 \pm 7.8$ & $39.6 \pm 16.7$ & $18.8 \pm 6.2$ \\
\hline & & & & & $\begin{array}{l}\text { Naftopidil } 50 \mathrm{mg} / \mathrm{d} \text { for } \\
4 \text { weeks, followed by } 75 \\
\mathrm{mg} / \mathrm{d} \text { for } 8 \text { weeks }\end{array}$ & & $70.3 \pm 7.8$ & $38.6 \pm 14.8$ & $18.9 \pm 6.1$ \\
\hline \multirow[t]{2}{*}{$\begin{array}{l}\text { Miyakita } \\
2010\end{array}$} & \multirow[t]{2}{*}{$2006-2007$} & \multirow[t]{2}{*}{ Japan } & \multirow[t]{2}{*}{$\begin{array}{l}\text { Multicen- } \\
\text { ter }\end{array}$} & \multirow{2}{*}{$\begin{array}{l}\text { Men with IPSS } \geq 8 \text { points; } \mathrm{QoL} \\
\text { score } \geq 3 \text { points; prostate vol- } \\
\text { ume measured by ultrasono- } \\
\text { graphic method } \geq 20 \mathrm{~mL} \text {; void } \\
\text { volume } \geq 100 \mathrm{~mL} \text {; and maximal } \\
\text { urinary flow rate }(\mathrm{Qmax})<15 \\
\mathrm{~mL} / \mathrm{s}\end{array}$} & $\begin{array}{l}\text { Silodosin } 4 \text { mg twice dai- } \\
\text { ly }\end{array}$ & \multirow{2}{*}{$\begin{array}{l}4 \text { weeks } \\
\text { (before } \\
\text { cross- } \\
\text { over)/total } \\
8 \text { weeks }\end{array}$} & $68.2 \pm 8.6$ & $41.3 \pm 25.3$ & $16.6 \pm 5.2$ \\
\hline & & & & & $\begin{array}{l}\text { Tamsulosin } 0.2 \mathrm{mg} \text { once } \\
\text { daily }\end{array}$ & & $70.1 \pm 8.9$ & $37.8 \pm 16.3$ & $18.2 \pm 5.8$ \\
\hline \multirow[t]{2}{*}{$\begin{array}{l}\text { Natarajan } \\
2015\end{array}$} & \multirow[t]{2}{*}{ 2013-2015 } & \multirow[t]{2}{*}{ India } & \multirow[t]{2}{*}{$\begin{array}{l}\text { Tertiary } \\
\text { hospital }\end{array}$} & \multirow[t]{2}{*}{$\begin{array}{l}\text { Men }>50 \text { years with bother- } \\
\text { some LUTS from BPH and IPSS } \\
>7\end{array}$} & $\begin{array}{l}\text { Silodosin } 8 \mathrm{mg} \text { once dai- } \\
\text { ly }\end{array}$ & \multirow[t]{2}{*}{12 weeks } & \multirow[t]{2}{*}{$61-62$} & \multirow[t]{2}{*}{ NR } & \multirow[t]{2}{*}{ NR } \\
\hline & & & & & $\begin{array}{l}\text { Tamsulosin } 0.4 \mathrm{mg} \text { once } \\
\text { daily }\end{array}$ & & & & \\
\hline \multirow{2}{*}{\multicolumn{2}{|c|}{ NCT007938192009 }} & \multirow[t]{2}{*}{ NR } & \multirow[t]{2}{*}{ NR } & \multirow{2}{*}{$\begin{array}{l}\text { Men } \geq 50 \text { years, with symptoms } \\
\text { of moderate-severe BPH and } \\
\text { nocturia ( } \geq 2 \text { episodes/night) }\end{array}$} & Silodosin 8 mg daily & \multirow[t]{2}{*}{12 weeks } & $64.6 \pm 8.03$ & NR & NR \\
\hline & & & & & Placebo once daily & & $64.2 \pm 8.92$ & & \\
\hline
\end{tabular}




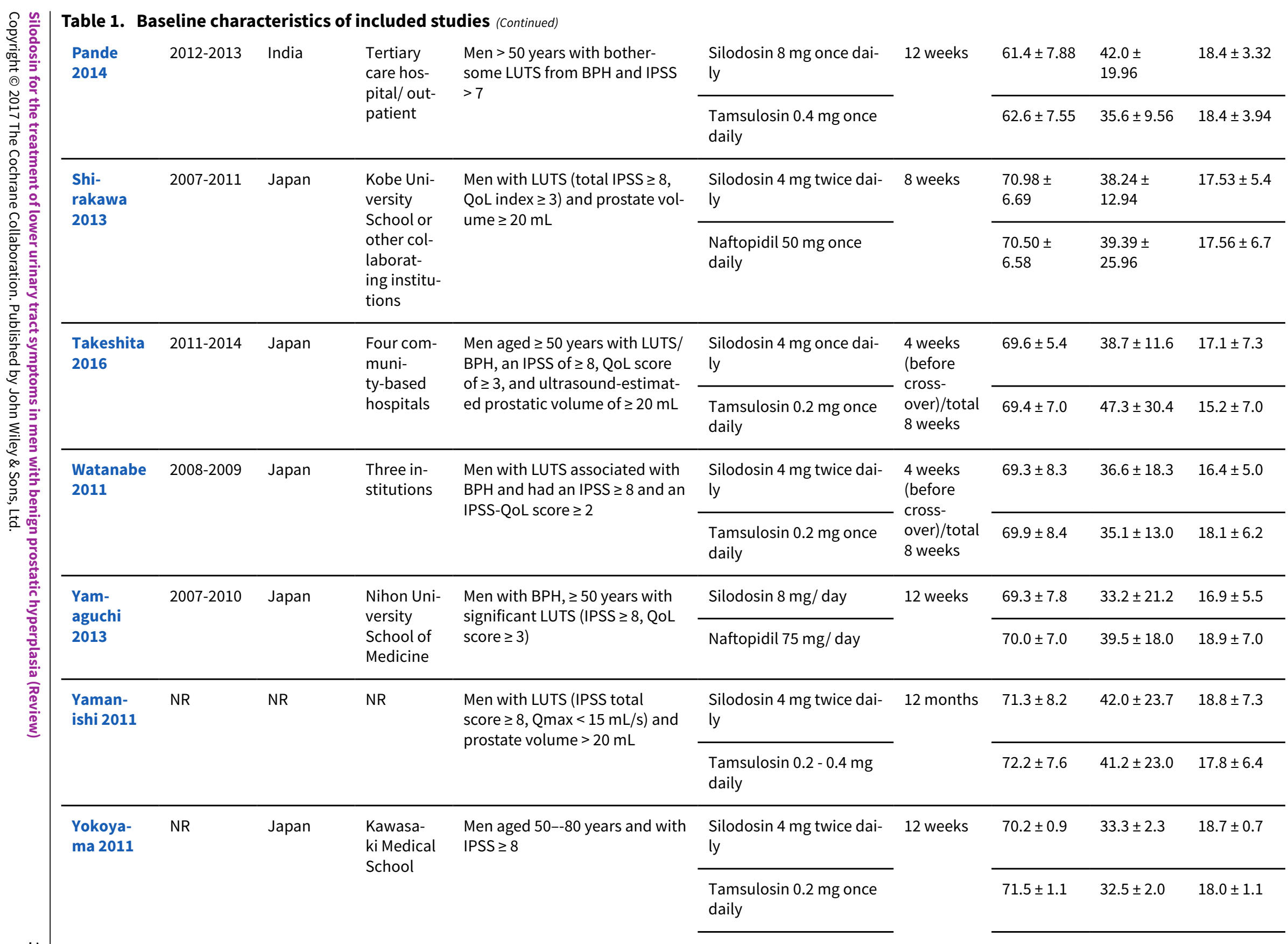




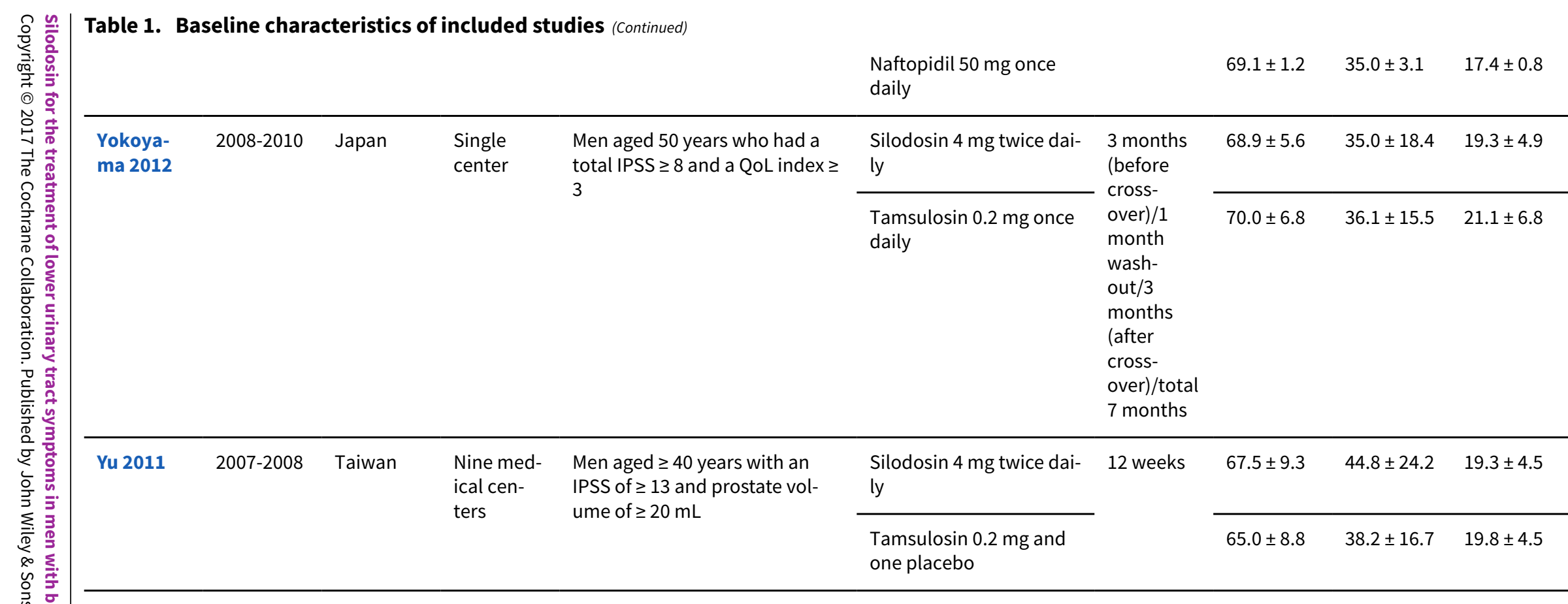

BPH: benign prostatic hyperplasia; IPSS: International Prostate Symptom Score; LUTS: lower urinary tract symptoms; NR: not reported; PVR: postvoid residual; Qmax: maximum flow rate; QoL: quality of life 
Table 2. Participants in included studies

\begin{tabular}{|c|c|c|c|c|c|}
\hline Study name & $\begin{array}{l}\text { Intervention(s) and compara- } \\
\operatorname{tor}(s)\end{array}$ & $\begin{array}{l}\text { Screened/eli- } \\
\text { gible }(\mathbf{N})\end{array}$ & $\begin{array}{l}\text { randomized } \\
(\mathrm{N})\end{array}$ & Analysed (N) & Finishing trial ( $\mathbf{N}(\%))$ \\
\hline \multirow[t]{4}{*}{ Chapple 2011} & Silodosin $8 \mathrm{mg}$ & $1228 / 955$ & 381 & 346 & $356(93.4)$ \\
\hline & Tamsulosin $0.4 \mathrm{mg}$ & & 384 & 347 & $364(94.7)$ \\
\hline & Placebo & & 190 & 168 & $172(90.5)$ \\
\hline & Total & & 955 & 861 & $892(93.4)$ \\
\hline \multirow[t]{4}{*}{ Jung 2012} & Silodosin $8 \mathrm{mg}$ & NR/138 & 48 & 48 & $48(100.0)$ \\
\hline & Tamsulosin $0.2 \mathrm{mg}$ & & 43 & 43 & $43(100.0)$ \\
\hline & Alfuzosin 10 mg & & 47 & 47 & $47(100.0)$ \\
\hline & Total & & 138 & 138 & $138(100.0)$ \\
\hline \multirow{4}{*}{$\begin{array}{l}\text { Kawabe } \\
2006 a\end{array}$} & Silodosin $8 \mathrm{mg}$ & $\mathrm{NR} / 457$ & 176 & 175 & $175(99.4)$ \\
\hline & Tamsulosin $0.2 \mathrm{mg}$ & & 192 & 192 & $192(100.0)$ \\
\hline & Placebo & & 89 & 89 & $89(100.0)$ \\
\hline & Total & & 457 & 456 & $456(99.7)$ \\
\hline \multirow{4}{*}{$\begin{array}{l}\text { Manjunatha } \\
2016 a\end{array}$} & Silodosin $8 \mathrm{mg}$ & $\mathrm{NR} / 90$ & 30 & 30 & $30(100.0)$ \\
\hline & Tamsulosin 0.4 mg & & 30 & 30 & $30(100.0)$ \\
\hline & Alfuzosin $10 \mathrm{mg}$ & & 30 & 30 & $30(100.0)$ \\
\hline & Total & & 90 & 90 & $90(100.0)$ \\
\hline \multirow[t]{3}{*}{ Marks 2009} & Silodosin $8 \mathrm{mg}$ & $2849 / 923$ & 466 & 466 & $413(88.6)$ \\
\hline & Placebo & & 457 & 457 & $419(91.6)$ \\
\hline & Total & & 923 & 923 & $832(90.1)$ \\
\hline \multirow[t]{3}{*}{ Masuda 2012} & Silodosin $4 \mathrm{mg}$ or $8 \mathrm{mg}$ & NR/92 & 44 & $30 / 83^{a}$ & $30(68.1)$ \\
\hline & Naftopidil 50 mg or 75 mg & & 48 & $34 / 79 a$ & $34(70.8)$ \\
\hline & Total & & 92 & $64 / 162^{a}$ & $64(69.5)$ \\
\hline \multirow{3}{*}{$\begin{array}{l}\text { Matsukawa } \\
2016\end{array}$} & Silodosin $4 \mathrm{mg}$ followed by $8 \mathrm{mg}$ & $N R / 350$ & 175 & 157 & $157(89.7)$ \\
\hline & $\begin{array}{l}\text { Naftopidil } 50 \text { mg followed by } 75 \\
\text { mg }\end{array}$ & & 175 & 157 & $157(89.7)$ \\
\hline & Total & & 350 & 314 & $314(89.7)$ \\
\hline
\end{tabular}


Table 2. Participants in included studies (Continued)

\begin{tabular}{|c|c|c|c|c|c|}
\hline \multirow{3}{*}{$\begin{array}{l}\text { Miyakita } \\
2010\end{array}$} & Silodosin 8 mg & NR/97 & 46 & 34 & 34 (73.9) \\
\hline & Tamsulosin $0.2 \mathrm{mg}$ & & 51 & 31 & $31(60.7)$ \\
\hline & Total & & 97 & 65 & $65(67.0)$ \\
\hline \multirow{3}{*}{$\begin{array}{l}\text { Natarajan } \\
2015\end{array}$} & Silodosin $8 \mathrm{mg}$ & $\mathrm{NR} / 57$ & 28 & NR & $N R$ \\
\hline & Tamsulosin $0.4 \mathrm{mg}$ & & 29 & NR & NR \\
\hline & Total & & 57 & NR & NR \\
\hline \multirow[t]{3}{*}{ NCT00793819 } & Silodosin $8 \mathrm{mg}$ & $215 / 209$ & 111 & 111 & $97(87.3)$ \\
\hline & Placebo & & 98 & 98 & $89(90.8)$ \\
\hline & Total & & 209 & 209 & $186(88.9)$ \\
\hline \multirow[t]{3}{*}{ Pande 2014} & Silodosin $8 \mathrm{mg}$ & $102 / 61$ & 32 & 26 & $26(81.2)$ \\
\hline & Tamsulosin $0.4 \mathrm{mg}$ & & 29 & 27 & $27(93.1)$ \\
\hline & Total & & 61 & 53 & $53(86.8)$ \\
\hline \multirow{3}{*}{$\begin{array}{l}\text { Shirakawa } \\
2013\end{array}$} & Silodosin $8 \mathrm{mg}$ & NR/121 & 61 & $56 / 59 a$ & $56(91.8)$ \\
\hline & Naftopidil $50 \mathrm{mg}$ & & 60 & $56 / 57^{a}$ & $56(93.3)$ \\
\hline & Total & & 121 & $112 / 116^{a}$ & $112(92.5)$ \\
\hline \multirow{3}{*}{$\begin{array}{l}\text { Takeshita } \\
2016\end{array}$} & Silodosin 4 mg & $N R / 34$ & 18 & 16 & $16(88.8)$ \\
\hline & Tamsulosin $0.2 \mathrm{mg}$ & & 16 & 14 & $14(87.5)$ \\
\hline & Total & & 34 & 30 & $30(88.2)$ \\
\hline \multirow{3}{*}{$\begin{array}{l}\text { Watanabe } \\
2011\end{array}$} & Silodosin 4 mg & NR/102 & 51 & $42 / 88^{a}$ & $42(82.3)$ \\
\hline & Tamsulosin $0.2 \mathrm{mg}$ & & 51 & $42 / 91^{a}$ & $42(82.3)$ \\
\hline & Total & & 102 & $84 / 179 a$ & $42(82.3)$ \\
\hline \multirow{3}{*}{$\begin{array}{l}\text { Yamaguchi } \\
2013\end{array}$} & Silodosin $8 \mathrm{mg}$ & $109 / 109$ & 58 & 53 & $53(91.3)$ \\
\hline & Naftopidil 75 mg & & 51 & 44 & $44(86.2)$ \\
\hline & Total & & 109 & 97 & $97(88.9)$ \\
\hline \multirow{3}{*}{$\begin{array}{l}\text { Yamanishi } \\
2011\end{array}$} & Silodosin $8 \mathrm{mg}$ & $\mathrm{NR} / 149$ & 75 & NR & NR \\
\hline & Tamsulosin $0.2-0.4 \mathrm{mg}$ & & 74 & NR & NR \\
\hline & Total & & 149 & NR & NR \\
\hline $\begin{array}{l}\text { Yokoyama } \\
2011\end{array}$ & Silodosin $8 \mathrm{mg}$ & $136 / 136$ & 45 & 41 & $41(91.1)$ \\
\hline
\end{tabular}


Table 2. Participants in included studies (Continued)

\begin{tabular}{|c|c|c|c|c|c|}
\hline & Tamsulosin $0.2 \mathrm{mg}$ & & 45 & 39 & $39(86.6)$ \\
\hline & Naftopidil 50 mg & & 46 & 42 & $42(91.3)$ \\
\hline & Total & & 136 & 122 & $122(89.7)$ \\
\hline \multirow{3}{*}{$\begin{array}{l}\text { Yokoyama } \\
2012\end{array}$} & Silodosin $8 \mathrm{mg}$ & $N R / 46$ & 23 & 23 & $23(100.0)$ \\
\hline & Tamsulosin $0.2 \mathrm{mg}$ & & 23 & 23 & $23(100.0)$ \\
\hline & Total & & 46 & 46 & $46(100.0)$ \\
\hline \multirow[t]{3}{*}{ Yu 2011} & Silodosin $8 \mathrm{mg}$ & NR/209 & 105 & 87 & $87(82.8)$ \\
\hline & Tamsulosin $0.2 \mathrm{mg}$ & & 104 & 83 & $83(79.8)$ \\
\hline & Total & & 209 & 170 & $170(81.3)$ \\
\hline \multirow[t]{6}{*}{ Grand total } & Interventions: silodosin & & 1955 & & $1684^{b}$ \\
\hline & Compartors: placebo & & 834 & & $769(92.2)$ \\
\hline & Compartors: tamsulosin & & 1049 & & $888^{b}$ \\
\hline & Compartors: naftopidil & & 380 & & $333(87.6)$ \\
\hline & Comparator: alfuzosin & & 77 & & $77(100.0)$ \\
\hline & Overall & & 4295 & & $3751^{b}$ \\
\hline
\end{tabular}

$\mathrm{N}$ : number; NR: not reported

$a$ Efficacy analysis/safety analysis.

b The number of participants who finished trials were not reported in two included studies (Natarajan 2015; Yamanishi 2011).

\section{AP PEN DICES}

\section{Appendix 1. Search strategies}

\section{Cochrane Library (via Wiley) search strategy}
1. "Prostatic Hyperplasia" [Mesh]
2. (hyperplasia NEAR/3 prostat*):ti,ab,kw
3. "hyperplasia of the prostate":ti,ab,kw
4. "prostatic hyperplasia":ab,ti
5. (hypertrophy NEAR/3 prostat*):ti,ab,kw
6. (adenoma* NEAR/3 prostat*):ti,ab,kw
7. "lower urinary tract symptom" [Mesh] 


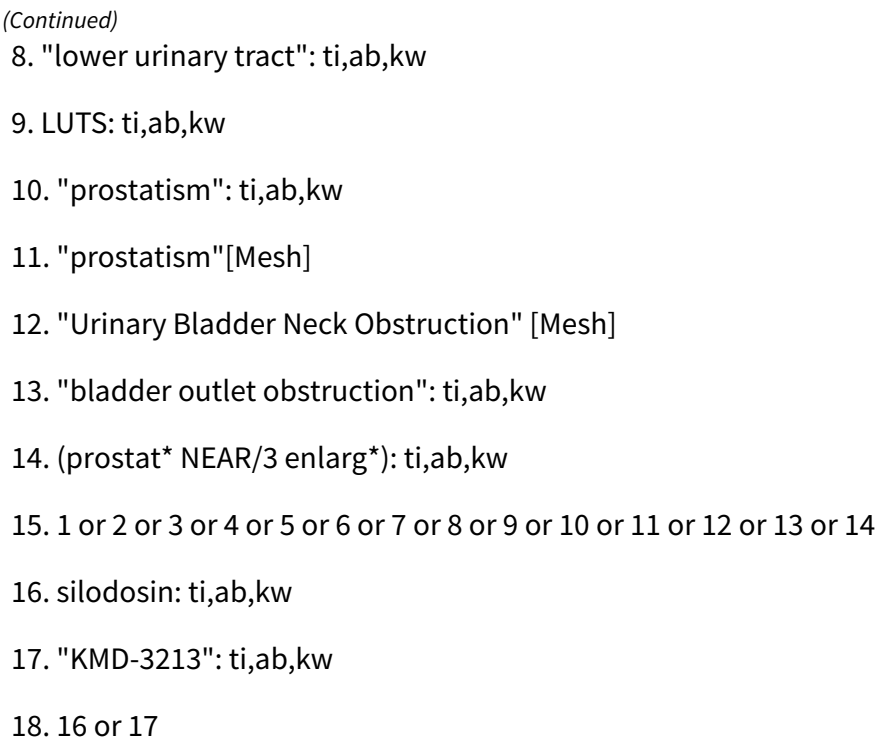

MEDLINE (via Pubmed) search strategy

1. "Prostatic Hyperplasia" [Mesh] or prostatic hyperplasia [TIAB]

2. "Lower Urinary Tract Symptoms" [Mesh] or lower urinary tract [TIAB] or LUTS [TIAB]

3. hyperplasia of the prostate $[T I A B]$

4. "Prostatic hypertrophy" [TIAB]

5. "Prostatic adenoma" [TIAB]

6. "Prostatism" [Mesh] or Prostatism [TIAB]

7. "Urinary Bladder Neck Obstruction" [Mesh] or "Urinary Bladder Neck Obstruction" [TIAB]

8. bladder outlet obstruction [TIAB]

9. 1 or 2 or 3 or 4 or 5 or 6 or 7 or 8

10. silodosin [Supplementary Concept]

11. silodosin $[\mathrm{TIAB}]$

12. KMD-3213 [TIAB]

13. rapaflo $[T I A B]$

14. urief $[T I A B]$

15. urorec $[\mathrm{TIAB}]$

16. 10 or 11 or 12 or 13 or 14 or 15

17. randomized controlled trial [PT]

18. controlled clinical trial [PT]

19. randomized [TIAB]

20. placebo [TIAB]

21. drug therapy [Sh]

22. randomly [TIAB] 
(Continued)

23. trial $[T I A B]$

24. groups $[T I A B]$

25.17 or 18 or 19 or 20 or 21 or 22 or 23 or 24

\section{9 AND 16 AND 25}

27. (animals [Mesh]) NOT (humans [Mesh] and animals [Mesh])

28. 26 NOT 27

\section{EMBASE (via Elsevier) search strategy}

1. 'prostate hypertrophy'/exp

2. $\left(\right.$ hyper $^{\star} \mathrm{NEAR} / 3$ prostat $\left.^{\star}\right): \mathrm{ab}, \mathrm{ti}$

3. (adenoma* NEAR/3 prostat $\left.{ }^{\star}\right): a b, t i$

4. 'BPH' or 'BPO' or 'BPE':ab,ti

5. 'lower urinary tract symptom'/exp

6. 'lower urinary tract' or 'LUTS':ab,ti

7. 'prostatism':ab,ti

8. 'prostatism'/exp

9. 'bladder obstruction'/exp

10. ('bladder* NEAR/3 obstruct*)' or 'BOO' :ab,ti

11. (prostat ${ }^{\star}$ NEAR/3 (enlarg* or obstruct $\left.\left.{ }^{\star}\right)\right): a b, t i$

12. ((urinary or urethra* or urination or LUT*) NEAR/3 (symptom* or complain*)):ab,ti

13. 1 or 2 or 3 or 4 or 5 or 6 or 7 or 8 or 9 or 10 or 11 or 12

14. 'silodosin'/exp

15. silodosin or 'KMD-3213' or kad3213 or rapaflo or silodyx or urief or urorec or Silofast or Thrupas:tw

16. '160970-54-7' or '160970-64-9' or '169107-04-4':rn

17. 14 or 15 or 16

18. random\$ or factorial\$ or crossover $\$$ or cross over\$ or 'cross-over $\$$ ' or placebo $\$$ or (doubl\$ adj blind\$) or (singl\$ adj blind\$) or assign\$ or allocat\$ or volunteer\$:tw

19. 'crossover procedure'/exp OR 'double blind procedure'/exp OR 'randomized controlled trial'/exp OR 'single blind procedure'/exp

20. 18 or 19

21. 13 AND 17 AND 20

22. ('animals'/exp) NOT ('humans'/exp and 'animals'/exp)

23. 21 NOT 22

\section{Scopus search strategy}

1. TITLE-ABS-KEY (hyperplasia W/3 prostat ${ }^{\star}$ )

2. TITLE-ABS-KEY (hypertrophy W/3 prostat ${ }^{\star}$ ) 
(Continued)

3. TITLE-ABS-KEY (adenoma* W/3 prostat ${ }^{\star}$ )

4. TITLE-ABS-KEY (prostat* W/3 (enlarg* or obstruct*))

5. TITLE-ABS-KEY ((urinary OR urethra* OR urination OR lut*) W/3 (symptom* OR complain*))

6. TITLE-ABS-KEY (prostatism)

7. TITLE-ABS-KEY (bladder* W/3 obstruct*)

8. TITLE-ABS-KEY ("lower urinary tract")

9. 1 or 2 or 3 or 4 or 5 or 6 or 7 or 8

10. TITLE-ABS-KEY (silodosin or 'KMD-3213' or rapaflo or silodyx or urief or urorec or Silofast or Thrupas)

11. CASREGNUMBER (160970-54-7 OR 160970-64-9 OR 169107-04-4)

12. 10 or 11

13. TITLE-ABS-KEY ("Double blind*" OR "Single Blind*" OR "Cross over stud*")

14. 9 AND 12 AND 13

Google Scholar search strategy

allintitle: ("Prostatic Hyperplasia" OR "prostate hypertrophy" OR "hyperplasia of the prostate" OR "lower urinary tract" OR "LUTS" OR prostatism OR "bladder obstruction" OR "bladder outlet obstruction") AND (silodosin OR KMD-3213 OR rapaflo OR Silodyx OR kad3213 OR urief OR urorec OR Silodal OR Rapilif OR Silofast OR Thrupas)

\section{Web of Science search strategy}

1. $\mathrm{TS}=\left(\right.$ hyper ${ }^{\star}$ NEAR/3 prostat $\left.{ }^{\star}\right)$ OR (adenoma* NEAR/3 prostat*) OR "BPH" OR "BPO" OR "BPE" OR "lower urinary tract" OR "luts" OR prostatism OR ("bladder NEAR/3 obstruct*") OR "BOO" OR (prostat* NEAR/3 (enlarg* or obstruct*)) OR ((urinary or urethra* or urination or LUT*) NEAR/3 (symptom* or complain*))

2. TS = (silodosin OR KMD-3213 OR rapaflo OR urief)

3. TS = "clinical trial*" OR "controlled trial*" OR "randomized controlled trial*" OR (single blind*) OR (double blind*)

4. 1 AND 2 AND 3

\section{ClinicalTrials.gov}

Basic search = ("Prostatic Hyperplasia" OR "prostate hypertrophy" OR "hyperplasia of the prostate" OR "lower urinary tract" OR "LUTS" OR prostatism OR "bladder obstruction" OR "bladder outlet obstruction") AND (silodosin OR KMD-3213 OR rapaflo OR urief OR Thrupas)

\section{World Health Organization International Clinical Trials Registry Platform Search Portal}

In the title = ("Prostatic Hyperplasia" OR "prostate hypertrophy" OR "hyperplasia of the prostate" OR "lower urinary tract" OR "LUTS" OR prostatism OR "bladder obstruction" OR "bladder outlet obstruction") AND In the intervention= (silodosin OR KMD-3213 OR rapaflo OR Silodyx OR urief OR urorec OR Silodal OR Thrupas)

\section{Appendix 2. Survey of trial investigators providing information on included trials}




\begin{tabular}{|c|c|c|c|}
\hline & $\begin{array}{l}\text { Date trial author } \\
\text { contacted (first) }\end{array}$ & $\begin{array}{l}\text { Date trial author } \\
\text { provided data (lat- } \\
\text { est) }\end{array}$ & $\begin{array}{l}\text { Data trial author provided } \\
\text { (short summary) }\end{array}$ \\
\hline Chapple 2011 & 22 Jan 2017 & 2 Feb 2017 & $\begin{array}{l}\text { Unadjusted change from baseline in IPSS and QoL, mean and } \\
\text { standard deviation of IPSS and QoL at endpoint ( } 12 \text { weeks), the } \\
\text { number of participants with acute urinary retention and surgi- } \\
\text { cal intervention. }\end{array}$ \\
\hline Jung 2012 & 18 Jan 2017 & 28 Feb 2017 & Author reply: "Full text was not published". \\
\hline Marks 2009 & $23 \mathrm{Jan} 2017$ & 23 Jan 2017 & $\begin{array}{l}\text { Author reply: "Pharmaceutics only have a data". We cannot } \\
\text { contact study supporter in pharmaceutics due to wrong email } \\
\text { address. }\end{array}$ \\
\hline Pande 2014 & 24 Jan 2017 & 18 May 2017 & $\begin{array}{l}\text { Mean and standard deviation of IPSS and QoL at baseline and } \\
\text { endpoint ( } 12 \text { weeks), the number of participants with acute uri- } \\
\text { nary retention, surgical intervention, cardiovascular adverse } \\
\text { events, and sexual adverse events. }\end{array}$ \\
\hline Takeshita 2016 & 24 Oct 2017 & 3 Nov 2017 & $\begin{array}{l}\text { Change from baseline to } 4 \text { weeks (before cross-over) IPSS and } \\
\text { QoL (mean and standard deviation). Treatment withdrawal and } \\
\text { adverse events at } 4 \text { weeks (before cross-over). Method of ran- } \\
\text { dom sequence generation and allocation concealment. }\end{array}$ \\
\hline Yamaguchi 2013 & 27 Jan 2017 & 1 Feb 2017 & $\begin{array}{l}\text { Change from baseline in IPSS and QoL (mean and standard de- } \\
\text { viation), the number of participants with treatment withdraw- } \\
\text { al, acute urinary retention, surgical intervention, and cardiovas- } \\
\text { cular adverse events. Method of random sequence generation } \\
\text { and blinding. }\end{array}$ \\
\hline
\end{tabular}

\begin{tabular}{|c|c|c|c|}
\hline Yamanishi 2011 & 27 Jan 2017 & 31 Jan 2017 & Author reply: "Full text was not published". \\
\hline Yokoyama 2011 & 30 Jan 2017 & 13 March 2017 & $\begin{array}{l}\text { Dates when study was conducted, study duration (interven- } \\
\text { tion), exclusion criteria, conflicts of interest, mean and stan- } \\
\text { dard deviation of IPSS and QoL at baseline and endpoint ( } 12 \\
\text { weeks), the number of participants with acute urinary retention } \\
\text { and surgical intervention. Method of random sequence genera- } \\
\text { tion and blinding. }\end{array}$ \\
\hline
\end{tabular}

Yokoyama $2012 \quad 24$ Oct $2017 \quad 29$ Oct 2017

Total number of participants who were analyzed and finishing the trial at 3 months (before cross-over), change from baseline to 3 months (before cross-over) in IPSS and QoL (mean and standard deviation), Treatment withdrawal at 3 months (before cross-over). Method of random sequence generation and blinding. Presence of published protocol.

\section{Footnotes}

IPSS: International Prostate Symptom Score; QoL: quality of life

\section{CONTRIBUTIONS OF AUTHORS}

JH Jung (JHJ): conception and study design, drafting the protocol, searching for trials, study selection, extracting data, assessing risk of bias, performing data analysis, interpretation of data, and drafting the review.

$\mathrm{J}$ Kim (JK): drafting the protocol, searching for trials, study selection, extracting data, assessing risk of bias, performing data analysis, and drafting the review. 
R MacDonald (RM): study design, drafting the protocol, providing clinical and methodological advices on the review, and final approval.

B Reddy (BR): providing clinical and methodological advice on the review, and drafting the review.

MH Kim (MHK): creating search strategies, drafting the protocol, and searching for trials.

P Dahm (PD): conception and study design, providing clinical and methodological advice on the review, and final approval.

\section{DECLARATIONSOF INTEREST}

JHJ: none known

JK: none known

RM: none known

BR: none known

MHK: none known

PD: PD serves as Co-ordinating Editor of Cochrane Urology. However, he was not involved in the editorial processing or decision-making for this review. Other editors of Cochrane Urology managed the editorial process, including final sign-off for this review.

\section{SOURCES OF SUPPORT}

\section{Internal sources}

- Yonsei University Wonju College of Medicine, Korea, South.

- Minneapolis VA Medical Center, Minneapolis, Minnesota, USA.

- University of Minnesota, Minneapolis, Minnesota, USA.

\section{External sources}

- No sources of support provided, Other.

\section{DIFFERENCES BETWEEN PROTOCOL AND REVIEW}

This review was based on a published protocol with differences as described here.

- Types of studies: we included parallel, randomized trials as well as cross-over designs. We revised the 'Types of studies' and 'Unit of analysis issues' section accordingly.

- Types of participants: we redefined the type of participants as adult men aged 40 years and over. Given that alpha-blockers are used to treat patients with all degrees of LUTS, we deleted the IPSS criterion under 'Types of participants'.

- Types of outcome measures: we renamed primary and secondary outcomes and added details in 'method and timing of outcome measurement' for all outcomes.

- Assessment of risk of bias in included studies: we added details with regards to assessing risk of bias. We considered all outcomes susceptible to performance bias and assessed them in one group. We redefined subjective and objective outcomes for detection bias.

- Subgroup and sensitivity analysis: we planned to perform subgroup and sensitivity analyses limited to the primary outcomes.

- Appendix: we have summarized the search strategy for each database in Appendix 1.

\section{N O T E S}

We have based parts of the Methods section of this protocol on a standard template developed by the Cochrane Metabolic and Endocrine Disorders Group, which has been modified and adapted for use by Cochrane Urology.

\section{N DEX TERMS}

\section{Medical Subject Headings (MeSH)}

Adrenergic alpha-1 Receptor Antagonists [ ${ }^{\star}$ therapeutic use]; Indoles [ ${ }^{\star}$ therapeutic use]; Lower Urinary Tract Symptoms [ ${ }^{\star}$ drug therapy] [etiology]; Naphthalenes [therapeutic use]; Piperazines [therapeutic use]; Prostatic Hyperplasia [ ${ }^{\star}$ complications]; Quinazolines [therapeutic use]; Randomized Controlled Trials as Topic; Urological Agents [*therapeutic use]

\section{MeSH check words}

Aged; Humans; Male 